PNL-3074

UC-60

\title{
Estimation of Wind Characteristics at Potential Wind Energy Conversion Sites
}

SRI International

333 Ravenswood Avenue

Menlo Park, California 94025

October 1979

Prepared for

Pacific Northwest Laboratory

Under Agreement B-29105-A-E

Pacific Northwest Laboratory

Operated for the U.S. Department of Energy

by Battelle Memorial Institute

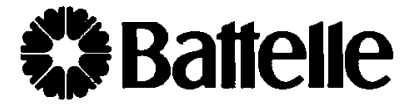




\title{
NOTICE
}

This report was prepared as an account of work sponsored by the United States Government. Neither the United States nor the Department of Energy, nor any of their employees, nor any of their contractors, subcontractors, or their employees, makes any warranty, express or implied, or assumes any legal liability or responsibility for the accuracy, completeness or usefulness of any information, apparatus, product or process disclosed, or represents that its use would not infringe privately owned rights.

The views, opinions and conclusions contained in this report are those of the contractor and do not necessarily represent those of the United States Government or the United States Department of Energy.

\author{
PACIFIC NORTHWEST LABORATORY \\ operaied by \\ BATTELLE \\ for the \\ UNITED STATES DEPARTMENT OF ENERGY \\ Under Contract EY-76-C-06-1830
}

\author{
Printed in the Uniced States of America \\ Available from \\ National Technical Information Service \\ United States Department of Commerce \\ 5285 Port Royal Road \\ Springfield, Virginia 22151
}

Price: Printed Copy $\$$

$\because$ Microfiche $\$ 3.00$

$\begin{array}{cc}\text { Pages } & \begin{array}{c}\text { NTIS } \\ \text { Selling Price }\end{array} \\ 001-025 & \$ 4.00 \\ 026-050 & \$ 4.50 \\ 051-075 & \$ 5.25 \\ 076-100 & \$ 6.00 \\ 101-125 & \$ 6.50 \\ 126-150 & \$ 7.25 \\ 151-175 & \$ 8.00 \\ 176-200 & \$ 9.00 \\ 201-225 & \$ 9.25 \\ 226-250 & \$ 9.50 \\ 251-275 & \$ 10.75 \\ 256-300 & \$ 11.00\end{array}$




\section{2}

ESTIMATION OF WIND CHARACTERISTICS AT POTENTIAL WIND ENERGY CONVERSION SITES
C. M. Bhumraikar
F. L. Ludwig
R. L. Mancuso

October 1979

Prepared for

Pacific Northwest Laboratory

Under Agreement B-29105-A-E

Prepared by

SRI International

333 Ravenswood Avenue

Men1o Park, CA 94025

Pacific Northwest Laboratory

Richland, Washington 99352 
- 


\title{
EXECUTIVE SUMMARY
}

\begin{abstract}
A practical method has been developed and applied to the problem of determining wind characteristics at candidate wind energy conversion sites where there are no available historical data. The method uses a mass consistent wind flow model (called "COMPLEX") to interpolate between stations where wind data are available. The COMPLEX model incorporates the effects of terrain features and airflow. The key to the practical application of COMPLEX to the derivation of wind statistics is the model's linearity. This allows the input data sets to be resolved into orthogonal components along the set of eigenvectors of the covariance matrix. The solution for each eigenvector is determined with COMPLEX; the hourly interpolated winds are then formed from linear combinations of these solutions.
\end{abstract}

The procedure requires: acquisition and merger of wind data from three to five stations, application of COMPLEX to each of the seven to 11 (depending on the number of stations for which wind data are available) eigenvectors, reconstruction of the hourly interpolated winds at the site from the eigenvector solutions, and finally, estimating the wind characteristics from the simulated hourly values. The report describes the methodology and the underlying theory. Possible improvements to the procedure are also discussed.

An appendix in the form of a Users' Manual gives step-by-step directions for the use of the procedures. Listings of computer programs used in the procedure are included. The complete procedure has been applied to eight potential wind energy conversion sites in a wide variety of topographical settings in the United States. The method provides qualitatively reasonable results; the estimated complete cost per site is about 500 dollars.

\section{A. Introduction}

In order to assess the economic viability of installing a wind energy conversion system (WECS) at a particular location, it is necessary to know the wind characteristics at that site. The required information includes the frequency distribution of wind speed, the joint frequency distribution of wind speed and direction, and the wind run durations for various wind speed levels, and the seasonal and diurnal variation of the wind speed. It is usually impractical to measure wind at all potential sites over a suitably long period of time because of the costs and delays involved. Therefore it is necessary to develop a methodology that can provide accurate estimates of wind characteristics economically for potential WECS sites from data that is already available. 
The major objective of the research described here was to develop a method for obtaining the required wind estimates. A versatile and practical method is required for generating the necessary wind information at hub level at a given site. The method should meet the following criteria:

- It should be applicable to a variety of sites and topographic settings.

- It should use only readily available conventional wind data from locations in the vicinity of the site.

- It should not depend on wind data from the site itself, or even within a radius of several kilometers.

A secondary objective of this study has been to demonstrate the applicability of the methodology that was developed, by estimating hub height wind characteristics for each of eight topographically diverse locations potentially suitable for wind energy utilization.

All the objectives of the research have been met by an approach that estimates hourly winds at hub height at any site by applying a physically based three-dimensional model. The model incorporates the effect of underlying terrain and utilizes available, conventional wind information from selected weather stations in the vicinity of the site. The required statistical wind characteristics are estimated from the hourly winds that have been synthesized with the aid of the model. We have selected this approach because it is versatile and makes use of important physical principles. The method can be applied to virtually any site, regardless of topographic setting. The approach requires only the readily available conventional surface wind data from weather stations in the vicinity of the site and a knowledge of the topography of the region; it does not require wind data at the site itself. The methodology can be followed step-bystep using the instructions given in this report. It will require about a person-week of effort and a few hundred dollars in computation and data acquisition costs for its application to a given site. The computation costs are not negligible, but they are certainly consistent with the importance of the problem.

\section{B. Description of the Theory and Method}

\section{Mathematical Interpolation Model Based on Physical Principles}

The physical principles governing the characteristics of wind flow follow from well known basic laws of physics. Theoretical modeling provides a convenient way to treat the many factors that operate simultaneously to affect the air flow over complex terrain. A practical mathematical model has been developed to obtain wind information at a given site. This model--called COMPLEX--is essentially an objective analysis computer program that interpolates values of wind from observations at a limited number of irregularly spaced stations located in remote locations in a variety of topographic settings. A complete description of COMPLEX model, its theory and model equations and the computer code are given in this report. The main features of the model are that it is completely objective and it provides solutions that are consistent with the conservation of mass which probably is the most important physical principle governing airflow over complex topography. The model equations are derived using a vertical coordinate system (called Sigma). It has the special advantage over other conventional coordinate systems in that it permits easy formulation of lower and upper boundary conditions in the boundary layer over complex terrain. Integration of the COMPLEX model over moun- 
tainous and valley terrain has shown that it responds realistically to underlying terrain--e.g., the wind tends to flow around the ridges. The vertical velocities are also realistic. Considering the fact that the COMPLEX model like most mathematical models involves many calculations, it is not practical to apply the model directly to a significantly large volume of hourly wind data. We have simplified this problem considerably through the use of linear transformations based on the eigenvectors of the covariance matrix. This is a commonly used method for reducing the number of variables while still retaining most of the information of the original data set.

\section{Use of Eigenvectors}

Even with the reduction in the number of variables (required to describe the input data to the COMPLEX model) through use of the eigenvectors, it would still require many categories to describe the full range of input conditions. However, the linear nature of the COMPLEX model has made it possible to use the eigenvectors in a unique way. The method requires that solutions be obtained directly for only the few eigenvectors. Then a method has been developed to construct the model solution for any arbitrary set of observations from linear combinations of those solutions.

Thus, the COMPLEX model need be applied directly only a very few times, typically 7 to 9 . It is this feature of the method that has made it feasible to apply a mass conservation model to the thousands of sets of hourly data that are required for a proper climatological description of the wind characteristics. Only a very manageable number of computer operations are now required.

\section{Derivation of Statistics from Estimates of Hourly Winds}

The most important consequence of our methodology is that it provides the solutions that can be obtained from a numerical model at a reasonable cost for each hour. Once the hourly winds have been estimated for a long period then it is possible to estimate virtually all the statistics that could be obtained if actual wind observations were available at the site. No special assumptions are required to interpolate averages, or run durations, or any other statistics for the location from statistics based on observations at other locations. It is even possible to use statistical computer programs that have been developed for use with actual wind observations. This feature provides a consistency with observational data bases that does not appear to be available with other approaches.

\section{Steps Required for Application of the Method}

The application of the methodology to a given wind energy conversion site is discussed in considerable detail in the Appendix to this report. The procedure is summarized in the following:

- Step 1: Select appropriate wind data stations. The selection is made by using subjective, but clearly identifiable criteria such as proximity to the site in question, general similarity of surrounding geographical area, variety of directions from the site to the data stations, availability of hourly and concurrent data at the data stations and so forth. 
- $\quad$ Step 2: Acquire and merge data.

(a) Order data (for stations selected in step 1) from National Climatic Center (NCC), Asheville, NC after discussing their availability, tape format, etc. with NCC personnel.

(b) Use the computer program (called SFCOBS1) that has been provided to prepare data files for merging.

(c) Merge the data from separate sites into a single data file using the computer program (MERGER) that has been provided.

- Step 3: Determine the eigenvectors and transform the data sets. Use the program XFORM which is described in the appendix. It calculates the covariance matrix, the means and the relevant number of eigenvectors (eight in case of four data stations or six in case of three stations). The means and eigenvectors are output on punch cards that are ready for use in Step 6. The program also transforms all the input data by calculating the inner products of the input data vectors with the eigenvectors and writes a tape for use in Step 7.

- Step 4: Select grid(s) for use with the COMPLEX model. The grids should be selected by considering the topographic area in the vicinity of the site. The grid spacing should be such that it adequately resolves the topographic features. If necessary, an optional fine grid may be selected and used in the immediate vicinity of the site.

- Step 5: Prepare gridded topography and estimate height of grid top. Overlay grid(s) selected in Step 4 on a United States Geological Survey (USGS) topographic map (1:250,000 series) and obtain the elevations at each grid point. It is then necessary to estimate the height of the top of the boundary layer by adding a value of $300 \mathrm{~m}$ to the highest elevation lying within the grid.

- Step 6: Obtain solutions for the mean, and for each eigenvector. Integrate the COMPLEX model, using the computer program listed in the Appendix, to obtain solutions for each eigenvector and for the mean of input wind data sets. The necessary inputs come from Steps 3 and 5. These solutions incorporate the topographic effects through the COMPLEX model.

- Step 7: Calculate hourly winds at hub height at the site. Use computer program REWND (given in the Appendix) to calculate appropriate linear combinations of solutions obtained at Step 6 . This requires the tape of transformed data from Step 3. The output of this step is a series of hourly wind speeds and directions that can be used to calculate hub height wind characteristics at the site.

- Step 8: Estimate hub height wind characteristics. Use the hourly wind at hub height obtained in Step 7 to obtain the following wind characteristics: 
(a) Use statistical package program (See Appendix) to obtain speed frequency distributions and joint frequency distributions of speed vs. direction.

(b) Use the computer program WINDY that has been provided to calculate run duration statistics, and diurnal and seasonal variability.

\section{Results}

The most important result of the research has been the step-by-step methodology just described. The ultimate test of that methodology will of course be its ability to reproduce observed wind statistics. That test has only begun. The results that we have obtained seem qualitatively reasonable. This reasonableness has been achieved with virtually no "tuning" of the method. There are several ways in which the model and its application could be improved. These include the incorporation of the effects of diurnal cycles of stability and boundary layer depth, and more efficient methods of processing some of the data.

The method has been applied to data from eight different locations. The costs to acquire complete wind statistics based on a year's data have been determined and they vary from about 400 to 600 dollars per site in materials and computer time, depending on the number of stations for which wind data are required. The labor required is about a person-week. As noted before, the report contains suggestions for further refinements that could reduce the costs of applying the method, but even in its present form it is quite inexpensive when compared to the importance of selecting appropriate WECS sites.

The report that follows this summary is divided into two parts. The first gives the complete details of the project. The objectives and approach are outlined. The theory is described in considerable detail and the results of the application of that theory are described. Finally, recommendations are given for research that could validate and refine the methodology.

The second part of this report is an Appendix that has been designed as a User's Guide to the methodology. Step-by-step instructions are given along with all the computer programs necessary for their execution. 


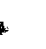




\section{CONTENTS}

\section{EXECUTIVE SUMMARY}

LIST OF ILLUSTRATIONS

LIST OF TABLES

I. INTRODUCTION

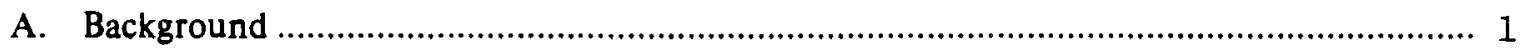

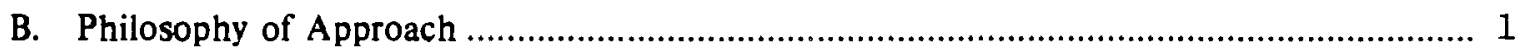

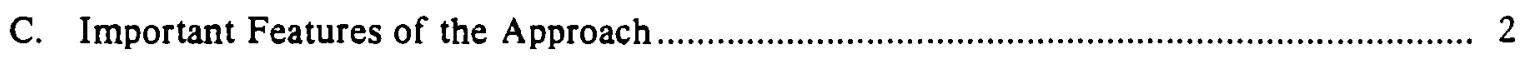

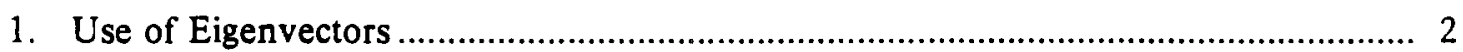

2. Derivation of Statistics from Estimates of Hourly Winds .................................... 2

3. Use of Mathematical Interpolation Model Based on Physical Principles....................... 3

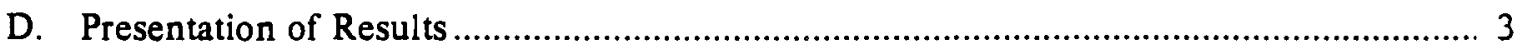

II METHOD FOR OBTAINING WIND CHARACTERISTICS AT A WIND ENERGY

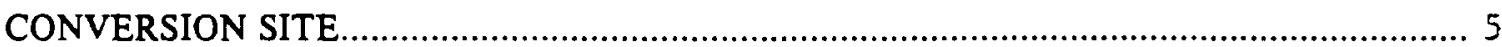

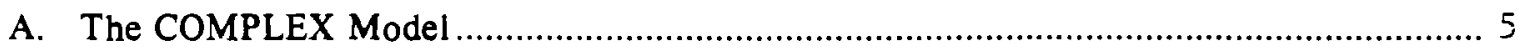

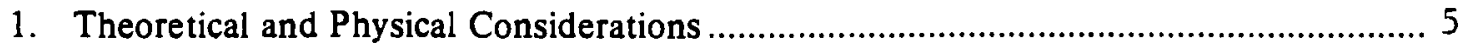

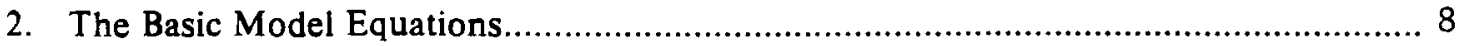

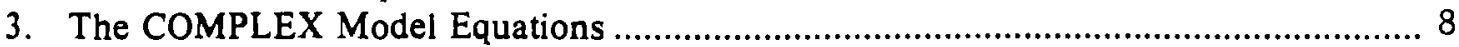

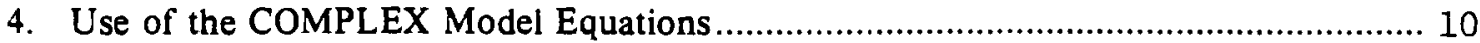

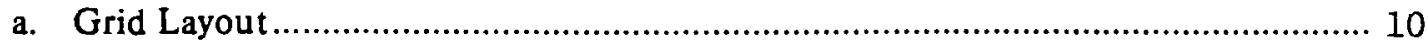

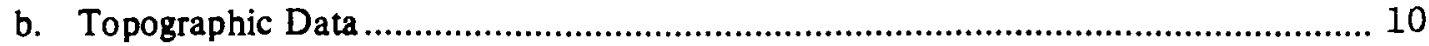

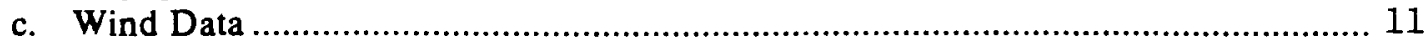

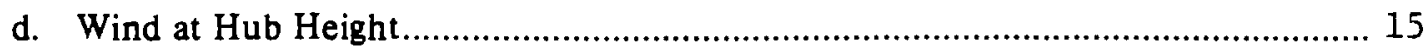

B. Reconstructing Hub Height Wind from the COMPLEX Model Solutions......................... 15

C. Estimating Hub Height Wind Characteristics ............................................................. 20 
III APPLICATION OF THE METHODOLOY TO EIGHT CANDIDATE WIND ENERGY CONVERSION SITES

A. The Sites, Data Stations, and Wind Data Used .......................................................... 23

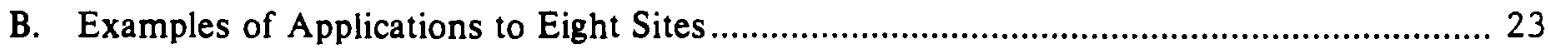

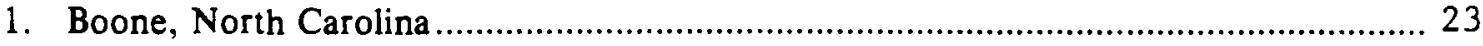

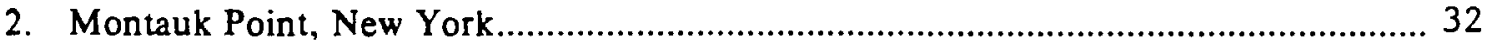

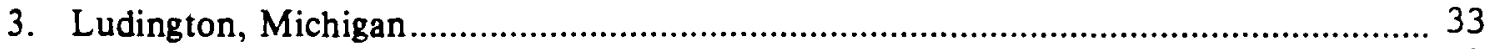

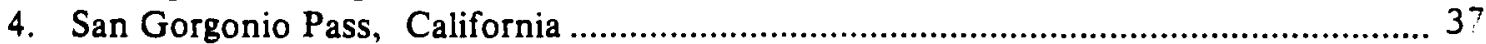

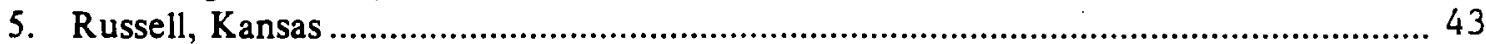

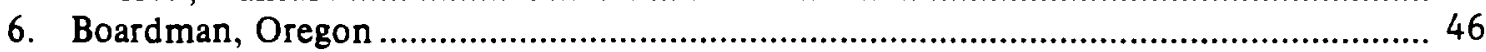

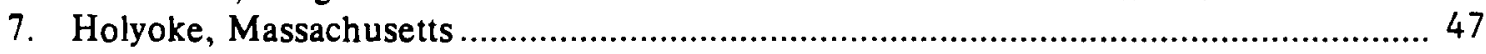

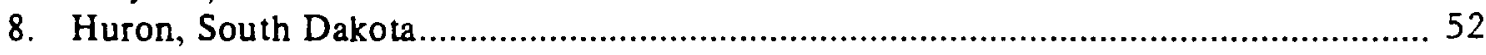

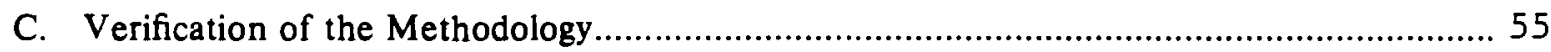

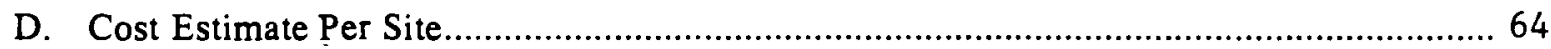

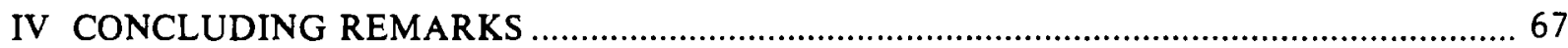

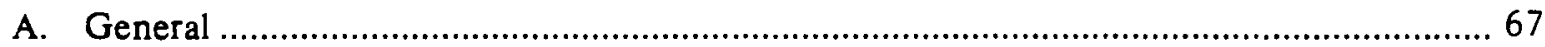

B. Suggestions for Possible Improvements and Refinements .....................................67

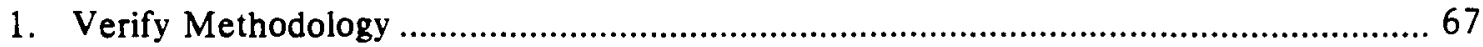

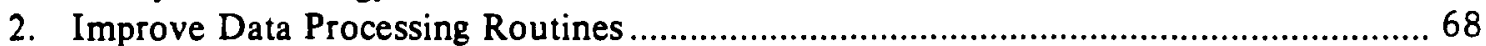

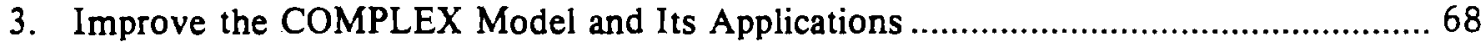

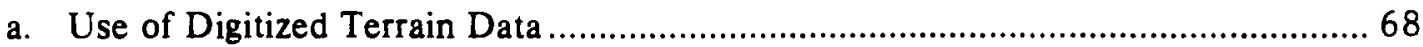

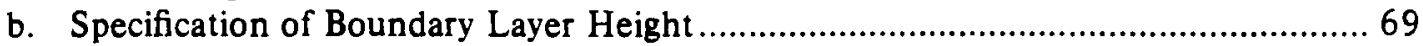

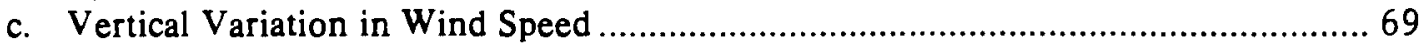

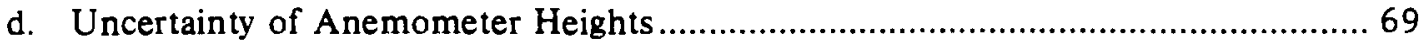

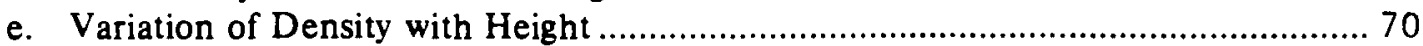

f. Influences of Synoptic and Mesoscale Weather Systems .................................... 70

g. Evaluation of the Suitability of Other Nearby Sites ........................................... 70

C. A Summary of Aspects that Should be Addressed by Future Research ........................ 71

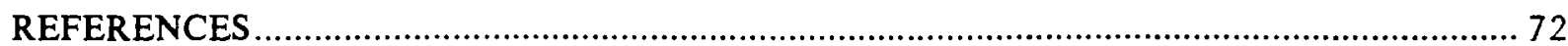




\section{APPENDIX: USER'S GUIDE FOR ESTIMATING WIND CHARACTERISTICS AT A GIVEN WIND ENERGY CONVERSION SITE}

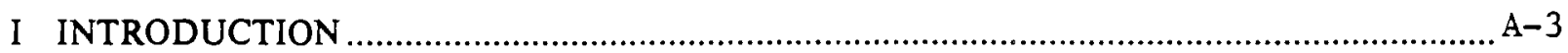

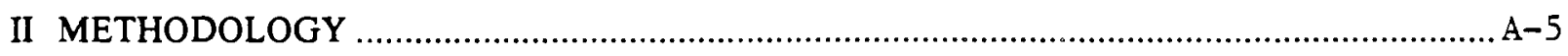

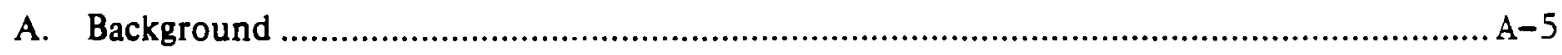

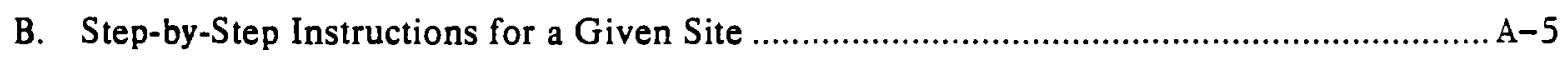

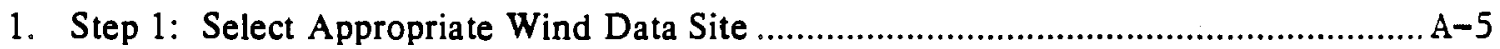

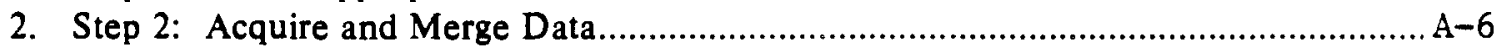

3. Step 3: Determine the Eigenvectors and Transform the Data Site ............................. A-10

4. Step 4: Select Grid(s) for Use with the COMPLEX Model......................................

5. Step 5: Prepare Gridded Topography and Estimate Height of Grid Top .....................A-13

6. Step 6: Obtain Solutions for the Mean and Each Eigenvector ....................................A-14

7. Step 7: Calculate Hourly Winds at Hub Height at the Site ....................................

8. Step 8: Estimate Hub Height Wind Characteristics...............................................

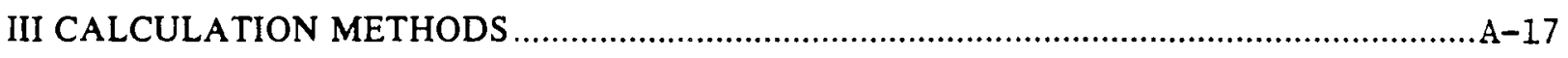

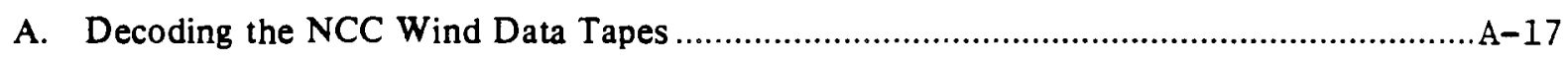

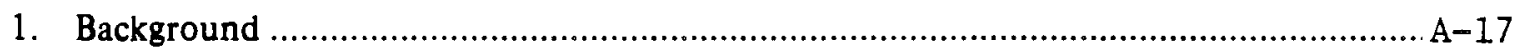

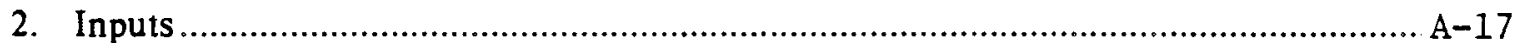

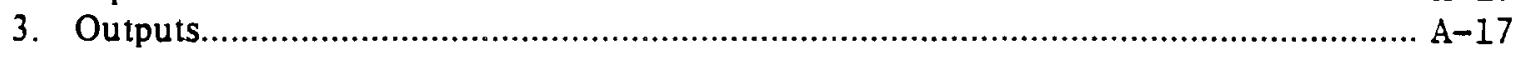

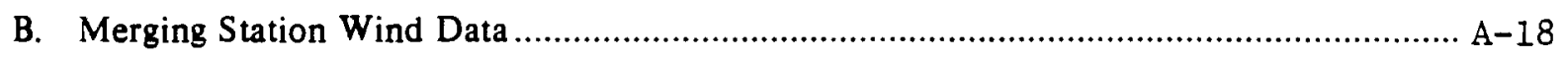

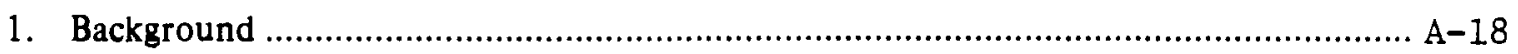

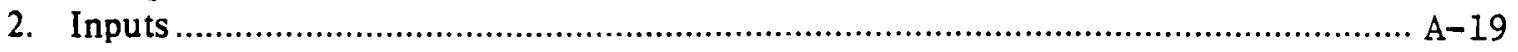

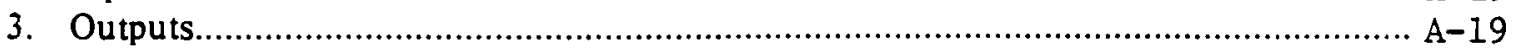

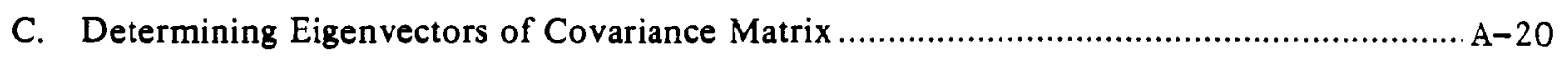

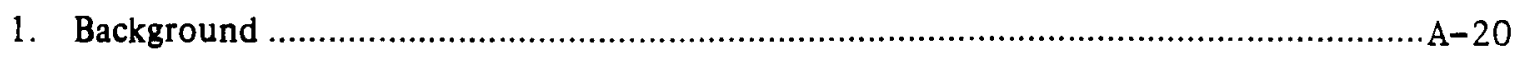

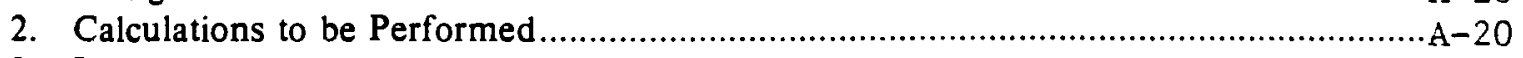

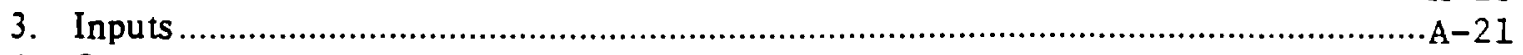

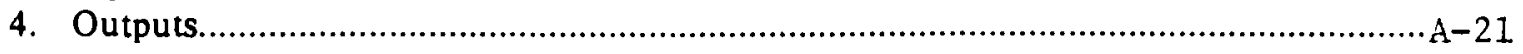

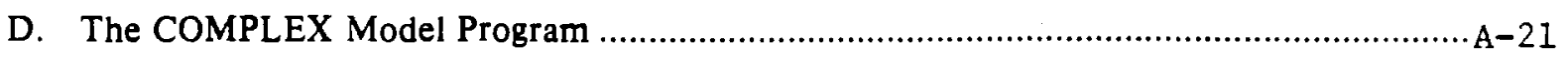

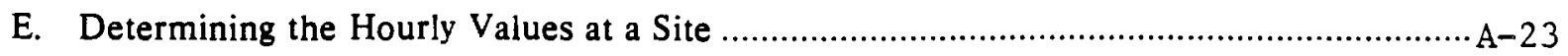

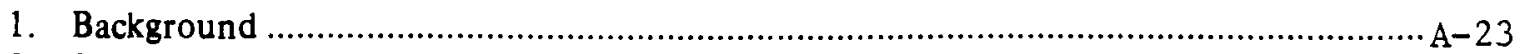

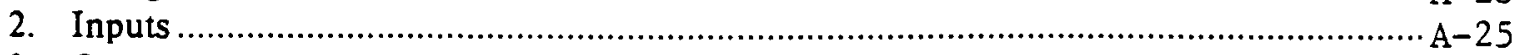

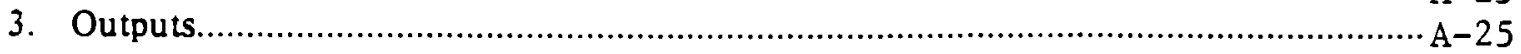




\section{CONTENTS (concluded)}

F. Estimating Hub Height Wind Characteristics at a Site ................................................ A-26

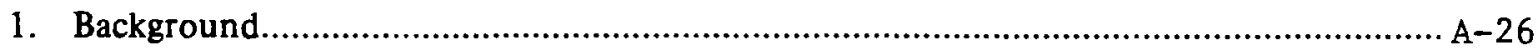

2. Program WINDY for Determining Run-Duration Statistics .................................. A-26

3. SPSS Program for Obtaining Statistical Summaries................................................ A-26

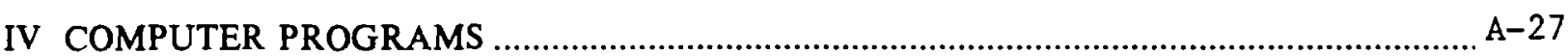

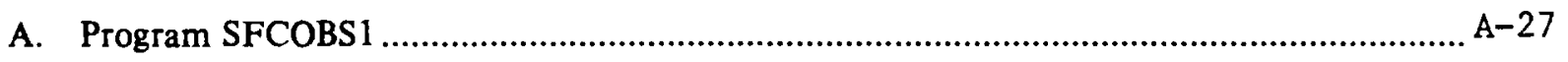

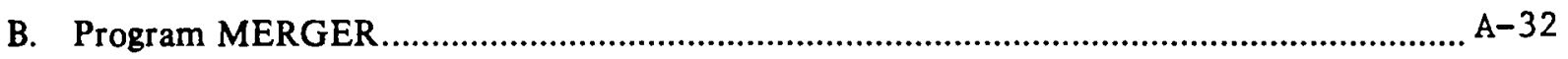

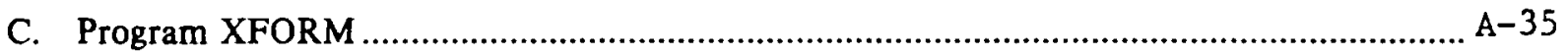

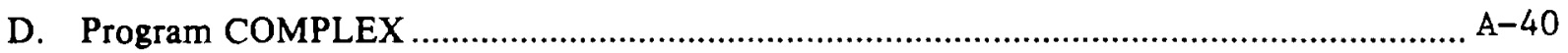

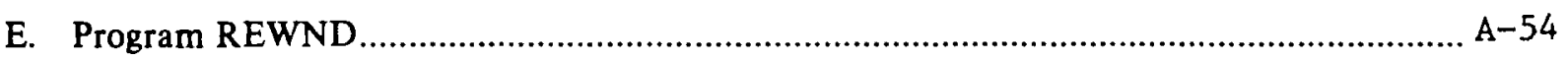

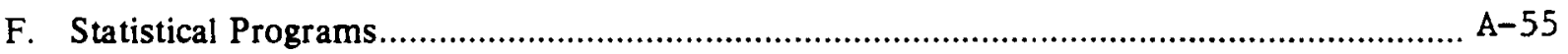

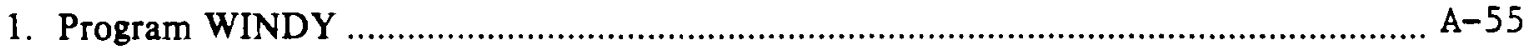

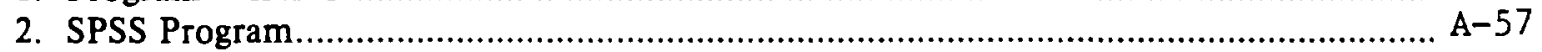

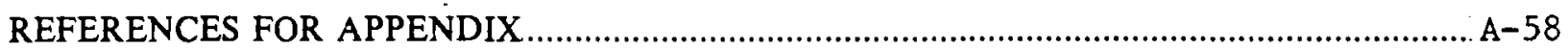




\section{ILLUSTRATIONS}

1 Schematic Diagram Showing Properties of the Sigma Coordinate System 7

2 Schematic Representation of a Three-Dimensional Grid at a Given Site

3 Example of the Use of a Coarse and Fine Grid at the Wind Energy Conversion Site at Boardman, Oregon

4 Contour Analysis of "Gridded" Topography (meters) for Boardman Obtained by Using the Grid Shown in Figure 3

5 Gridded Wind Field ( $\mathrm{m} \mathrm{s}^{-1}$ ) Derived from Wind Vectors at Four Stations Shown in Figure 4

6 Vector Difference $\left(\mathrm{m} \mathrm{s}^{-1} \times 10\right)$ Between the COMPLEX-Model-Generated Winds and the Wind Field Shown in Figure 5

7 Schematic Representation of the Grid for Solving Finite Difference Equation

8 Schematic Representation of the Method by Which the COMPLEX Model Solutions are Reconstructed

9 Locator Map for the WEC Site at Boone, North Carolina, and the Four Data Stations

10 Frequency Distribution of Hub Height Wind Speed at Boone, North Carolina, for the Period 1954

11 Run Duration Analysis of Hub Height Annual Mean Wind Speed at Boone, North Carolina, for the Period 1954

12 Joint Frequency Distribution of Annual Wind Speed and Direction at Hub Height at Boone, North Carolina, for the Period 1954

13 Annual Mean Hub Height Wind Speed Variability at Boone, North Carolina, for the Period 1954

14 Locator Map for the WEC Site at Montauk Point, New York, and the Three Data Stations

15 Frequency Distribution of Hub Height Wind Speed at Montauk Point, New York, for the Period 1954

16 Run Duration Analysis of Hub Height Annual Mean Wind Speed at Montauk Point, New York, for the Period 1954 
17 Joint Frequency Distribution of Annual Wind Speed and Direction at Hub Height at Montauk Point, New York, for the Period 1954

18 Annual Mean Hub Height Wind Speed Variability at Montauk, New York, for the Period 1954

19 Locator Map for the WEC Site at Ludington, Michigan, and the Four Data Stations

20 Frequency Distribution of Hub Height Wind Speed at Ludington, Michigan, for the Period 1952

21 Run Duration Analysis of Hub Height Annual Mean Wind Speed at Ludington, Michigan, for the period 1952

22 Joint Frequency Distribution of Annual Wind Speed and Direction at Hub Height at Ludington, Michigan for the Period 1952

23 Annual Mean Hub Height Wind Speed Variability at Ludington, Michigan, for the Period 1952

24 Locator Map for the WEC Site at San Gorgonio Pass, California, and the Four Data Stations

25 Frequency Distribution of Hub Height Wind Speed at San Gorgonio Pass, California, for the Period June 1949-May 1950

26 Run Duration Analysis of Hub Height Annual Mean Wind Speed at San Gorgonio Pass, California, for the Period June 1949-May 1950

27 Joint Frequency Distribution of Annual Wind Speed and Direction at Hub Height at San Gorgonio Pass, California, for the period June 1949-May 1950

28 Annual Mean Hub Height Wind Speed Variability at San Gorgonio Pass, California, for the Period June 1949-May 1950

29 Locator Map for the WEC Site at Russell, Kansas, and the Three Data Stations

30 Frequency Distribution of Hub Height Wind Speed at Russell, Kansas, for the Period 1954

31 Run Duration Analysis of Hub Height Annual Mean Wind Speed at Russell, Kansas, for the Period 1954

32 Joint Frequency Distribution of Annual Wind Speed and Direction at Hub Height at Russell, Kansas, for the Period 1954

33 Annual Mean Hub Height Wind Speed Variability at Russell, Kansas, for the Period 1954 
35 Frequency Distribution of Hub Height Wind Speed at Boardman, Oregon, for the Period 1961

36 Run Duration Analysis of Hub Height Annual Mean Wind Speed at Boardman, Oregon, for the Period 1961

37 Joint Frequency Distribution of Annual Wind Speed and Direction at Hub Height at Boardman, Oregon, for the Period 1961

38 Annual Mean Hub Height Wind Speed Variability for Boardman, Oregon, for the Period 1961

39 Locator Map for the WEC Site at Holyoke, Massachusetts, and the Four Data Stations

40 Frequency Distribution of Hub Height Wind Speed at Holyoke, Massachusetts, for the Period June 1951-May 1952

41 Run Duration Analysis of Hub Height Annual Mean Wind Speed at Holyoke, Massachusetts, for the Period June 1951-May 1952

42 Joint Frequency Distribution of Annual Wind Speed and Direction at Hub Height at Holyoke, Massachusetts, for the Period June 1951-May 1952

43 Annual Mean Hub Height Wind Speed Variability at Holyoke, Massachusetts, for the Period June 1951-May 1952

44 Locator Map for the WEC Site at Huron, South Dakota, and the Three Data Stations

45 Frequency Distribution of Hub Height Wind Speed at Huron, South Dakota, for the Period 1954

46 Run Duration Analysis of Hub Height Annual Mean Wind Speed at Huron, South Dakota, for the Period 1954

47 Joint Frequency Distribution of Annual Wind Speed and Direction at Hub Height at Huron, South Dakota, for the period 1954

48 Annual Mean Hub Height Wind Speed Variability at Huron, South Dakota, for the period 1954

A-1 General Outline of Overall Approach

A-2 Four Examples of Maps that Display the Location and Types of Data Available from Wind Observing Stations

(a) Data Collection Stations for the Five Years Ending in 1973

(b) Stations with Data on Magnetic Tape 
Figure No.

Page No.

(c) Stations with Wind Summaries with Five or More Years of Data A-9

(d) Stations of Upper Air Reporting Network A-9

A-3 Schematic Representation of Coarse and Fine Grids A-13

A-4 Schematic Representation of the Organization of the Output Records from Program MERGER

A-19

A-5 Flow Diagram for the COMPLEX Model

A-22 


\section{TABLES}

1 Candidate Wind Energy Conversion Sites

2 Data Stations and the Period of Data for Each of the Eight Candidate Wind Energy Conversion Sites

3. Eigenvectors of the Covariance Matrix and the Mean Vectors at Data Stations, and Hub Height Wind at WEC Site

$4 \quad$ Verification of the Methodology Described in the Text

5 Cost Estimate for Obtaining Hub Height Wind Characteristics at a Site Using One Year's Hourly Wind Data

$6 \quad$ Suggested Future Improvements and Refinements

A-1 Stations with Summarized Wind Data (All Hours Combined)

A-2 Input Cards for Decoding Program

A-3 Input Cards for the COMPLEX Model

A-4 Input Cards for Program REWND 



\section{ACKNOWLEDGMENTS}

We wish to express our appreciation to Professor Mariano A. Estoque of the University of Miami, Florida, for making his wind model available to us; that model has formed the basis from which the COMPLEX model was developed during this project at SRI International. We are also thankful to Professor Estoque for acting as a consultant during the model development phase of the project.

The cooperation and help of the National Climatic Center, Asheville, N.C., in providing the necessary wind data so vital for this project is also acknowledged.

Many people at SRI International have contributed significantly to the research. We would like to give special thanks to:

- Charles Norwood and George Byrd for their valuable discussions and assistance on mathematical aspects of this project.

- Kathleen Chaikin and Marleen Mandt for their help with the data processing and calculations of wind statistics.

- Russell Trudeau for this painstaking extraction of gridded topographical information.

- Joyce Kealoha and Linda Jones for their special assistance in the preparation of the report.

Finally, we wish to thank the project monitor, Dr. David Renné for his helpful suggestions and the coordination that he has provided. 


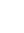




\section{INTRODUCTION}

\section{A. Background}

In order to assess the economic viability of installing a wind energy conversion system (WECS) at a particular location, it is necessary to know the wind characteristics at that site. This information includes such items as the frequency distribution of wind velocity, the wind run durations for various wind velocity levels, and the seasonal and diurnal variation of the wind speed. In most cases it is impractical to make measurements of wind at all potential sites over a suitably long time period, because such a step would be extremely costly and would cause significant delays in the implementation of wind energy conversion. This report describes a method that has been specifically designed to provide hourly hub height estimates of wind data (and hence wind characteristics) for eight selected locations. For this study, hub height is assumed to be at $45.7 \mathrm{~m}$.

\section{B. Philosophy of Approach}

We considered two approaches for generating wind information at a potential site:

(1) Using long records of hourly wind data from locations in the vicinity of the site in question, calculate statistical wind characteristics at these locations, and then interpolate these statistics to the site itself.

Estimate hourly wind data at hub height at the site. This could be done by applying a physically based three-dimensional model that incorporates the effect of terrain and utilizes available conventional wind information from selected locations in the vicinity of the site. Then, the required wind characteristics can be estimated from the model-generated hourly wind data.

We have selected the second approach because we believe that this approach is more versatile and incorporates important physical principle. The method that has been developed can be applied to sites in remote locations in a variety of topographic settings. Moreover, this approach does not require wind data at the site itself, and it requires only the readily available conventional surface wind data from weather stations in the vicinity of the site.

Perhaps the most important constraint that we have imposed on ourselves in the development of the methodology described here is that it must be practical. The economic importance of the WECS problem justifies more than a cursory investment of time and effort. Nevertheless, a method that is overly complicated and difficult to apply would be self-defeating because it would go unused. Our philosophy has demanded a methodology that can be followed step-by-step and that will require less than about a person-week of effort and a few hundred dollars in computation and data acquisition costs, per site, for its application. 
The methodology given in the Appendix meets all the criteria. It requires the execution of only a few relatively simple tasks in sequence. The computation costs are not negligible, but they are certainly consistent with the importance of the problem. Several techniques have been used in order to develop a method that is simple to apply and yet makes effective use of as much information as is feasible.

\section{Important Features of the Approach}

\section{Use of Eigenvectors}

As noted above, the approach described here is based on the philosophy that hourly winds should be determined from available observations using some realistic mathematical description of the physical processes involved. Unfortunately, most mathematical models require too many calculations to be considered for direct application to a significantly large number of hours. Originally, the intention was to circumvent this problem by classifying each hour's input data into one of a limited number of categories. The solution would be obtained from the mathematical model for each category. Then the appropriate solution was to be chosen for each hour, based on the category into which that hour's data fell.

With the approach described in the preceding paragraph, one faces the problem of classifying sets of six to ten numbers--i.e. the wind components at three to five locations. The problem is simplified considerably if the number of variables is kept small. One of the most commonly used methods for reducing the number of variables, while still retaining most of the information in the original data set, is through the use of linear transformations based on the eigenvectors of the covariance matrix. Lorenz (1956) has given a very good description of the method as it applies to the description of temperature and pressure observations.

Even with the reduction in the number of variables required to describe the input data, it appeared that it would still require about a hundred categories (or more) to describe the full range of input conditions. Therefore, other possibilities were explored. It was determined that the mathematical character of the airflow model is such that its outputs are linear combinations of its inputs; therefore the solution for any arbitrary set of inputs can be formed from an appropriate linear combination of solutions for a limited number of independent input data sets. The eigenvectors have proved to be an attractive basis for forming these solutions.

\section{Derivation of Statistics from Estimates of Hourby Winds}

The approach that has been adopted will be described later. The most important consequence of the approach is that it allows the solutions that can be obtained from a sophisticated model to be determined at a reasonable cost for each hour. If one has hourly estimates of winds, then it is possible to determine virtually all the statistics that could be obtained if actual wind observations were available at the site. No special assumptions are required to interpolate means, or run durations, or any of the other statistics for the location from the statistics based on observations at other locations. It is even possible to use computer programs that may have been developed for use with actual wind observations. This feature provides a consistency with observational data bases that does not appear to be available with other approaches. 


\section{Use of a Mathematical Interpolation Model Based on Physical Principles}

The physical principles governing the variations of wind statistics throughout a complex area are not well established, but the physical principles governing the behavior of the wind itself can be derived from the basic principles of physics, and they are well known. Thus, if the interpolation is done before the statistics are calculated, it allows the effects of these principles to be included. This is one of the reasons for the choice of the approach described here.

In his summary of considerations that are relevant to the problem of siting WECS units, Davidson (1964) discussed the complexity of meteorological conditions in rough terrain. He described procedures that should be followed during the site selection process to allow for consideration of the complexities. In very complicated terrain, without much available meteorological information it is difficult to follow the procedures. However, theoretical numerical modeling can provide the required information about terrain effects. Such modeling is perhaps the only way to treat the many factors that operate simultaneously to affect the airflow in complex terrain.

Consistent with our approach as well as the above considerations, we have selected and refined a mathematical model for obtaining hourly wind information at a given site. This model--called COMPLEX--is essentially an objective analysis computer program that interpolates values of wind from observations at a limited number of irregularly spaced stations located in a variety of remote topographic settings. A complete description of the COMPLEX model theory and equations is given in Section II, and computer code is given in Section IV of Appendix. Its main features are that it is completely objective and it provides solutions that are consistent with the conservation of mass, probably the most important physical principle governing airflow over complex topography.

\section{Presentation of the Results}

An attempt has been made to prepare this report so that it could serve a dual function. The first is as a conventional final report of research results, describing the background and philosophy of the research, the theory, the results, and finally the suggestions for further research. The second function is to serve as a Users' Manual that gives step-by-step guidance through the methodology that has been developed during the research. The main text of this report is designed to be the conventional Final Report. The Appendix is the Users' Manual complete with computer programs and instructions for their use.

We urge the reader to read the main text of this report before proceeding to the Appendix and applying the methodology. The methods are straightforward and easily applied. However, since the ease of application also makes it quite possible to misapply the methods or to apply them inappropriately it is very important that it be applied judiciously after understanding its theoretical basis. 


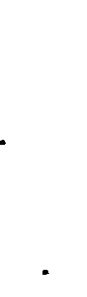




\section{METHOD FOR OBTAINING WIND CHARACTERISTICS AT A WIND ENERGY CONVERSION SITE}

\section{A. The COMPLEX Model}

\section{Theoretical and Physical Considerations}

The COMPLEX model, which has been developed in consultation with Dr. M. A. Estoque of the University of Miami, is a modified version of the model developed by Sherman (1975). It is a three-dimensional numerical model based on a variational method of objective analysis. It adjusts observations of horizontal wind at a limited number of scattered locations, interpolated to a horizontal grid and extrapolated in the vertical. The adjustment process involves minimizing the mean square difference between the adjusted and the observed wind velocity components and is constrained so that the equation of continuity of mass of incompressible fluid is satisfied.

Following Sherman (1975), the basic equations of the COMPLEX model using $z$ as vertical coordinate can be written as:

$$
\begin{aligned}
& 2 \alpha_{1}^{2}\left(u-u_{o}\right)-\frac{\partial \lambda}{\partial x}=0 \\
& 2 \alpha_{1}^{2}\left(v-v_{o}\right)-\frac{\partial \lambda}{\partial y}=0 \\
& 2 \alpha_{2}^{2}\left(w-w_{o}\right)-\frac{\partial \lambda}{\partial z}=0 \\
& \frac{\partial u}{\partial x}+\frac{\partial v}{\partial y}+\frac{\partial w}{\partial z}=0
\end{aligned}
$$

Here, $u, v$, and $w$ are the three wind components, corresponding to a cartesian coordinate system $(x, y, z) ; \lambda$ is the Lagrange multiplier. Equation (4) is the equation of continuity for an incompressible fluid. The quantities, $\alpha_{1}^{2}$ and $\alpha_{2}^{2}$ are weighting factors. The subscript 0 indicates observed values. Equations (1) through (4) represent a set of simultaneous equations whose unknowns are $u, v, w$, and $\lambda$. Therefore, if $u_{0}, v_{0}$, and $w_{0}$ are given, one can solve for the unknowns. We have modified Equations (1) through (4) by using the so-called sigma $(\sigma)$ system instead of $z$ as the vertical coordinates. The vertical coordinate $\sigma$ is defined as:

$$
\sigma \equiv \frac{z-h(x, y)}{H(x, y)-h(x, y)}
$$

where $h(x, y)$ is the height of the terrain above a certain reference level--e.g., sea level; and $\mathrm{H}(\mathrm{x}, \mathrm{y})$ is the corresponding height of the boundary layer or elevated temperature inversion. The surfaces, $h(x, y)$ and $H(x, y)$, are assumed to be rigid boundaries. The relationships between the sigma and the $z$ coordinates are given by: 


$$
\begin{aligned}
& \text { At } z=h(\text { terrain surface), } \sigma=0 \\
& \text { At } z=H \text { (boundary layer top), } \sigma=1 .
\end{aligned}
$$

In addition to these, one can deduce the relationships between vertical velocities in the two coordinate systems. This is done by differentiating (total differentiation) Equation (5) with respect to time; the differentiation is indicated by the dot symbol. Thus,

$$
\dot{\sigma}(H-h)-\dot{h}(\sigma-1)+\dot{H}=\dot{z}(=w),
$$

where

$$
\begin{aligned}
& \dot{z}=\frac{d z}{d t}=w \\
& \dot{h}=\frac{\partial h}{\partial t}+u \frac{\partial h}{\partial y}+v \frac{\partial h}{\partial y}+w \frac{\partial h}{\partial z}=u \frac{\partial h}{\partial x}+v \frac{\partial h}{\partial y} \\
& \dot{H}=\frac{\partial H}{\partial t}+u \frac{\partial H}{\partial x}+v \frac{\partial H}{\partial y}+w \frac{\partial H}{\partial z}=u \frac{\partial H}{\partial x}+v \frac{\partial H}{\partial y}
\end{aligned}
$$

Also, since $\sigma$ is constant at $z=h$ and $z=H$, then by definition,

$$
\left.\begin{array}{l}
\text { At } z=h \text { or } \sigma=0: \dot{\sigma}=0 \\
\text { At } z=H \text { or } \sigma=1: \dot{\sigma}=0
\end{array}\right\}
$$

where $\dot{\sigma}$ is the vertical velocity in $\sigma$ coordinate system.

The properties embodied in Eqs. (6) and (7) provide special advantages of the $\sigma$ system over the $z$ system. Their simplicity makes it possible to formulate lower and upper boundary conditions easily for complex terrain and boundary layer. These properties are summarized in Figure 1.

The following relationships between the $\sigma$ and $z$ coordinate systems along $x$ and $y$ coordinates provide a means for transforming horizontal derivatives from one coordinate system to another:

$$
\begin{aligned}
& \left(\frac{\partial}{\partial x}\right)_{\sigma}=\frac{\partial}{\partial z}\left(\frac{\partial z}{\partial x}\right)_{\sigma}+\left(\frac{\partial}{\partial x}\right)_{z} \\
& \left(\frac{\partial}{\partial y}\right)_{\sigma}=\frac{\partial}{\partial z}\left(\frac{\partial z}{\partial y}\right)_{\sigma}+\left(\frac{\partial}{\partial y}\right)_{z}
\end{aligned}
$$

In the above, the subscripts $\sigma$ and $z$ indicate that the derivatives are evaluated at constant $\sigma$ and $z$ surfaces, respectively. The corresponding relationship between vertical derivatives can be derived with the aid of Eq. (5). Thus,

$$
\frac{\partial}{\partial z}=\frac{\partial}{\partial \sigma} \frac{\partial \sigma}{\partial z}=\frac{1}{H-h} \frac{\partial}{\partial \sigma}
$$




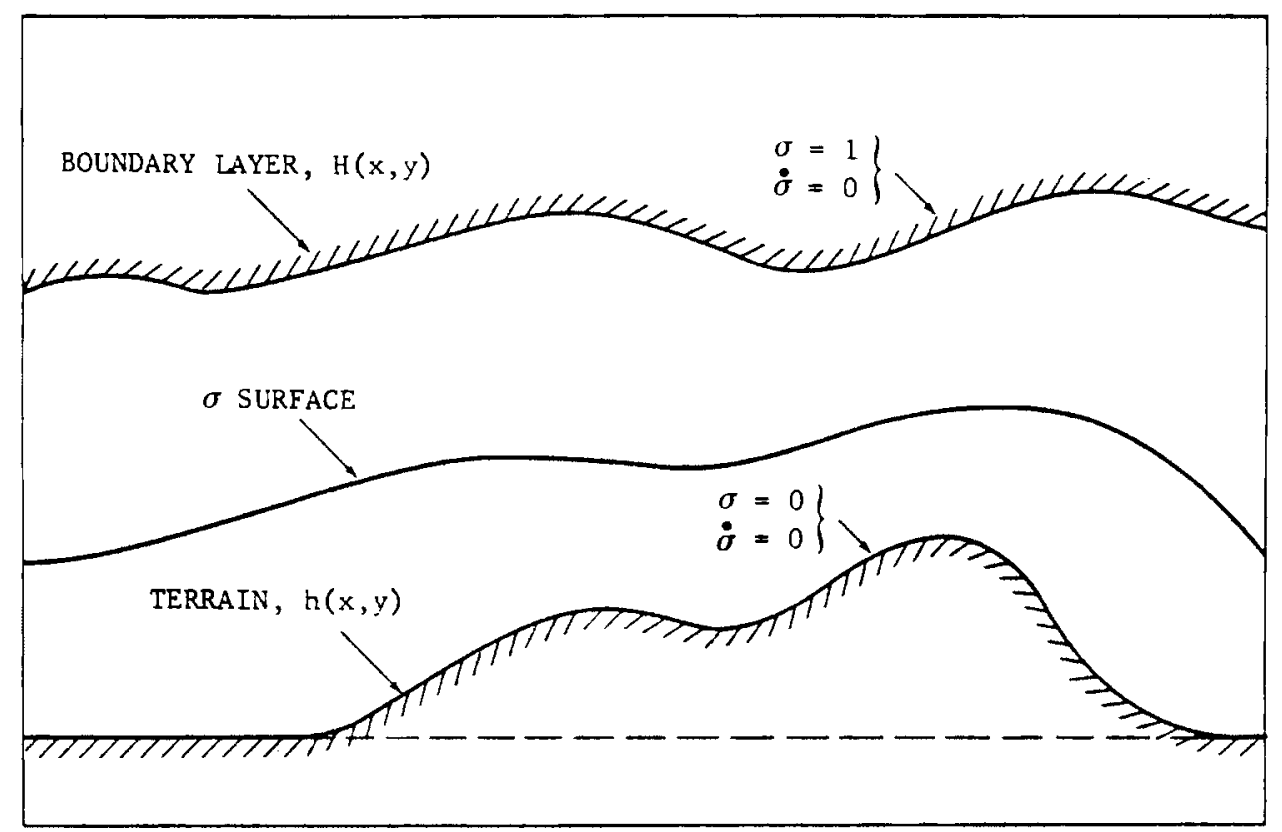

FIGURE 1 SCHEMATIC DIAGRAM SHOWING PROPERTIES OF THE SIGMA COORDINATE SYSTEM

The Euler-Lagrange equations (1) through (4) can be transformed into $\sigma$ coordinate system by using Eqs. (5), (7), (9), (10), and (11). For example, the continuity equation in the $\sigma$ coordinate system can be written as

$$
\frac{\partial}{\partial x}[(H-h) u]+\frac{\partial}{\partial y}[(H-h) v]+\frac{\partial}{\partial \sigma}[(H-h) \dot{\sigma}]=0
$$

or

$$
\frac{\partial u^{*}}{\partial x}+\frac{\partial v^{*}}{\partial y}+\frac{\partial w^{*}}{\partial \sigma}=0
$$

where

$$
\begin{aligned}
& \mathrm{u}^{*}=\mathrm{u}(\mathrm{H}-\mathrm{h}) \\
& \mathrm{v}^{*}=\mathrm{v}(\mathrm{H}-\mathrm{h}) \\
& \mathrm{w}^{*}=\dot{\sigma}(\mathrm{H}-\mathrm{h})
\end{aligned}
$$

Noting the analogy between $u, v, w, z$, and $u^{*}, v^{*}, w^{*}$, and $\sigma$ in Eqs. (4) and (12), we can write the Euler-Lagrange equations in the $\sigma$ coordinate system as follows: 


$$
\left.\begin{array}{l}
2 W_{H}\left(u^{*}-u_{o}^{\prime}\right)-\frac{\partial \lambda}{\partial x}=0 \\
2 W_{H}\left(v^{\cdot}-v_{o}^{\cdot}\right)-\frac{\partial \lambda}{\partial y}=0 \\
2 W_{v}\left(w^{*}-w_{o}^{\circ}\right)-\frac{\partial \lambda}{\partial \sigma}=0
\end{array}\right\}
$$

Together with the equation of continuity, Eq. (12), we have a complete set of equations. The quantities $W_{H}$ and $W_{V}$ represent the weights assigned to the modified horizontal $\left(\mathrm{u}^{*}\right.$ and $\left.\mathrm{v}^{*}\right)$ and the vertical wind $\left(w^{*}\right)$ components, respectively; these are determined through numerical experiments. Two properties of the set may be mentioned. First, through Eq. (12) the mass conservation is imposed in the adjustment process. Second, the difference between the observed and the adjusted values of $u^{*}, v^{*}$, and $w^{*}$ can be minimized on the basis of Eq. (14).

\section{The Basic Model Equations}

The basic equations of the COMPLEX model have been derived from Eqs. (12) and (14). For example, by eliminating $v^{*}$ and $w^{*}$, and $\lambda$ from these equations we obtain

$$
\frac{\partial^{2} u^{*}}{\partial x^{2}}+\frac{\partial^{2} u^{*}}{\partial y^{2}}+\frac{W_{H}}{W_{\mathrm{v}}}\left(\frac{\partial^{2} \mathrm{v}^{*}}{\partial \sigma^{2}}\right)=\frac{\partial^{2} u_{o}^{*}}{\partial y^{2}}+\frac{W_{H}}{W_{\mathrm{v}}} \frac{\partial^{2} u_{o}^{*}}{\partial \sigma^{2}}-\frac{\partial}{\partial x}\left(\frac{\partial \mathrm{v}_{o}^{*}}{\partial y}+\frac{\partial w_{o}^{*}}{\partial \sigma}\right)
$$

Similar equations involving $\mathrm{v}^{*}$ and $\mathrm{w}^{*}$ can be obtained by respectively eliminating $\left(u^{*}, w^{*}\right.$ and $\left.\lambda\right)$ and $\left(u^{*}, v^{*}\right.$, and $\left.\lambda\right)$ from Eqs. (12) and (14). These equations are

$$
\begin{aligned}
& \frac{\partial^{2} \mathrm{v}^{\cdot}}{\partial x^{2}}+\frac{\partial^{2} \mathrm{v}^{\cdot}}{\partial y^{2}}+\frac{W_{H}}{W_{\mathrm{v}}}\left(\frac{\partial^{2} u^{\cdot}}{\partial \sigma^{2}}\right)=\frac{\partial^{2} \mathrm{v}_{o}^{*}}{\partial x^{2}}+\frac{W_{H}}{W_{\mathrm{v}}} \frac{\partial^{2} \mathrm{v}_{o}^{*}}{\partial \sigma^{2}}-\frac{\partial}{\partial y}\left(\frac{\partial u_{o}^{*}}{\partial x}+\frac{\partial w_{o}^{*}}{\partial \sigma}\right) \\
& \frac{\partial^{2} w^{*}}{\partial x^{2}}+\frac{\partial^{2} w^{*}}{\partial y^{2}}+\frac{W_{H}}{W_{v}}\left(\frac{\partial^{2} w^{\cdot}}{\partial \sigma^{2}}\right)=-\frac{W_{H}}{W_{v}} \frac{\partial}{\partial \sigma}\left(\frac{\partial u_{o}^{*}}{\partial x}+\frac{\partial v_{o}^{*}}{\partial y}\right)+\frac{\partial^{2} w_{o}^{*}}{\partial x^{2}}+\frac{\partial^{2} w_{o}^{*}}{\partial y^{2}}
\end{aligned}
$$

\section{The COMPLEX Model Equations}

In general, Eqs. (15), (16), and (17) can be integrated over any type of terrain for obtaining wind components at a location at which no observations are available. However, as stated earlier, our specific requirements are that the method developed for obtaining wind at a potential site must

- Be economical

- Provide wind at hub height

- Use conventional surface (anemometer level) wind at a limited number of scattered locations in the vicinity of the site. 
Thus we have modified Eqs. (12) and (15) through (17) by replacing $\sigma$ with a new vertical coordinate $\zeta$, where

$$
\zeta=A \ln \left(\frac{\sigma}{\sigma_{a}}\right)
$$

and $A$ is an empirical parameter, $\sigma$ is defined by Eq. (5), and $\sigma_{a}$ represents the value of $\sigma$ at anemometer height $(10 \mathrm{~m})$.

For the purpose of this study, Equations (12) and (15) through (17) have been modified to conform to the following requirements:

(1) The maximum number of levels in the vertical is 10 and grid spacing in the vertical is equal. Thus, by definition, since $\zeta$ varies from 0 to $1, \Delta \zeta$ is 0.111 .

(2) The hub height $(45.7 \mathrm{~m})$, at a given site always corresponds to level 4.

(3) Level 1 always corresponds to the anemometer level $(10 \mathrm{~m})$. In this case, $\sigma_{a}$, by definition, is a function of the top of the boundary layer, $H$, as well as terrain height, $h$.

The implication of items (2) and (3) together is that for any given site the parameter A [Eq. (18)] can be treated as a constant so long as the level and the local elevation of hub height at the site is not changed. Typical value of $A$ used in this study is .22 .

The transformation of Eqs. (12) and (15) through (17) from the $\sigma$ to the $\zeta$ coordinate is made by using the relationships

$$
\frac{\partial}{\partial \sigma}=F_{1} \frac{\partial}{\partial \zeta} ; \frac{\partial^{2}}{\partial \sigma^{2}}=F_{2} \frac{\partial}{\partial \zeta}+F_{3} \frac{\partial^{2}}{\partial \zeta^{2}}
$$

where

$$
F_{1} \equiv \frac{A}{\sigma_{a}} e^{-\zeta / A} ; F_{2} \equiv-\frac{F_{1}^{2}}{A} ; F_{3} \equiv F_{1}^{2}
$$

Thus the modified form of Eqs. (12) and (15) through (17) in the new vertical coordinate system, $\zeta$, can be written as

$$
\begin{aligned}
& \frac{\partial^{2} u^{\cdot}}{\partial x^{2}}+\frac{\partial^{2} u^{\cdot}}{\partial y^{2}}+\frac{W_{H}}{W_{\mathrm{v}}}\left(F_{2} \frac{\partial u^{\cdot}}{\partial \zeta}+F_{3} \frac{\partial^{2} u^{\cdot}}{\partial \zeta^{2}}\right)=\frac{\partial^{2} u_{0}^{\cdot}}{\partial y^{2}}+\frac{W_{H}}{W_{\mathrm{v}}} \\
& \left(F_{2} \frac{\partial u_{o}^{*}}{\partial \zeta}+F_{3} \frac{\partial^{2} u_{o}^{*}}{\partial \zeta^{2}}\right)-\frac{\partial}{\partial x}\left(\frac{\partial \mathrm{v}_{o}^{*}}{\partial y}+F_{1} \frac{\partial w_{o}^{*}}{\partial \zeta}\right) \\
& \frac{\partial^{2} v^{\bullet}}{\partial x^{2}}+\frac{\partial^{2} v^{\bullet}}{\partial y^{2}}+\frac{W_{H}}{W_{v}}\left(F_{2} \frac{\partial v^{\bullet}}{\partial \zeta}+F_{3} \frac{\partial^{2} v^{\bullet}}{\partial \zeta^{2}}\right)=\frac{\partial^{2} v_{o}^{\bullet}}{\partial x^{2}}+\frac{W_{H}}{W_{v}}
\end{aligned}
$$




$$
\begin{aligned}
& \left(F_{2} \frac{\partial v_{o}^{*}}{\partial \zeta}+F_{3} \frac{\partial^{2} v_{o}^{*}}{\partial \zeta^{2}}\right)-\frac{\partial}{\partial y}\left(\frac{\partial u_{o}^{*}}{\partial x}+F_{1} \frac{\partial w_{o}^{*}}{\partial \zeta}\right) \\
& \frac{\partial^{2} w^{*}}{\partial x^{2}}+\frac{\partial^{2} w^{*}}{\partial y^{2}}+\frac{W_{H}}{W_{\mathrm{v}}}\left(F_{2} \frac{\partial w^{*}}{\partial \zeta}+F_{3} \frac{\partial^{2} w^{*}}{\partial \zeta^{2}}\right)=\frac{\partial^{2} w_{o}^{*}}{\partial x^{2}}+\frac{\partial^{2} w_{o}^{*}}{\partial y^{2}}- \\
& \frac{W_{H}}{W_{\mathrm{v}}} \cdot F_{1} \frac{\partial}{\partial \zeta}\left(\frac{\partial u_{0}^{\cdot}}{\partial x}+\frac{\partial \mathrm{v}_{0}^{-}}{\partial y}\right) \\
& \frac{\partial u^{\bullet}}{\partial x}+\frac{\partial v^{\bullet}}{\partial y}+F_{1} \frac{\partial w^{*}}{\partial \zeta}=0
\end{aligned}
$$

Equations (19) through (22) constitute the "working equations" of the COMPLEX

model.

\section{Use of the COMPLEX Model Equations}

In actual practice the wind at a given site can be obtained by integrating, independently, the finite difference form of Eqs. (20) through (22). The integrations are performed by applying a relaxation method. The final solution is in the form of horizontal and vertical components of wind at various levels in the vertical that have been adjusted for the underlying terrain effects and that satisfy the mass conservation equation (22).

\section{a. Grid Layout}

Since finite difference forms of the COMPLEX model equations are integrated, it is necessary to prescribe a three-dimensional grid encompassing a given site. Figure 2 shows a schematic representation of such a grid. The grid spacing in the east and north directions is prescribed to be equal; the grid spacing in the vertical is variable such that a greater resolution is attained in the lower levels of the atmosphere.

Figure 3 shows a $10-\mathrm{km}$ horizontal grid superimposed on a base relief map for the area around Boardman, Oregon. This is one of several candidate sites being considered for wind energy conversion. There are 14 grid points along the $x$ direction and 11 grid points along the $y$ direction. In some instances where the terrain features are very complex and one grid is not able to resolve the terrain features adequately, we have used a fine grid in conjunction with a relatively coarse grid. Figure 3 also shows a fine grid $(2 \mathrm{~km})$ encompassing Boardman, together with the $10-\mathrm{km}$ grid. This fine grid provides a much better resolution of topography in the immediate vicinity of the site. There are 10 grid points in vertical and typical values for the heights at different levels, for this site, are shown in Figure 2.

\section{b. Topographic Data}

For integrating the model equations on a grid, it is also necessary to provide gridded topography, which can be obtained manually by laying the grid on terrain maps obtainable from United States Geological Survey (USGS) and reading off the terrain heights at each grid point. Figure 4 shows the contour analysis of the gridded topography for Boardman for the $10-\mathrm{km}$ grid. A comparison of this with Figure 3 shows that the gridded topography is quite representative of the actual topography within the $10-\mathrm{km}$ grid. (Details of obtaining gridded topography manually are given in the Appendix, Section II-B, Step 5). 
TYPICAL

LEVEL

HE IGHTS

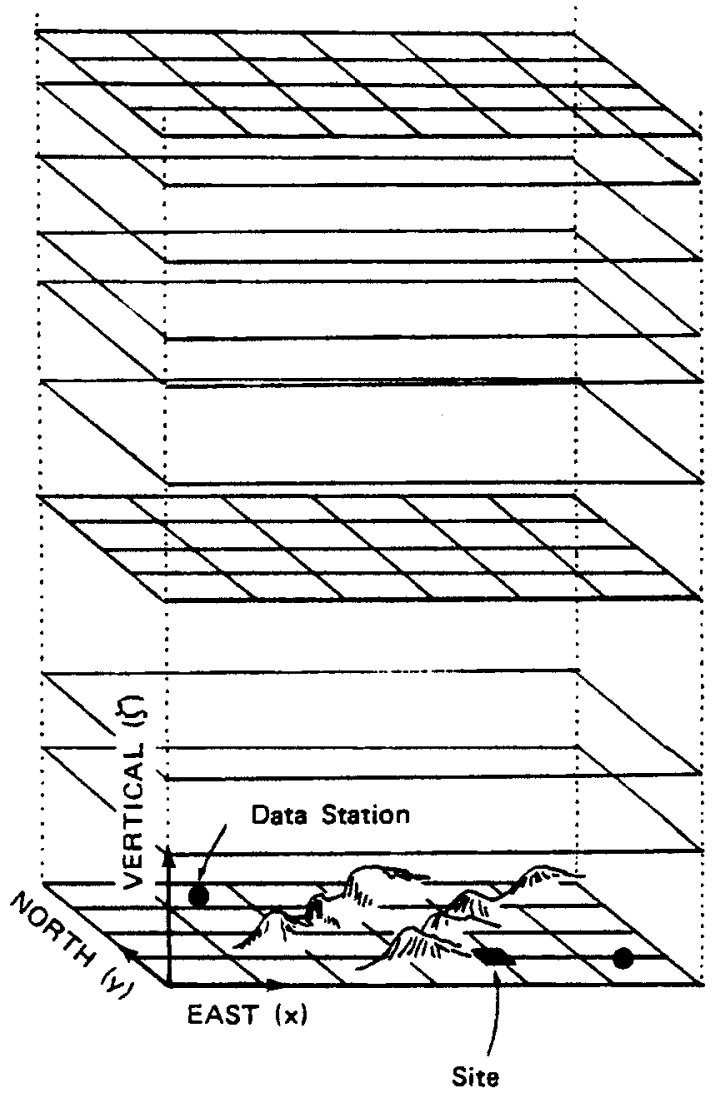

(m)

Represents Inversion or

10 Top of Boundary Layer

956

576

8

347

7

209

6

125.9

5

75.9

4 Represents Hub Level

45.7

3

27.5

2

16.6

1. Represents Anemometer

10 Level

FIGURE 2 SCHEMATIC REPRESENTATION OF A THREEDIMENSIONAL GRID AT A GIVEN SITE

c. Wind Data

\section{1) Horizontal Wind}

The gridded wind information is generated by an objective analysis technique developed by Mancuso and Endlich (1973), which uses wind observations at irregularly spaced synoptic weather stations. Thus it is necessary to select three or four stations in the vicinity of a given site at which conventional surface wind data are available. The selection of these stations as well as the period of data, though somewhat subjective, is based on clearly identifiable criteria. We have considered the following criteria in the selection process:

(i) The data stations should be reasonably close to the WECS site.

(ii) The geographical area surrounding the wind station should be similar to that surrounding the potential wind energy conversion site--e.g., both the station and the WEC site in the same river valley if possible. 


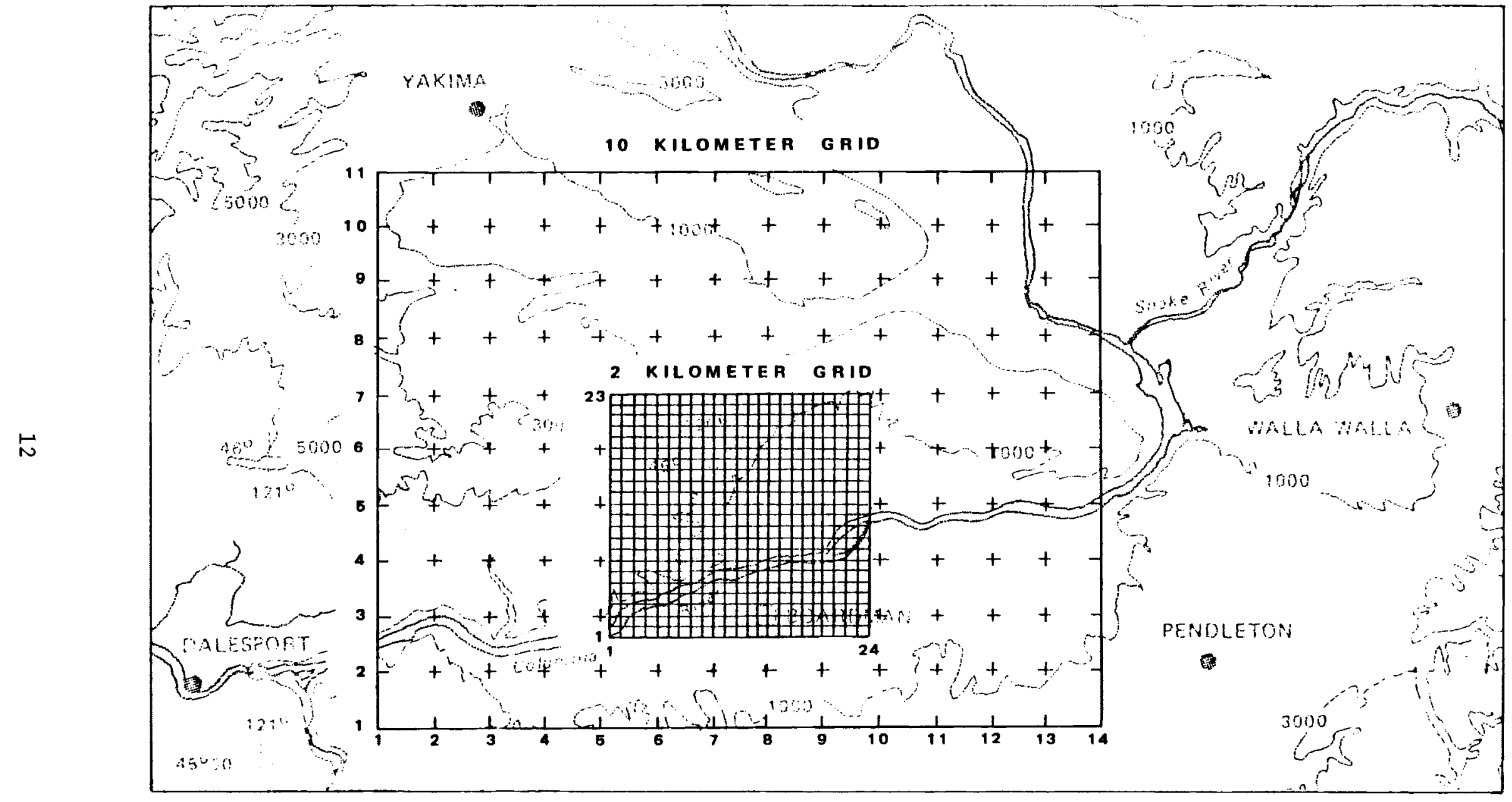

FIGURE 3 EXAMPLE OF THE USE OF A COARSE AND FINE GRID AT THE WIND ENERGY CONVERSION SITE AT BOARDMAN, OREGON 
(iii) A variety of directions from study site to wind sta-

tion should be represented--i.e., the wind stations should surround the study site.

(iv) Twenty-four or more observations per day should be available, but 8 per day could be used with appropriate temporal interpolation.

(v) Nearby upper-air data should be available.

(vi) At least one or two years of data are desirable, from all stations associated with a given site.

The importance of the first four criteria is fairly obvious. We want the measured winds to be as closely related as possible to the unknown winds at the study site, and we believe that proximity and similarity of surroundings contribute positively to the desired relationship. The third criterion is important if there are large-scale gradients in the wind field; several observations clustered to one side of the study site would give a biased indication of the prevailing winds. The method as described uses 24 observations per day and this is most desirable; hence, the fourth criterion. However, as noted, the method could be adopted to use fewer observations.
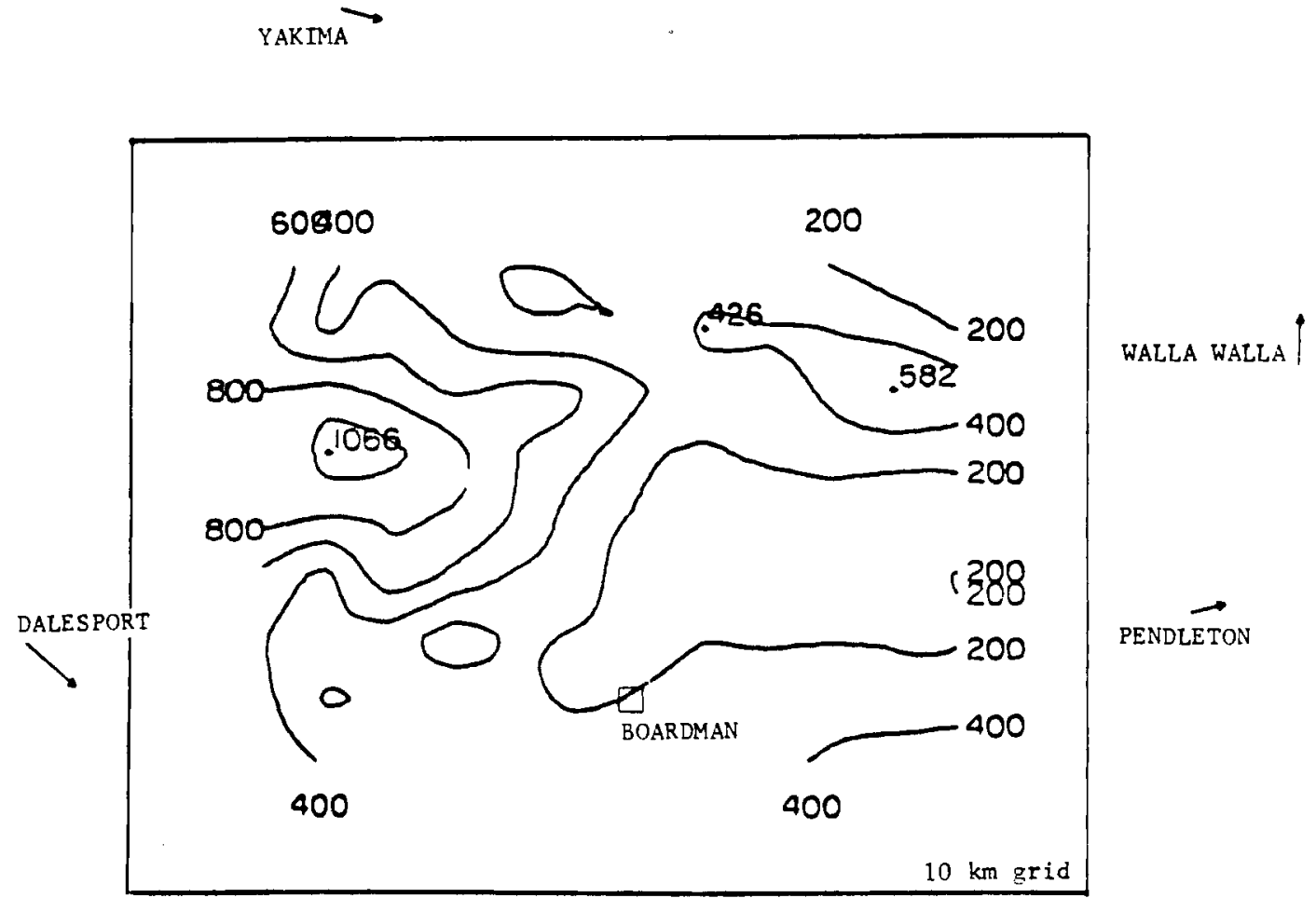

FIGURE 4 THE CONTOUR ANALYSIS OF GRIDDED TOPOGRAPHY (m) FOR BOARDMAN OBTAINED BY USING THE GRID SHOWN IN FIGURE 3. MEAN WIND VECTORS FOR THE YEAR 1961 AT FOUR DATA STATIONS ARE ALSO SHOWN. 
Initially, we sought upper air data because it provides some measure of vertical shear that we felt might be required. However, as the method has developed, upper air data have not been used. The sixth criterion is necessary because the COMPLEX model requires concurrent data from surrounding data stations.

Figure 3 shows four such data stations in the region surrounding Boardman; these are Dalesport, Yakima, Walla Walla, and Pendleton. Figure 4 shows an example of surface wind data at these four stations, and Figure 5 shows the interpolated wind field derived from these without incorporating the effect of topographic features.

\section{2) Vertical Profile of Wind}

The vertical distribution of wind on a 3-D grid is obtained by using a power law formulation of the form

$$
\frac{V_{2}}{V_{1}}=\left(\frac{Z_{2}}{Z_{1}}\right)^{\alpha}
$$

where $V_{2}, V_{1}$ are wind speeds at heights $Z_{2}$ and $Z_{1}$, respectively, and $\alpha$ is a dimensionless exponent. Though the value of $\alpha$ depends on atmospheric stability, wind speed, and surface roughness, a value of $1 / 7$ for smooth surface has been widely used by engineers and meteorologists alike. Recent research has indicated that whereas a value of $1 / 7$ (based on wind tunnel experiments) is reasonably valid for long-term averages under neutral stability conditions, it is perhaps more realistic to estimate $\alpha$ for each site. An average value of $0.23 \pm 0.03$ has been estimated on the basis of tower data at four sites in different areas of the United States (Justus and Mikhail, 1976). While it is difficult to justify one value of $\alpha$ for all the sites, for the pur-

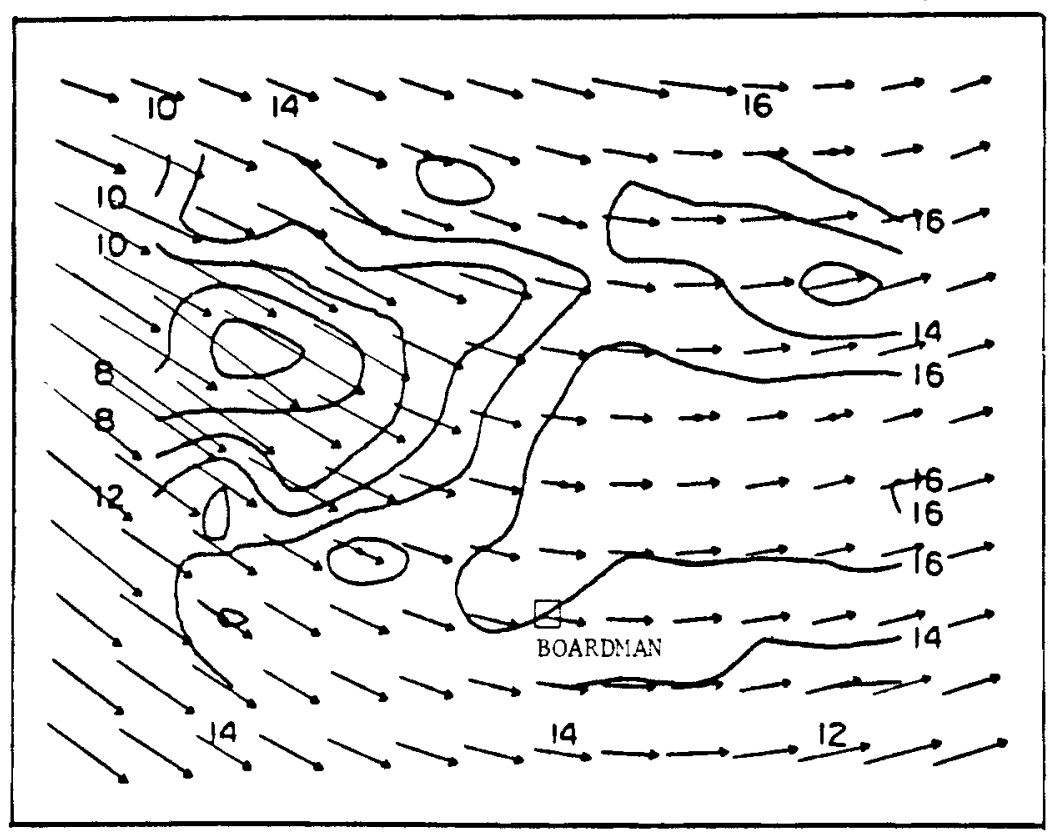

FIGURE 5 GRIDDED WIND FIELD DERIVED FROM WIND VECTORS AT FOUR STATIONS SHOWN IN FIGURE 4. NO TOPOGRAPHIC EFFECTS ARE INCORPORATED. 
pose of our research we have chosen a value of 0.2 , which is the average of the published values of Touma (1977) for neutral conditions at various locations. This value also corresponds closely to that suggested by Justus and Mikhail (1976). It should be noted that we have used a power law [Eq. (23)] only to obtain an initial vertical profile required for solving Eqs. (20) through (22). It is not used to obtain hub height wind, which is in fact obtained as a solution of Eqs. (20) through (22).

\title{
d. Wind at Hub Height $(45.7 \mathrm{~m})$
}

The wind and topographic information in gridded form is input as boundary conditions for solving Eqs. (20) through (22). In brief, the sequence of steps for calculating the adjusted values for $u, v$, and $w$ is:

\author{
- Solve Eq. (22) for $w^{*}$ \\ - Solve Eq. (20) for $\mathrm{u}^{*}$ \\ - $\quad$ Solve Eq. (21) for $\mathrm{v}^{*}$ \\ - $\quad$ Compute $u, v$, and $\dot{\sigma}$ from Eq. (13) \\ - Using the values of $u, v$, and $\dot{\sigma}$, compute $w$ from Eq. (7).
}

The resulting solution provides three-dimensional grid-point values of wind that explicitly incorporate the effect of topographic features. (Details about the method of using the COMPLEX model are given in the Appendix.) Figure 6 shows the vector difference between COMPLEX model solutions at grid points and the corresponding wind field shown in Figure 5 . It is seen that when topographic effects are included through the COMPLEX model, the wind tends to go around the ridges and down the slope of the higher elevations. The figure also shows that wind speeds increase over ridges, which is consistent with the results reported by Elliot (1977) for the speeds ranging up to $12 \mathrm{~ms}^{-1}$.

The hub height solution is provided without any further horizontal and/or vertical interpolation or extrapolation because, as discussed before, the model formulations have been set up such that a site is always located at a grid point and the hub level always corresponds to the fourth level of the grid.

\section{B. Reconstructing Hub Height Wind from the COMPLEX Model Solutions}

The applications of the COMPLEX model will in general involve only a limited number of input variables. For example, the applications presented later have used the u (west-to-east) and $v$ (south-to-north) components of the winds at either three or four locations. Hence, the input variables have been either six or eight in number. The modeling process described in Section II-A determines the winds at each grid point as linear combinations of those inputs. The fact that the solutions are linear combinations of the inputs suggests that solutions for several "standard", linearly independent input data sets might be combined appropriately to find the solution for any arbitrary input data set. This supposition is valid, and it forms the basis for the hourly solutions. 


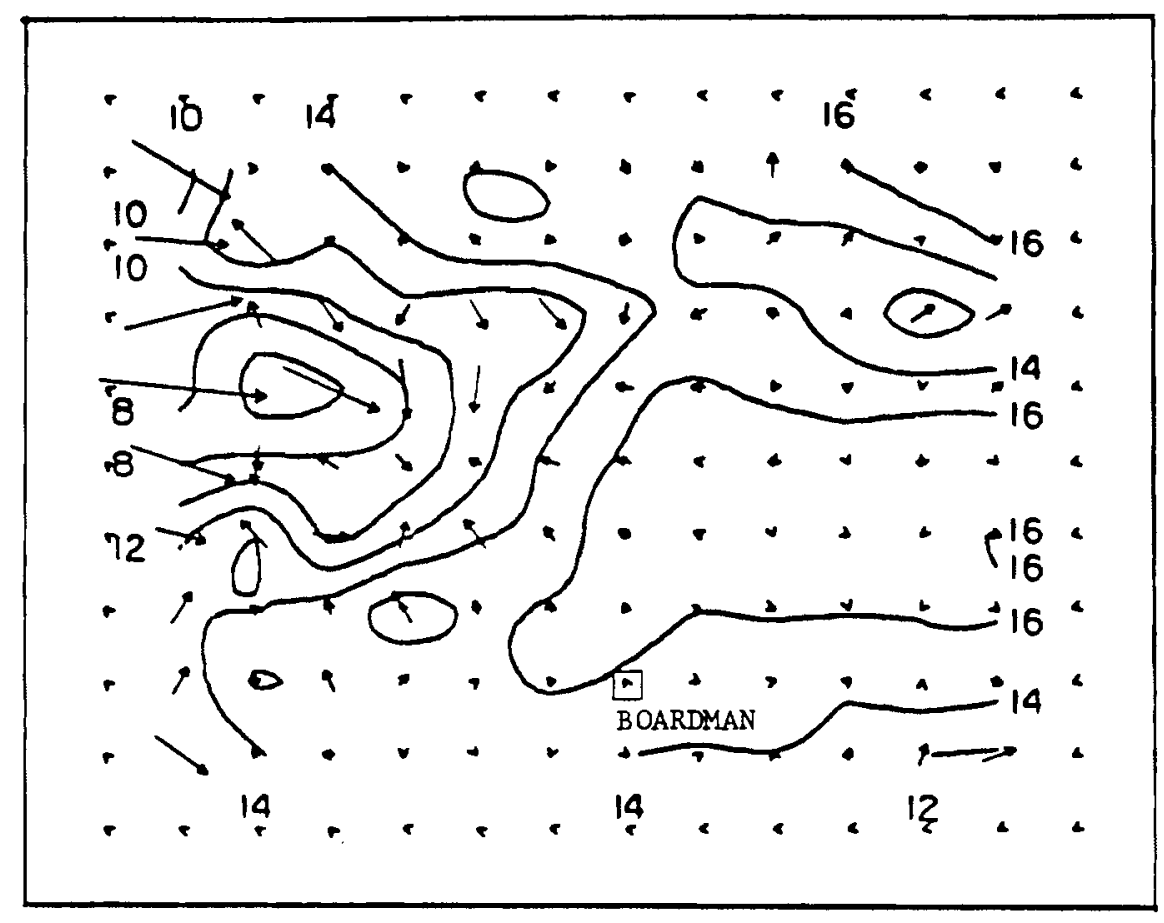

FIGURE 6 VECTOR DIFFERENCE $\left(\mathrm{m} \mathrm{s}^{-1} \times 10\right)$ BETWEEN COMPLEX MODEL-GENERATED WINDS AND THE WIND FIELD SHOWN IN FIGURE 5.

The finite difference solutions of the partial differential equation

$$
\nabla^{2} \phi=F(x, y, z)
$$

form the basis of the COMPLEX model where $\phi$ is the unknown variable. The assumption that the solution for an arbitrary set of inputs can be expressed as a linear combination of solutions means that if

$$
\phi^{1} \text { is a solution for } F^{1}
$$

and

$$
\phi^{2} \text { is a solution for } F^{2}
$$

then $a \phi^{1}+b \phi^{2}$ will be a solution for $a F^{1}+b F^{2}$. $\quad F^{2}$. Here, a and $\mathrm{b}$ are constants, $F^{1}$ and $F^{2}$ are input data sets, $\phi^{1}$ and $\phi^{2}$ are the corresponding solution sets, and the grid spacing and other characteristics of finite difference methods remain unchanged.

It can be shown that the above generalization is true. The proof here is limited to two dimensions for clarity, but can be extended by induction to three dimensions. Consider the finite difference form of Eq. (24):

$$
\phi_{i-1, j}+\phi_{i+1, j}-4 \phi_{i, j-1}+\phi_{i, j-1}+\phi_{i, j+1}=F_{i, j}
$$

where the equation is to be solved over the region $o<i<I ; o<j<J$. This region and the grid numbering system are illustrated in Figure 7.

The following proof was provided by George Byrd, Programmer in the Statistical Analysis and Computation Department, SRI International. 


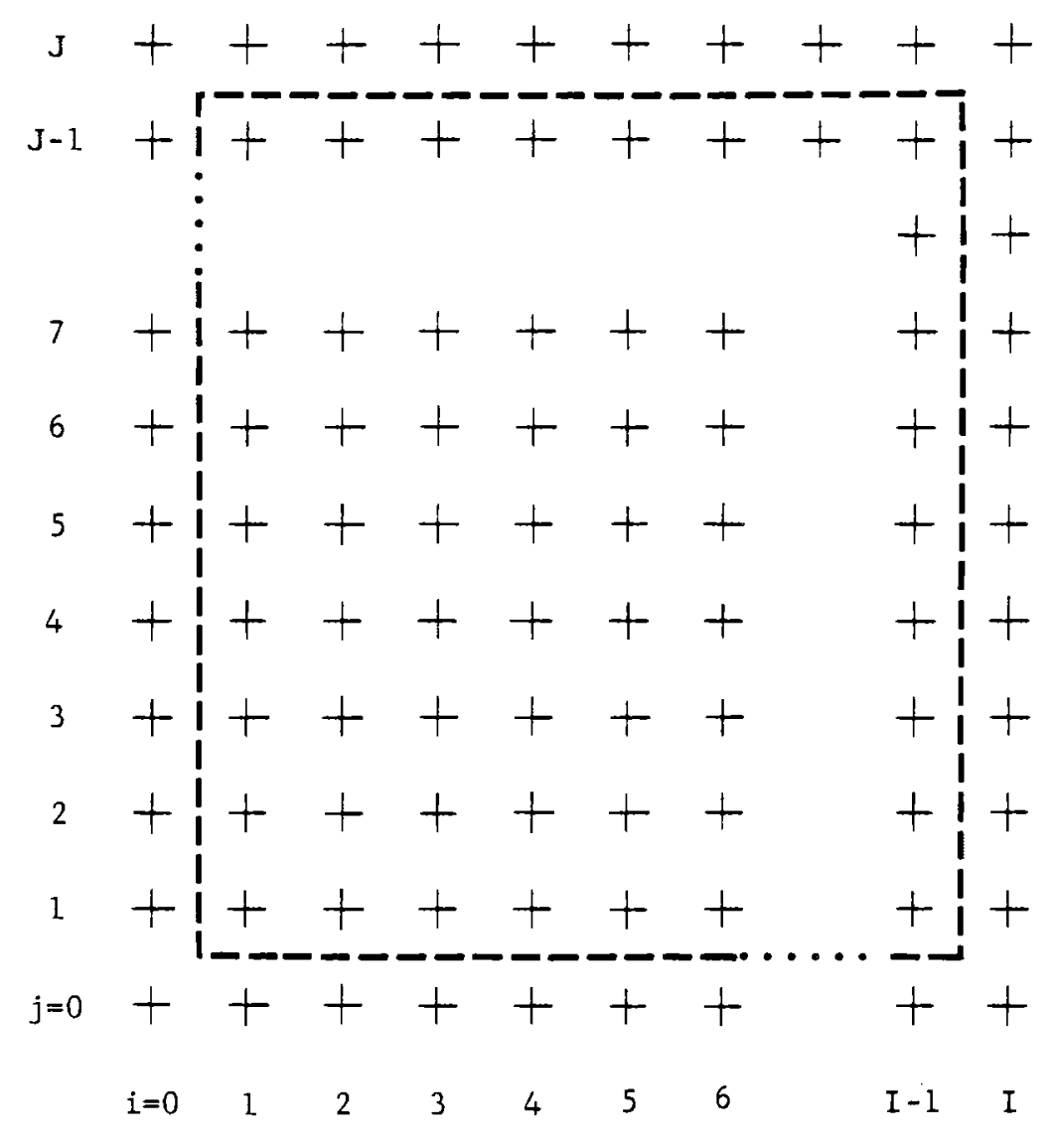

FIGURE 7 SCHEMATIC REPRESENTATION OF THE GRID FOR SOLVING FINITE DIFFERENCE EQUATION

The values on the perimeter $\phi_{o, j}, \phi_{i, o}, \phi_{I, j}, \phi_{i, J}$ are derived from the observed input winds and are held fixed through the calculations, as are certain interior values if they are near an observation point. The finite difference equation given above can then be written for each grid point within the solution area, yielding (I-1)x(J-1) linear equations with as many unknowns:

$$
\begin{aligned}
& \phi_{0, j}, \phi_{i, o}, \phi_{I, j}, \text { and } \phi_{i, J} \\
& \phi_{0,1}+\phi_{2,1}-4 \phi_{1,1}+\phi_{1,0}+\phi_{1,2}=F_{1,1} \\
& \phi_{1,1}+\phi_{3,1}-4 \phi_{2,1}+\phi_{2,0}+\phi_{2,2}=F_{2,1} \\
& \dot{:} \\
& \dot{\cdot} \\
& \phi_{I-2, J-1}+\phi_{I, J-1}-4 \phi_{I-1, J-1}+\phi_{I-1, J-2}+\phi_{I-1, J}=F_{I-1, J-1} .
\end{aligned}
$$

These equations may be solved in any appropriate manner, including a relaxation method (Southwell, 1946). The solutions $\phi_{i, j}$ will by definition be linear with respect to $F_{i, j}$. The convergence criterion of an interative solution will affect the linearity of the resulting $\phi_{i, j}$. That is, the smaller the error allowed for convergence, the smaller the error, $\epsilon$, in the linear relationship 


$$
\begin{aligned}
& \nabla^{2}\left(a \phi^{1}+b \phi^{2}\right)=a F^{1}+b F^{2}+\epsilon \text { where } \\
& a \nabla^{2} \phi^{1}=a F^{1} \text { and } b \nabla^{2} \phi^{2}=b F^{2}
\end{aligned}
$$

This problem can also be approached in a continuous space. Since the $\nabla^{2}$ is linear--i.e.,

$$
\nabla^{2}\left(\phi^{1}+\phi^{2}\right)=\nabla^{2} \phi^{1}+\nabla^{2} \phi^{2}
$$

the above result follows.

Figure 8 is a schematic representation of how the above results are applied to the problem at hand. The upper part of the figure shows that there is an equation that relates the observed wind components for each site for a given hour $h_{1}$ to a linear combination of column vectors. The coefficients of the linear combination for the hour $h_{1}$, are symbolized by $a_{1} h^{1}$ through $a_{8} h^{1}$. Since the number of components in the column vectors and the number of column vectors is greater than the number of elements in the input data set, it is possible to find appropriate linear combination as long as at least 8 (in the example shown here) of the column vectors are linearly independent. The first eight column vectors are independent because they are the orthonormal eigenvectors of the covariance matrix derived from the complete data set. Any linearly independent set of vectors would do, but there are advantages to using the eigenvectors.

As long as the individual column vectors are linearly independent, it will always be possible to find a set of coefficients, $a_{j}$, that will satisfy the equation. These coefficients are the inner products of the input data vector and the eigenvectors:

$$
a_{j}^{h}=\sum_{k=1}^{N}\left(d_{k}^{h}-\bar{d}_{k}\right) \cdot b^{j k}
$$

where

$a_{j}^{h}=$ the coefficient of the jth eigenvector for the hth hour

$d_{k}^{h}=$ is the kth datum of the input data set for the hth hour. For example $d_{1}^{h}$ might be the $\mathrm{u}$ component observed at hour $\mathrm{h}$ at the first site; $d_{2}^{h}$, the $\mathrm{v}$ component at that site; $d_{3}^{h}$, the u component at the second site and so forth.

$\bar{d}_{k}=$ is the average over all input data sets of the kth datum.

$b_{j k}=$ is the kth element of the jth eigenvector.

$\mathbf{N}=$ the number of elements in the eigenvectors, i.e., twice the number of stations from which input data are used.

The superscripts $h$ identify the terms that change from hour to hour. It should be noted that the determination of the hourly coefficients is quite simple and does not require a large amount of computation.

The implication of the linearity of the program COMPLEX is that the solutions for each of the eigenvectors can be combined linearly using the coefficients for the hour $a_{j}^{h}$ to obtain the solution that would have been obtained using the observed data set as an input. This is shown schematically in Figure 8. The central part of the figure shows that solutions may be obtained for each of the eigenvectors as an input to the model. These solutions are referred to as $\left(u_{s 1}, v_{s 1}\right)$ through $\left(u_{s 8}, v_{s 8}\right)$. A solution is also required for the mean of the input data $\left(\bar{u}_{s}, \bar{v}_{s}\right)$ 


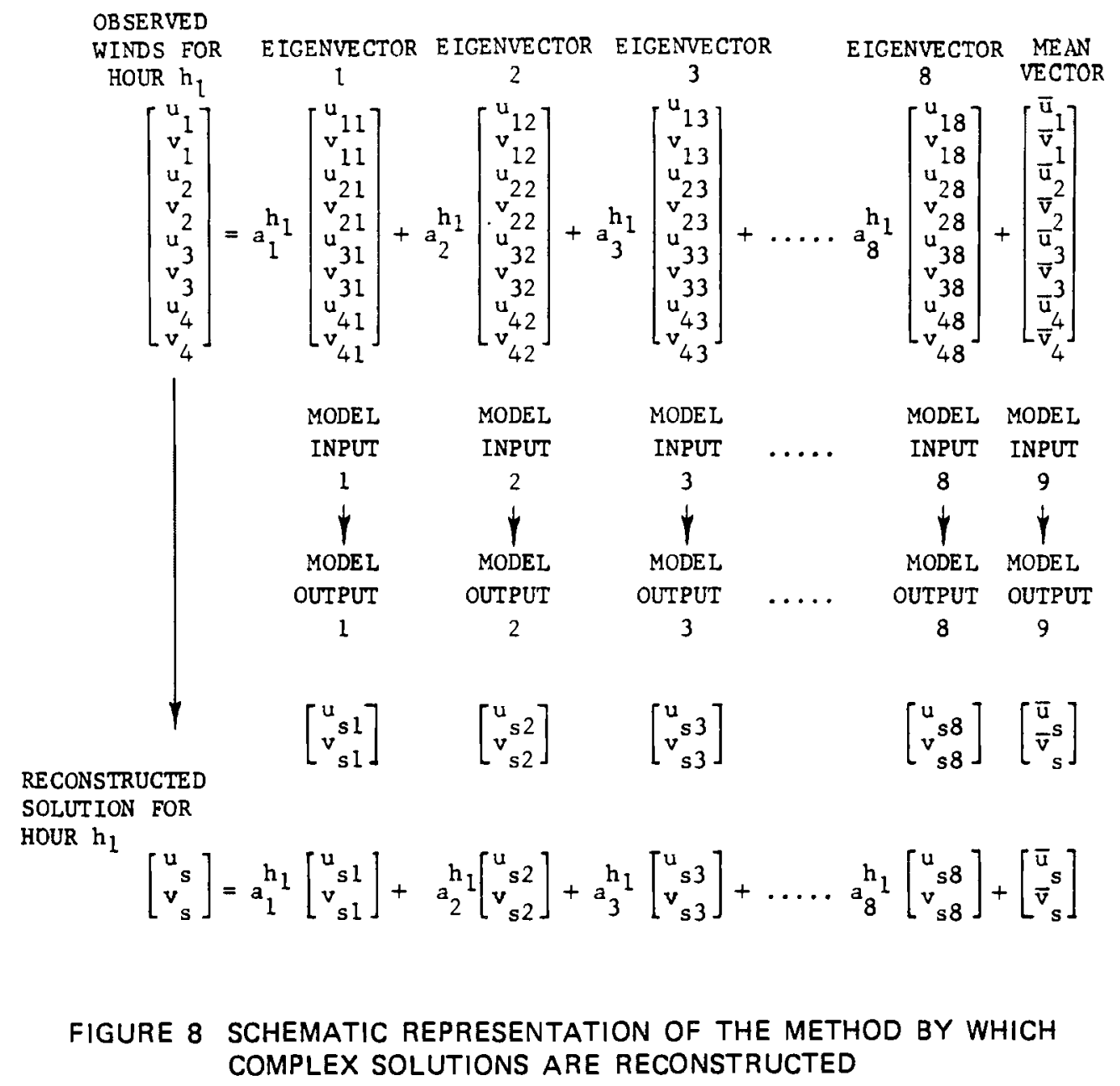

by summing eight pairs of numbers and the mean for each of the two components. The application of the model has been reduced to a very manageable number of arithmetic operations.

It should be remembered that the choice of eigenvectors of the covariance matrix as the basis vectors for the calculations was originally made to provide a method for reducing the number of required descriptors in order to simplify the job of classifying the input data sets.

At the bottom, Figure 8 shows how these solutions are linearly combined to give the same solution that would be obtained by applying the COMPLEX model directly to the hourly input data. In the applications discussed in this report the solution is for the hub-height grid point but any other grid point would serve as well. The linear combination of the separate solutions for a given hour uses the coefficients $\left(a_{h} \ldots a_{8}\right)$ derived from the input data set for the same hour.

The advantages of using linear combinations of solutions are obvious. By far the most important advantage is that the COMPLEX model need be applied directly only a very few times. In the example illustrated in Figure 8, the COMPLEX model is applied only nine times, once for the mean and once for each basis vector. After that, the hourly solutions can be determined by first calculating the inner products. In the example, each inner product requires only the summation of the products of eight pairs of numbers, and there are only eight such inner products to be determined. After the inner products are known, the solution is achieved 
When it was decided to exploit the linear properties of the model, a reduction in the number of required descriptors was no longer imperative. However, we have continued to use the eigenvectors because we foresee the possibility that it may be desirable to filter out random, smallscale effects. The eigenvectors could provide a simple means for such filtering. The major features of the input data sets are described by the eigenvectors that represent most of the variance in the data. We have found that about $75 \%$ of the variance is generally represented by half the eigenvectors or fewer. In some topographically smooth areas such as Huron, South Dakota, or Russell, Kansas, one eigenvector (of six) represents more than half of the variance, and two represent about $80 \%$. Thus, the use of eigenvectors presents an opportunity to simplify the data representations considerably while still retaining most of the available information.

The covariance matrix used to derive the eigenvectors does not have to be based on all the available data. One or two years should be enough. Then, hourly inner products and reconstructed solutions could be obtained for as long a period as there were data from all the stations. The method is still applicable if there are some hours when data are missing from a station. In the computer programs presented in the Appendix, the most recent valid observation is always used; if data are missing, the last valid observation is substituted.

\section{Estimating Hub Height Wind Characteristics}

The problem of determining wind statistics from a long sequence of hourly values is one that has been solved of ten. The methods described to this point have been designed to provide the required sequence at the candidate site. From that sequence, the following statistical descriptions, among others, may be required:

(1) A frequency distribution of wind speed

(2) A joint frequency distribution of wind speed and direction

(3) Seasonal variability in wind speed

(4) Diurnal variability in wind speed

(5) Run duration analysis for wind speeds:

(a) Above or below $4 \mathrm{~m} \mathrm{~s}^{-1}$

(b) Between 10 and $25 \mathrm{~m} \mathrm{~s}^{-1}$

(6) Frequency of wind gusts above $25 \mathrm{~m} \mathrm{~s}^{-1}$.

The first three requirements are quite standard and we have chosen to use available computer program packages to calculate frequency distributions and joint frequency distributions. The speeds have been averaged as scalars, rather than vectors. The joint frequency distributions have been displayed as contingency tables of number of occurrences of various combinations of speed category ( $2 \mathrm{~m} \mathrm{~s}^{-1}$ class intervals) and direction (16-point compass). The frequency distributions of wind speed have been displayed in tabular form using $2 \mathrm{~m} \mathrm{~s}^{-1}$ class intervals.

For estimating frequency distribution of winds gusting above cut-out speed (COS) of 26 $\mathrm{m} \mathrm{s}^{-1}$, we have used the concept of "gust factor" for obtaining gust velocity from hourly (aver- 
aged) winds calculated by the COMPLEX model. Here gust factor is defined as the ratio of the mean velocity over a short period to the hourly mean. We have used a value of 1.4 for the gust factor, which has been determined from the relation between observed fastest mile and the hourly mean of which it is a part. (Fastest mile is defined as the fastest speed that one mile of wind passes the station.) We recognize that using one value for gust factor is an approximation because it varies not only with gust duration but also with hourly mean velocity (Hollister, 1970). For example, observations have shown that the gust factor for gust duration of $10 \mathrm{~s}$ is 1.45; this value becomes 1.25 for a gust duration of $60 \mathrm{~s}$. Also, gust factor can vary from 1.2 to 1.35 when the hourly wind velocity varies from $14 \mathrm{~m} \mathrm{~s}^{-1}$ to $50 \mathrm{~m} \mathrm{~s}^{-1}$. Thus the frequency distributions of wind speed also serve as the bases for describing the frequency distribution of winds gusting above cut-off speed.

Run duration statistics were determined by counting the number of instances when sequences of winds fitting certain descriptions $\left(<4 \mathrm{~m} \mathrm{~s}^{-1}, \geqslant 4 \mathrm{~m} \mathrm{~s}^{-1}\right.$, and between 10 and $\left.25 \mathrm{~m} \mathrm{~s}^{-1}\right)$ persisted for one hour only, for two hours, for three hours, and so forth.

The next section of this report presents examples of the required statistics derived for eight locations using the approaches described above. Although the statistics presented are based on only about one year's data, the methods are applicable to much longer periods. The emphasis in the research reported here has been on the development of a practical and realistic methodology for deriving such statistics, so the demonstration applications have treated a wide variety of locales, but for limited time periods, since longer periods do not contribute materially to the methodology development or demonstration. 


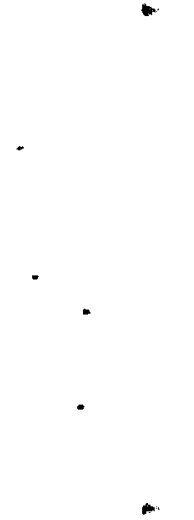

, 


\section{APPLICATION OF THE METHODOLOGY TO EIGHT CANDIDATE WIND ENERGY CONVERSION SITES}

\section{A. The Sites, Data Stations, and Wind Data Used}

Table 1 lists the eight candidate wind energy conversion system (WECS) sites for which hub height wind characteristics have been estimated by applying the methodology described in the previous section. For this study hub height has been prescribed to be at $45.7 \mathrm{~m}$ above local surface. It is seen that the locations of the selected sites are characterized by varying complexities of topographic features.

Table 2 lists the data stations selected for each site. It also shows the periods for which data were acquired from the National Climatic Center (NCC), Asheville, North Carolina, and the 12-month period for which the data have actually been used in conjunction with our methodology.

The table shows that we have selected four data stations for each of seven sites, and three for Montauk Point. However, since the methodology is not expected to use the data at the site itself (or within a radius of $8 \mathrm{~km}$ ) we have not used data at Huron and Russell for estimating wind characteristics at these two sites; instead, we have used these data to verify the method at the two sites.

Table 2 also shows that data at almost all stations are for the pre-1964 period. We have selected this period because the hourly wind data are readily available and it is quite expensive to acquire hourly wind data for post-1964 periods. (In general, NCC has prepared only 3hourly data since 1964.) The table also shows that for at least two stations (Holyoke and San Gorgonio Pass) we have used 12-month data spread over two different years. This is necessary because, as discussed in preceding sections, the methodology requires concurrent data from several stations surrounding a given site. And, as shown in Table 2, San Gorgonio Pass and Holyoke had at least one station at which data for a whole year were not available.

It should be noted that lack of concurrent data at the same stations over a long period of time does not mean that the method cannot be used. It would be quite possible to apply the method with one set of three or four stations for one time period, and some other set of stations for a different period. This sould be somewhat more difficult, but not out of the question.

\section{B. Examples of Application to Eight Sites}

\section{Boone, North Carolina}

Figure 9 shows the location of the candidate site, Boone, together with the significant topographic features in the region surrounding it. The site is located at an elevation of $4420 \mathrm{ft}(1348 \mathrm{~m})$, and the data stations surrounding the site are at elevations ranging from $1525 \mathrm{ft}(465 \mathrm{~m})$ at Bristol to $2253 \mathrm{ft}(687 \mathrm{~m})$ at Asheville. This shows that there is a significant gradient of terrain between the site and the selected data locations. 
Table 1

CANDIDATE WIND ENERGY CONVERSION SITES*

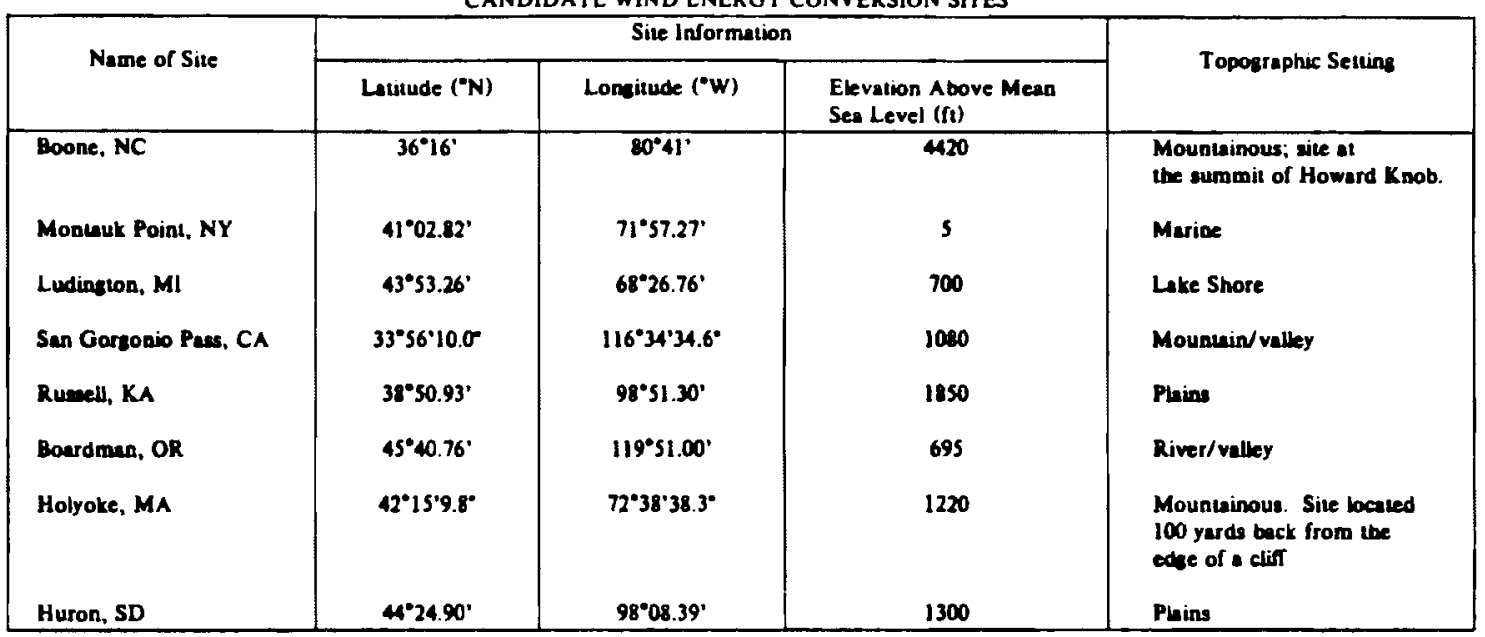

- The aitea have been elected by Baltelle Pacific Northwest Leboratories, Richland, Washinglon, who have provided all the pertinent information aboul the exact boation and elevation of each site.

We have used a coarse grid and a fine grid for Boone. The coarse grid mesh size is $3 \mathrm{~km}$ and the UTM coordinates (zone 17) of its origin (southwest corner) are $439.1 \mathrm{~km}$ east and $4009.9 \mathrm{~km}$ north. The number of grid points of the coarse grid are 20 in both the east and the north direction; the site location in this grid is at the point $(10,9)$. The fine grid mesh size is $1 \mathrm{~km}$, and there are $21 \mathrm{grid}$ points toward the east and north. The coordinates of the origin of the fine grid in the coarse grid are $(15,14)$ and the site location in the fine grid has coordinates $(14,12)$.

The Input section of Table $3(\mathrm{a})$ shows the eigenvectors of the covariant matrix and mean of surface wind data for the year 1954 at the four data stations shown in Figure 9. This section of the table gives the input data used for each integration of the COMPLEX model. The corresponding hub height solutions are shown in the Output section of Table 3(a). The hourly winds at hub height at Boone have been reconstructed from these nine solutions. The calculated hourly winds for the site have been used to derive the hub-level wind characteristics, which are shown in Figures 10 through 13.

Figure 10 shows frequency distributions of annual hourly mean wind speeds and wind speeds gusting above $25.2 \mathrm{~m} \mathrm{~s}^{-1}$. It shows that annually the most frequent speed (mode) is about $5 \mathrm{~m} \mathrm{~s}^{-1}$, though there are instances of strong winds up to $55 \mathrm{~m} \mathrm{~s}^{-1}$. As regards gust speed, the frequency distribution shows that on more than $92 \%$ of occasions winds do not gust above $26 \mathrm{~m} \mathrm{~s}^{-1}$.

Run durations (Figure 11) have been compiled for the cases when wind speed is above and below $4 \mathrm{~m} \mathrm{~s}^{-1}$, and when it lies between 10 and $25 \mathrm{~m} \mathrm{~s}^{-1}$. The figure shows that winds between 10 and $25 \mathrm{~m} \mathrm{~s}^{-1}$ persisted for 32 hours only once. 
Table 2

DATA STATIONS AND THE PERIOD OF DATA FOR EACH OF THE EIGHT CANDIDATE WIND ENERGY CONVERSION SITES

\begin{tabular}{|c|c|c|c|c|}
\hline Name of Site & Data Stations & $\begin{array}{c}\text { Period of Hourly } \\
\text { Wind Data Acquired } \\
\text { from NCC } \\
\end{array}$ & $\begin{array}{c}\text { 12-Month Period } \\
\text { for Which Data Were } \\
\text { Actually Used }\end{array}$ & $\begin{array}{l}\text { Are Hourly Wind } \\
\text { Data Available } \\
\text { at the Site? }\end{array}$ \\
\hline Boone, NC & $\begin{array}{l}\text { Asheville, NC } \\
\text { Hickory, NC } \\
\text { Pulaski, VA } \\
\text { Bristol, TN }\end{array}$ & \begin{tabular}{|l|}
$1948-57$ \\
$1949-54$ \\
$1949-54$ \\
$1948-57$
\end{tabular} & 1954 & No \\
\hline Montauk Pt., NY & $\begin{array}{l}\text { Quonsett Pt., RI } \\
\text { Westhampton, NY } \\
\text { Nantucket, MA }\end{array}$ & $\begin{array}{l}\text { March 1948-1954 } \\
\text { April 1951-59 } \\
1948-57\end{array}$ & 1954 & No \\
\hline Ludington, MI & $\begin{array}{l}\text { Traverse City, MI } \\
\text { Muskegon, MI } \\
\text { Cadillac, MI } \\
\text { Green Bay, WI } \\
\text { (Austin/Straubel) }\end{array}$ & $\begin{array}{l}1949-52 \\
1948-58 \\
1948-54 \\
\text { Sept. } 1949-58\end{array}$ & 1952 & No \\
\hline San Gorgonio Pass, CA & $\begin{array}{l}\text { Beaumont, CA } \\
\text { Indio/Coachella, CA } \\
\text { San Bernardino/Norton, CA } \\
\text { Riverside/March,CA }\end{array}$ & \begin{tabular}{|l|} 
1948-Aug. 1953 \\
Nov 1948-May 1950 \\
$1949-58$ \\
$1949-58$
\end{tabular} & $\begin{array}{l}\text { June } 1949 \text { through } \\
\text { May } 1950\end{array}$ & No \\
\hline Russell, KA & $\begin{array}{l}\text { Salina, KA } \\
\text { Hill City, KA } \\
\text { Dodge City, KA } \\
\text { Russell, KA }\end{array}$ & $\begin{array}{l}1949.57 \\
1949-54 \\
1948-58 \\
\text { Nov } 1950.59\end{array}$ & $\begin{array}{l}\text { Dec } 1953 \text { through } \\
\text { Nov } 1954\end{array}$ & $\begin{array}{l}\text { Yes: but not used in } \\
\text { estimating wind } \\
\text { characteristics. }\end{array}$ \\
\hline Boardman, OR & $\begin{array}{l}\text { Pendelton, OR } \\
\text { Yakima, WA } \\
\text { Walla Walla, WA } \\
\text { Dalesport, WA }\end{array}$ & \begin{tabular}{|l|}
$1959-68$ \\
$1959-68$ \\
$1955-65$ \\
$1955-64$
\end{tabular} & 1961 & No \\
\hline Holyoke, MA & $\begin{array}{l}\text { West Lebanon, NH } \\
\text { Windsor Locks, MA } \\
\text { Westfield, MA } \\
\text { Chicopee Falls, MA }\end{array}$ & $\begin{array}{l}1949-58 \\
1949 \\
1949-\mathrm{May} 1952 \\
1949-59\end{array}$ & $\begin{array}{l}\text { June } 1951 \text { through } \\
\text { May } 1952\end{array}$ & No \\
\hline Huron, SD & $\begin{array}{l}\text { Watertown, SD } \\
\text { Sioux Falls, SD } \\
\text { Pierre, SD } \\
\text { Huron. SD }\end{array}$ & $\begin{array}{l}1948-54 \\
1948-58 \\
1948-58 \\
1951-56 \\
\end{array}$ & $\begin{array}{l}\text { Dec. } 1953 \text { through } \\
\text { Nov. } 1954\end{array}$ & $\begin{array}{l}\text { Yes: But not used } \\
\text { in estimating wind } \\
\text { characteristics. }\end{array}$ \\
\hline
\end{tabular}

Figure 12 shows the joint frequency distribution of wind speed and direction; an interpretation of the information contained in the figure is also given. The figure shows that stronger winds (speed $>16 \mathrm{~m} \mathrm{~s}^{-1}$ ) are usually from a southerly direction, though there are significant occurrences of northerly winds with speeds $>16 \mathrm{~m} \mathrm{~s}^{-1}$.

Diurnal and seasonal variabilities are shown in Figure 13. The diurnal variability shows that the wind speed is greater than the mean from 10:00 am to 6:00 pm. The seasonal variability indicates stronger wind speed during winter and spring than in summer or fall. It is interesting to note that the values for winter and spring are almost identical--as is the case for summer and fall. 


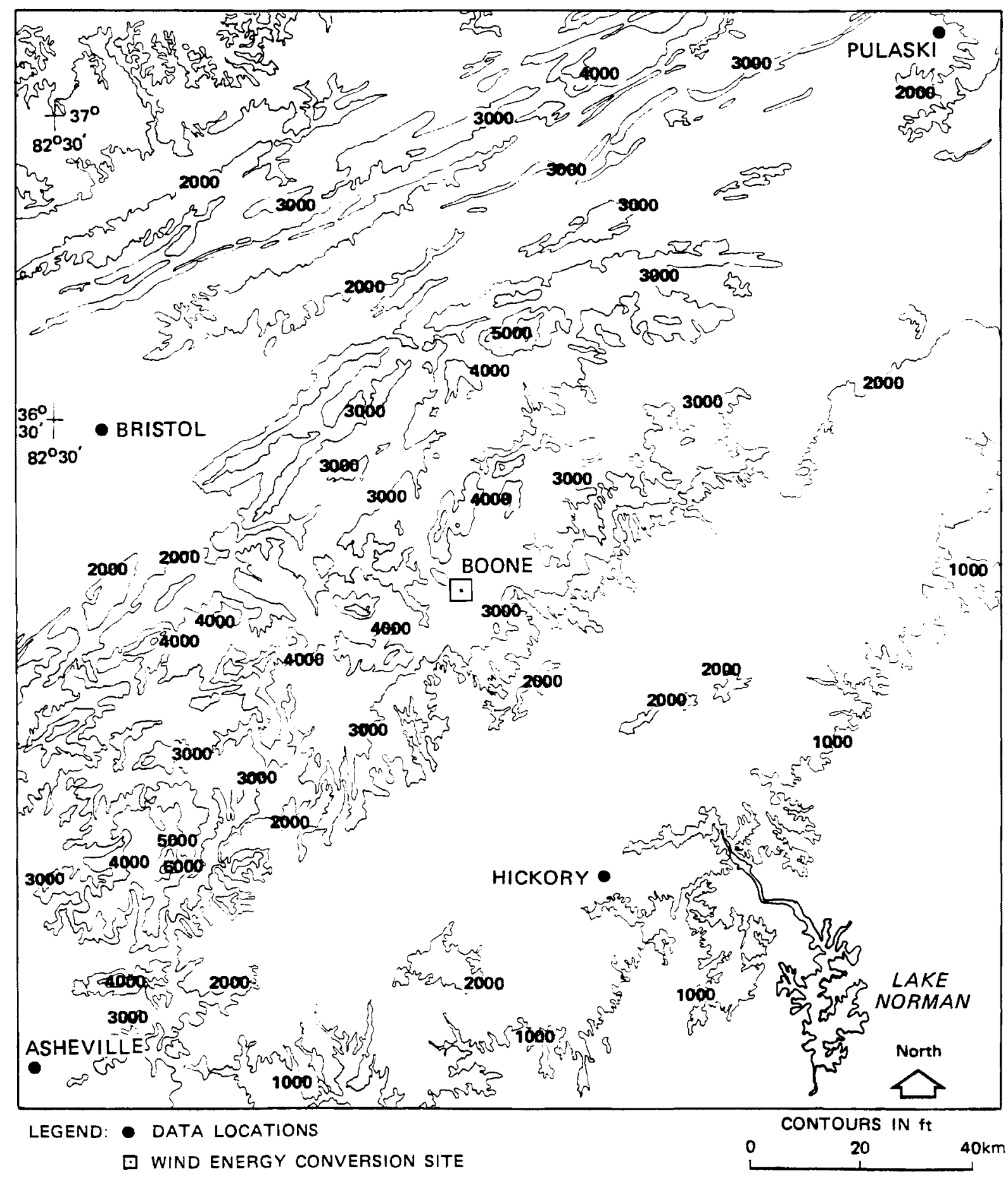

FIGURE 9 LOCATOR MAP FOR WEC SITE AT BOONE, NORTH CAROLINA AND THE FOUR DATA STATIONS 
Table 3

EIGENVECTORS OF THE COVARIANCE MATRIX AND THE MEAN VECTORS AT DATA STATIONS,

AND HUB HEIGHT WIND AT WEC STTE

(a)

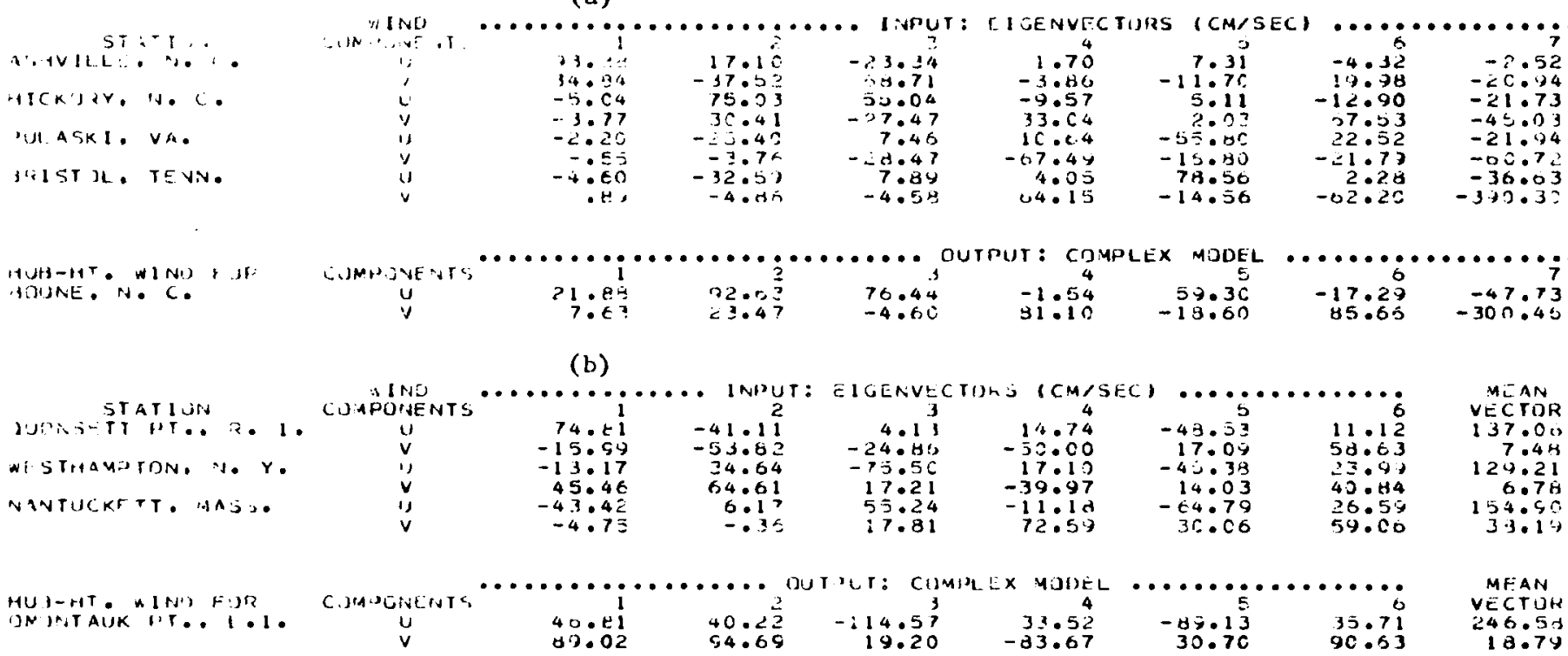

(c)

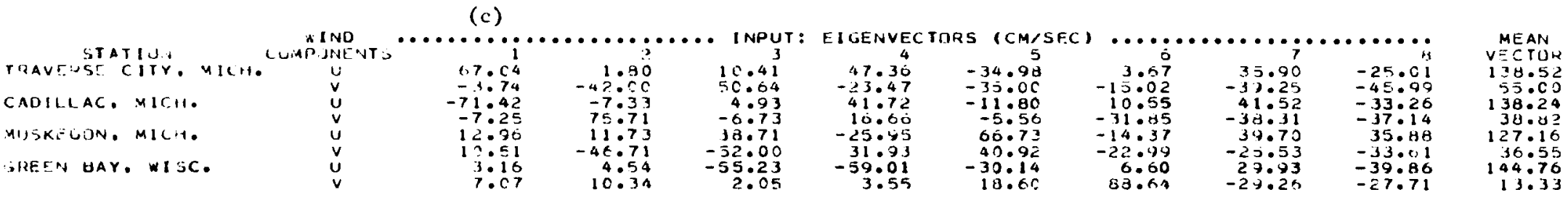

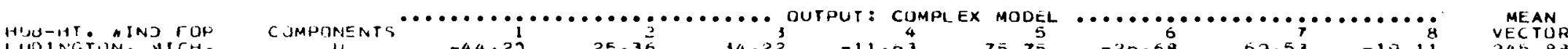

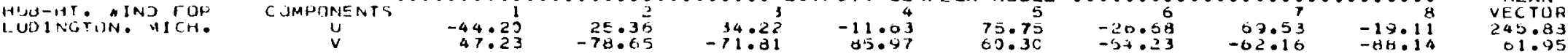
(d)

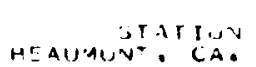
[NDI]. CA.

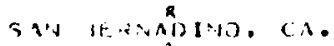

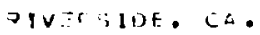

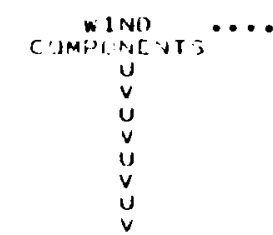

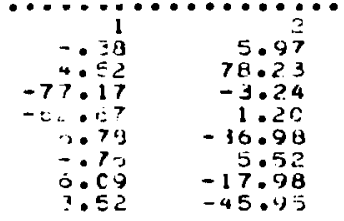

ICM/SEC
5
-27.34
45.66
13.02
-5.79
46.83
50.21
1.09
11.09
41.55
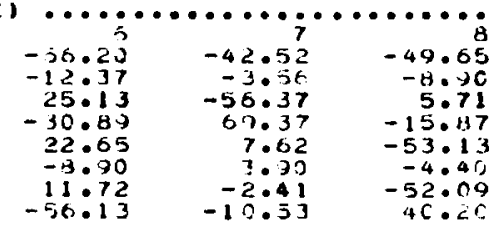

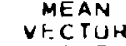
09.36 101.99 92.44 $\begin{array}{rl}7 & 3.45 \\ -113.95\end{array}$

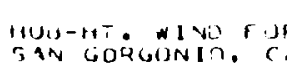
Commintistis $\cdots$ $\begin{array}{rl}-37 & 1 \\ -3.2 & 18 \\ -2.23 & \end{array}$ $\begin{array}{ccc}-7.59 & 17.43\end{array}$ DUTPUT = comp EX MOUEL . . . . . . . . . . . . . . . 
Table 3

EIGENVECTORS OF THE COVARIANCE MATRIX AND THE MEAN VECTORS AT DATA STATIONS, AND HUB HEIGHT WIND AT WEC SITE (Concluded)

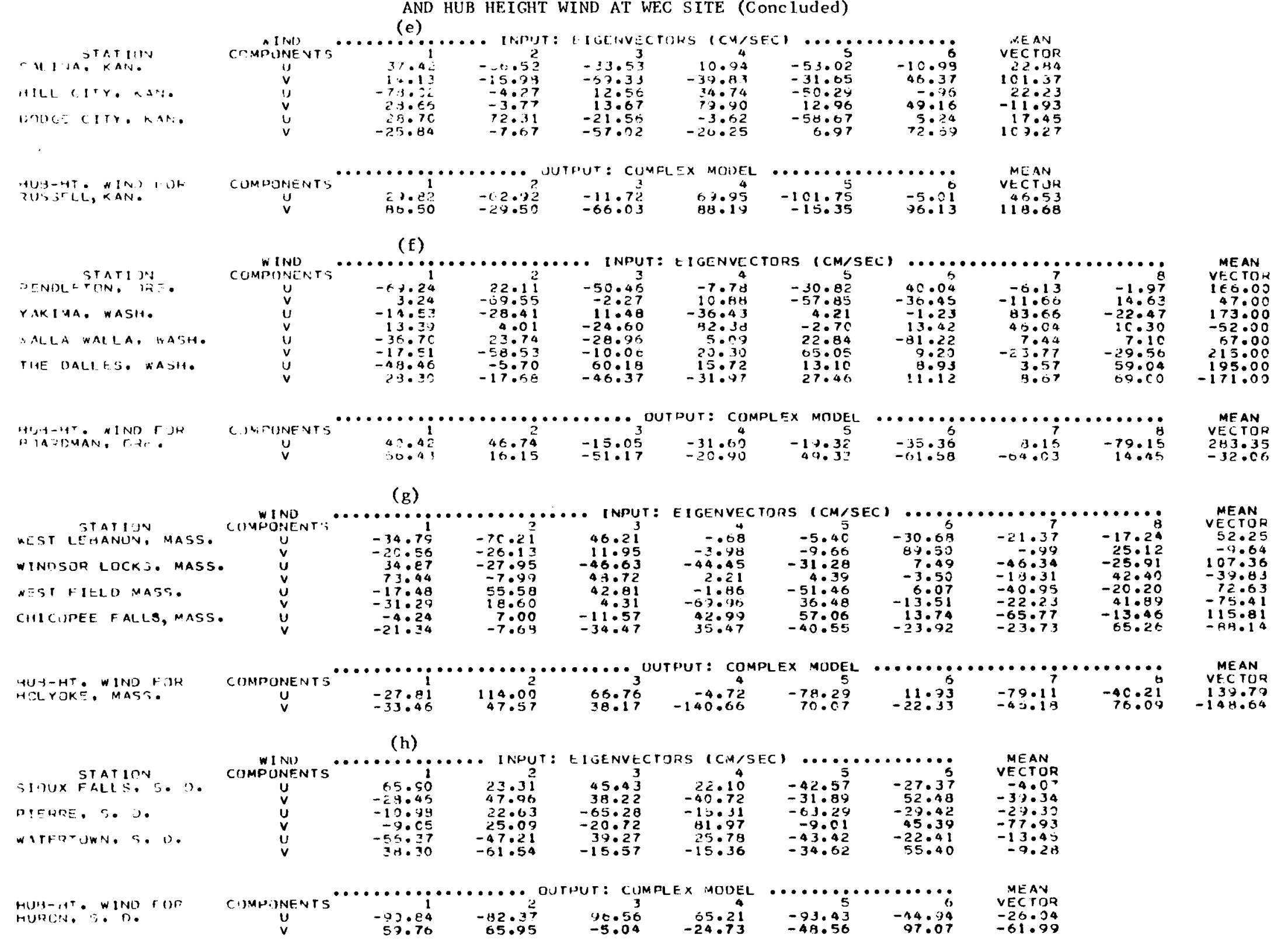




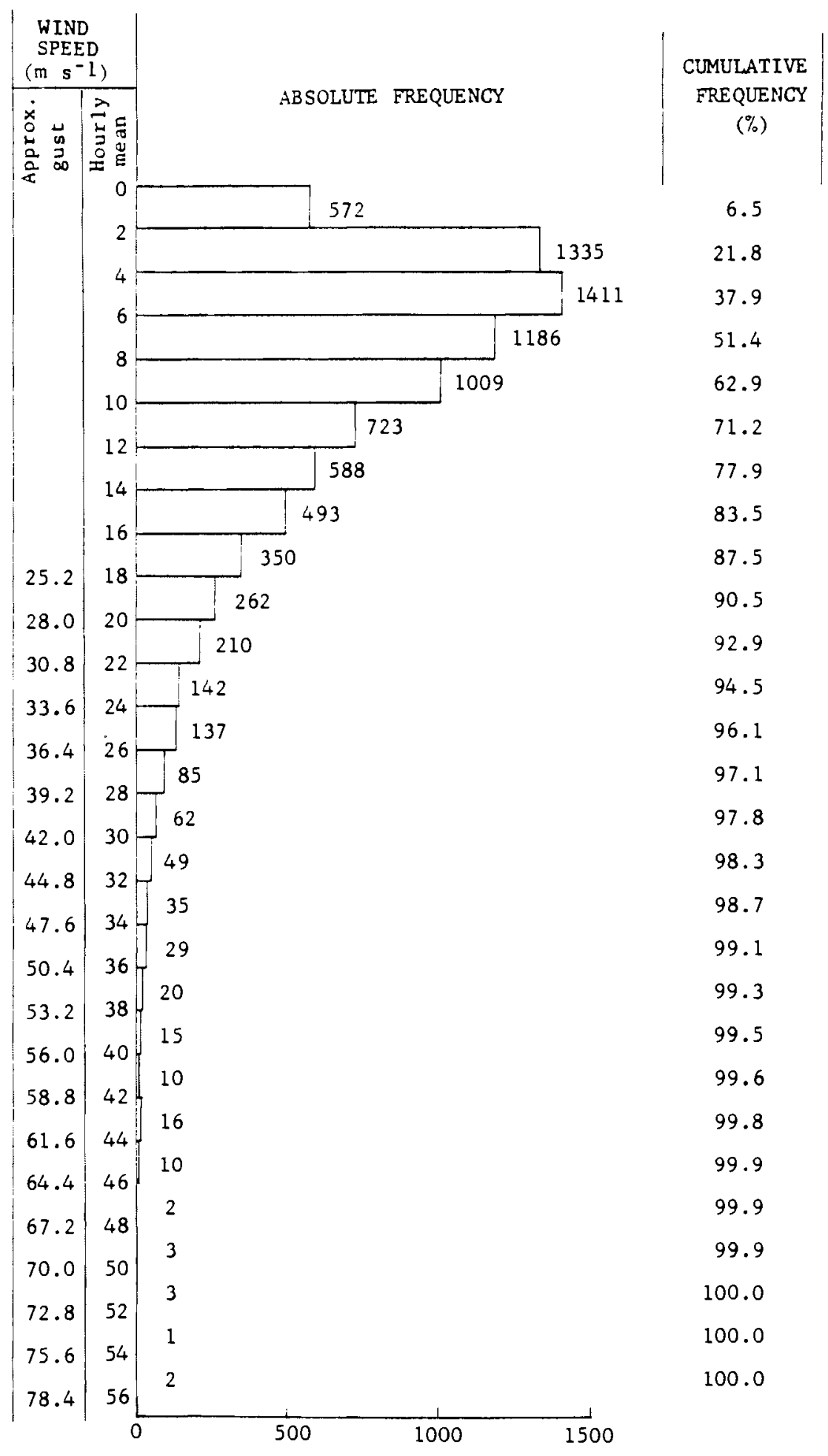

FIGURE 10 FREQUENCY DISTRIBUTION OF HUB HEIGHT $(45.7 \mathrm{~m})$ WIND SPEED AT BOONE, NORTH CAROLINA FOR THE PERIOD 1954 Wind speed categories are for annual mean and gusts above $25.2 \mathrm{~m} \mathrm{~s}^{-1}$. 


\begin{tabular}{|c|c|c|c|c|}
\hline \multirow{2}{*}{$\begin{array}{c}\text { RUN } \\
\text { DURATION } \\
\text { (hours) }\end{array}$} & $\begin{array}{l}\mathrm{NL} \\
\text { WIND }\end{array}$ & $\begin{array}{l}\text { ER } \\
\text { EED }\end{array}$ & $\begin{array}{l}\text { IMES } \\
\left.s^{-1}\right) \text { IS : }\end{array}$ & \multirow{2}{*}{$\begin{array}{l}\text { BOONE, NORTH CAROLINA } \\
\text { SAMPLE EXPLANATION }\end{array}$} \\
\hline & $<4$ & $\geqslant 4$ & $10-25$ & \\
\hline
\end{tabular}

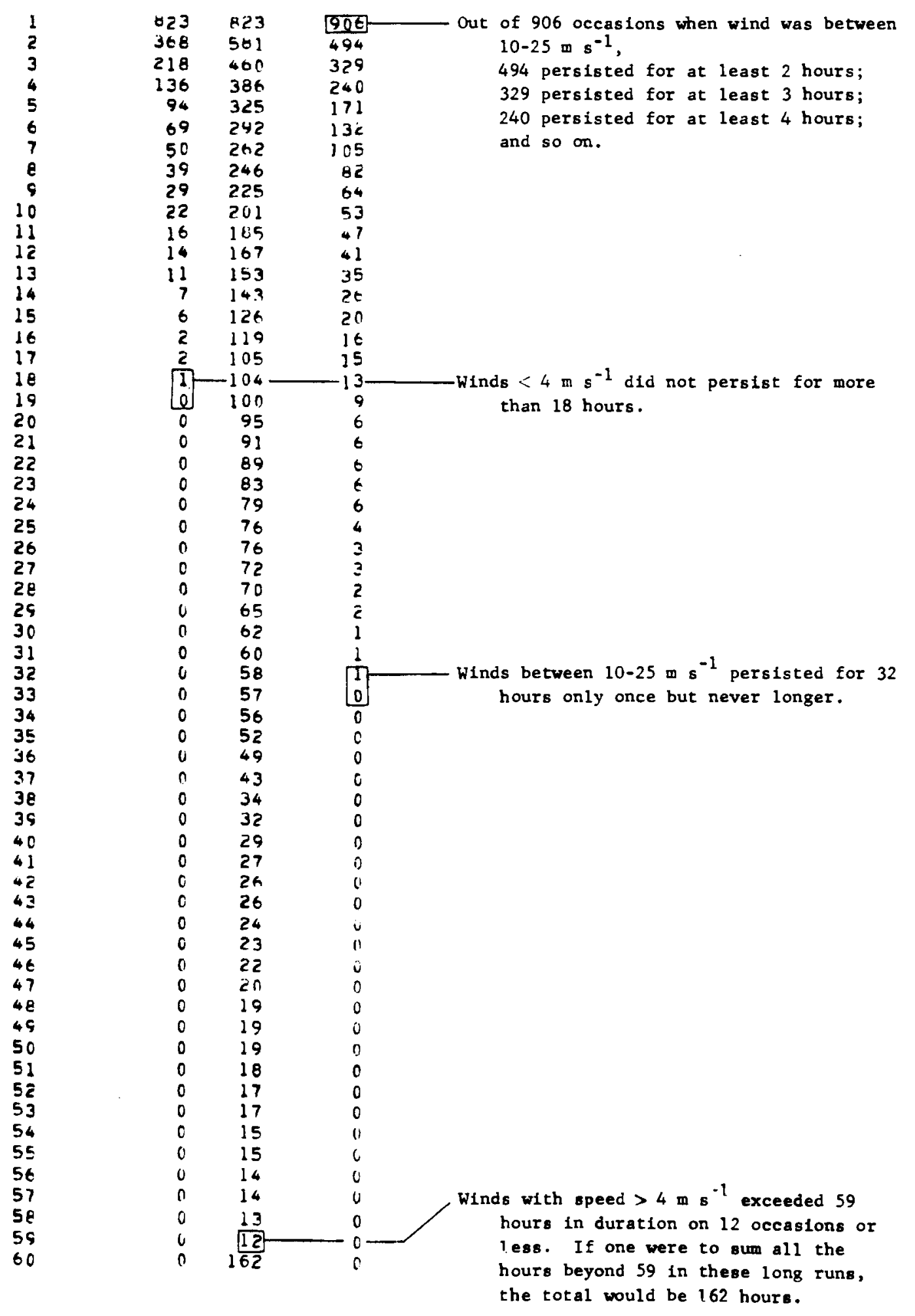

FIGURE 11 RUN DURATION ANALYSIS OF HUB HEIGHT (45.7m) ANNUAL MEAN WIND SPEED AT BOONE, NORTH CAROLINA FOR THE PERIOD 1954 
DIRECTION

\begin{tabular}{|c|c|c|c|c|c|c|c|c|c|c|c|c|c|c|c|c|c|c|}
\hline SPEED & ! & NNE & NE & ENE & E & ESE: & SE & SSE & $\mathrm{s}$ & ssw & SW & WSW & $w$ & WNW & NW & NNW & N & $1^{\text {POTAL }}$ \\
\hline $0-3.99$ & $\begin{array}{l}\text { * COUNT } \\
\text { ROW PCT } \\
\text { COL PCT } \\
\text { TOT PCT }\end{array}$ & $\begin{array}{r}114 \\
6.2 \\
11.1 \\
1.6\end{array}$ & $\begin{array}{rr}i & 124 \\
1 & 6.5 \\
1 & 16.1 \\
1 & 1.0\end{array}$ & $\begin{array}{r}31 \\
2.7 \\
21.0 \\
.6\end{array}$ & $\begin{array}{r}47 \\
2.5 \\
91.6 \\
.5\end{array}$ & $\begin{array}{r}36 \\
1.4 \\
40.9 \\
.4\end{array}$ & $\begin{array}{r}.4 \\
2.3 \\
0 n .3 \\
.5\end{array}$ & $\begin{array}{r}80 \\
3.1 \\
4.99 \\
.7\end{array}$ & $\begin{array}{r}79 \\
3.5 \\
25.9 \\
.8\end{array}$ & $\begin{array}{r}1.2 \\
7.4 \\
12.2 \\
1.6\end{array}$ & $\begin{array}{r}109 \\
4.9 \\
19.9 \\
1.9\end{array}$ & $\begin{array}{r}165 \\
8.7 \\
20.9 \\
1.9\end{array}$ & $\begin{array}{r}101 \\
8.9 \\
18.0 \\
1.8\end{array}$ & $\begin{array}{r}149 \\
7.8 \\
1 \\
1 \\
1 \\
1.7\end{array}$ & $\begin{array}{r}173 \\
9.1 \\
37.3 \\
2.0\end{array}$ & $\begin{array}{r}100 \\
9.9 \\
30.7 \\
2.1\end{array}$ & $\begin{array}{rr}1 & 200 \\
1 & 11.0 \\
1 & 16,0 \\
1 & 2.4\end{array}$ & $\begin{array}{l}1907 \\
21.0\end{array}$ \\
\hline $4-7.99$ & $\begin{array}{l}\text { COUNT } \\
\text { ROW PCT } \\
\text { COI. PCT } \\
\text { TOT PCT }\end{array}$ & $\begin{array}{r}200 \\
10.0 \\
26.1 \\
3.2\end{array}$ & $\begin{array}{r}107 \\
6.0 \\
21.1 \\
1.9 \\
1.9\end{array}$ & $\begin{array}{r}02 \\
2.4 \\
25.5 \\
.7\end{array}$ & $\begin{array}{l}0 ? \\
1: 6 \\
11: 6 \\
.5\end{array}$ & $\begin{array}{r}42 \\
1.6 \\
4: 1 \\
35\end{array}$ & $\begin{array}{r}25 \\
1.0 \\
34.2 \\
. .3\end{array}$ & $\begin{array}{r}51 \\
2.0 \\
34.0 \\
.0\end{array}$ & $\begin{array}{r}93 \\
3.6 \\
31.5 \\
1.1\end{array}$ & $\begin{array}{r}1 \\
1 \\
1 \\
1.5 \\
1 \\
1 \\
1.1 .4 \\
2.4\end{array}$ & $\begin{array}{r}269 \\
10.0 \\
63.5 \\
3.5\end{array}$ & $\begin{array}{r}220 \\
8.5 \\
35.9 \\
2.5\end{array}$ & $\begin{array}{r}164 \\
6.3 \\
39.3 \\
1.9\end{array}$ & $\begin{array}{r}1 \pm 3 \\
5: 5 \\
34: 9 \\
1.0\end{array}$ & $\begin{array}{r}190 \\
7.3 \\
+0.9 \\
2,2\end{array}$ & $\begin{array}{r}212 \\
6.2 \\
34.0 \\
2.4\end{array}$ & $\begin{array}{r}391 \\
15.3 \\
151.8 \\
1.5\end{array}$ & $\begin{array}{l}2547 \\
29.6\end{array}$ \\
\hline $0-11.99$ & $\begin{array}{l}\text { COUNT } 1 \\
\text { ROW PCT } \\
\text { COL PCT } \\
\text { TOT PCT I }\end{array}$ & $\begin{array}{r}213 \\
12.3 \\
19.9 \\
2.4\end{array}$ & $\begin{array}{r}153 \\
11.8 \\
1 \\
19: 9 \\
1\end{array}$ & $\begin{array}{r}75 \\
4.3 \\
30.4 \\
.4\end{array}$ & $\begin{array}{r}19 \\
1.1 \\
16.6 \\
.2\end{array}$ & $\begin{array}{r}.5 \\
10.2 \\
.1\end{array}$ & $\begin{array}{r}3 \\
.2 \\
\therefore \quad 1 \\
.0\end{array}$ & $\begin{array}{r}13 \\
0 \\
10.2 \\
.1\end{array}$ & $\begin{array}{r}54 \\
3.3 \\
19.1 \\
.17\end{array}$ & $\begin{array}{cc}1 & 218 \\
1 & 12.6 \\
1 & 10.7 \\
1 & 2.5\end{array}$ & $\begin{array}{r}2.3 \\
13.5 \\
6.5 \\
2.9\end{array}$ & $\begin{array}{r}123 \\
7.1 \\
20: 1 \\
1.4\end{array}$ & $\begin{array}{r}50 \\
394 \\
10.1 \\
.1\end{array}$ & $\begin{array}{r}32 \\
3.0 \\
14.5 \\
.6\end{array}$ & $\begin{array}{r}30 \\
16.8 \\
16.0 \\
.7\end{array}$ & $\begin{array}{r}133 \\
7.7 \\
21.7 \\
1.0\end{array}$ & $\begin{array}{r}306 \\
17.7 \\
24.6 \\
3.5\end{array}$ & $\begin{array}{l}1732 \\
14,8\end{array}$ \\
\hline $12-15.99$ & $\begin{array}{l}\text { COUNT } \\
\text { ROW PCT } \\
\text { COL. PCT I } \\
\text { TOT PCT I }\end{array}$ & $\begin{array}{r}146 \\
13.5 \\
13.6 \\
1.7\end{array}$ & $\begin{array}{r}128 \\
11.8 \\
1 \\
1 \\
1 \\
1.5\end{array}$ & $\begin{array}{r}44 \\
4: 1 \\
18: 1 \\
.5\end{array}$ & 年 & $\begin{array}{l}1 \\
10 \\
0\end{array}$ & $\begin{array}{l}1 \\
\therefore 1 \\
.1\end{array}$ & .6 & $\begin{array}{r}35 \\
3.2 \\
11.9 \\
. .4\end{array}$ & $\begin{array}{cc}1 & j \neq 2 \\
1 & 1 \% .4 \\
1 & 10.5 \\
1 & 2.2\end{array}$ & $\begin{array}{r}111 \\
15.0 \\
15.5 \\
2.0\end{array}$ & $\begin{array}{r}\quad 71 \\
6.6 \\
11.6 \\
1 \\
1.8\end{array}$ & $\begin{array}{l}28 \\
2.6 \\
6 ! ? \\
? .3\end{array}$ & $\begin{array}{l}1.2 \\
1.1 \\
3.4 \\
.1\end{array}$ & $\begin{array}{r}3 ! \\
2.9 \\
6,7 \\
?\end{array}$ & $\begin{array}{l}56 \\
5.2 \\
9.1 \\
.6\end{array}$ & $\begin{array}{r}161 \\
169 \\
13.0 \\
1 \quad 1.8\end{array}$ & $\begin{array}{l}1081 \\
12,3\end{array}$ \\
\hline $\begin{array}{l}16 \text { AND } \\
\text { OVER }\end{array}$ & $\begin{array}{r}\text { COUN' } \\
\text { ROW PCT } \\
\text { COI. PCT I } \\
\text { TOT PCT I }\end{array}$ & $\begin{array}{r}31.0 \\
21.8 \\
29.3 \\
3,6\end{array}$ & $\begin{array}{r}197 \\
13.7 \\
13.6 \\
13.2 \\
1\end{array}$ & $\begin{array}{r}11 \\
.8 \\
\therefore .5 \\
.1\end{array}$ & $\begin{array}{l}\dot{y} \\
0 \\
0 \\
0\end{array}$ & $\begin{array}{l}0 \\
0 \\
0 \\
0\end{array}$ & $\begin{array}{l}0 \\
0 \\
0 \\
0\end{array}$ & $\begin{array}{l}u \\
0 \\
0 \\
u\end{array}$ & $\begin{array}{r}33 \\
2: 4 \\
11: 9 \\
: 4\end{array}$ & $\begin{array}{c}310 \\
1 \\
41.7 \\
40 \\
4\end{array}$ & $\begin{array}{r}21 . \hat{~} \\
19.1 \\
85.0 \\
3 . ?\end{array}$ & $\begin{array}{r}34 \\
2.4 \\
5.5 \\
.9\end{array}$ & $\begin{array}{r}.3 \\
.3 \\
1.2 \\
.1\end{array}$ & $\begin{array}{l}2 \\
.1 \\
.6\end{array}$ & $\begin{array}{r}3 \\
.3 \\
1.1 \\
.1\end{array}$ & $\begin{array}{r}24 \\
1.7 \\
3.9 \\
.3\end{array}$ & $\begin{array}{lr}1 & 170 \\
1 & 11.8 \\
1 & 13.7 \\
1 & 1.8\end{array}$ & $\begin{array}{l}10.43 \\
16.5\end{array}$ \\
\hline & COLUMN & $\begin{array}{l}1072 \\
12.2\end{array}$ & $\begin{array}{l}704 \\
8.0\end{array}$ & $\begin{array}{l}243 \\
2.8\end{array}$ & $\begin{array}{l}113 \\
1.3\end{array}$ & $\begin{array}{l}00 \\
100\end{array}$ & $\begin{array}{l}73 \\
.8\end{array}$ & $\begin{array}{l}12 t \\
1.5\end{array}$ & $\begin{array}{l}205 \\
3.4\end{array}$ & $\begin{array}{ll}\because 107 \\
\because & 1301\end{array}$ & $\begin{array}{l}111.4 \\
1 ? .4\end{array}$ & $\begin{array}{l}613 \\
7.0\end{array}$ & $\begin{array}{ll}911 \\
9.8\end{array}$ & $\begin{array}{l}350 \\
4.1\end{array}$ & $\begin{array}{l}964 \\
5.3\end{array}$ & 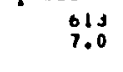 & $\begin{array}{l}124.3 \\
14.2\end{array}$ & $\begin{array}{r}8700 \\
100.0\end{array}$ \\
\hline
\end{tabular}

* CounT: The total number of occurrences of that particular combination of speed and direction. e.g. For the shaded area, there are 370 occurrences of wind whose direction is sSW and speed is greater than $16 \mathrm{~m} \mathrm{~s}^{-1}$.

ROW PCT The \% occurrences of a particular speed class from a given direction. e.g. out of 1443 occurrences with speed $>16 \mathrm{~m} \mathrm{~s}^{-1}, 25.6 \%$ occurrences had a sSW direction.

COL PCT The \% occurrences of a particular direction class with a given wind speed. e.g. out of 1167 occurrences of wind with a SSW direction, $31.7 \%$ occurrences were of speeds $>16 \mathrm{~m} \mathrm{~s}^{-1}$.

TOT PCT Percentage of total occurrences in the year. e.g. $\frac{370}{8670}=4.2 \%$.

FIGURE 12 JOINT FREQUENCY DISTRIBUTION OF ANNUAL WIND SPEED (m s $\mathrm{s}^{-1}$ ) AND DIRECTION AT HUB HEIGHT $(45.7 \mathrm{~m})$ AT BOONE, NORTH CAROLINA, FOR THE PERIOD 1954 


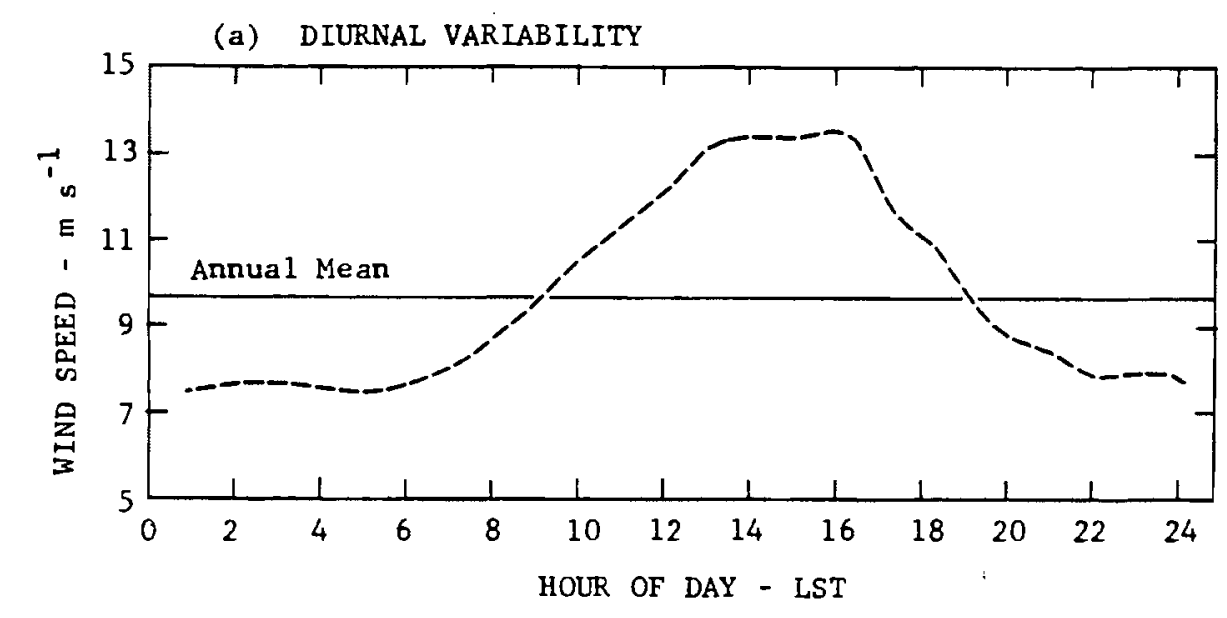

(b) SEASONAL VARIABILITY

\begin{tabular}{|c|c|c|c|c|}
\hline SEASON & WINTER & SPR ING & SUMMER & FALI \\
\hline Wind speed $\mathrm{m} \mathrm{s}^{-1}$ & 10.27 & 10.98 & 8.69 & 8.98 \\
\hline
\end{tabular}

FIGURE 13 ANNUAL MEAN HUB HEIGHT $(45.7 \mathrm{~m})$ WIND SPEED VARIABILITY AT BOONE, NORTH CAROLINA, FOR THE PERIOD 1954

\section{Montauk Point, New York}

Figure 14 shows the locations of Montauk Point and the three data stations in its vicinity. This site is characterized by a typical marine setting, and no significant topographic features exist in the region considered.

Only one grid has been used for Montauk Point, and the UTM coordinates (zone 19) of its origin (southwest corner) are $251.8 \mathrm{~km}$ east, and $4547 \mathrm{~km}$ north. The grid mesh size is $2 \mathrm{~km}$, and there are $15 \mathrm{grid}$ points in the east and north directions. The site coordinates within the grid are $(8,5)$.

Table 3(b) shows the eigenvectors of the covariant matrix and the mean derived from the available hourly conventional surface wind data for 1954 at the three data stations Quonsett Point, Nantucket, and Westhampton. It may be noted that in this case there are six eigenvectors instead of eight obtained for the sites with four data locations. The table also shows the calculated hub height wind for each eigenvector and for the mean that has been used to obtain hourly hub level wind characteristics at Montauk Point. The required hub height wind characteristics derived from these calculated hourly winds are shown in Figures 15 and 18. The result appears to be consistent with the features expected for the marine type of situation. For example, the diurnal variability is not as marked as in the case of Boone. Also, the joint frequency distribution of speed versus direction shows that the most frequent direction (overall) for relatively strong winds $\left(-12 \mathrm{~m} \mathrm{~s}^{-1}\right)$ is WSW, which is representative of typical winter cold air outbreak conditions when the air-sea interaction produces quite strong low-level winds. 


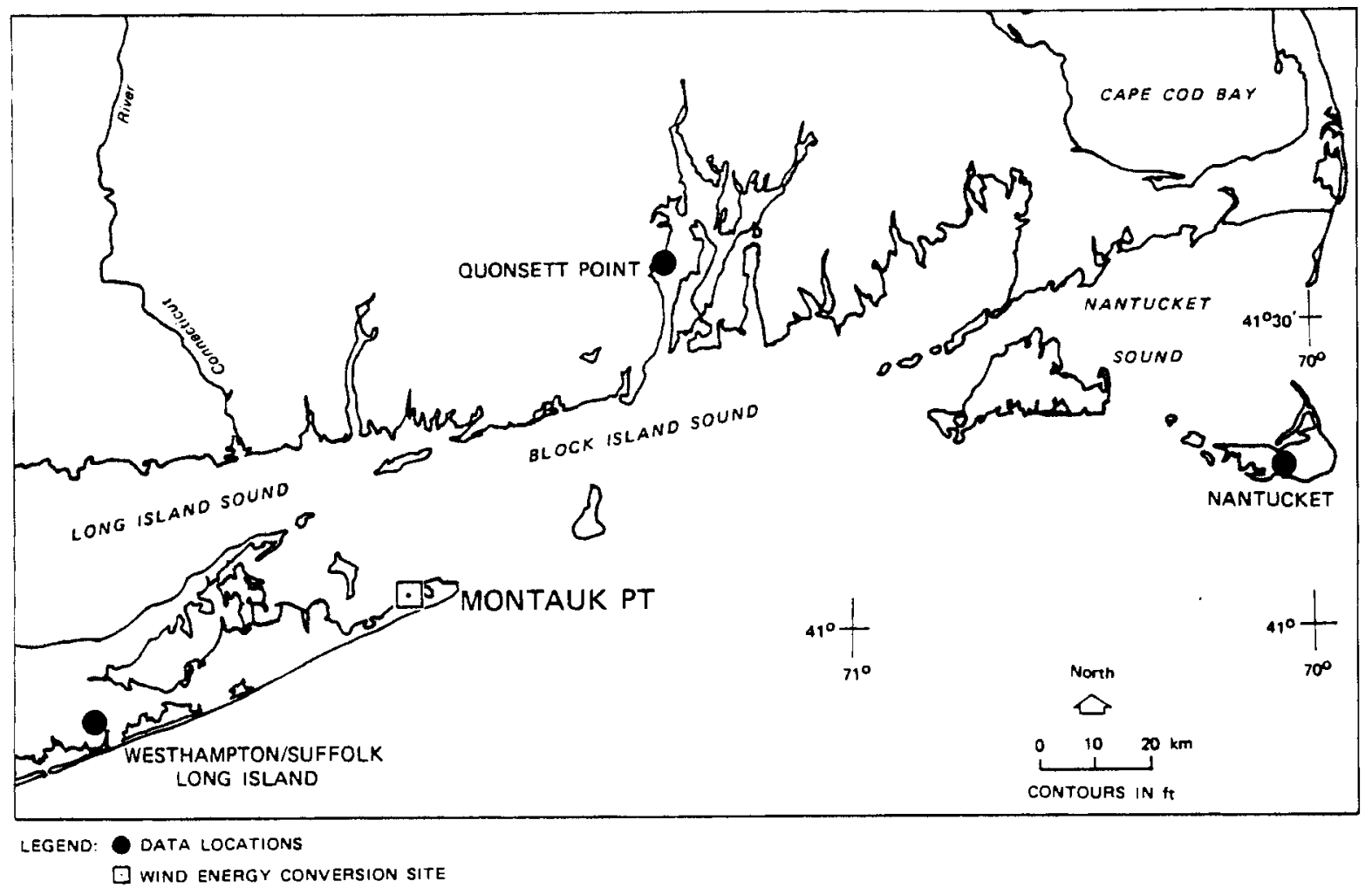

FIGURE 14 LOCATOR MAP FOR THE WEC SITE AT MONTAUK POINT, NEW YORK AND THE THREE DATA STATIONS

\section{Ludington, Michigan}

Figure 19 shows the location of Ludington on the coast of Lake Michigan. Of the four data stations selected for Ludington, Cadillac lies at a relatively high elevation $(<1200 \mathrm{ft}$, or $366 \mathrm{~m}$ ). Muskegan and Green Bay are located in essentially flat terrain. To the west of the site there is a vast expanse of water, devoid of any complex terrain features.

This is the only site for which we have used four data stations and a single grid. The origin of this 2-km grid (zone 16) in UTM coordinates is $544.5 \mathrm{~km}$ east and $4859.8 \mathrm{~km}$ north. There are 21 grid points toward east and 17 grid points toward north; the site is located at the grid point $(4,6)$. Table 3 (c) shows the eigenvectors and mean calculated from the surface wind data for 1952 at the four data stations; it also shows the hub height winds at Ludington corresponding to each principal component and mean. The wind characteristics at hub height, derived from the reconstructed hourly wind data for the 12-month period, are shown in Figures 20 through 23 . The joint frequency of speed versus direction shows that there is a distinct tendency for winds to have a northwest direction, though relatively weaker winds $(<4 \mathrm{~m}$ $\mathrm{s}^{-1}$ ) are most frequently from an eastern direction. This perhaps can be attributed to lake breeze/land breeze characteristics--e.g., while the lake breeze from the western direction does not encounter significant frictional effects when it reaches Ludington, the land breeze would be affected by underlying terrain effects. 


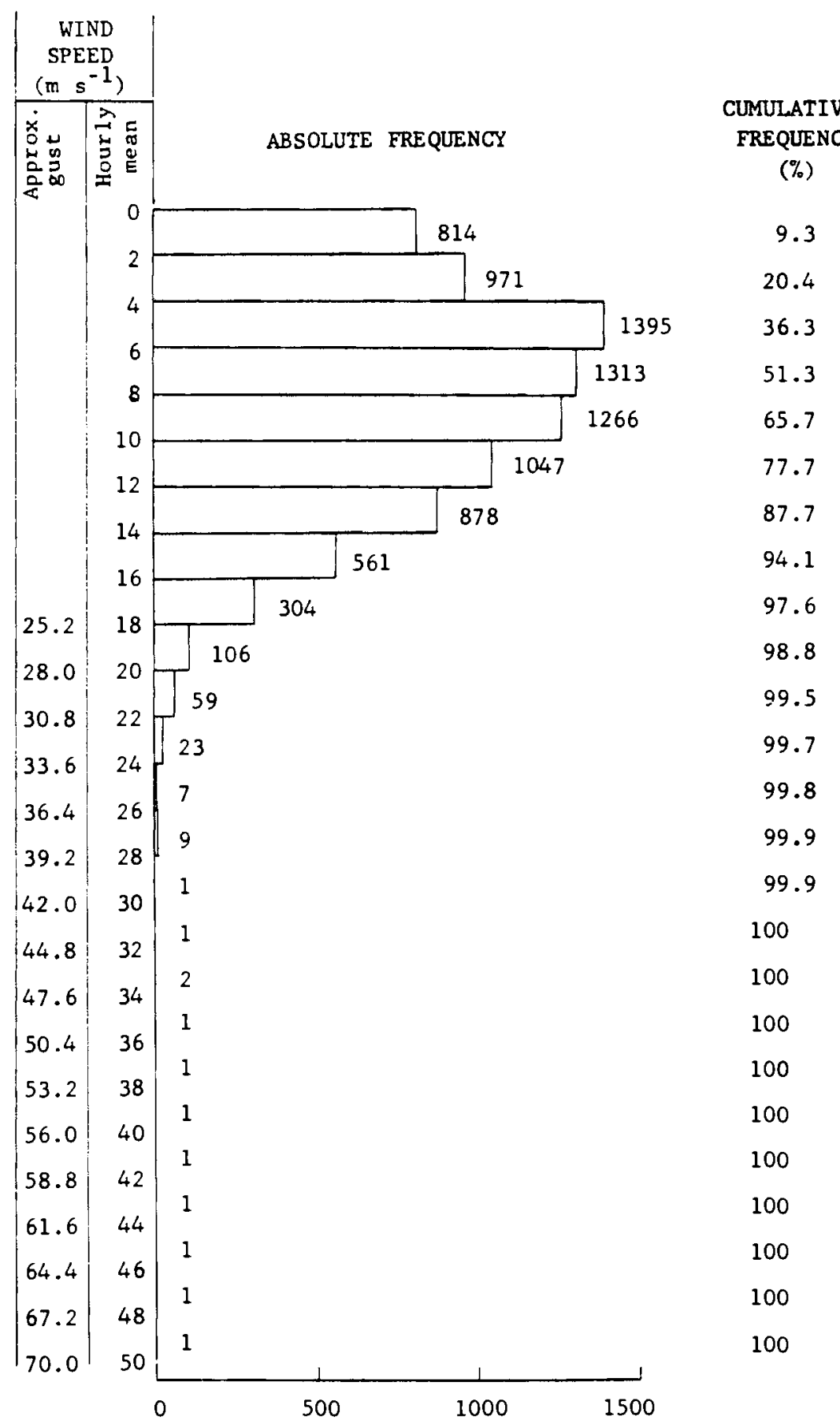

FIGURE 15 FREOUENCY DISTRIBUTION OF HUB HEIGHT (45.7) WIND SPEED AT MONTAUK POINT, NEW YORK FOR THE PERIOD 1954. Wind speed categories are for annual mean and gusts above $25.2 \mathrm{~m} \mathrm{~s}^{-1}$. 


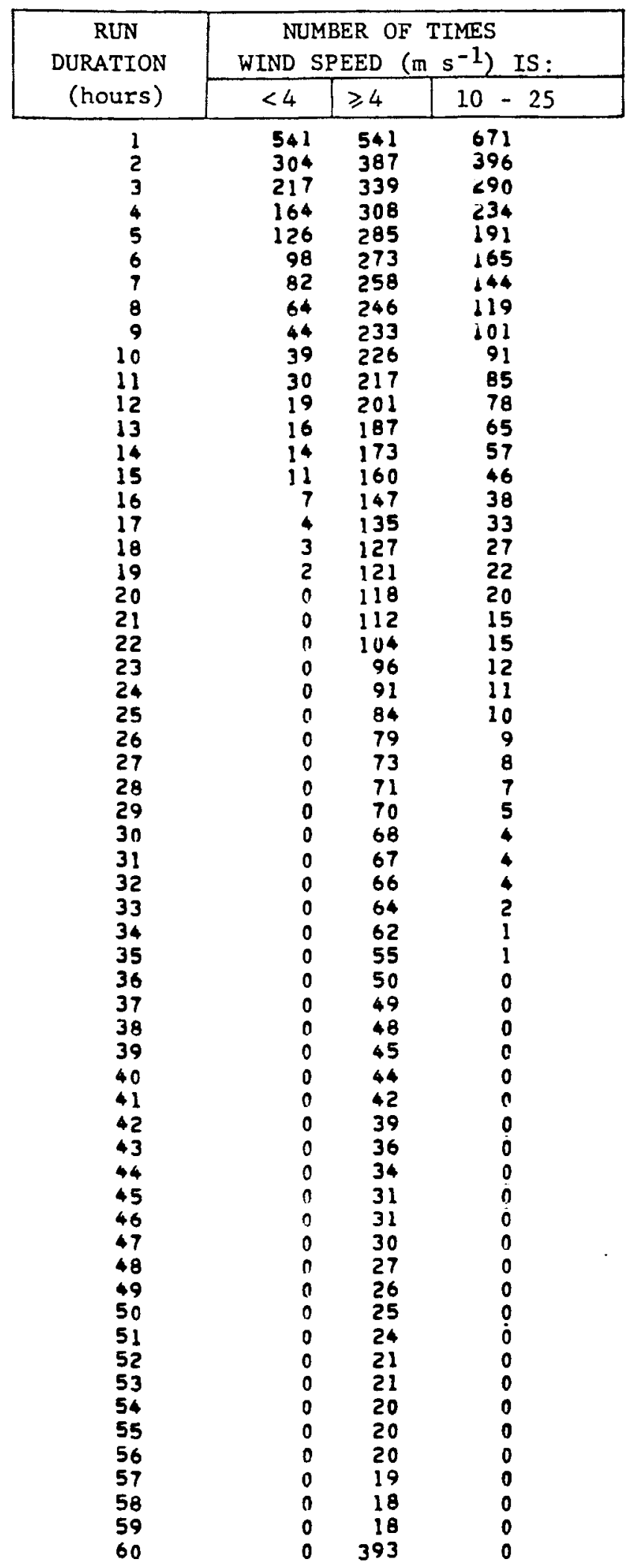

FIGURE 16 RUN DURATION ANALYSIS OF HUB HEIGHT $(45.7 \mathrm{~m})$ ANNUAL MEAN WIND SPEED AT MONTAUK POINT, NEW YORK FOR THE PERIOD 1954 
DIRECTION

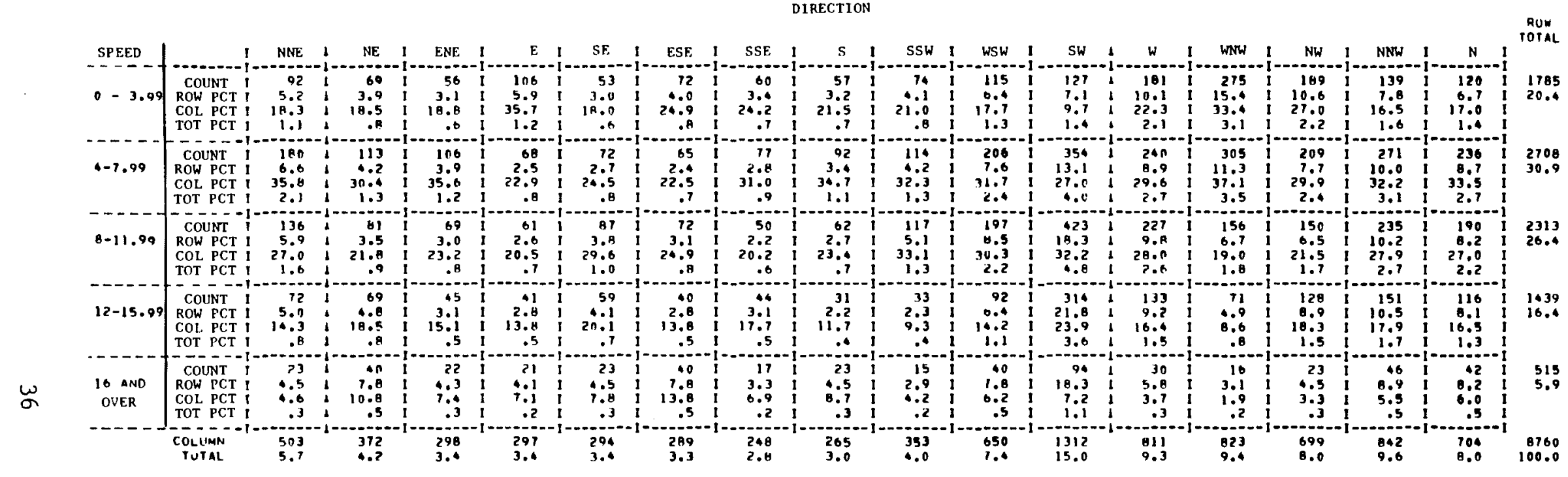

FIGURE 17 JOINT FREQUENCY DISTRIBUTION OF ANNUAL WIND SPEED $\left(\mathrm{m} \mathrm{s}^{-1}\right)$ AND DIRECTION AT HUB HEIGHT $(45.7 \mathrm{~m})$ AT MONTAUK POINT, NEW YORK FOR THE PERIOD 1954 
(a) DIURNAL VARIABILITY

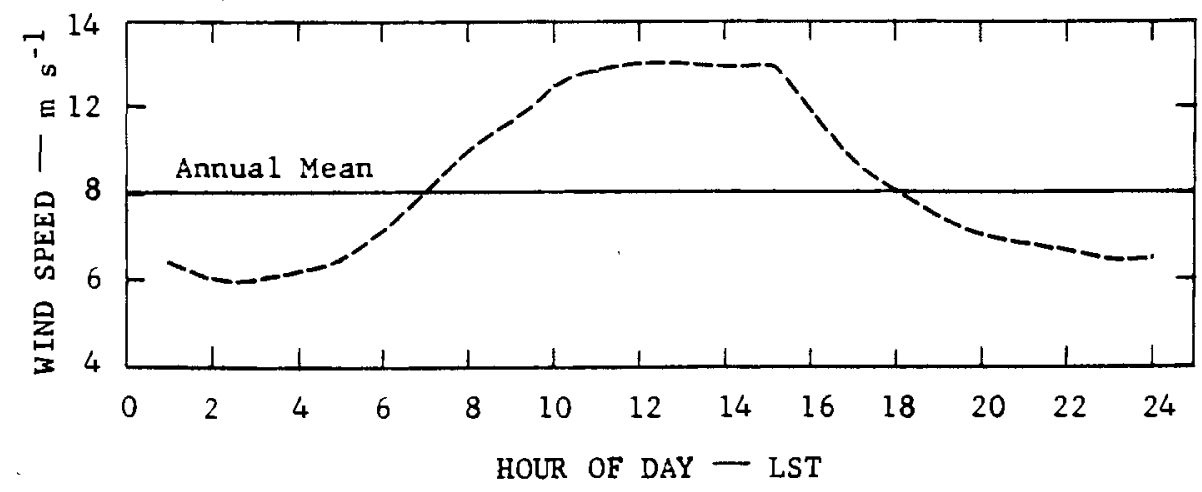

(b) SEASONAL VARIABILITY

\begin{tabular}{|c|c|c|c|c|}
\hline SEASON & WINTER & SPR ING & SUMMER & FALL \\
\hline Wind speed $\left(\mathrm{m} \mathrm{s}^{-1}\right)$ & 8.71 & 9.14 & 7.40 & 7.73 \\
\hline
\end{tabular}

FIGURE 18 ANNUAL MEAN HUB HEIGHT $(45.7 \mathrm{~m})$ WIND SPEED VARIABILITY AT MONTAUK POINT, NEW YORK FOR THE PERIOD 1954

\section{San Gorgonio Pass, California}

Figure 24 shows the location of San Gorgonio Pass and the surrounding terrain features. It is seen that the site is situated between two distinct high-altitude mountains, an $11,000 \mathrm{ft}(3,353 \mathrm{~m})$ peak to the north and a $10,000 \mathrm{ft}$ peak to the south. The topography gradient in either direction is very strong; it is as much as $10,000 \mathrm{ft}(3,048 \mathrm{~m})$ over a distance of $30 \mathrm{~km}$ to the northwest and $9,000(2,742 \mathrm{~m})$ over $20 \mathrm{~km}$ to the southwest. Also, there exist some very low lying areas in the region--e.g., in the vicinity of Indio.

The data stations selected for San Gorgonio are also shown in the figure. It can be seen that the four stations are distributed relatively nonsymmetrically about the WECS site because we have avoided selecting data stations located in areas that do not possess topographic features representative of those found in the vicinity of the site. For example, we have not selected any data station located in the Mojave desert to the north.

For San Gorgonio Pass, we have used two grids, with mesh sizes of $10 \mathrm{~km}$ for the coarse grid and $2.5 \mathrm{~km}$ for the fine grid. The UTM coordinates of the origin of the coarse grid (zone 11) are $539 \mathrm{~km}$ east and $3755.3 \mathrm{~km}$ north. The coarse grid has 14 grid points to the east and 9 to the north; the corresponding numbers of the fine grid points are 21 and 15 , respectively. The site location in the coarse grid is $(9,5)$ and that in the fine grid is $(13,8)$.

The Input section of Table 3(d) shows the eigenvectors and the mean vector inputs for the COMPLEX model, and the corresponding hub height solutions for San Gorgonio are shown in the Output section. The hub height wind characteristics derived on the basis of hourly surface wind observations at the four selected locations for the 12 -month period June 1949 


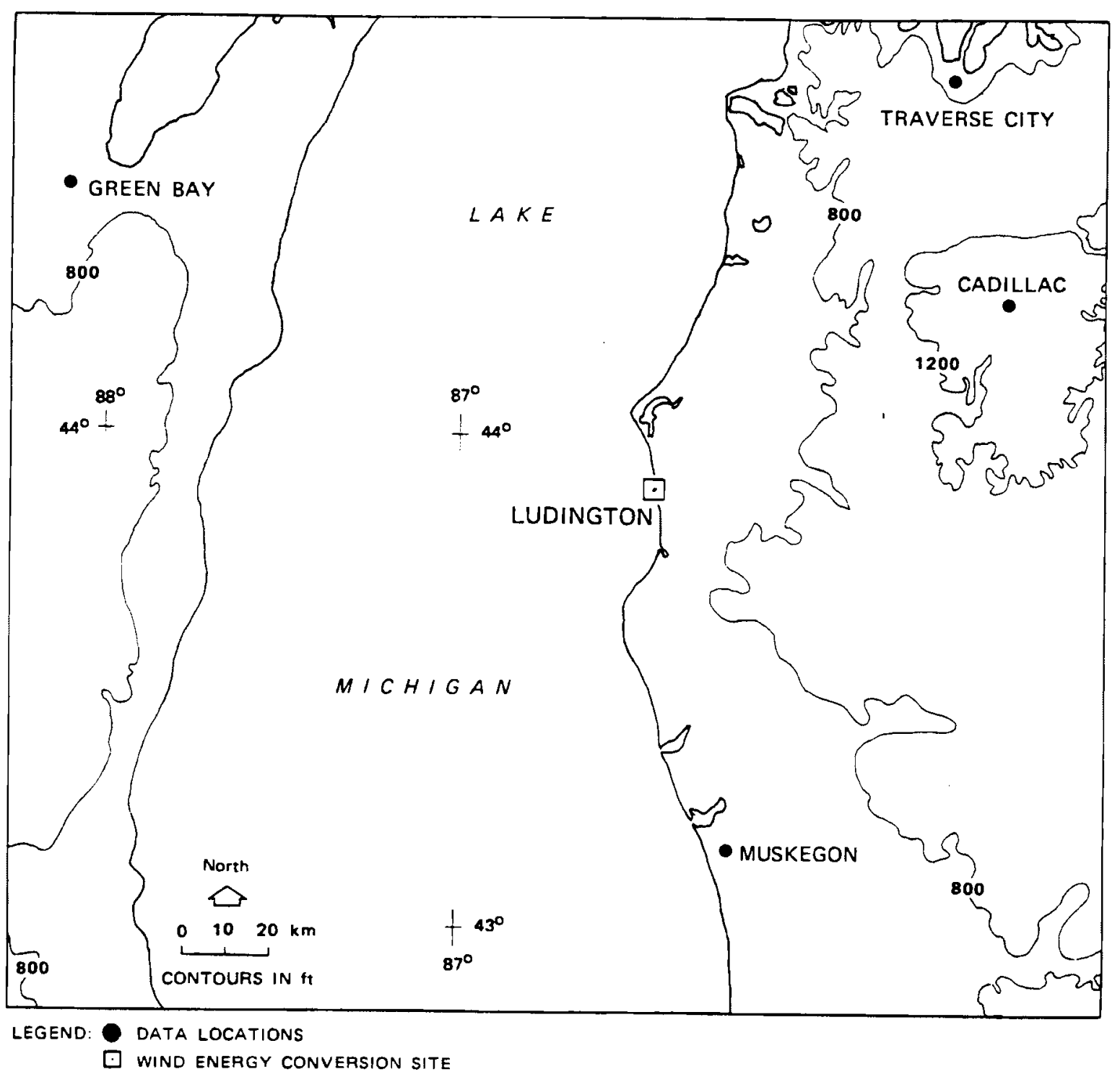

FIGURE 19 LOCATOR MAP FOR THE WEC SITE AT LUDINGTON, MICHIGAN AND THE FOUR DATA STATIONS

to May 1950 are shown in Figures 25 through 28.

The wind speeds calculated for San Gorgonio appear to be very low. For example, the annual mean is $3.3 \mathrm{~m} \mathrm{~s}^{-1}$. The diurnal variation of annual wind speed, while showing relatively stronger winds in the afternoon, has a range of $2 \mathrm{~m} \mathrm{~s}^{-1}$. The run duration (Figure 26) shows that there are very few occasions when wind speed exceeded $10 \mathrm{~m} \mathrm{~s}^{-1}$. For example, there are only two occasions when winds between 10 and $25 \mathrm{~m} \mathrm{~s}^{-1}$ persisted for 8 hours. The speed frequency distribution shows that there are no winds gusting above the cut-off speed of $26 \mathrm{~m} \mathrm{~s}^{-1}$. The joint frequency distribution of speed versus direction shows that the most frequent direction is from the NW sector for wind speed of $4 \mathrm{~m} \mathrm{~s}^{-1}$ or less. Also, there are only two occasions when wind from the WSW has a speed greater than $16 \mathrm{~m} \mathrm{~s}^{-1}$. 


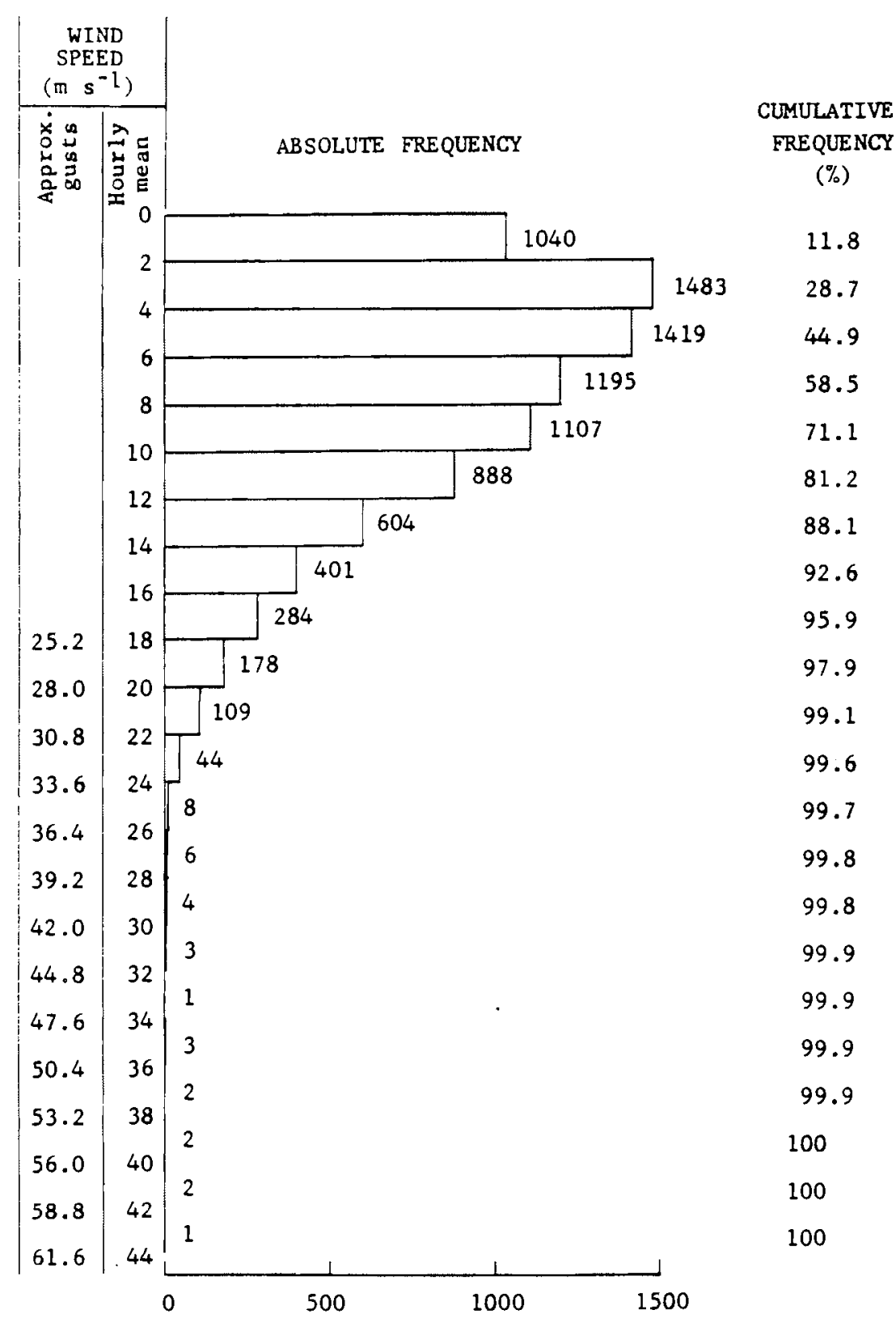

FIGURE 20 FREQUENCY DISTRIBUTION OF HUB HEIGHT $(45.7 \mathrm{~m})$ WIND SPEED AT LUDINGTON, MICHIGAN FOR THE PERIOD 1952. Wind speed categories are for annual mean and gusts above $25.2 \mathrm{~m} \mathrm{~s}^{-1}$. 


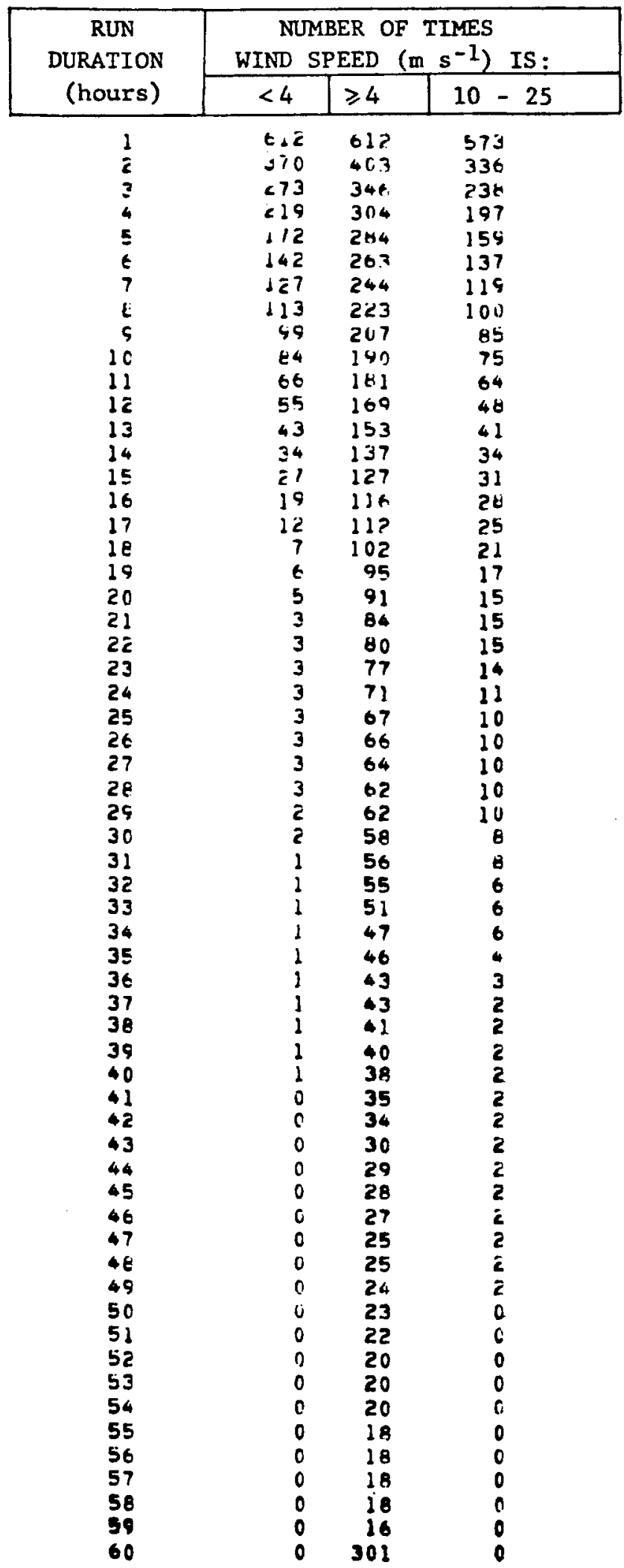

FIGURE 21 RUN DURATION ANALYSIS OF HUB HEIGHT $(45.7 \mathrm{~m})$ ANNUAL MEAN WIND SPEED AT LUDINGTON, MICHIGAN FOR THE PERIOD 1952 


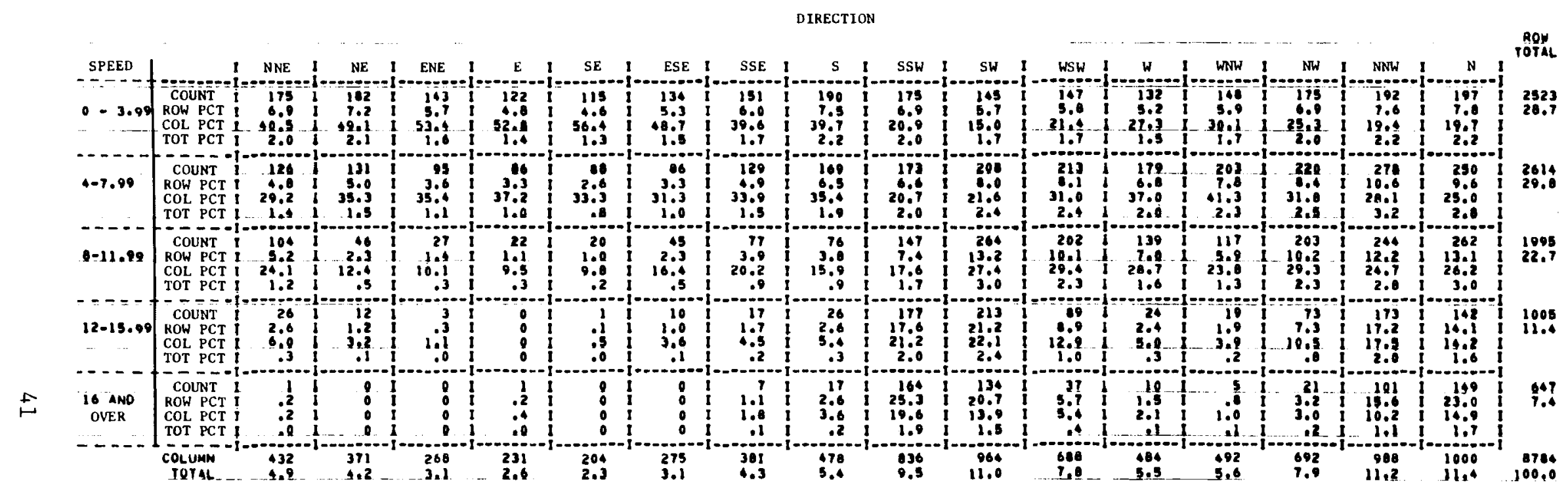

FIGURE 22 JOINT FREQUENCY DISTRIBUTION OF ANNUAL WIND SPEED $\left(\mathrm{m} \mathrm{s}^{-1}\right)$ AND DIRECTION AT HUB HEIGHT (45.7 m) AT LUDINGTON, MICHIGAN FOR THE PERIOD 1952 
(a) DIURNAL VARIABILITY

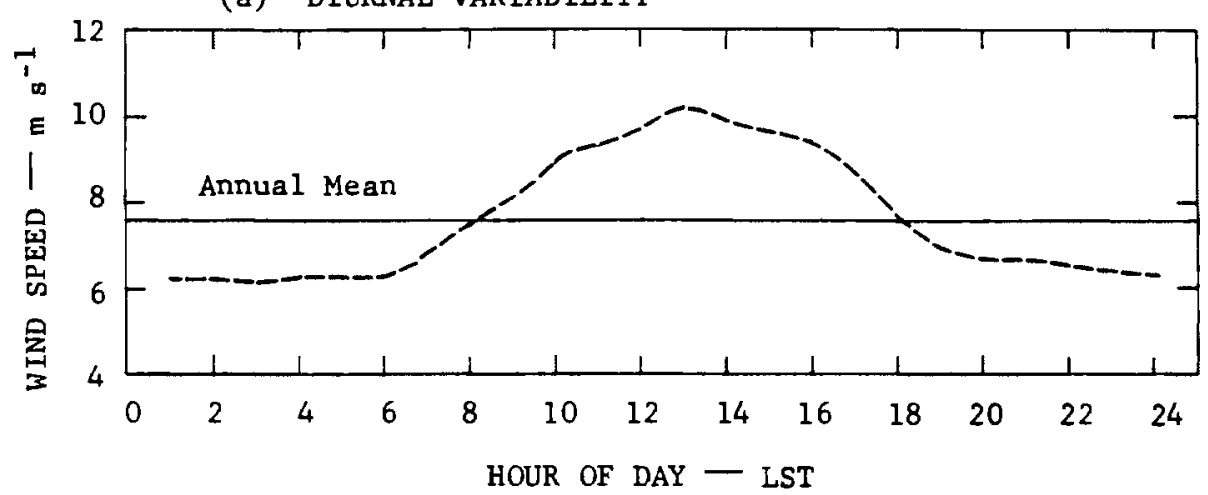

(b) SEASONAL VARIABILITY

\begin{tabular}{|c|c|c|c|c|}
\hline SEASON & WINTER & SPRING & SUMMER & FALL \\
\hline Wind speed $\left(\mathrm{m} \mathrm{s}^{-1}\right.$ ) & 8.19 & 7.64 & 7.08 & 7.58 \\
\hline
\end{tabular}

FIGURE 23 ANNUAL MEAN HUB HEIGHT $(45.7 \mathrm{~m})$ WIND SPEED VARIABILITY AT LUDINGTON, MICHIGAN FOR THE PERIOD 1952

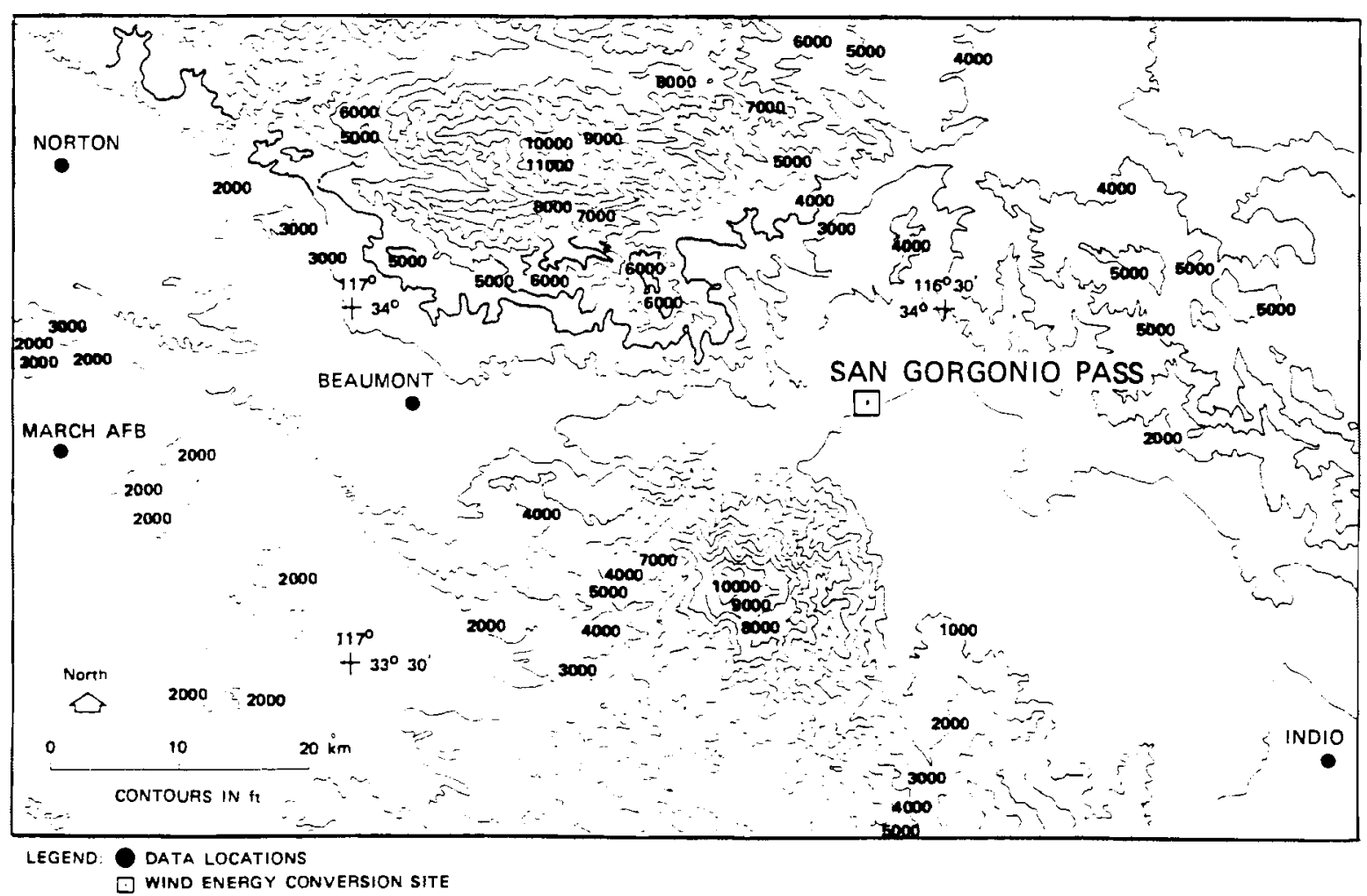

FIGURE 24 LOCATOR MAP FOR THE WEC SITE AT SAN GORGONIO PASS, CALIFORNIA AND THE FOUR DATA STATIONS 


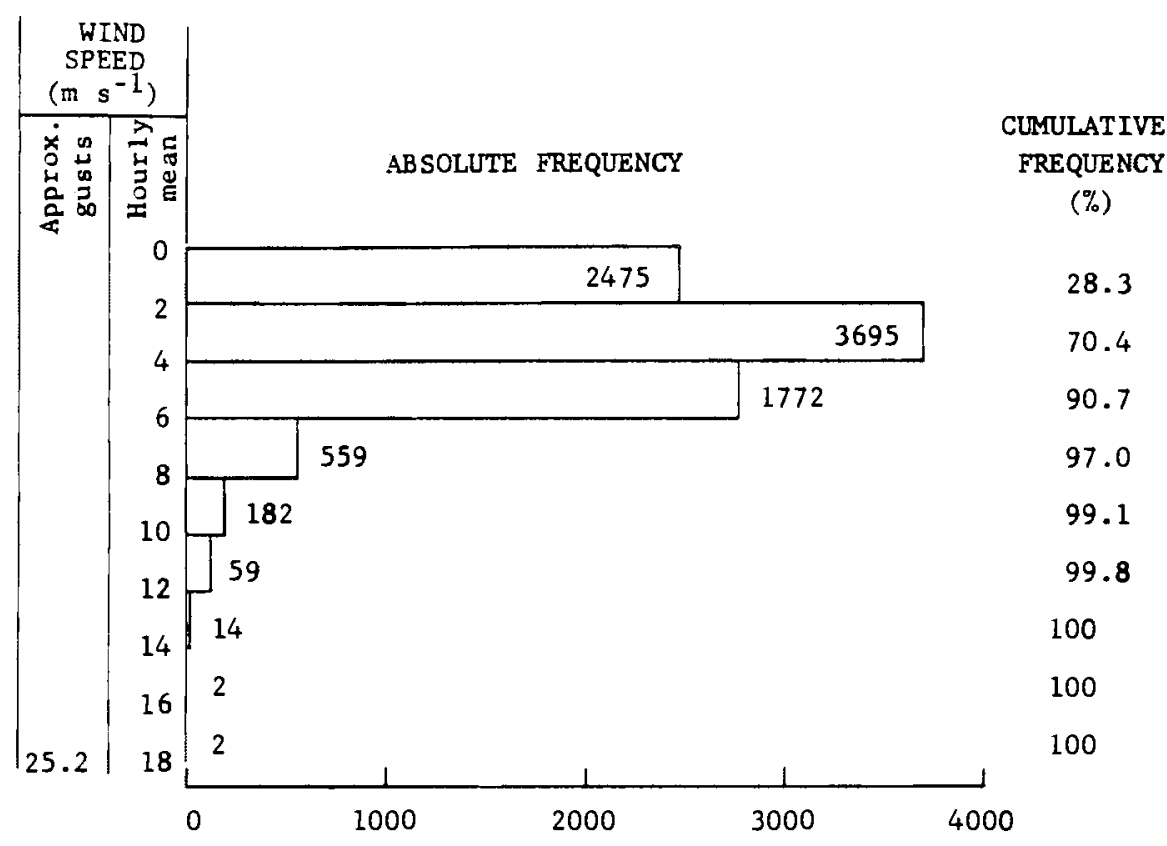

FIGURE 25 FREQUENCY DISTRIBUTION OF HUB HEIGHT $(45.7 \mathrm{~m})$ WIND SPEED AT SAN GORGONIO PASS, CALIFORNIA FOR THE PERIOD JUNE 1949 - MAY 1950. Wind speed categories are for annual mean and gusts above $25.2 \mathrm{~m} \mathrm{~s}^{-1}$.

\section{Russell, Kansas}

Figure 29 shows the locations of Russell and the three data stations surrounding it. The topography of the site location and its surroundings is typical of the Great Plains; there are no significant gradients in the terrain features.

In this case we have used only one grid with a mesh size of $2 \mathrm{~km}$, and this is quite adequate to resolve the actual topography for the grid. The UTM coordinates of the origin of the grid (zone 14) are $568.6 \mathrm{~km}$ east and $4300.5 \mathrm{~km}$ north. The number of grid points to the east and north are 21 and 15 , respectively, and the site is located at the grid point $(13,7)$.

Table 3 (e) shows the six eigenvectors of the covariant matrix and the mean derived from the hourly wind data (at the three data locations) for 1954. As in the case of Montauk Point, the input to the COMPLEX model consists of six eigenvectors plus the mean; the corresponding seven outputs are shown in the Output section of the table. The wind characteristics derived from the hourly hub level wind calculated from these hub level solutions are shown in Figures 30 through 33. The joint speed and direction frequency shows that the most frequent direction for strong winds $\left(>16 \mathrm{~m} \mathrm{~s}^{-1}\right)$ is from the SW. The duration analysis shows that winds between 10 and $25 \mathrm{~m} \mathrm{~s}^{-1}$ persist more frequently for 20 hours, but they persist (in this speed range) only twice for 37 hours. There are 27 occasions when winds with speed $>4$ $\mathrm{m} \mathrm{s}^{-1}$ exceeded 59 hours in duration. The diurnal variation and seasonal variations are typical of the Great Plains region. 


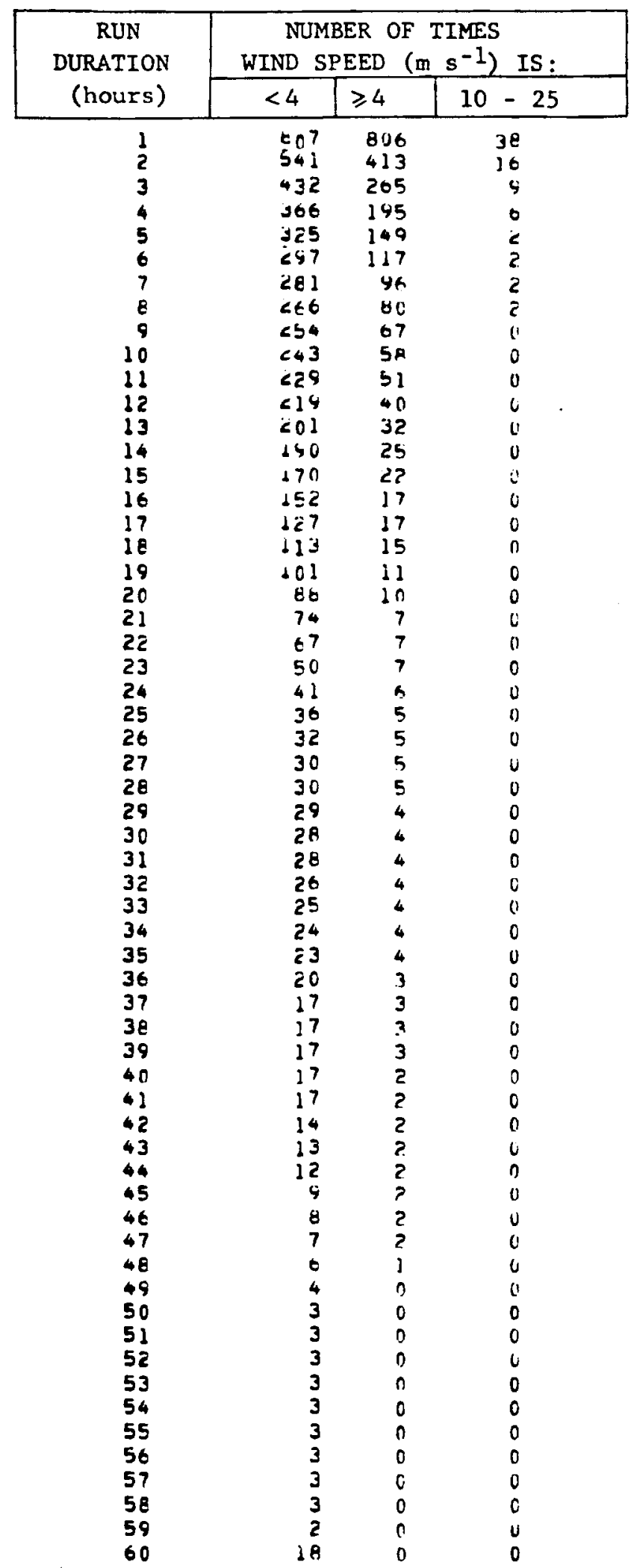

FIGURE 26 RUN DURATION ANALYSIS OF HUB HEIGHT(45.7m) ANNUAL MEAN WIND SPEED AT SAN GORNONIO PASS, CALIFORNIA FOR THE PERIOD JUNE 1949 - MAY 1950 


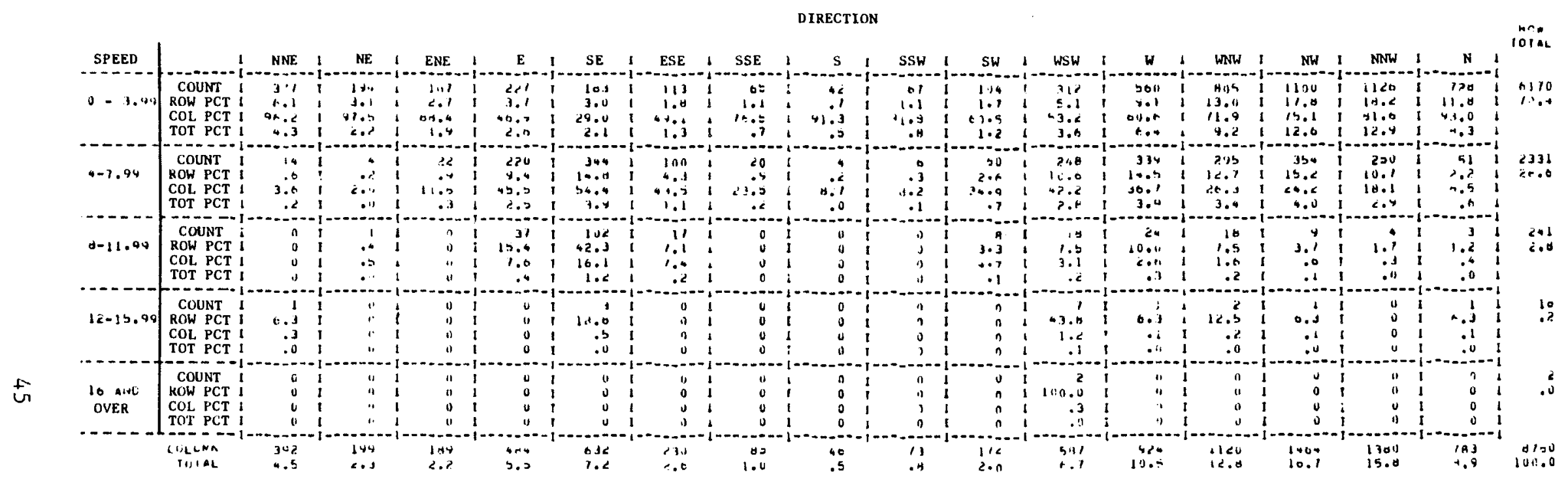

FIGURE 27 JOINT FREQUENCY DISTRIBUTION OF ANNUAL WIND (m s-1) AND DIRECTION AT HUB HEIGHT $(45.7 \mathrm{~m})$ AT SAN GORGONIO PASS, CALIFORNIA FOR THE PERIOD JUNE 1949 - MAY 1950 


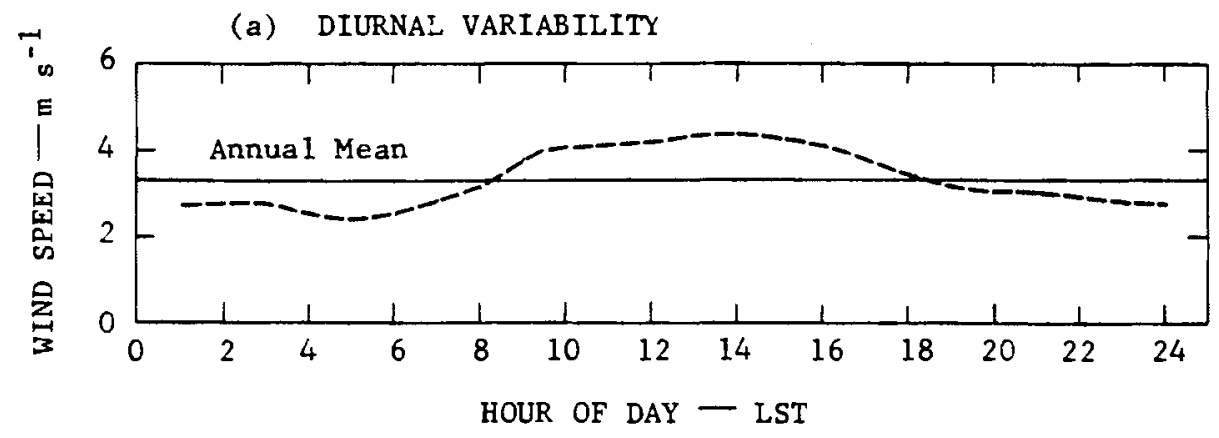

(b) SEASONAL VARIABILITY

\begin{tabular}{|c|c|c|c|c|}
\hline SEASON & WINTER & SPRING & SUMMER & FALL \\
\hline Wind speed $\left(\mathrm{m} \mathrm{s}^{-1}\right)$ & 3.36 & 3.43 & 3.35 & 3.07 \\
\hline
\end{tabular}

FIGURE 28 ANNUAL MEAN HUB HEIGHT $(45.7 \mathrm{~m})$ WIND SPEED VARIABILITY AT SAN GORGONIO PASS, CALIFORNIA FOR THE PERIOD JUNE 1949 - MAY 1950

\section{Boardman, Oregon}

Figure 34 shows the locations of Boardman and the four stations from which wind data have been used for estimating hub height wind characteristics at Boardman. The topography in the region considered by us is characterized by ridges to the northwest and southeast of Boardman, while the site itself and one of the data stations (Dalesport) are located in the Columbia River Valley.

We have used two grids for Boardman. The coarse and fine grid mesh sizes are 10 $\mathrm{km}$ and $2 \mathrm{~km}$, respectively, and the UTM coordinates (zone 11) of the origin of the coarse grid are $278.7 \mathrm{~km}$ east and $5062.3 \mathrm{~km}$ north. The coarse grid has 14 grid points to the east and 11 to the north; the corresponding grid points for the fine grid are 21 and 21 , respectively. The site is located at the grid point $(8,3)$ in the coarse grid, and at $(14,10)$ in the fine grid.

Table 3(f) shows input wind components for eight eigenvectors of the covariant matrix and the mean for 1961; it also shows the corresponding hub height stations obtained by integrating the complex model.

The hub level wind characteristics at Boardman are shown in Figures 35 through 38. Annually, the mode (the most frequent) speed is about $4 \mathrm{~m} \mathrm{~s}^{-1}$; however, Figure 35 shows that higher wind speeds (up to $16 \mathrm{~m} \mathrm{~s}^{-1}$ ) are also quite frequent. There are very few instances when annual mean wind speed exceeded $30 \mathrm{~m} \mathrm{~s}^{-1}$.

The peak-gust analysis (Figure 35) shows that on more than $98 \%$ of the occasions wind did not gust above $26 \mathrm{~m} \mathrm{~s}^{-1}$. The duration analysis (Figure 36) shows that winds with speeds between 10 and $25 \mathrm{~m} \mathrm{~s}^{-1}$ do not persist for more than 34 hours, except one occasion.

The most frequent direction (Figure 37) is NW for wind speeds that range from 4 to $8 \mathrm{~m} \mathrm{~s}^{-1}$. Also, for strong wind speeds $\left(>16 \mathrm{~m} \mathrm{~s}^{-1}\right)$ the wind direction is predominantly from the WNW. 


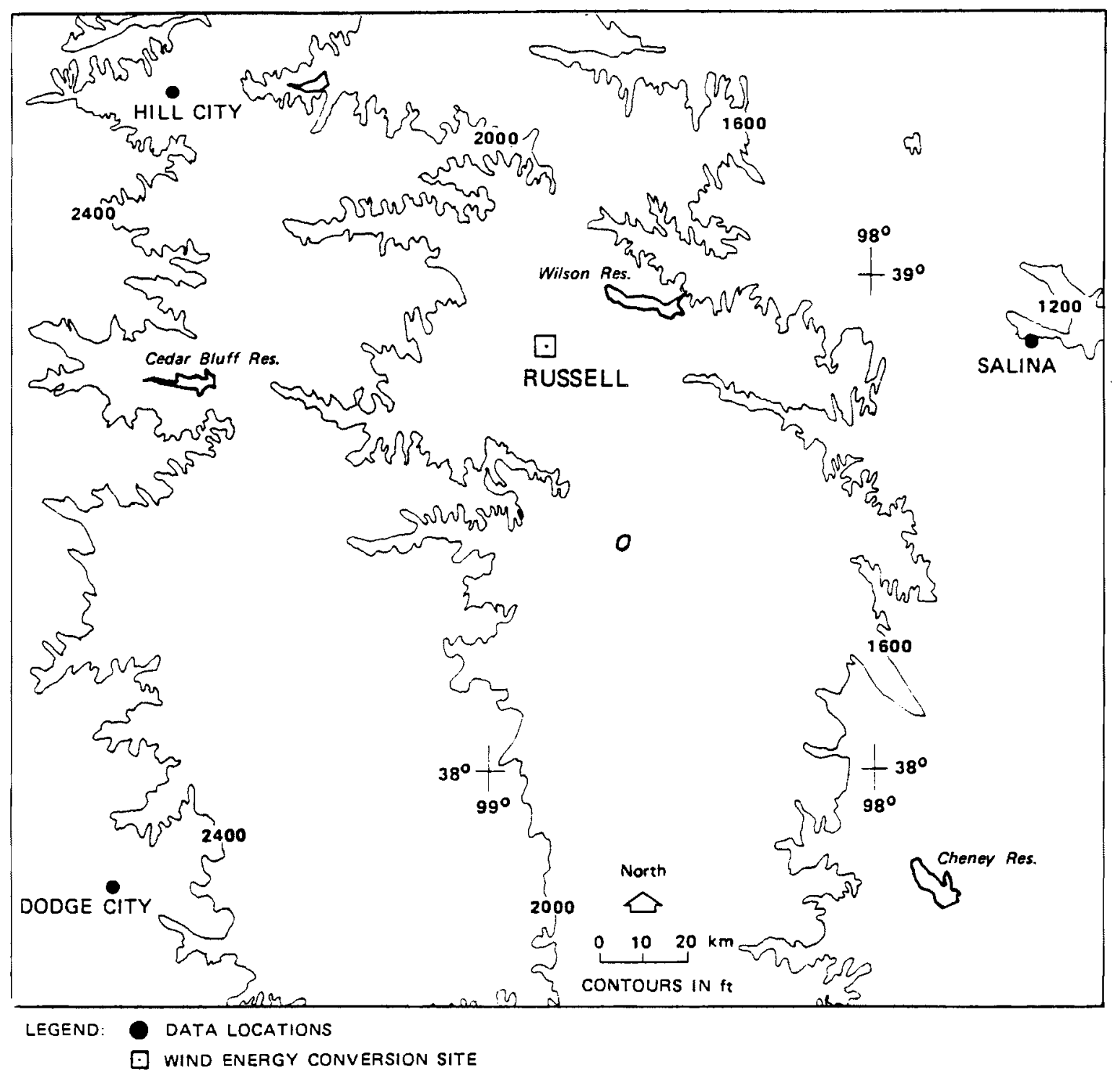

FIGURE 29 LOCATOR MAP FOR THE WEC SITE AT RUSSELL, KANSAS AND THE THREE DATA STATIONS

\section{Holyoke, Massachusetts}

Figure 39 shows locations of Holyoke and the four data stations. It is seen that the region is characterized by complex terrain features consisting of mountains and the Connecticut river. The site itself, though located at an elevation of $1220 \mathrm{ft}(372 \mathrm{~m})$, is in close proximity to the river valley. A predominant north-south orientation of the terrain has been specifically selected to avoid choosing data stations from the western regions near Albany and the Hudson River.

We have utilized two grids for Holyoke; the coarse and fine grid mesh sizes are 10 $\mathrm{km}$ and $2.5 \mathrm{~km}$, respectively. The UTM coordinates of the origin of the coarse grid (zone 18) are $694.4 \mathrm{~km}$ east and $4680.9 \mathrm{~km}$ north. The number of grid points for the coarse grid to the 


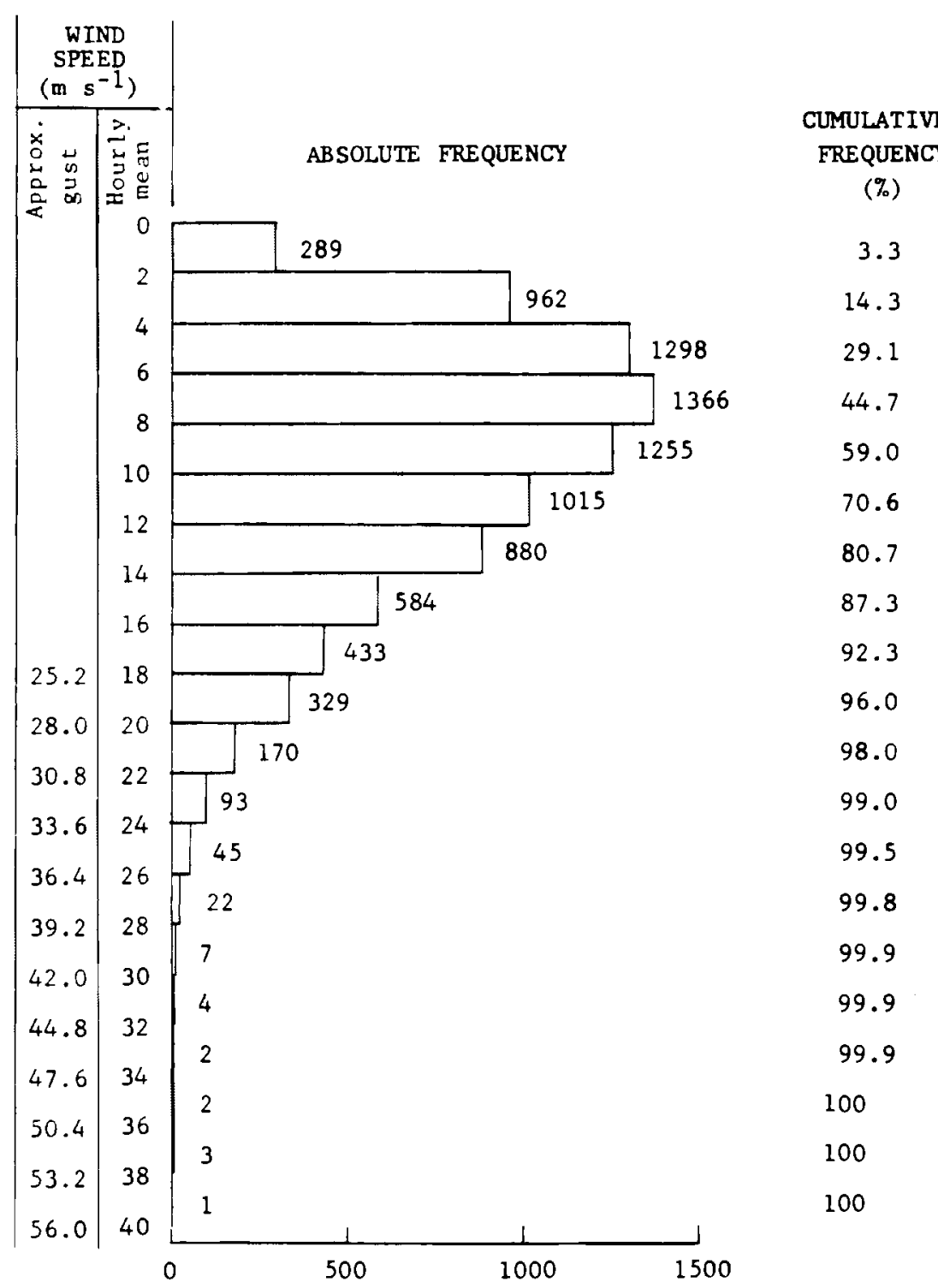

FIGURE 30 FREQUENCY DISTRIBUTION OF HUB HEIGHT $(45.7 \mathrm{~m})$ WIND SPEED AT RUSSELL, KANSAS FOR THE PERIOD 1954. Wind speed categories are for annual mean and gusts above $25.2 \mathrm{~m} \mathrm{~s}^{-1}$.

east and north are 11 and 15 , and the number of grid points for the fine grid are 21 and 21 , respectively. The site is located at the grid point $(7,10)$ in the coarse grid, and $(12,13)$ in the fine grid.

Table $3(\mathrm{~g})$ shows the mean and eight eigenvectors of the covariant matrix derived from the hourly surface wind data for the period June 1951 to May 1952 for four stations, West Lebanon, Windsor Locks, Westfield, and Chicopee Falls. The corresponding hub height solutions at Holyoke are shown in the table. The wind characteristics derived from reconstructed hourly winds at Holyoke are shown in Figures 40 through 43. 


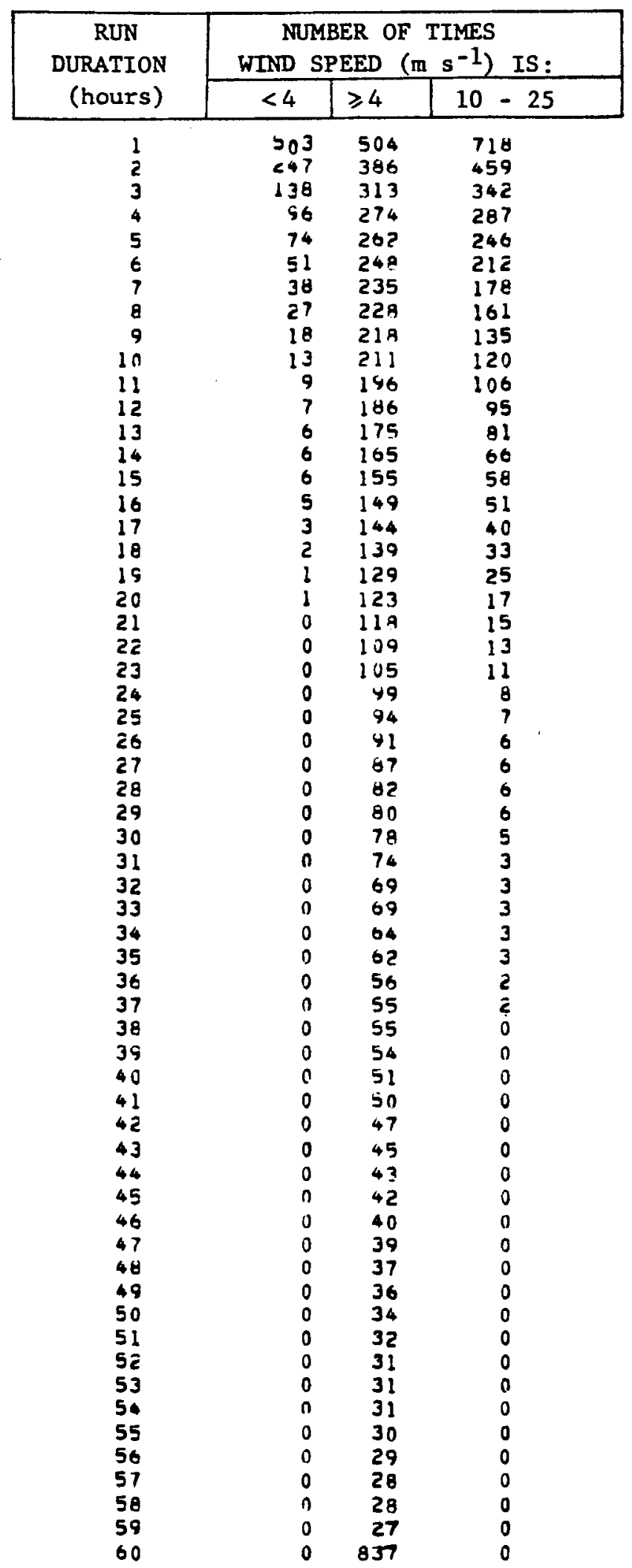

FIGURE 31 RUN DURATION ANALYSIS OF HUB HEIGHT $(45.7 \mathrm{~m})$ ANNUAL MEAN WIND SPEED AT RUSSELL, KANSAS FOR THE PERIOD 1954 
DIRECTION

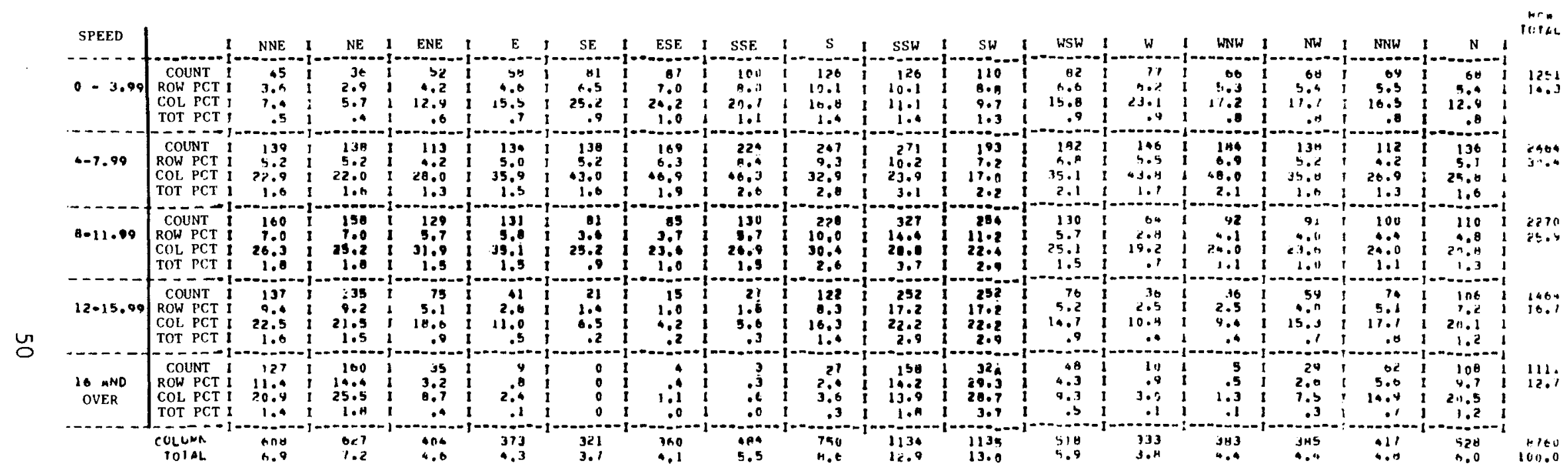

FIGURE 32 JOINT FREQUENCY DISTRIBUTION OF ANNUAL WIND SPEED (m $\mathrm{s}^{-1}$ ) AND DIRECTION AT HUB HEIGHT $(45.7 \mathrm{~m})$ AT RUSSELL, KANSAS FOR THE PERIOD 1954 
(a) DIURNAL VARIABILITY

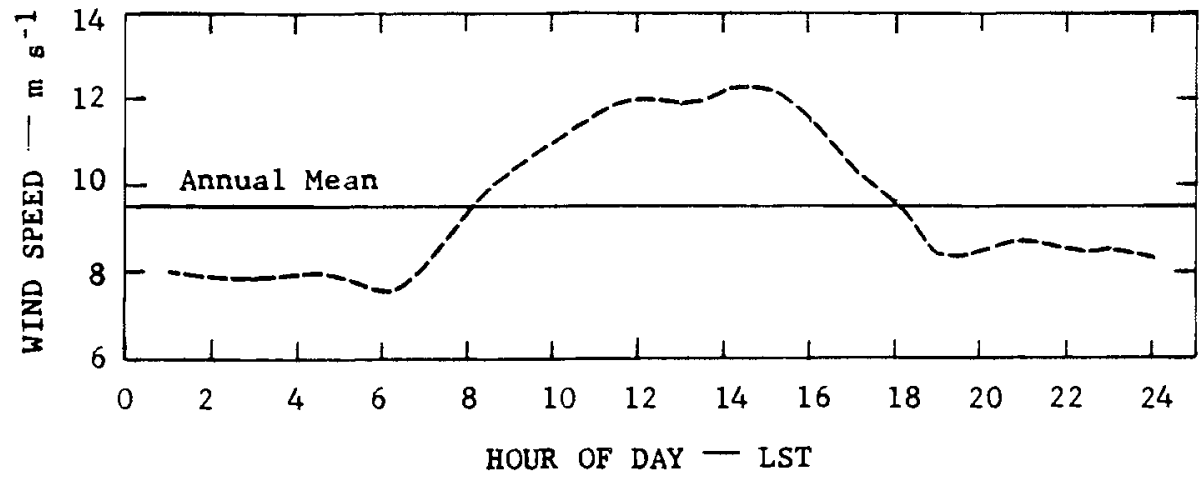

(b) SEASONAL VARIABILITY

\begin{tabular}{|c|c|c|c|c|}
\hline SEASON & WINTER & SPRING & SUMMER & FALL \\
\hline Wimd speed $\left(\mathrm{m} \mathrm{s}^{-1}\right)$ & $\mathbf{8 . 3 9}$ & 9.75 & 10.20 & 9.80 \\
\hline
\end{tabular}

FIGURE 33 ANNUAL MEAN HUB HEIGHT $(45.7 \mathrm{~m})$ WIND SPEED VARIABILITY AT RUSSELL, KANSAS FOR THE PERIOD 1954

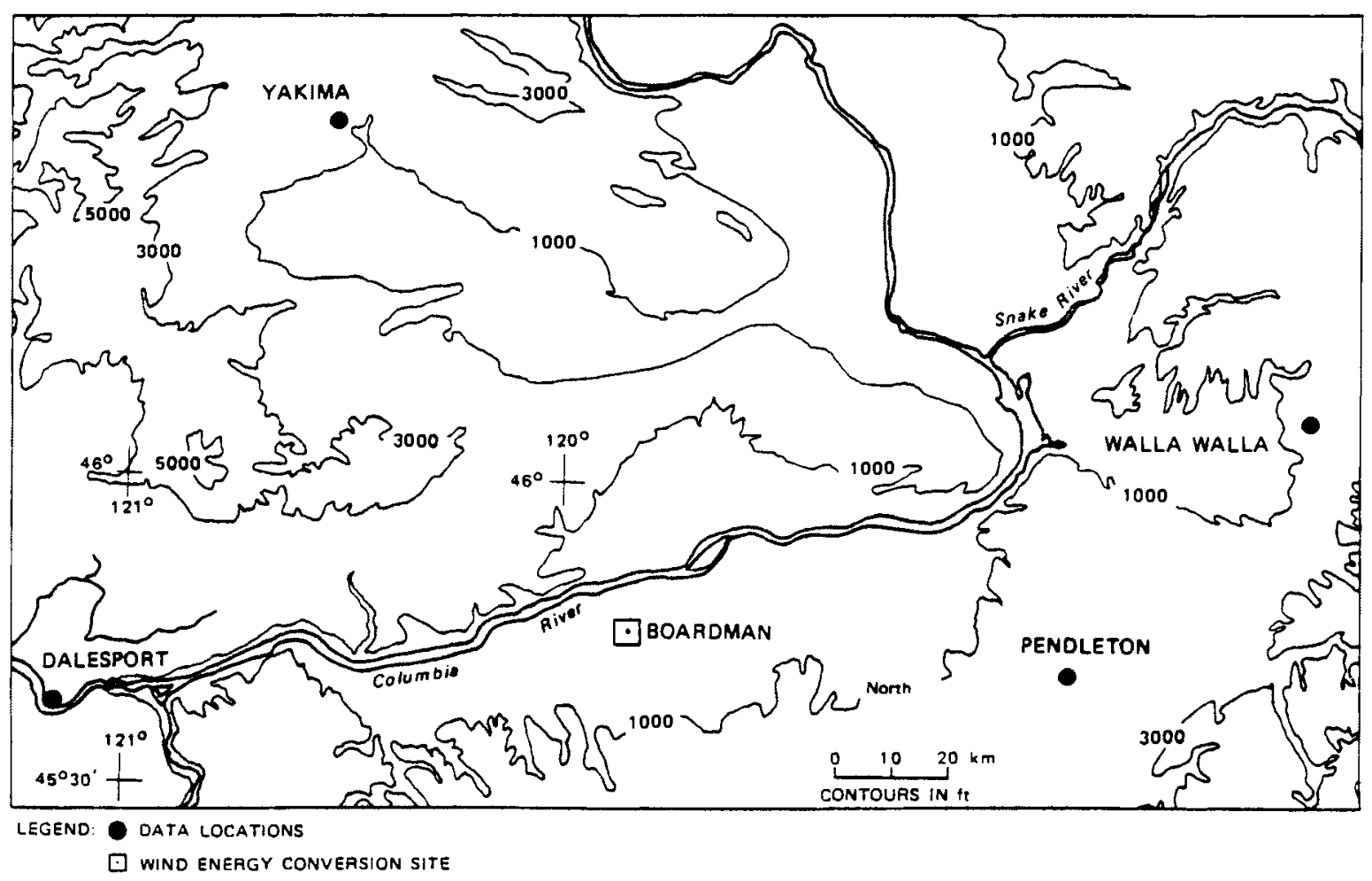

FIGURE 34 LOCATOR MAP FOR THE WEC SITE AT BOARDMAN, OREGON AND THE FOUR DATA STATIONS 


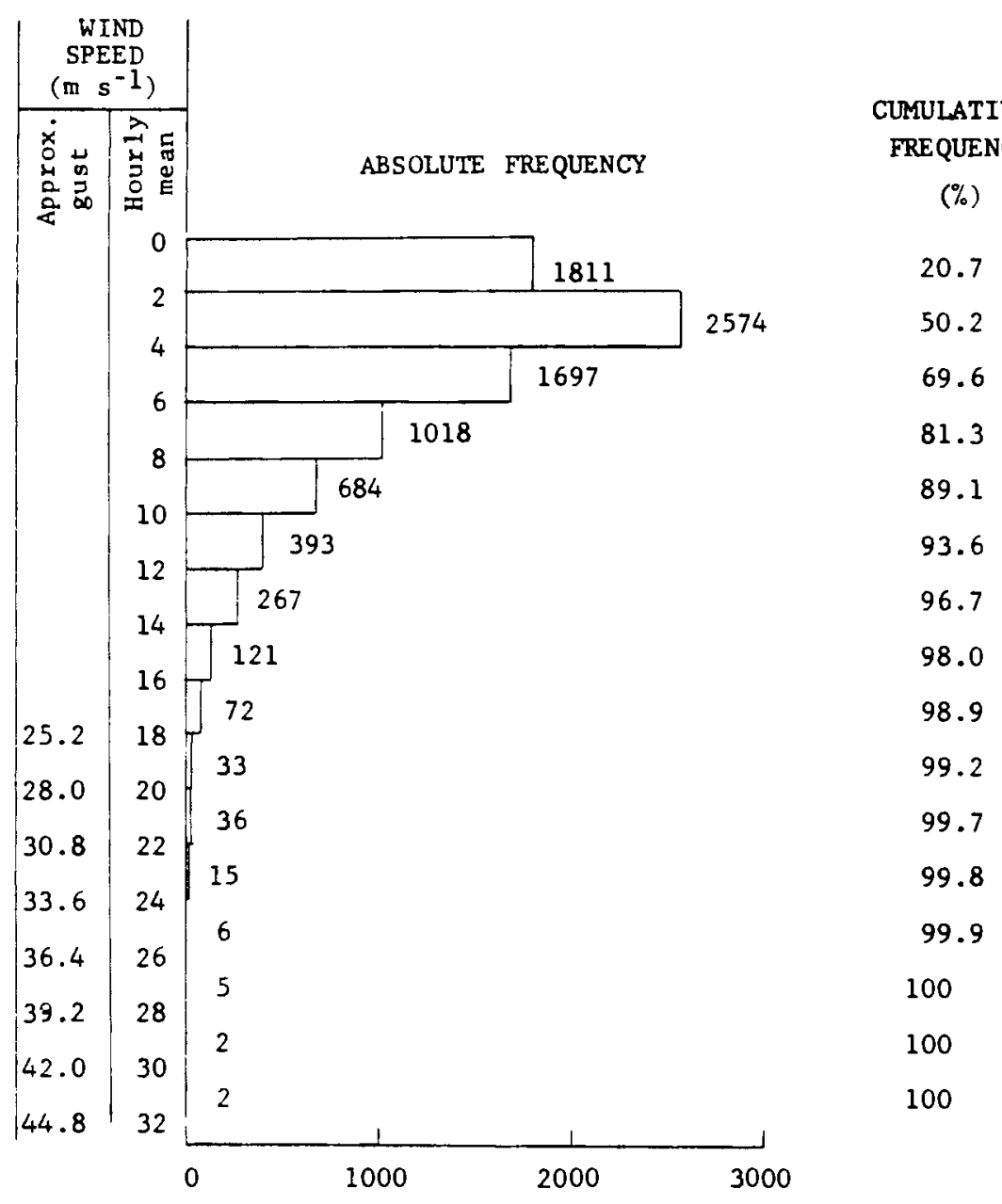

FIGURE 35 FREQUENCY DISTRIBUTION OF HUB HEIGHT $(45.7 \mathrm{~m})$ WIND SPEED AT BOARDMAN, OREGON FOR THE PERIOD 1961. Wind speed categories are for annual mean and gusts above $25.2 \mathrm{~m} \mathrm{~s}^{-1}$.

In general, the wind speeds are relatively low, with very few (2\%) occasions when they exceed $16 \mathrm{~m} \mathrm{~s}^{-1}$. The most predominant direction, as expected due to topography, is from the north, though there are some occasions ( $10 \%$ or so) when the wind is from the SSW or NNW. The occasions when the wind gusts above $26 \mathrm{~m} \mathrm{~s}^{-1}$ are less than $1 \%$. The diurnal and seasonal variability ranges are quite small.

\section{Huron, South Dakota}

Figure 44 shows the location and topographic features of Huron. The general features are similar to those described for Russell, Kansas (Figure 29). The terrain is rather flat without any significant gradients. Only one grid (grid mesh size $2 \mathrm{~km}$ ) is used for Huron, and the UTM coordinates of its origin (zone 14) are $568.6 \mathrm{~km}$ east and $4918.1 \mathrm{~km}$ north. The number of grid points to the east and north are, respectively, 21 and 15 . There are three data stations selected for Huron. The mean vector and six eigenvectors derived from hourly surface wind data for 1954 at these three stations are shown in the Input section of Table $3(\mathrm{~h})$. The hub height wind for Huron reconstructed from the solutions also shown in the Output section have been used to derive hub level wind characteristics, which are shown in Figures 45 through 


\begin{tabular}{|c|c|c|c|}
\hline \multirow{2}{*}{$\begin{array}{c}\text { RUN } \\
\text { DURATION } \\
\text { (hours) }\end{array}$} & \multicolumn{3}{|c|}{$\begin{array}{l}\text { NUMBER OF TIMES } \\
\left.\text { WIND SPEED (m } \mathrm{s}^{-1}\right) \text { IS : }\end{array}$} \\
\hline & $<4$ & $\geqslant 4$ & $10-25$ \\
\hline 1 & 1002 & 1001 & 298 \\
\hline 2 & 011 & 547 & 146 \\
\hline 3 & $\$ 48$ & 389 & 93 \\
\hline 4 & $\$ 46$ & 311 & 67 \\
\hline 5 & $<45$ & 252 & 58 \\
\hline 6 & $<36$ & 207 & 48 \\
\hline 7 & 150 & 182 & 41 \\
\hline 8 & $17 ?$ & 104 & 30 \\
\hline 9 & 146 & 146 & 30 \\
\hline 10 & 124 & 131 & 21 \\
\hline 11 & 99 & $1+8$ & 19 \\
\hline 12 & 92 & 101 & 15 \\
\hline 13 & 82 & 83 & 14 \\
\hline $\begin{array}{l}14 \\
15\end{array}$ & $\begin{array}{l}71 \\
55\end{array}$ & $\begin{array}{l}74 \\
64\end{array}$ & 12 \\
\hline 16 & 49 & إ & 6 \\
\hline 17 & $3 B$ & 47 & 5 \\
\hline 18 & 32 & 42 & 3 \\
\hline 19 & 29 & 36 & 3 \\
\hline 20 & 23 & 33 & 3 \\
\hline 21 & 20 & 25 & 2 \\
\hline 22 & 19 & 23 & 2 \\
\hline 23 & 17 & 21 & 1 \\
\hline 24 & 15 & 21 & 1 \\
\hline 25 & 14 & 21 & 1 \\
\hline 26 & 11 & 19 & 1 \\
\hline 27 & 9 & 18 & 1 \\
\hline 22 & 8 & 17 & 1 \\
\hline 29 & 7 & 17 & 1 \\
\hline 30 & 7 & 16 & 1 \\
\hline 31 & 7 & 16 & 1 \\
\hline 32 & 7 & 16 & 1 \\
\hline 33 & 6 & 14 & 1 \\
\hline 34 & 6 & 13 & 0 \\
\hline 35 & 6 & 12 & 0 \\
\hline 36 & 4 & 12 & 0 \\
\hline 37 & 4 & 12 & 0 \\
\hline 38 & 4 & 10 & 0 \\
\hline 39 & 4 & 10 & 0 \\
\hline 40 & 4 & 9 & 0 \\
\hline 41 & 4 & 7 & 0 \\
\hline 42 & 4 & 7 & 0 \\
\hline 43 & 4 & 6 & 0 \\
\hline 44 & 3 & 5 & 0 \\
\hline 45 & 3 & 4 & 0 \\
\hline 46 & 3 & 4 & 0 \\
\hline 47 & 2 & $?$ & 0 \\
\hline 48 & z & ? & 0 \\
\hline 49 & 2 & ? & 0 \\
\hline 50 & 2 & 1 & 0 \\
\hline 51 & 2 & 1 & 0 \\
\hline 52 & $?$ & 1 & 0 \\
\hline 53 & $?$ & 1 & 0 \\
\hline 54 & 2 & 1 & 0 \\
\hline 55 & 2 & 1 & 0 \\
\hline 56 & 1 & 1 & 0 \\
\hline 57 & 1 & 0 & 0 \\
\hline
\end{tabular}

FIGURE 36 RUN DURATION ANALYSIS OF HUB HEIGHT $(45.7 \mathrm{~m})$ ANNUAL MEAN WIND SPEED AT BOARDMAN, OREGON FOR THE PERIOD 1961 
DIRECTION

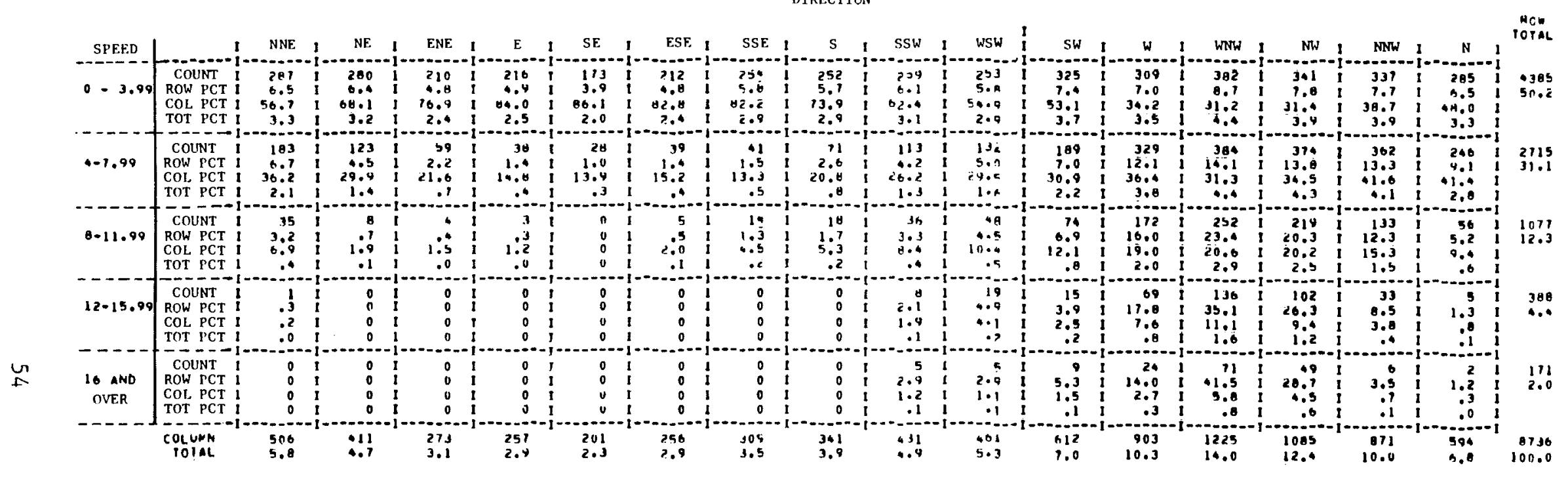

FIGURE 37 JOINT FREQUENCY DISTRIBUTION OF ANNUAL WIND SPEED $\left(\mathrm{m} \mathrm{s}^{-1}\right)$ AND DIRECTION AT HUB HEIGHT $(45.7 \mathrm{~m})$ AT BOARDMAN, OREGON FOR THE PERIOD 1961 
(a) DIURNAL VARIABILITY

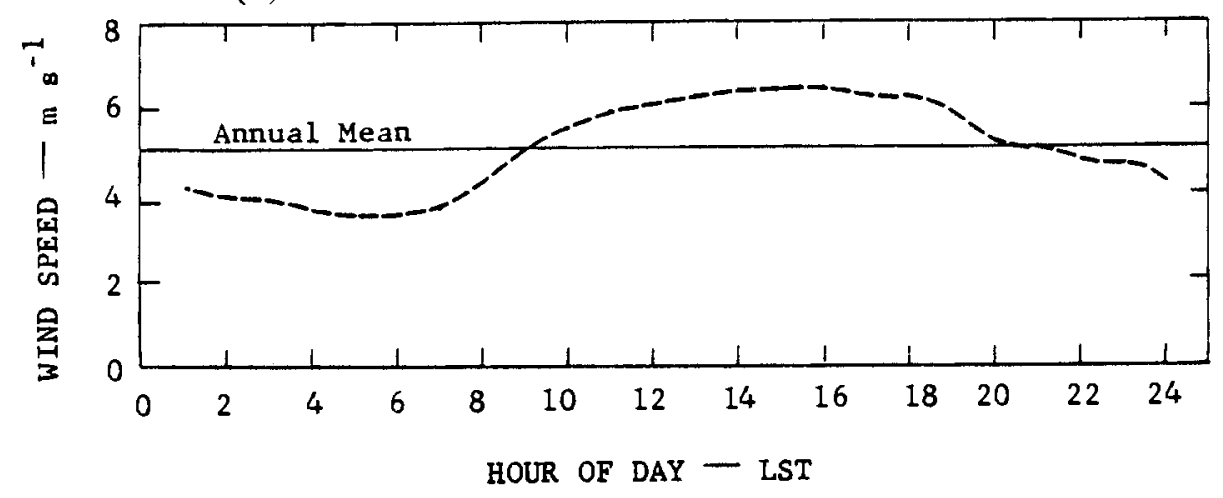

(b) SEASONAL VARIABILITY

\begin{tabular}{|c|c|c|c|c|}
\hline SEASON & WINTER & SPR ING & SUMMER & FALL \\
\hline Wind speed $\left(\mathrm{m} \mathrm{s}^{-1}\right)$ & 4.59 & 5.53 & 5.12 & 5.00 \\
\hline
\end{tabular}

FIGURE 38 ANNUAL MEAN HUB HEIGHT $(45.7 \mathrm{~m})$ WIND SPEED VARIABILITY AT BOARDMAN, OREGON FOR THE PERIOD 1961

48. Hourly wind speeds are generally lower than $36 \mathrm{~m} \mathrm{~s}^{-1}$, with the annual mode being about 6 $\mathrm{m} \mathrm{s}^{-1}$. There is only one occasion when wind speed exceeds $45 \mathrm{~m} \mathrm{~s}^{-1}$. The peak gust analysis shows that on about $6 \%$ of the occasions, wind gusts exceeded $26 \mathrm{~m} \mathrm{~s}^{-1}$ (the cut-off speed).

Data for 1954 for Huron show that there is no one particular predominant wind direction. On about $10 \%$ of the occasions it is from the south, and on about $9 \%$ of the occasions from the north (NNE) or ESE.

\section{Verification of the Methodology}

As discussed in the preceding text, we have applied the methodology developed in this project to obtain hub height wind characteristics at eight selected wind energy conversion sites. We have used only the available conventional surface wind data at selected stations for deriving the needed hourly wind information. We have NOT used the data at the site itself (or within eight $\mathrm{km}$ from it) for estimating the required wind characteristics. However, as shown in Table 2, although hourly wind data are not available at six sites for the 12 -month periods used in this study, they are available for Huron and Russell. This implies that the methodology cannot be validated (by comparing calculated and observed wind data) for six out of eight sites. However, we have verified the methodology for Huron and Russell by the following procedure:

(1) Calculate annual mean speed by using the hourly surface wind data actually observed at Huron and Russell. Here it is assumed that "surface" implies the anemometer height of $10 \mathrm{~m}$.

(2) Extrapolate the value obtained in (1) above to hub height $(45.7 \mathrm{~m})$, by using the same power law [Eq. (23)] as is used with the COMPLEX model. 


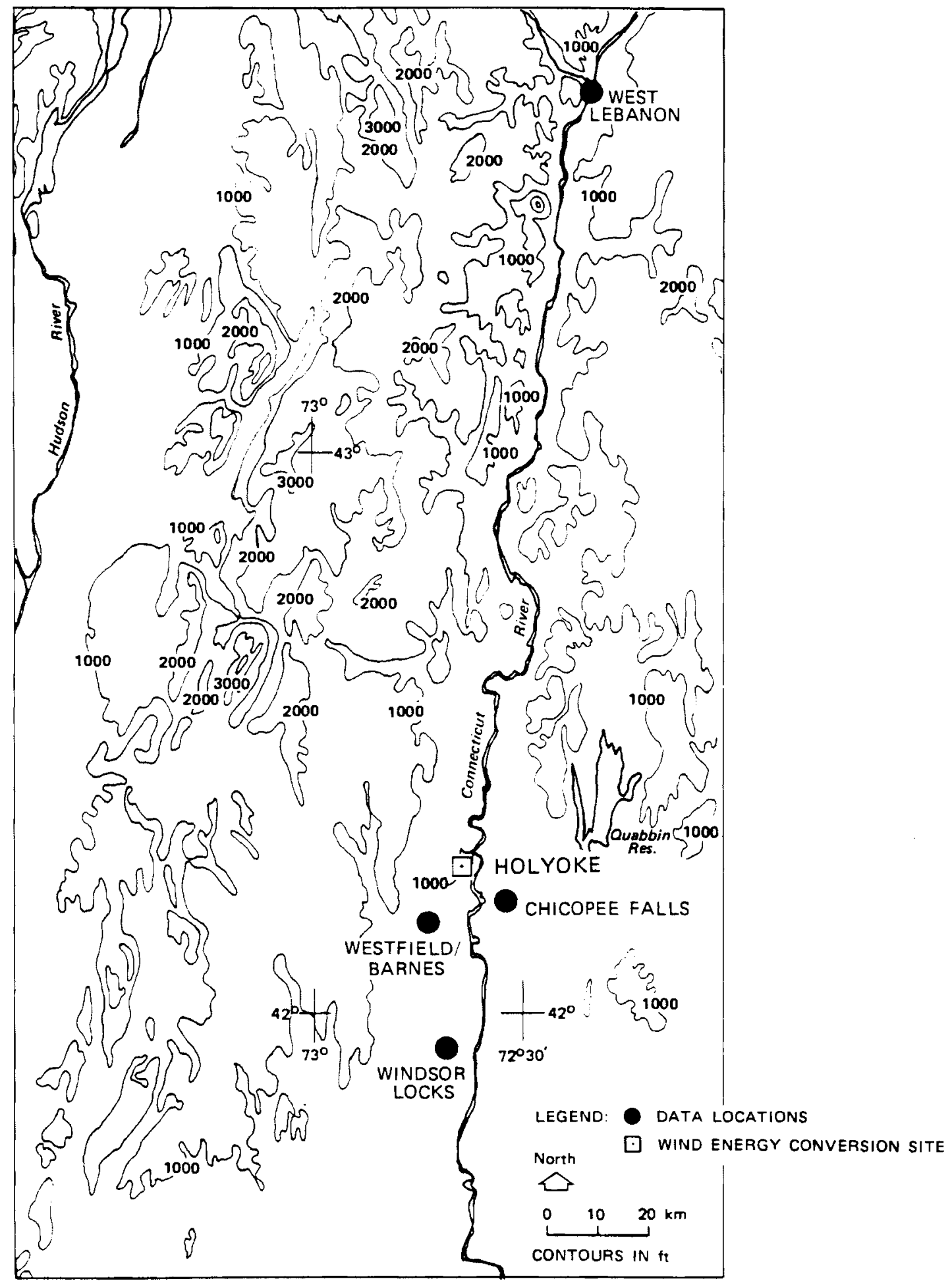

FIGURE 39 LOCATOR MAP FOR THE WEC SITE AT HOLYOKE, MASSACHUSETTS AND THE FOUR DATA STATIONS 


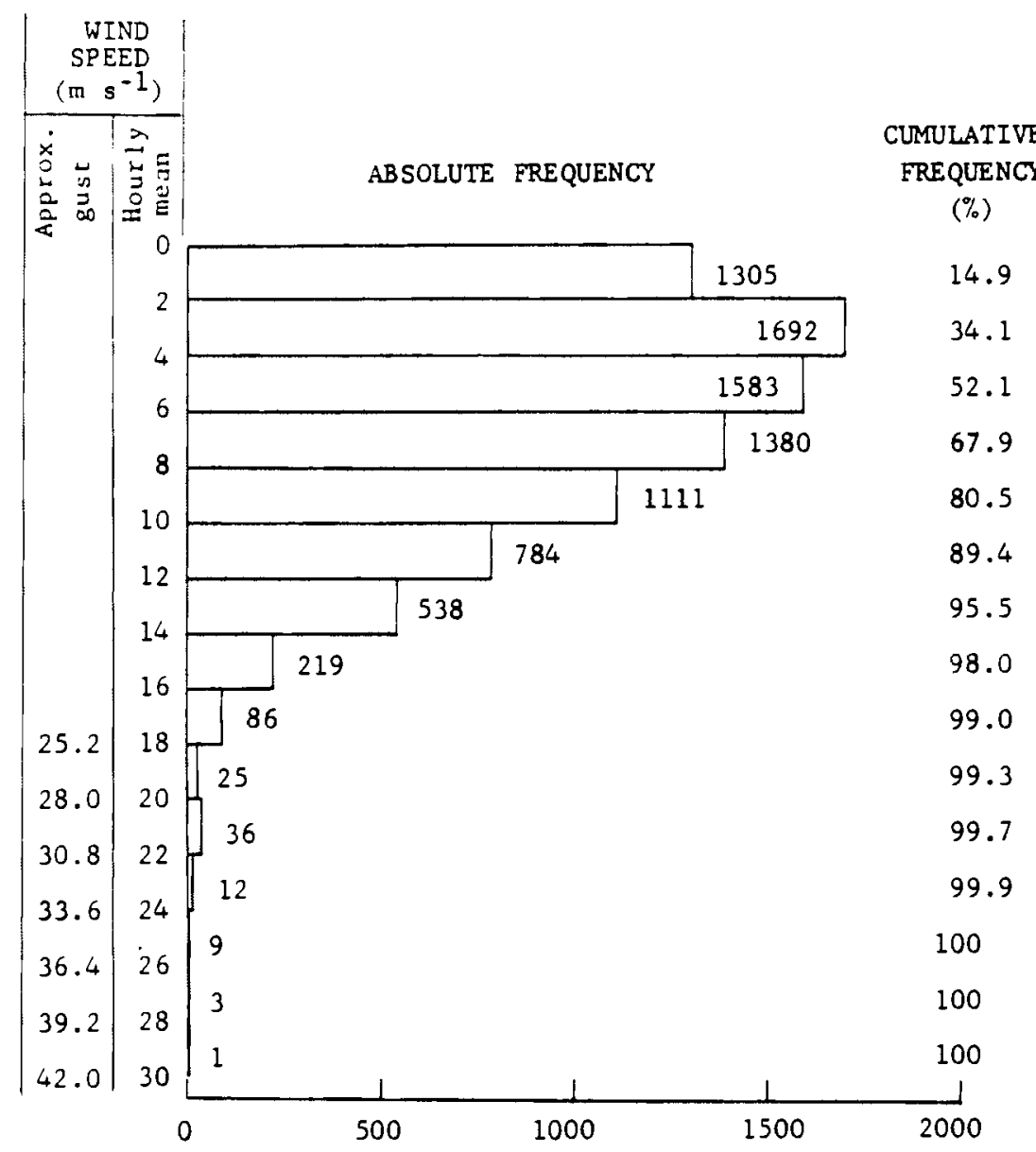

FIGURE 40 FREQUENCY DISTRIBUTION OF HUB HEIGHT $(45.7 \mathrm{~m})$ WIND SPEED AT HOLYOKE, MASSACHUSETTS FOR THE PERIOD JUNE 1951 - MAY 1952. Wind speed categories are for annual mean and gusts above $25.2 \mathrm{~m} \mathrm{~s}^{-1}$.

(3) Compare the "observed" (extrapolated) value of the mean at hub height with the value calculated by the COMPLEX model.

Table 4 shows the comparison for Huron and Russell. (To complete the record we have included annual mean values for other sites also.) The results of verification show that while the method performed very satisfactorily for Russell, it overestimated the wind at Huron (at least the annual mean) by about $25 \%$. While it remains to be seen how the results for other sites compare with actual observations, we believe that the verification of the methodology, as described above, is not satisfactory and that it is necessary to perform a more controlled and elaborate verification before a judgement can be passed on the accuracy of the method.

An examination of the values for hub height annual mean wind at the other six sites shows that while the values at most sites appear to be "reasonable", the value for San Gorgonio Pass appears to be very low, considering the type of terrain around the site. While it is difficult to pinpoint a reason for this low value without systematic tests with the COMPLEX model, we think it may be attributed to the procedure of prescribing that the top of the boundary layer be 


\begin{tabular}{|c|c|c|c|}
\hline \multirow{2}{*}{$\begin{array}{c}\text { RUN } \\
\text { DURATION } \\
\text { (hours) }\end{array}$} & \multicolumn{3}{|c|}{$\begin{array}{l}\text { NUMBER OF TIMES } \\
\text { WIND SPEED }\left(m \mathrm{~s}^{-1}\right) \text { IS : }\end{array}$} \\
\hline & $<4$ & $\geqslant 4$ & $10-25$ \\
\hline $\begin{array}{l}1 \\
2 \\
3 \\
4 \\
5 \\
6 \\
7 \\
8 \\
9 \\
10 \\
11 \\
12 \\
13 \\
14 \\
15 \\
16 \\
17 \\
18 \\
19 \\
20 \\
21 \\
22 \\
23 \\
24 \\
25 \\
26 \\
27 \\
28 \\
29 \\
30 \\
31 \\
32 \\
33 \\
34 \\
35 \\
36 \\
37 \\
38 \\
39 \\
40 \\
41 \\
42 \\
43 \\
44 \\
45 \\
46 \\
47 \\
48 \\
49 \\
50 \\
50 \\
51 \\
52 \\
53 \\
54 \\
59\end{array}$ & 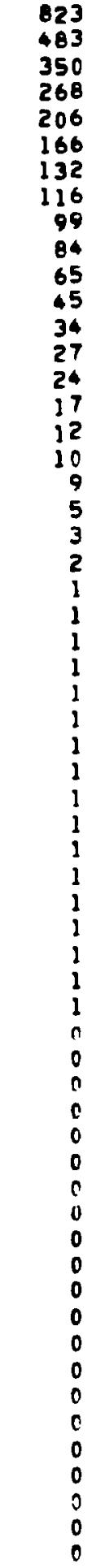 & 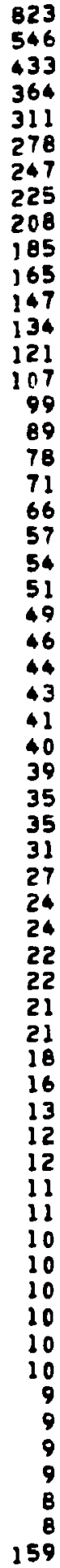 & 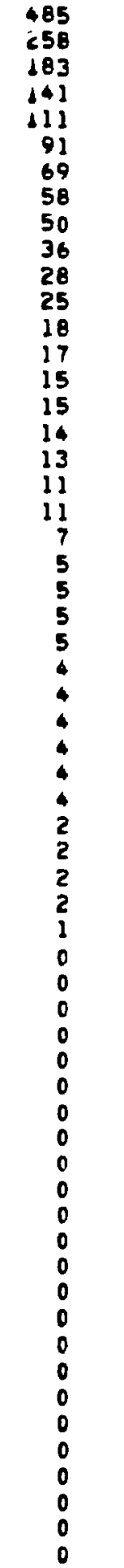 \\
\hline
\end{tabular}

FIGURE 41 RUN DURATION ANALYSIS OF HUB HEIGHT $(45.7 \mathrm{~m})$ ANNUAL MEAN WIND SPEED AT HOLYOKE, MASSACHUSETTS FOR THE PERIOD JUNE 1951 - MAY 1952 


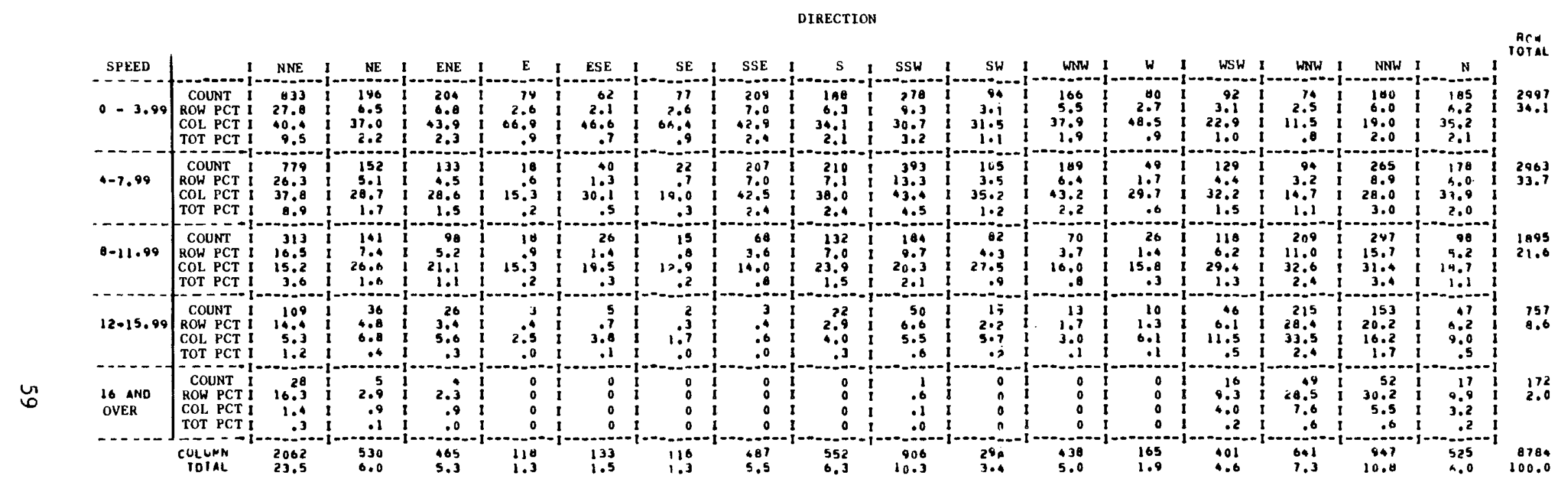

FIGURE 42 JOINT FREQUENCY DISTRIBUTION OF ANNUAL WIND SPEED (m s-1) AND DIRECTION AT HUB HEIGHT $(45.7 \mathrm{~m})$ AT HOLYOKE, MASSACHUSETTS FOR THE PERIOD JUNE 1951 - MAY 1952 


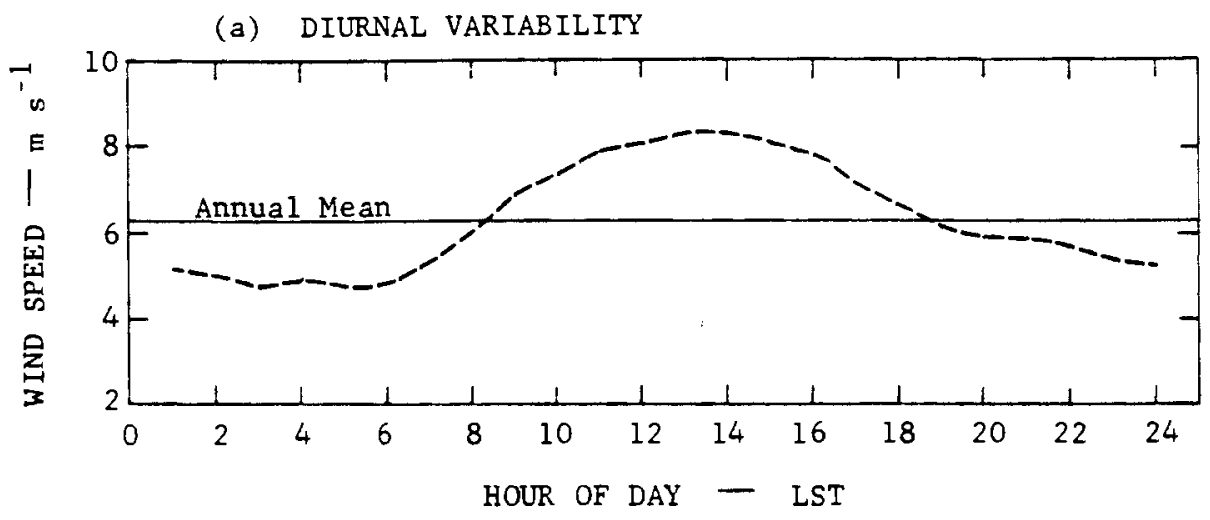

(b) SEASONAL VARIABILITY

\begin{tabular}{|c|c|c|c|c|}
\hline SEASON & WINTER & SPRING & SUMMER & FALL \\
\hline Wind speed $\left(\mathrm{m} \mathrm{s}^{-1}\right)$ & 6.81 & 6.70 & 5.36 & 6.37 \\
\hline
\end{tabular}

FIGURE 43 ANNUAL MEAN HUB HEIGHT $(45.7 \mathrm{~m})$ WIND SPEED VARIABILITY AT HOLYOKE, MASSACHUSETTS FOR THE PERIOD JUNE 1951 - MAY 1952

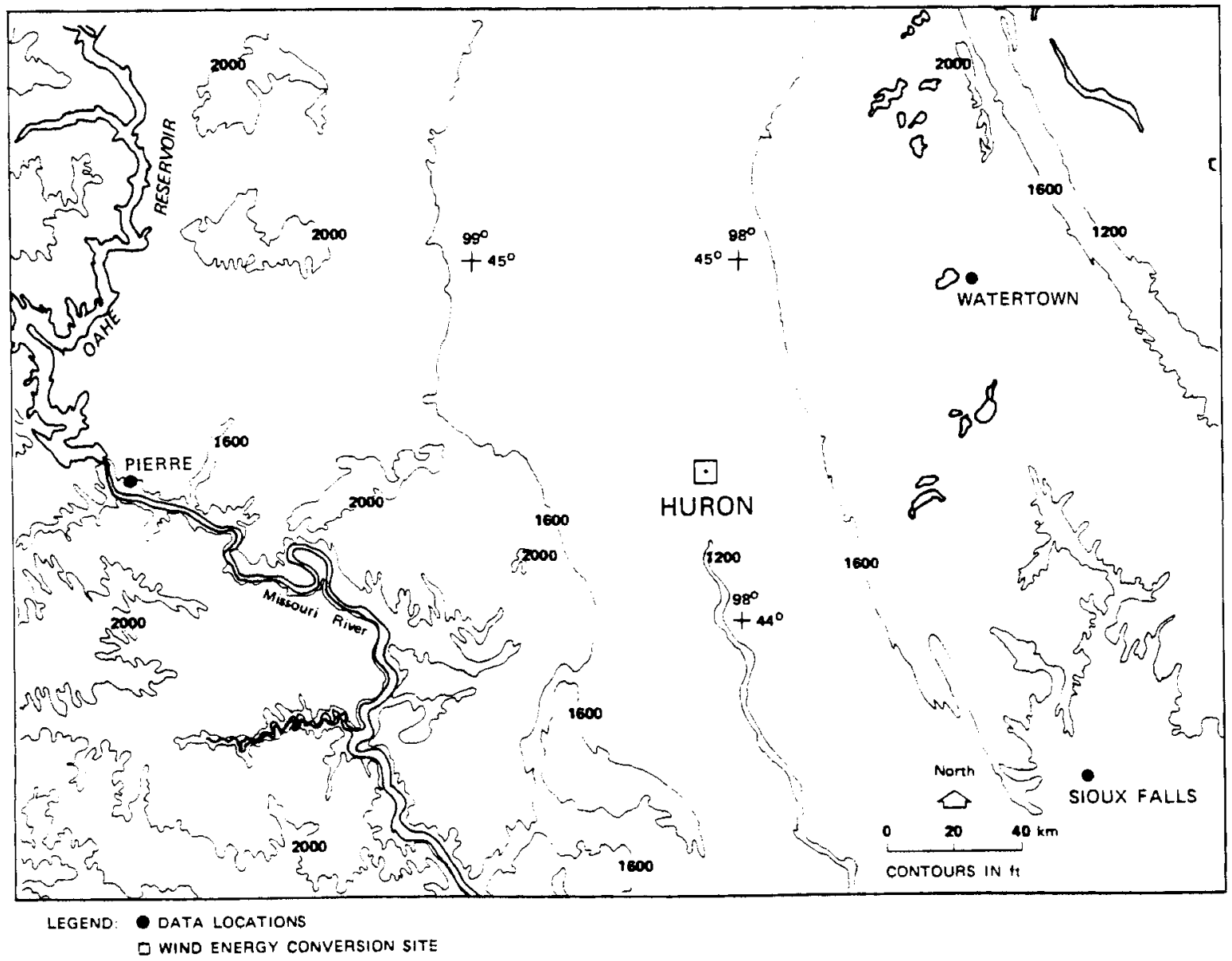

FIGURE 44 LOCATOR MAP FOR THE WEC SITE AT HURON, SOUTH DAKOTA AND THE THREE DATA STATIONS 


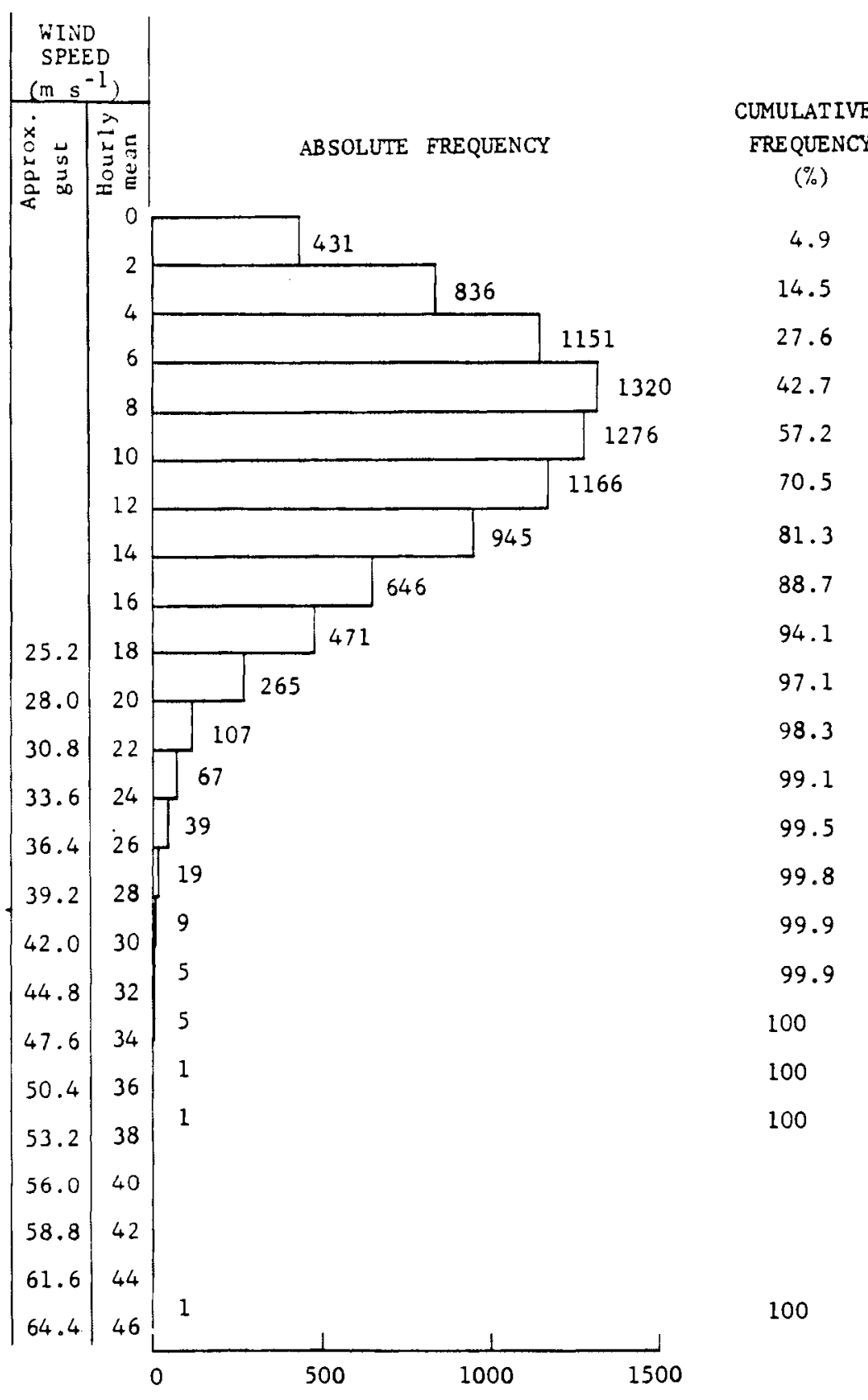

FIGURE 45 FREQUENCY DISTRIBUTION OF HUB HEIGHT $(45.7 \mathrm{~m})$ WIND SPEED AT HURON, SOUTH DAKOTA FOR THE PERIOD 1954. Wind speed categories are for annual mean and gusts above $25.2 \mathrm{~m} \mathrm{~s}^{-1}$. 


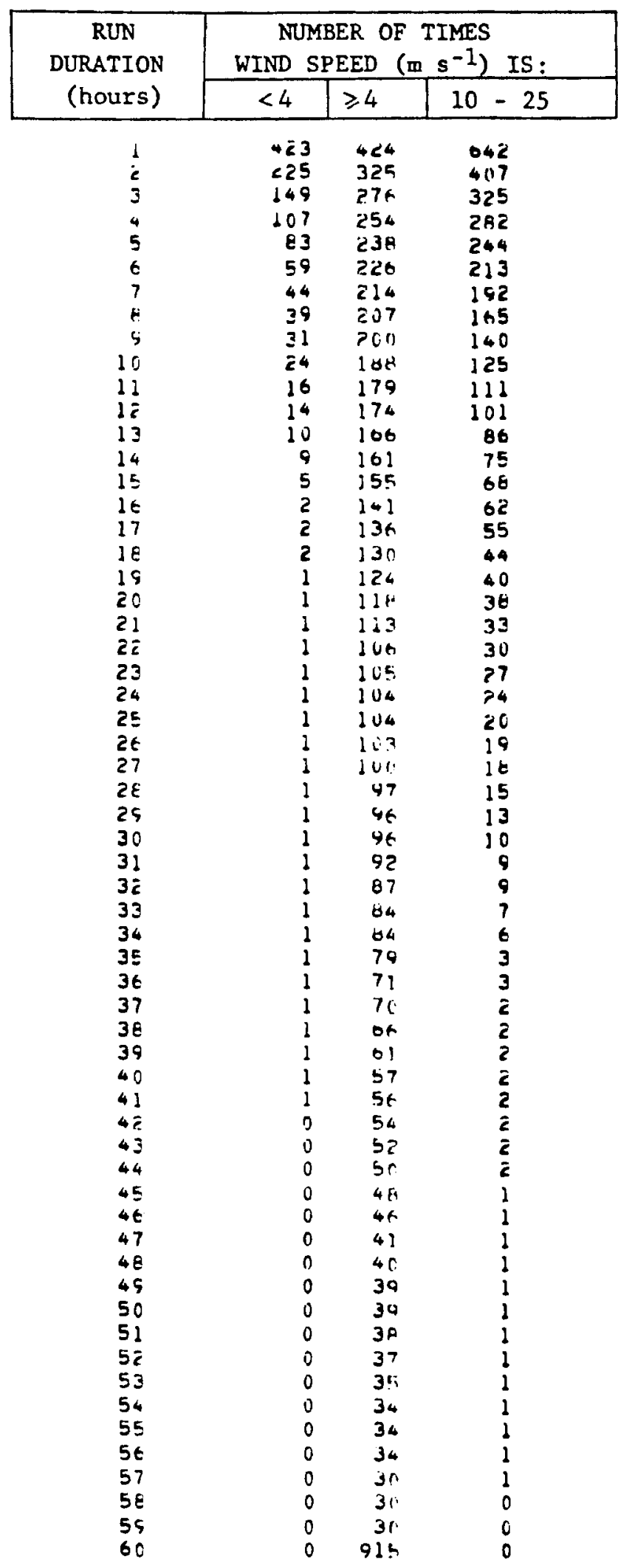

FIGURE 46 RUN DURATION ANALYSIS OF HUB HEIGHT $(45.7 \mathrm{~m})$ ANNUAL MEAN WIND SPEED AT HURON, SOUTH DAKOTA FOR THE PERIOD 1954 


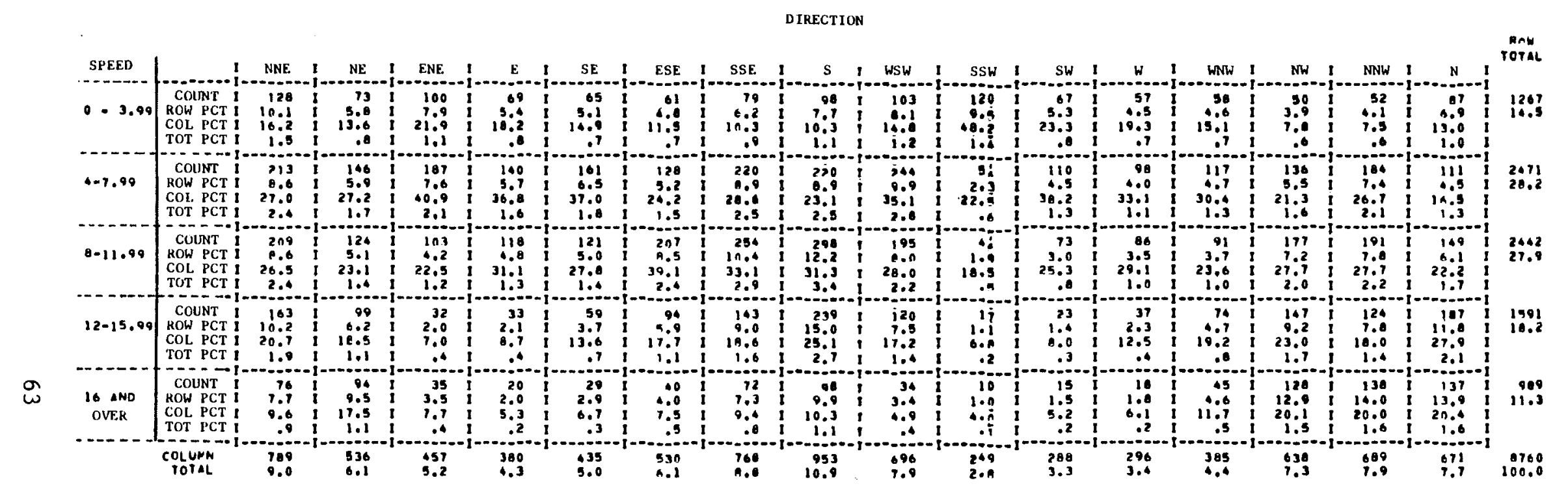

FIGURE 47 JOINT FREQUENCY DISTRIBUTION OF ANNUAL WIND SPEED $\left(\mathrm{m} \mathrm{s}^{-1}\right)$ AND DIRECTION AT HUB HEIGHT $(45.7 \mathrm{~m})$ AT HURON, SOUTH DAKOTA FOR THE PERIOD 1954 
(a) DIURNAL VARIABILITY

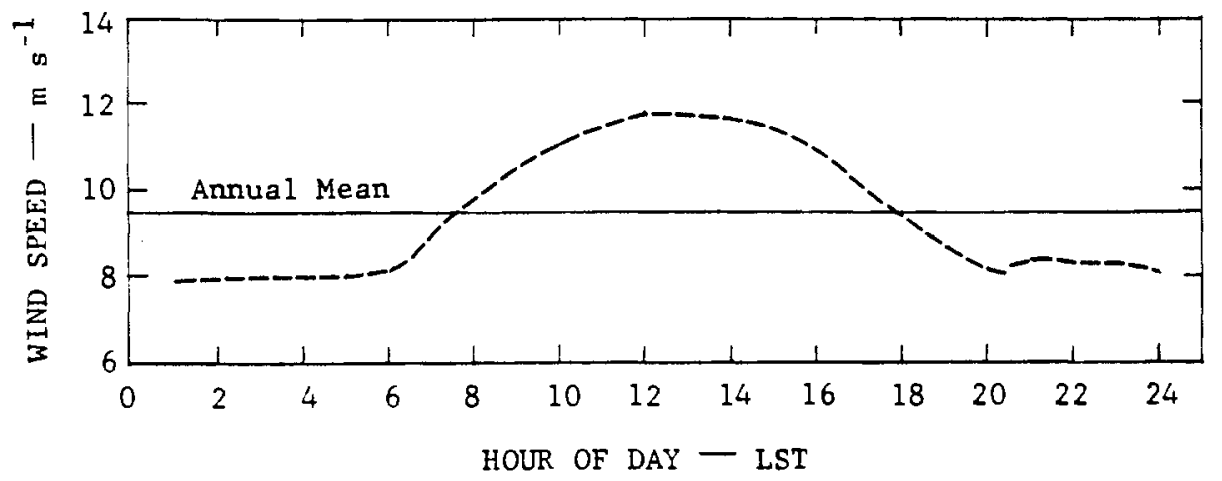

(b) SEASONAL VARIABILITY

\begin{tabular}{|c|c|c|c|c|}
\hline SEASON & WINTER & SPRING & SUMMER & FALL \\
\hline Wind speed $\left(\mathrm{m} \mathrm{s}^{-1}\right)$ & 9.50 & 11.08 & 8.49 & 8.89 \\
\hline
\end{tabular}

FIGURE 48 ANNUAL MEAN HUB HEIGHT $(45.7 \mathrm{~m})$ WIND SPEED VARIABILITY AT HURON, SOUTH DAKOTA FOR THE PERIOD 1954

at a fixed height above the highest terrain value in the grid; this results in a boundary layer top at $3 \mathrm{~km}$ for San Gorgonio Pass--a decidedly unrealistic value for any location. However, since in this phase of research, we are more concerned with the development of a uniform methodology for all sites rather than tuning it for specific sites, we did not perform any additional numerical experiments for any particular site.

\section{Cost Estimate per Site}

In general there are eight clearly identifiable steps involved in applying our methodology to a given wind energy conversion site. However the actual operational application can differ from one site to another, depending on the number of data stations selected for the site and/or the number of grids that are used wih the COMPLEX model. Table 5 shows typical costs incurred at each step of the application of the methodology. These estimates are shown for two types of sites. These are:

- A site that uses four data stations and two grids

- A site that uses three data stations and one grid.

On the basis of our experience it is seen that it would cost 570 dollars to apply the method to the first type, and 420 dollars for the second type. Evidently the cost will be different if one or more combinations of the above-mentioned variations in the number of data stations and grids are used. For example, one may want to use four stations with one grid or three stations with two grids, and so on.

We wish to stress that the estimates shown in Table 5, particularly those for person-hours, are based on the consideration that the work is performed at one stretch and the individuals using the methodology have already acquired some experience with the method and are not involved in other work. 
Table 4

VERIFICATION OF THE METHODOLOGY DESCRIBED IN THE TEXT

\begin{tabular}{|l|c|c|c|}
\hline \multicolumn{1}{|c|}{ Site } & $\begin{array}{c}\text { Actually Observed Annual } \\
\text { Mean Surface Wind Speed } \\
(\mathrm{m} / \mathrm{s})\end{array}$ & $\begin{array}{c}\text { Observed (Extrapolated) } \\
\text { Annual Mean Wind Speed } \\
(\mathrm{m} / \mathrm{s})\end{array}$ & $\begin{array}{c}\text { Calculated Hub Height } \\
\text { Annuai Mean WindSpeed } \\
(\mathrm{m} / \mathrm{s})\end{array}$ \\
\hline Boone, NC & -- & -- & 9.7 \\
Montauk Point, NY & -- &.- & 8.5 \\
Ludington, MI & -- & -- & 7.6 \\
San Gorgonio Pass, CA & -- & -- & 3.3 \\
Russell, KA & 6.9 & 9.4 & 9.5 \\
Boardman, OR & -- & -- & 5.1 \\
Holyoke, MA & -- & -- & 6.3 \\
Huron, DS & 5.14 & 7.20 & 9.3 \\
\hline
\end{tabular}

Table 5

COST ESTIMATE FOR OBTAINING HUB HEIGHT WIND CHARACTERISTICS AT A SITE USING ONE YEAR'S HOURLY WIND DATA

\begin{tabular}{|c|c|c|c|c|}
\hline \multirow[t]{2}{*}{ Step } & \multicolumn{2}{|c|}{$\begin{array}{l}\text { Site with Two Grids } \\
\text { and Four Data Stations }\end{array}$} & \multicolumn{2}{|c|}{$\begin{array}{c}\text { Site with One Grid } \\
\text { and Three Data Stations }\end{array}$} \\
\hline & $\begin{array}{l}\text { Computer Cost } \\
\text { (dollars) }\end{array}$ & Person-Hours & $\begin{array}{l}\text { Computer Cost } \\
\text { (dollars) }\end{array}$ & Person-Hours \\
\hline $\begin{array}{l}\text { 1. Select data station } \\
\text { locations from USGS } \\
\text { maps }\end{array}$ & 6.00 & 0.5 & 4.00 & 0.5 \\
\hline $\begin{array}{l}\text { 2. Acquire data tapes } \\
\text { from NCC at } \$ 60 \text { per } \\
\text { station }+\$ 10 \text { for } \\
\text { phone calls. }\end{array}$ & 250.00 & 16 & 190.00 & 16 \\
\hline $\begin{array}{l}\text { 3. Decode NCC tapes and } \\
\text { merging wind data } \\
\text { for one year }\end{array}$ & 150.00 & 7 & 115.00 & 16 \\
\hline $\begin{array}{l}\text { 4. Calculate eigenvectors } \\
\text { and the mean from } \\
\text { Step-3 data for one } \\
\text { year }\end{array}$ & 17.00 & 2 & 14.00 & 2 \\
\hline $\begin{array}{l}\text { 5. Extract gridded } \\
\text { topography manually }\end{array}$ & -- & 12 & -. & 8 \\
\hline $\begin{array}{l}\text { 6. Integrate COMPLEX } \\
\text { model for the mean and } \\
\text { for each eigenvector }\end{array}$ & 100.00 & 1 & 50.00 & 0.5 \\
\hline $\begin{array}{l}\text { 7. Reconstruct hourly wind } \\
\text { data at hub height }\end{array}$ & 15.00 & 2 & 15.00 & 2 \\
\hline $\begin{array}{l}\text { 8. Estimate hub height } \\
\text { wind characteristics }\end{array}$ & 32.00 & 2 & 32.00 & 2 \\
\hline Total Per Site & $\$ 570.00$ & 42.5 & $\$ 420.00$ & 40 \\
\hline
\end{tabular}





\section{CONCLUDING REMARKS}

\section{A. General}

The methodology described in this report not only is based on sound physical and theoretical principles, but it has also proved to be versatile and practical. This versatility and practicality has been demonstrated by the application of the method to eight sites located in diverse topographic settings. Four of the sites used for the demonstration are in complex terrain; two are in flat terrain and two are near interfaces between land and water. Although it has not yet been possible to validate and define the methodology completely by comparison with existing observations, it is already apparent that the method provides qualitatively reasonable results in all cases except perhaps for the San Gorgonio Pass location in California. The limited validation discussed in Section III has shown that the method has considerable potential for providing accurate estimates of wind, based on available conventional wind and topographical data alone. Similar conclusions can also be drawn from comparisons of the results obtained during this study with the average wind speeds observed during recent short-term, special observation programs at several of the sites.

\section{B. Suggestions for Possible Improvements and Refinements}

The research described in this report has been devoted almost solely to the development of a practical, physically consistent methodology for estimating wind characteristics at a site where no information is available. As was noted above, attempts at validation and refinement have been very limited during this phase of the project. In spite of constraints imposed by lack of verification data and limited time and funds, a very promising methodology has resulted. The methodology is certainly promising enough to warrant systematic verification, refinement, and improvement. Table 6 summarizes the areas where we feel future research effort is warranted in order to make the methodology more accurate and more practical. The remainder of the main text discusses the entries in Table 6 in more detail.

\section{Verify Methodology}

As explained elsewhere, it has not been possible to conduct a thorough evaluation of the performance of the methodology during this project. This has been in large part due to the fact that the relevant wind data have not been available from the study sites. However, such data are now being collected and could serve as the basis for future validation.

Several possible refinements are discussed below. It seems worthwhile to combine the verification and the refinement phases of future research. Probably the best approach would be to divide the sites into two groups of four and use the observations of one group to refine the methodoloy until it performed well for those four sites. The other group of four would serve as "controls", and their data would provide a check of the generality of the methods as refined. Each group should contain one land/water interface station, one flat terrain station, and two complex topography stations. 
TABLE 6

SUGGESTED FUTURE IMPROVEMENTS AND REFINEMENTS

1. Verify methodology

2. Improve data processing routines

3. Improve COMPLEX model and its applications

a. Use of digitized terrain data

b. Boundary layer height specification

c. Vertical variation in wind speed

d. Uncertainty of anemometer heights

e. Variation of density with height

f. Influences of synoptic and mesoscale weather systems

g. Evaluation of the suitability of other nearby sites

4. Aspects of the methodology that should be addressed in future research

\section{Improve Data Processing Routines}

The initial step of reading and merging data from several locations has proved to be one of the more expensive steps. Any improvements in this stage would make the method more practical and less expensive, although they would not improve its accuracy. The merging operations have not been very expensive, but the initial reading of the data tapes has required considerable decoding and processing. We would recommend that alternative formats for recording the data be explored with the National Climatic Center. It may be necessary to develop several different decoding routines, each one specific for a different manufacturer's machines. In any event, there appears to be considerable potential for reducing the costs of the methods through the development of efficient reading and decoding programs.

\section{Improve the COMPLEX Model and Its Applications}

\section{a. Use of Digitized Terrain Data}

One of the most tedious aspects of the application of the COMPLEX wind model is the preparation of the gridded terrain heights from topographic maps. Since this project was undertaken, we have become aware of another source of terrain data that is in a much more convenient form. The National Cartographic Center in Reston, Virginia, has digitized terrain heights available for the $1: 250,000$ scale maps that were used during this project ("Digital Terrain Tapes--NCIC User's Manual"). It would be much more convenient to use the magnetic tape data; a program could be written to read the digitized terrain data and prepare the necessary inputs for the COMPLEX model. 


\section{b. Specification of Boundary Layer Height}

In the current version of the COMPLEX model, boundary layer height is not a function of time of day and is prescribed as a function solely of the highest terrain level in the grid. Future research should explore the possibility of prescribing the boundary layer height as a function of both space and time. One possible approach to this would be to use the information provided by Holzworth (1972). This report provides information about mixing depth during the afternoon and the early morning hours. Each day could be divided into two or three time periods and the COMPLEX model could be applied using different boundary layer heights for each of those time periods. Such a change should improve the ability of the model to treat diurnal variations in winds.

\section{c. Vertical Variation in Wind Speed}

Just as the boundary layer depth is known to vary with time of day and stability, so is the value of the exponent $\alpha$ used in the power law [Eq. (23)]. Such changes in the value of $\alpha$ may affect the winds considerably, and it is important that the value of $\alpha$ be prescribed more accurately, both as a function of time of day, or stability, and as a function of the local topographic roughness.

Further research is required into the sensitivity of the model to changes in the value of $\alpha$. If diurnal changes in $\alpha$ were incorporated into the application of the model, it could be done in combination with diurnal changes in boundary layer height.

\section{d. Uncertainty of Anemometer Heights}

An examination of weather station histories shows that there was little consistency in the placement of wind measuring instruments until recent years. This could pose a serious problem when old historical data are used for assessing winds at hub heights. We have discussed a procedure for minimizing this problem in the Appendix, Section III-D. The approximation described in the appendix can probably be improved upon. It would be worthwhile to explore the sensitivity of the method to uncertainties in anemometer heights. If it should prove to be an important factor, then the methodology can be changed to account for different heights of the anemometers or, perhaps better still, to make use of more recent wind data.

In recent years, wind instruments have been more carefully placed and at more nearly uniform, standard heights. The only reason that the more recent data has not been used is that they are archived at the National Climatic Center at only three-hour intervals. It should not be difficult to change the overall methodology so that it could use three-hourly data. The best approach would use current methods to estimate hub-height winds at three hour intervals, and then interpolate the intermediate hours.

There are both advantages and disadvantages to the use of winds recorded at three hourly intervals. The disadvantages are fairly obvious; a measured wind is preferable to one interpolated between the observation times. However, winds sampled at 3-hour intervals should be adequate for all the required statistics, except those where run durations are involved. Even for run duration calculations, the errors cannot amount to more than 2-hours in duration. The main advantage to the use of eight-per-day wind data is that the data available for more recent years, when only eight observations per day have been archived, come from better sited anemometers. In recent years anemometers tend to be more uniform in height (10 m) and further removed from obstructions. 


\section{e. Variation of Density with Height}

The version of the COMPLEX model given here uses a constant value of atmospheric density. We have assumed that the effect of variation of density with height is apt to be quite small in comparison with uncertainties in the wind measurements themselves and the anemometer heights. However, Elliot (1977) has reported that the vertical variation of density may be an important factor in determining available wind power. Therefore, further research should probably include sensitivity tests with the model to determine if such would be the case.

\section{f. Influences of Synoptic and Mesoscale Weather Systems}

The use of the eigenvectors in combination with computer modeling should allow us to relate, at least in a subjective way, the important features of the air flow pattern to the larger scale weather systems. As has been noted before, the most important features of the air flow patterns can be described with only a few eigenvectors. It should be possible, in turn, to relate the coefficients of these eigenvectors to various kinds of weather patterns. In this way, the model could be used to determine the local effect of those various kinds of weather systems. Once this is done it should be possible to evaluate how the statistics derived for a given, limited time period might vary from the longer-term climatological conditions. The relationship would of course be derived from determining the relative frequencies of various kinds of weather systems during the short period versus the longer climatological period.

Another possible approach to incorporating the influence of synoptic and mesoscale weather systems would be to use larger-scale weather information to help define the initial conditions. We believe it is possible to parameterize the mesoscale influences and introduce them into the COMPLEX model by modifying the model equations so that the mesoscale component can be represented through perturbation techniques. It might even be possible to incorporate the effect of horizontal variability of mesoscale wind over complex terrain (Nappo, 1977) by modifying COMPLEX model equations so that they include horizontal temperature and moisture gradients.

\section{g. Evaluation of the Suitability of Other Nearby Sites}

The methodology described here can be altered slightly to provide estimates of wind characteristics at more than one location in the same general area. It would seem more worthwhile to alter the methodology to take advantage of this capability so that the relative merits of several sites in the vicinity of the prime candidate site could be evaluated at the same time.

It is also possible to determine the wind characteristics at two or more heights at the same location. This would provide information about vertical wind shear at the site. Vertical wind shear can be very important to the siting of the instrument.

Although the model can provide information about wind shear, it would probably be better to apply a more sophisticated boundary layer model to the terrain in the immediate vicinity of a candidate site. Such applications would be limited to wind conditions that had been identified by the general methodology as being most frequent, or otherwise important. We feel that it would be important to explore all of these refinements in the methodology that would aid in the final site selection process. 


\section{A Summary of the Aspects of the Methodology that Should be Addressed in Future Research}

It should be apparent from the above enumeration of recommended areas of future research that there are three general categories in which the recommendations fall. These are:

- Improvements in the efficiency and reduction of costs

- Refinements in the treatment of potentially important physical processes

- Tests of the performance of the methodology.

Although the methodology developed here has already proved to be very practical, and appears to be reasonably accurate and reliable, it is very important that further improvements be made. The costs of wind machines are so great that a reliable method must be available to help with the siting of those machines. However, it is not sufficient that the method be reliable; it must also be practical and simple enough so that persons charged with choosing sites for these machines will not be reluctant to use it. All the recommendations that have been given above for further research are directed toward the development of a methodology that fits that description. 


\section{REFERENCES}

Davidson, B., 1964: 'Sites for Wind Power Installations,' World Meteorological Organization Technical Note No. 63, WMO No. 156.TP.76.

'Digital Terrain Tapes--NCIC User's Guide,' Office of Research and Technical Standards, 519 National Center, Reston, Virginia.

Elliot, D.L., 1977: 'Synthesis of National Wind Energy Assessments,' BNWL-2220WIND-5, Contract EY-76-C-06-1830, Battelle Pacific Northwest Laboratories, Richland, Washington, $45 \mathrm{pp}$.

Hollister, S.C., 1970: 'The Engineering Interpretation of Weather Bureau Records for Wind Loading on Structures,' Building Science Series No. 30, National Bureau of Standards, $169 \mathrm{pp}$.

Holzworth, G.C., 1972: 'Mixing Heights, Wind Speeds, and Potential for Urban Air Pollution Throughout the Contiguous United States,' Report AP-11, Environmental Protection Agency, Office of Air Programs, Research Triangle Park, Raleigh, North Carolina.

Justus, C.G. and S.A. Mikhail, 1976: "Height Variations of Wind Speed and Wind Distribution Statistics," Geophys. Res. Lett., 3, pp. 261-264.

Lorenz, E.N., 1956: 'Empirical Orthogonal Functions and Statistical Weather Prediction,' prepared by Massachusetts Institute of Technology for the U.S. Air Force under Contract AF 19(604) 1566. Defense Document Center, Alexandria, Virginia, No. $110268,49 \mathrm{pp}$.

Nappo, C.J., 1977: 'Horizontal Variability of Mesoscale Winds over Complex Terrain,' preprint volume, Joint Conference of Application of Air Pollution Meteorology, November 29-December 2, 1977, Salt Lake City, Utah, published by American Meteorological Society, Boston, Massachusetts.

Southwell, R.V., 1946: Relaxation Methods in Theoretical Physics, Clarendon Press, Oxford, England, pp. 20-25.

Touma, J.S., 1977: "Dependence of Wind Profile Law on Stability for Various Locations," J. Air Poll. Contr. Assoc., 27, 9, pp. 863-866. 


\section{APPENDIX \\ USER'S GUIDE FOR ESTIMATING THE WIND CHARACTERISTICS AT A GIVEN WIND ENERGY CONVERSION SITE}


: 


\section{INTRODUCTION}

The objective of the research reported here has been to develop a methodology for generating wind information and the estimates of wind characteristics (statistics) at hub level (45.7 m) at eight potential wind energy conversion system (WECS) sites. The philosophy, theory, and basic assumptions of our approach have been discussed extensively in the main text. We have also described the application and results of our approach for eight selected demonstration wind energy conversion sites. The results have indicated that our methodology is quite versatile, practical, and economical for calculating hub height wind characteristics at a given site (located on any type of terrain), and on the basis of available conventional wind data.

Section II of this appendix gives step-by-step instruction for using the methodology, Section III provides a detailed description of the methods of calculation, and Section IV contains complete listings of all programs used in these calculations. 


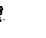

. 


\section{METHODOLOGY}

\section{A. Background}

In conformity with our philosophy of approach, the overall methodology can be classified into three main tasks. These are:

- Data acquisition and processing of wind data

- Development of the COMPLEX Model to obtain hub height winds at locations at which no wind data are available

- Applications of the methodology for estimating hub level wind characteristics.

Figure A-1 is a diagram of the overall approach.

\section{B. Step-by-Step Instructions for a Given Site}

\section{Step 1: Select Appropriate Wind Data Stations}

(a) Acquire 1:250,000 series topographic maps from United States Geological Survey (USGS).

(b) Plot candidate WECS site on appropriate USGS map.

(c) Select data stations in the vicinity of the WECS site on the basis of criteria described in the main text (Section II-A-4-c).

(d) Examine the wind records at the selected stations and identify the period for which data are required.

(e) Solicit information from National Climatic Center (NCC), Asheville, North Carolina, regarding the actual availability of required data.

(f) Request the relevant hourly wind data tapes from NCC for the period of interest and the corresponding selected stations. Wind data from the WECS site itself may also be requested (if available), but these should not be used with the methodology. Instead, these can be used to verify the performance of the methodology (see Box 4a in Figure A-1). For example, though we did order wind data from Huron, South Dakota, and Russell, Kansas, we have not used these data for estimating wind characteristics at these sites. 


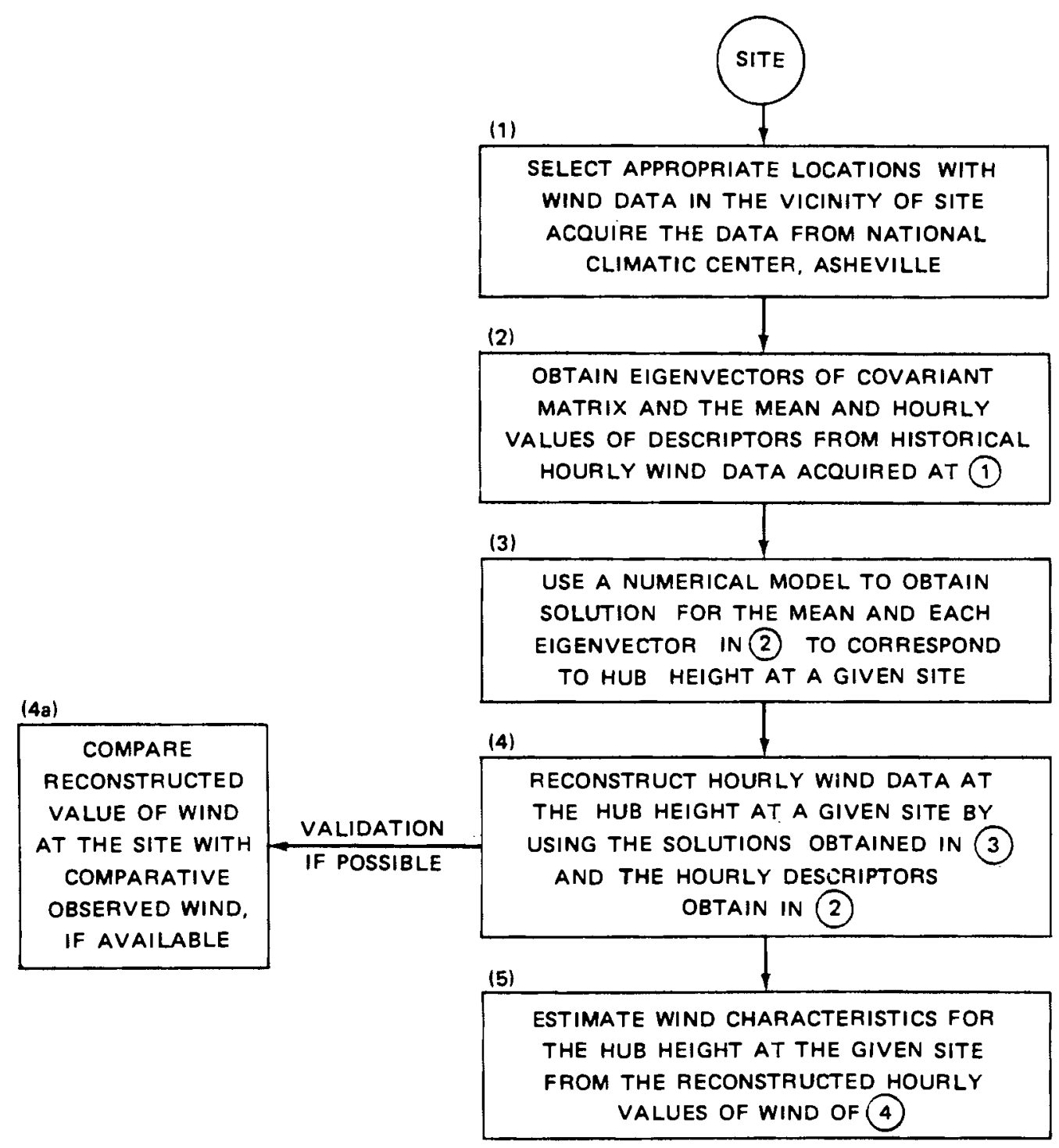

FIGURE A-1. GENERAL OUTLINE OF OVERALL APPROACH

2. Step 2: Acquire and Merge Data

\section{a. Data Acquisition}

Data acquisition begins with the selection of stations from which data are to be acquired. Several factors are important to this selection process. These are discussed in Section II-A-4-c of the main text. Very briefly, the following factors should be considered:

- Selected stations should surround the study site.

- Selected stations should be at least $8 \mathrm{~km}$ from the study site. 
- Round-the-clock, hourly data are desirable, but interpolation of data archived at 3-hour intervals might be possible.

- Stations whose local topographic setting is similar to the study site are preferable.

- Concurrent data periods are required for all selected stations.

Two publications entitled: "Initial Wind Energy Data Assessment Study" (Changery, 1975) and "Index-Summarized Wind Data" (Changery et al., 1977) are very useful to the data site selection process and should be consulted. These publications are specifically designed to inform people of existing and available wind data. Figure A-2 shows four examples of the many types of maps that display the location of various wind observing stations. Figure A-2(a) is a plot of the approximately 2000 stations that collect wind data. Less than half, or about 700 stations, take observations 24 hours a day. The rest take observations during daylight hours, every three or every six hours, or irregularly to meet local air traffic needs. Figure A-2(b) depicts stations for which digitized wind data are available. Before 1964 all data were hourly; after that time, beginning in January 1965 , only every third hourly observation was digitized. Figure A-2(c) is a display of stations with summarized wind data available in various formats. Although the summaries are produced from digitized data, they can be hand tabulated for some selected locations without digitized data. Figure A-2(d) shows a network of pibal and rawinsonde stations from which upper air winds are available. An appendix to Changery's report (1975) lists all the stations that have summarized wind data. An examples of these tabulations is shown in Table A-1 for the state of Alabama. Once a WECS site has been selected for study, plotted on a map, and checked against the available wind stations, it is an easy matter to compile a list of the nearby stations by name, latitude, and longitude, for submission to the $\mathrm{Na}$ tional Climatic Center (NCC) of the Environmental Data Service. A request to the NCC should include a statement of your needs, and the requirements of the data. The request can be sent to:

\author{
National Climatic Center \\ Federal Building \\ Asheville, NC 28801 \\ Attn: User Services \\ (704) $258-2850 \times 683$
}

Available data may be acquired on paper, microfilm, or in digitized form. Data can also be specially keypunched. In the methodology described here, the most convenient form for the data to be acquired is on magnetic tape in the TDF-14 format.

Once lists of available candidate data stations have been obtained from the $\mathrm{NCC}$, the final station selection and ordering can be done. The station selection procedure is necessarily somewhat subjective, but the criteria listed earlier should help the user select three or four appropriate sites and the best time periods for those sites. Our suggestion is to use the most recent period for which hourly data are available from all the selected sites. The data can be ordered from the NCC at the above address. However, it is usually best to discuss availability, tape formats, and so forth with NCC personnel on the phone before the order is actually placed. The filling of orders is usually done expeditiously; data are generally delivered within a few weeks. 


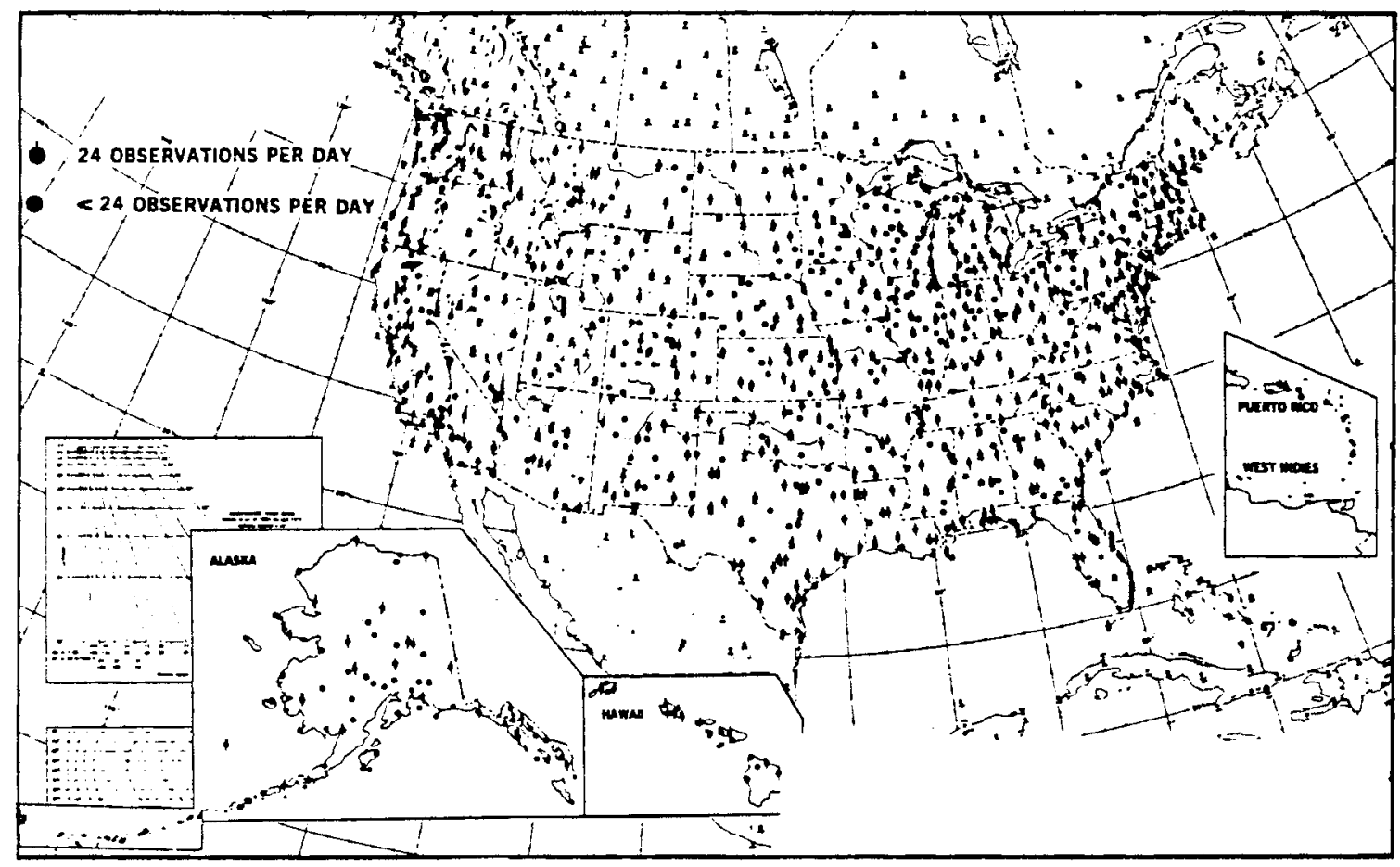

(a) DATA COLLECTION STATIONS FOR THE FIVE YEARS ENDING IN 1973

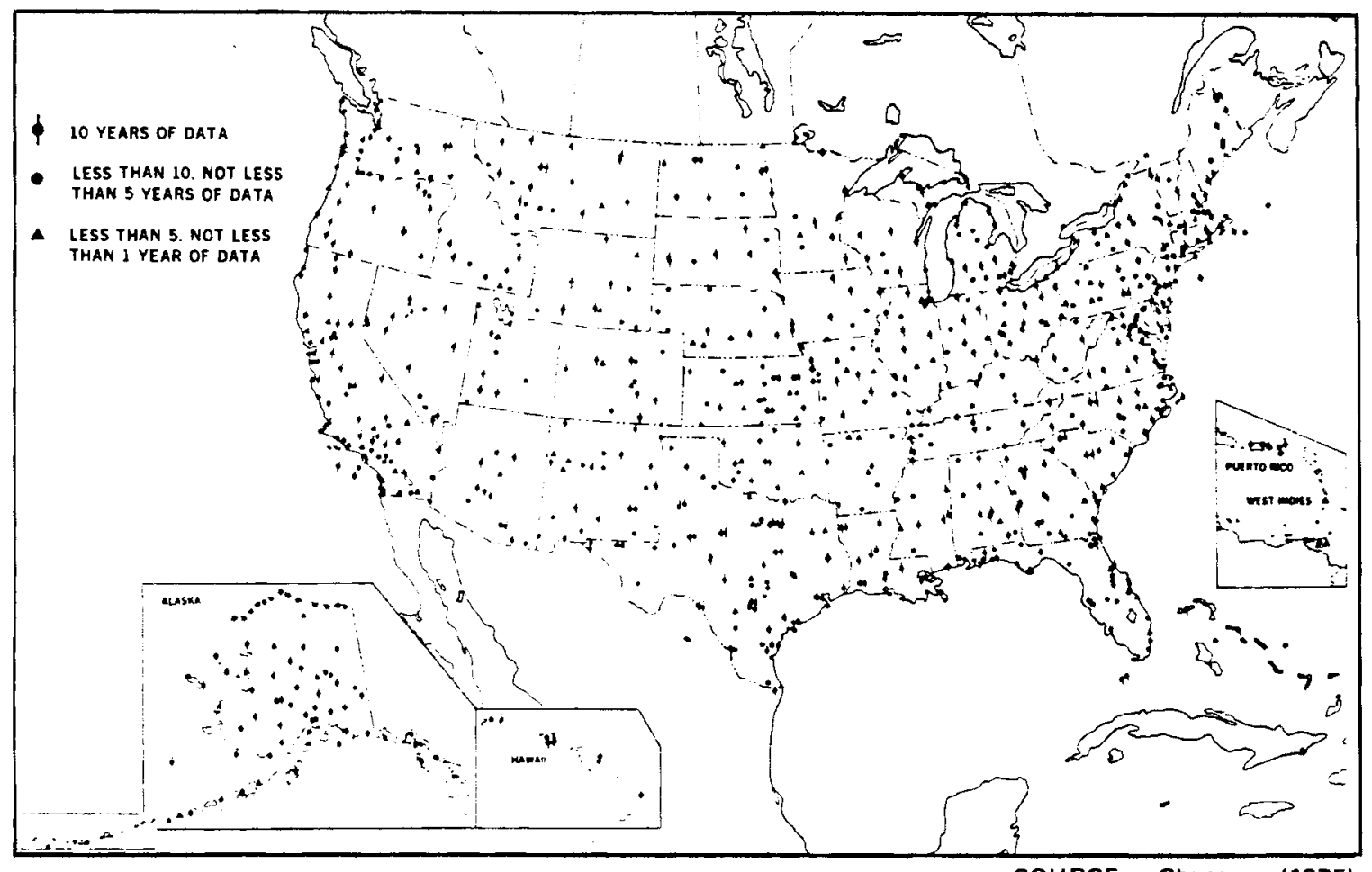

(b) STATIONS WITH DATA ON MAGNETIC TAPE

FIGURE A-2 FOUR EXAMPLES OF MAPS THAT DISPLAY THE LOCATION AND TYPE OF DATA AVAILABLE FROM WIND OBSERVING STATIONS 


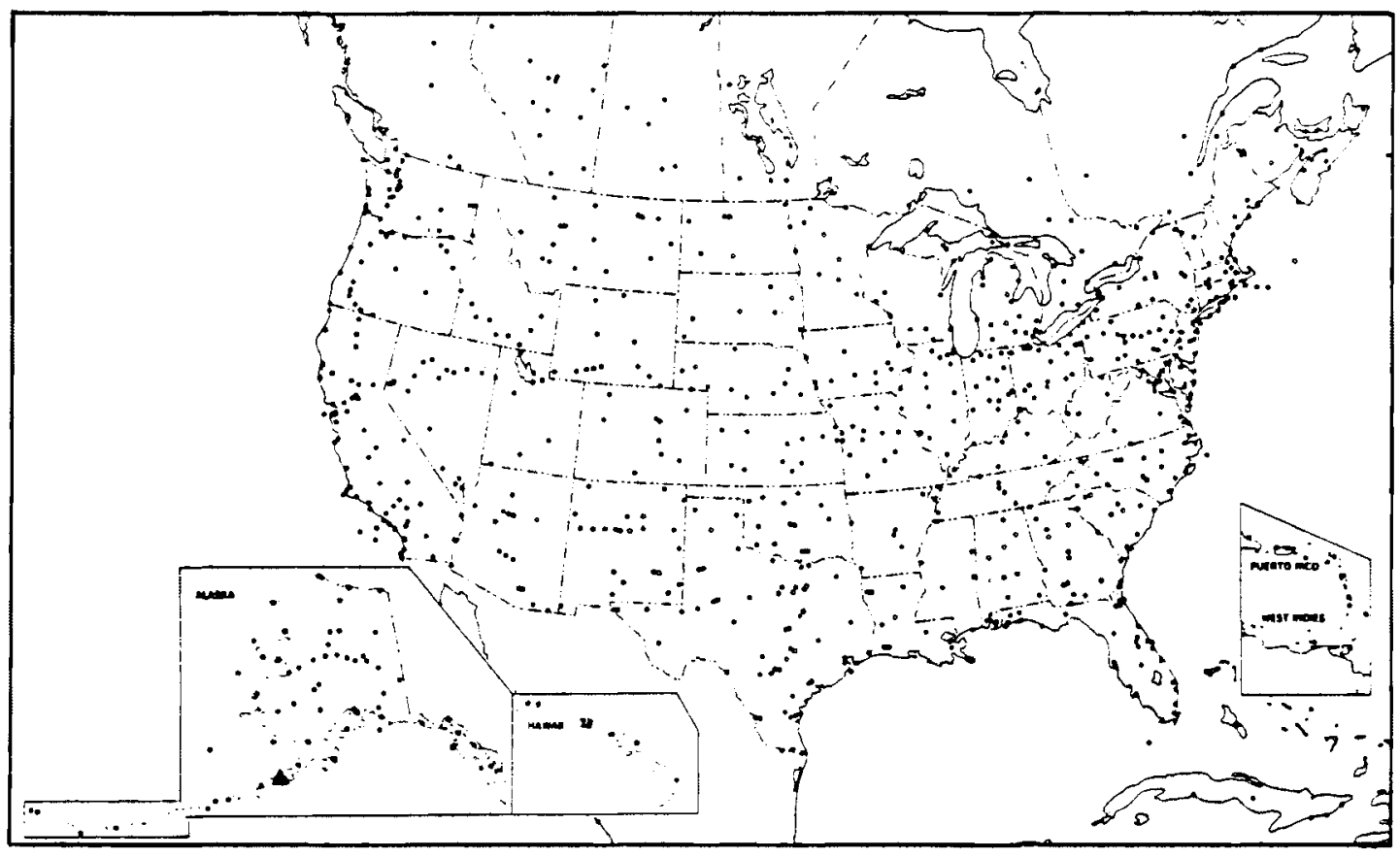

(c) STATIONS WITH WIND SUMMARIES FOR FIVE OR MORE YEARS OF DATA

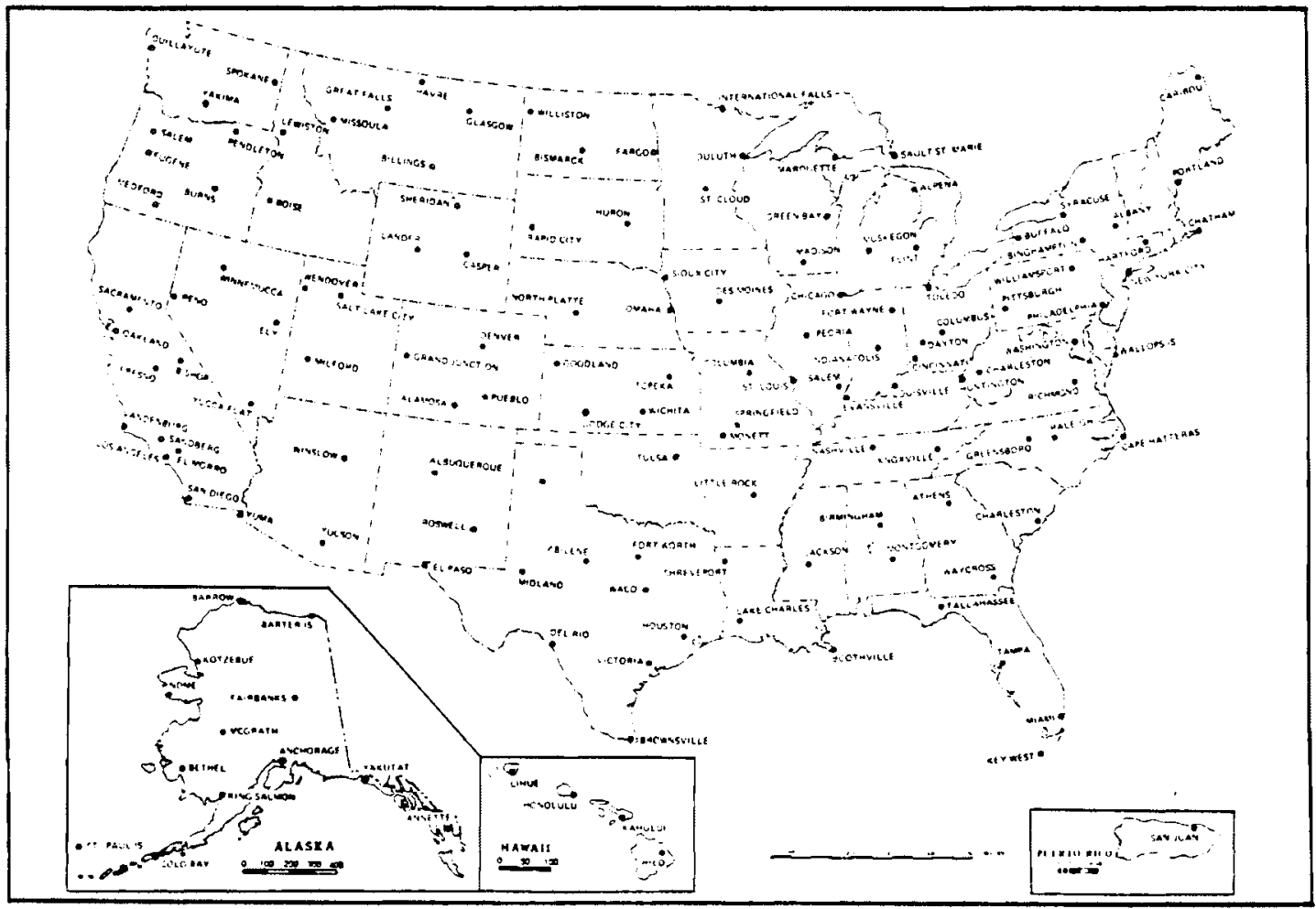

(d) STATIONS OF UPPER AIR REPORTING NETWORK

SOURCE: Changary (1975).

FIGURE A-2 FOUR EXAMPLES OF MAPS THAT DISPLAY THE LOCATION AND TYPE OF DATA AVAILABLE FROM WIND OBSERVING STATIONS (Concluded) 


\section{b. Unpacking and Rewriting the Data}

The data tapes from the NCC contain hourly meteorological data from a long period of time for a single station. It is necessary to extract the most important data, especially winds, and then combine data from several locations. If the user has a computer program that reads the NCC data tapes on his machine, it should be used to create disk files that can be merged later. If the user intends to employ the program MERGER described in Section III of this appendix, the disk file should be organized in 98-word records, one for each day. The first word should be the station identification number and the second should be the 6-digit date-year, month, day. The remaining 96 words should be arranged in 24 groups of 4 , corresponding to the 24 hours of the day. Within each group of 4 , the first two words should be the wind direction in a 16-point system, with $1=\mathrm{N}$ and $16=\mathrm{NNW}$, and the wind speed in meters per second. The remaining two words in each group of four are not used at this time. They have been provided so that the methodology could be modified to include consideration of other parameters (e.g., atmospheric stability class).

A computer program, SFCOBS1, has been written to prepare the data files for merging, but this particular program is only suitable for use with machines that are compatible with a Control Data Corporation CDC 6400 . Other machines will require their own decoding procedures. If a CDC machine is used, then Section II of this appendix should be consulted for the information necessary to use the program SFCOBS1.

\section{c. Merging of the Data}

After disk files have been created for each station's data set, they should be merged into a single data file. The program MERGER will do this. The information necessary for its use is given in Section III of this appendix, and a FORTRAN listing of the program is given in Section IV. Some modifications of the program code may be necessary, especially with regard to the way in which ends of files are detected. The program, as given in Section IV, is suitable for a CDC 6400 .

\section{Step 3: Determine the Eigenvectors and Transform the Data Sets}

As noted before, the methodology requires that the input data sets be transformed to a new basis--we have used the eigenvectors of the covariance matrix as the new basis. Step 3 requires application of a computer program like XFORM, which is described in detail in Section III of this appendix. The program XFORM calculates the covariance matrix and means and the eigenvectors for the covariance matrix. It then writes a new file of the transformed input variables. The eigenvectors and the means are output in punched card form suitable for direct input to the COMPLEX model in Step 6. The transformed data are written to a file (tape or disk) suitable for input to the program REWND in Step 7.

As noted in the description of the program XFORM in Section III, it makes use of some matrix manipulation subroutines from the IMSL sof tware package. If that package is not available, it may be necessary to provide your own subroutines for calculating means, and the variance and covariance matrices. The computer programs listed in Section IV contain extensive comments that should make it relatively easy to substitute other subroutines with similar functions.

\footnotetext{
International Mathematical and Statistical Library
} 
4. Step 4: Select Grid(s) for Use with the COMPLEX Model

(a) Overlay an arbitrary grid on the USGS topographic map on which the location of the site and selected data stations have been plotted.

(b) Examine the topographic features of the area covered by grid and determine by trial and error the horizontal grid spacing such that the grid resolves the real topographic features quite adequately. (For applying our methodology, it is not necessary that the data stations lie within the grid.) If the grid is found to be satisfactory, adjust its origin such that the WECS site lies at a grid point. Also, note down the UTM coordinates of the origin of the chosen grid.

(c) Determine the east and north boundaries of the grid. This has to be done subjectively by carefully examining the topographical features; care should be taken not to exclude very significant features from the grid. Another important consideration in selecting the grid size has to do with computer expenses, because the cost of integrating the numerical model depends on the number of grid points of the threedimensional grid. Thus, sound judgement should be exercised in selecting a grid such that a satisfactory compromise can be effected between a desire to depict terrain features realistically and the overall economics of applying the methodology.

(d) Examine the need for a finer grid and select one if found necessary. In certain instances of very complex terrain features in the vicinity of a WECS site, the grid spacing selected in Step 4(b) may be coarse and unable to resolve the topographic features realistically. In such cases, select a fine grid encompassing the immediate vicinity of the site. The fine grid may extend about $50 \mathrm{~km}$ in the east and north directions from an arbitrary origin within the coarse grid selected earlier. The grid spacing for the fine grid should also be selected by considering the expenses as well as realistic representation of actual topography. As a rule of thumb, if DS represents the grid spacing, then

$$
(D S)_{\text {fine }}=\beta(D S)_{\text {coarse }}
$$

where $\beta$ is a proportionality constant $<1$. The actual value of $\beta$ depends on the grid spacing for coarse grid and the total number of grid points that can be used economically with the fine grid. For example, in case of Boone, North Carolina, the coarse grid spacing is $3 \mathrm{~km}$ and the fine grid spacing is $1 \mathrm{~km}$. Thus, $\beta$ has a value of $1 / 3$ for Boone. The value of $\beta$ for Boardman, Holyoke, and San Gorgonio Pass is $1 / 5$, $1 / 4$ and $1 / 4$, respectively.

It is very important to note here that the grid point at which a WECS site is located must be the SAME with both the coarse and fine grids.

Figure A-3 shows a schematic representation of both coarse and fine grids. The grid points (i.e., intersections) are counted from origin $(1,1)$ located at the SW corner of the grid.

$\mathrm{C}$ is the origin of the coarse grid, which has 6 points in the east and 6 points in the north direction. The mesh of the coarse grid is, say, $10 \mathrm{~km}$, so that the grid extends $50 \mathrm{~km}$ to the east and $50 \mathrm{~km}$ to the north. The site is located at the grid point (4, 3 ) in the coarse grid. 


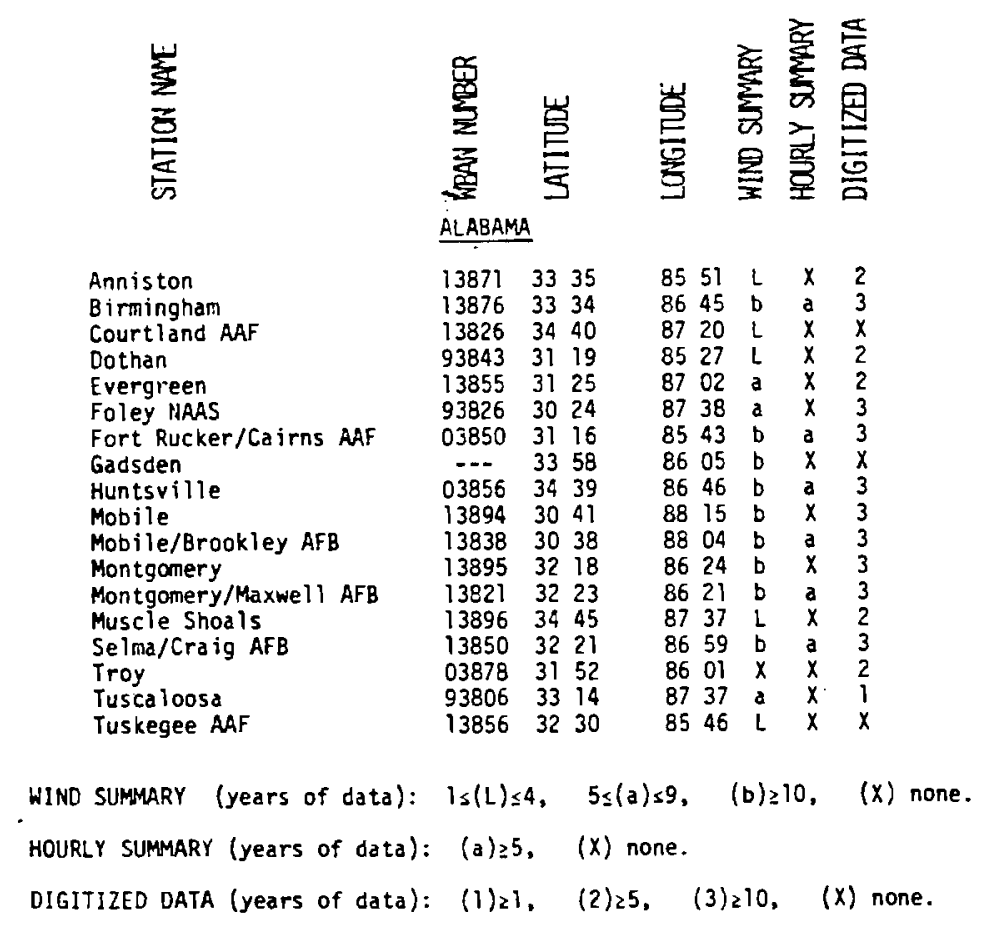

$F$ is the origin of the fine grid. The grid spacing in this case is $5 \mathrm{~km}$, and there are 7 grid points to the east and 5 grid points to the north. The WECS site, though at the same location as in the coarse grid, is located at the grid point $(5,3)$ in the fine grid.

(e) Locate the data stations ( 3 or 4 ) selected at Step 1 on the grid(s) selected in the preceding sub-step [Step 4(d)]. Determine the $x$ and $y$ coordinates of each station in units of grid mesh size or fractions thereof in the coarse grid only. For example, in Figure A-3 the $x, y$ coordinates of Station 1 are $-3.5 x$ and $3.5 y$, respectively. Similarly, the coordinates of Station 2 are $(5.6 \mathrm{x}, 4.8 \mathrm{y})$ and so forth. It is not necessary to obtain the coordinates of data stations relative to the fine grid.

(f) Obtain the coordinates of the origin of the fine grid (if a fine grid is used) in the coarse grid by proceeding as follows. Divide the large grid into the grid mesh units used in the small grid. Then locate the point of origin of the small grid, expressed in these units. For example in Figure A-3, if the mesh size of the coarse grid were $5 \mathrm{~km}$ (instead of $10 \mathrm{~km}$ ), then the grid point $(2,2)$ in the $10-\mathrm{km}$ grid would become $(3,3)$ in the $5-\mathrm{km}$ grid units, and thus the location of $F$, the origin of the fine grid. is at the point $(3,3)$. 


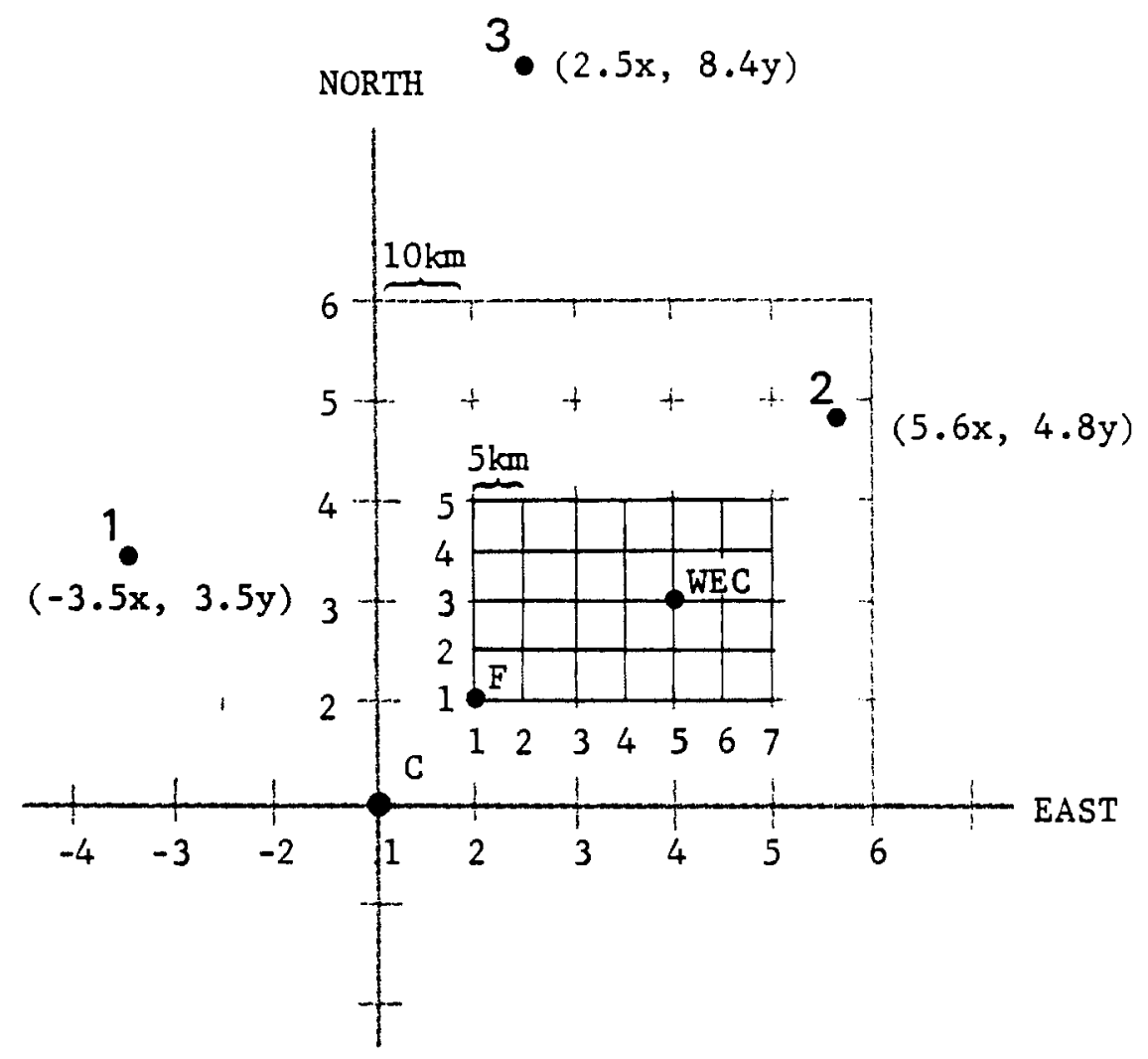

FIGURE A-3 SCHEMATIC REPRESENTATION OF COARSE AND FINE GRIDS

Completion of Step 4 furnishes various parameters that are required as input parameters to COMPLEX model. These are: the number of grid points in the east and north directions (for fine and/or coarse grids); the $x, y$ coordinates of data stations relative to the coarse grid; and, in appropriate cases, the coordinates of the origin of the fine grid in the coarse grid expressed in terms of the grid mesh spacing of the fine grid. The grid point location of the WECS site in the fine and/or coarse grid is also obtained. All these parameters are listed in Section III-D (Table A-3) together with their formats for punched cards.

\section{Step 5: Prepare Gridded Topography and Estimate Height of Grid Top}

(a) Use USGS topographic maps of the 1:250,000 series. Overlay the coarse grid on the map such that the WECS site is at one of the grid points. The WECS site may be located anywhere in the grid, though a location on the grid boundaries should be avoided.

(b) Align the grid north-south with a longitude closest to the WECS site. If appropriate, place the fine grid such that the WECS site is at a grid intersection; this automatically ensures that some of the grid points in the coarse and fine grids are coincident.

(c) Read off topographic heights at each grid point to the nearest $10 \mathrm{ft}$. If the grid point lies between two contour lines, estimate the value at the grid point by linear interpolation. 
(d) Estimate the height of the boundary layer (ZTOP) for use as an input to the COMPLEX model. This can be done by the formula:

$$
Z T O P=Z_{\max }+1000 \mathrm{ft}
$$

where $Z_{\max }$ is the highest value of elevation anywhere on the grid. (This is an approximation, and better techniques need to be formed for estimating ZTOP).

(e) Determine the exact elevation of the WECS site.

(f) Record and punch gridded topographic data as well as ZTOP and the elevation of the site in the format given in Section III-D (Table A-3). These data are punched in units of tens of feet, which are converted into CGS units by the COMPLEX model.

\section{Step 6: Obtain Solutions for the Mean and Each Eigenvector}

Run the COMPLEX model in succession for the mean and each eigenvector of wind data at the data stations. The input information needed to run COMPLEX has been obtained in Steps 3(a), 4 and 5. This consists of the following:

- Grid parameters such as grid spacing, and the number of grid points in the east and north directions (Step 4)

- Gridded topography, height of the boundary layer, and elevation of the site (Step 5)

- $x, y$ coordinates of data stations in the grid (Step 4)

- Wind components at the data stations [Step 3(a)].

The input formats are given in Section III-D (Table A-3); the computer program for COMPLEX is given in Section IV-D. The output (FORMAT: 2I5, 2F10.2) of integrating COMPLEX model consists of $u, v$ components of wind at hub height at the given site. This is in a form suitable for input at Step 7. The number of solutions to be obtained for COMPLEX depends on the number of data stations associated with a given site. For example, if there are four data locations at a site, Step 3 provides eight eigenvectors of the covariant matrix plus the mean. In this case the COMPLEX model should be integrated nine times (eight for each eigenvector and once for the mean) and the output consists of nine sets of $(u, v)$ components of wind at hub height from which hourly winds are reconstructed in Step 7. In case of three data locations, the COMPLEX model is integrated seven times.

\section{Step 7: Calculate Hourby Winds at Hub Height at the Site}

The program REWND given in Section III calculates the appropriate linear combinations of the solutions obtained for the eigenvectors from the applications of the program COMPLEX. This provides a series of hourly wind speeds and directions that can be used to calculate statistics in Step 8. The inputs for the program REWND are the card outputs from COMPLEX and the transformed data file produced by the program XFORM in Step 4. The use of program REWND is described in detail in Section III. 


\section{Step 8: Estimate Hub Height Wind Characteristics}

Once the hourly wind values are available from Step 7, they can be processed to provide many different kinds of statistics. Several approaches are possible. For example, special FORTRAN programs can be written to provide specific kinds of statistics. Section IV contains the listing of one such program, WINDY. This particular program determines the frequency with which the wind speed stayed in certain categories (e.g., $4 \mathrm{~m} \mathrm{~s}^{-1}, 10$ to $25 \mathrm{~m} \mathrm{~s}^{-1}$ ). It calculates how often the wind remained within a category for one hour, and of those instances, how often it stayed in the same category for a second or third hour. The program also provides mean wind speeds according to the season and the hour of the day.

Another approach to the calculation of statistics is to use standard sof tware packages. Section III gives two examples from the Statistical Package for the Social Sciences (Nie, et al., 1975). These examples calculate the frequency distribution of the wind speed and display it as a histogram on the line printer. The other SPSS program prepares a contingency table of wind speed versus wind direction. The SPSS and FORTRAN programs given in Section IV will provide the statistical parameters that are most often required for WECS siting purposes. The simulated hourly data could serve to provide virtually any other kind of statistics, should they be required. It is obviously not possible to foresee all the possibilities and to provide computer programs for each. 


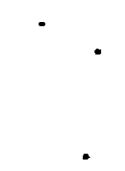




\section{CALCULATION METHODS}

\section{A. Decoding the NCC Wind Data Tapes}

\section{Background}

The first step in the procedure is to convert the data into a form that can be used in subsequent steps. Weather data are conventionally available as a time sequence of observations at a single station on a single tape. The method requires hour-by-hour wind observations from several stations. Therefore, the data from the individual stations must be merged. This is done by decoding the data from each of the stations of interest and then creating a disk file of those data. Once disk files have been created for each of the stations, those files are merged into a single file and written on tape (or disk).

This section describes the decoding and merger routines and the structure of the files that they create. It should be noted that decoding routines are usually suitable only for one class of machines. The program given at the end of Section IV works on a CDC 6400, as do all the programs given here. Some modifications will be required for use on other equipment.

It should be noted that any existing program that the user may already have for decoding surface observation tapes from the National Climatic Center could be used instead of the program given here. In general, the alterations that will be required are very simple. They only need be made to provide an output that is compatible with the MERGER program. The formats of the required outputs are discussed later in this section.

\section{Inputs}

Two types of input are required to operate the decoding program. First, of course, is the data tape. It is read from logical unit 1. The tape read by the program given here is 7 track, 800 BIP, BCD, and it is in the standard format TDF14 from the National Climatic Center.

The other inputs define the beginning and end dates to be decoded, and alphabetic header information to be included in the printout. Table A-2 shows the input card requirements. It should be noted that although the inputs will define which records are to be read and used, it is more efficient to skip as many records as possible on the input tape to avoid unnecessary reading, buffering, and checking by the computer. The tape records are blocked such that a record contains the data for six hours.

\section{Outputs}

The decoding program creates a file on logical unit 2. This file contains one 98-word record for each day's data. Each day's record begins with station identification number and a 6-digit date in the form of year, month, and day. The remainder of the record consists of 24 
Table A-2

INPUT CARDS FOR DECODING PROGRAM

\begin{tabular}{|c|c|c|c|}
\hline Card No. & Variable Name & Format & Description and Remarks \\
\hline 1 & $\begin{array}{l}\text { STAN } \\
\text { BDATE,EDATE }\end{array}$ & $\begin{array}{l}\text { F10.0 } \\
2 \mathrm{~F} 10.0\end{array}$ & $\begin{array}{l}\text { Station Identification number } \\
\text { Beginning and end dates, } \\
\text { 6-digit, year/mo/day }\end{array}$ \\
\hline 2 & HEADER & $25 \mathrm{~A} 3$ & $\begin{array}{l}\text { 75-Character alphabetic } \\
\text { description of the run }\end{array}$ \\
\hline
\end{tabular}

groups of four numbers each. Each group corresponds to one hour of the day, beginning with 0100 (local standard time) and proceeding through 2400. Within each hour group, the first number is wind direction in al6-point system, where 1 is a wind from the north and 16 is from the NNW. The second number of each group is the wind speed in meters per second. The third and fourth numbers of the group are not used in subsequent calculations, but are provided in case some other information (such as temperature and stability index) might be required in other applications.

The output of the program SFCOBSI serves as the input to the MERGER program. As noted earlier, if the user already has a program for decoding tapes of surface observations from the National Climatic Center, then that program should be used. The only alterations that would be required would be those necessary to produce 98 -word records containing the information described above. The number -999 is used as an indicator of invalid data.

The program given below prints information in the 98 -word record that is written on tape for the first day of the run and for the first day of each month during the run.

The FORTRAN listing of the SFCOBSI computer program for decoding the NCC tapes on a CDC 6400 is given in Section IV-A.

\section{B. Merging Station Wind Data}

\section{Background}

As noted before, all the data processing procedures treat the data on an hour-byhour basis, so the data from the separate stations must be brought together. The program MERGER operates on the output data files from program SFCOBS1. The program listing given at the end of this section is for a version that merges data from four input stations, but the listing also includes comments that show the modifications required for merging data from five inputs.

During the merging process, the program converts the wind speed and direction information into a north-south component ( $v$, positive for air movement toward the north) and an east-west component ( $u$, positive toward the east). Provisions are made for including other information (e.g., temperature, cloud cover, or stability) in the output records in case the methodology evolves in a direction that requires such information. However, in the current version, only the wind components are used. 
The program has provisions for checking to make sure that the proper stations are being treated. The program also checks to make sure that the dates from the different input records are always in agreement.

\section{Inputs}

A single card input is required for the program MERGER. The card format is (20X, $5 F 10.0,4 X, I 1)$. The first five number fields are used to input the station identification numbers for the data to be merged. The final input integer tells the number of files (up to 4 in the version shown here) to be merged.

The major inputs for this program are the files created by the program SFCOBS1. The first of these files, corresponding to the station identifier in the first field of the card input, is read from logical unit 11. The second input is read from logical unit 12, and so forth. The format of each of the files is that of the output of SFCOBS1 (i.e., 98-word record for each day). Each day's record begins with the station identifier and a 6-digit date (year/month/day). This is followed by 24 groups of four numbers each, corresponding to the 24 hours from 0100 to 2400. Each group has direction (16-points: $1=\mathrm{N}, 2=\mathrm{NNE}, \ldots 16=\mathrm{NNW}$ ) and speed (m $\mathrm{s}^{-1}$ ) as the first two numbers in the group; the other two numbers in each group are not used.

\section{Outputs}

The program MERGER writes 490-word records to logical unit 16. Each record contains the merged data for one day. The first 480 words are organized into 24 groups of 20 . Each group corresponding to one hour (from 0100 to 2400 ). Within the groups of 20 , the organization is four groups of five numbers each. The first two numbers of each group correspond to the $u$ and $v$ wind components, respectively, for one of the input stations. The final 10 numbers give the station identifiers and the dates of the records (these last numbers should all be the same). Figure A-4 shows schematically how the records are organized.

\begin{tabular}{|c|c|c|c|c|}
\hline Hour & Station 1 & Station 2 & Station 3 & Station 4 \\
\hline 1 & $\mathrm{U}, \mathrm{V} ; \mathrm{X}, \mathrm{X}, \mathrm{X}$ & $\mathrm{U}, \mathrm{V} ; \mathrm{X}, \mathrm{X}, \mathrm{X}$ & $\mathrm{U}, \mathrm{V}, \mathrm{X}, \mathrm{X}, \mathrm{X}$ & $\mathrm{U}, \mathrm{V}, \mathrm{X}, \mathrm{X}, \mathrm{X}$ \\
\hline 2 & $\mathrm{U}, \mathrm{V}, \mathrm{X}, \mathrm{X}, \mathrm{X}$ & $\mathrm{U}, \mathrm{V}, \mathrm{X}, \mathrm{X}, \mathrm{X}$ & . $\cdot \cdot$ & $\mathrm{U}, \mathrm{V}, \mathrm{X}, \mathrm{X}, \mathrm{X}$ \\
\hline - & ; & ; & ; & \\
\hline - & - & ; & ; & \\
\hline - & - & ; & ; & \\
\hline \multirow[t]{2}{*}{24} & $U, V, X, X, X$; & $\mathrm{U}, \mathrm{V}, \mathrm{X}, \mathrm{X}, \mathrm{X}$ & $\mathrm{U}, \mathrm{V}, \mathrm{X}, \mathrm{X}, \mathrm{X}$ & $\mathrm{U}, \mathrm{V}, \mathrm{X}, \mathrm{X}, \mathrm{X}$ \\
\hline & ID $1 \ldots$ ID & Dates .....X & & \\
\hline
\end{tabular}

FIGURE A.4 SCHEMATIC REPRESENTATION OF THE ORGANIZATION OF THE OUTPUT RECORDS FROM PROGRAM MERGER 
The program MERGER also provides some printed output. If a date is skipped, the input data for the following day from each station and the merged output data are printed. The same kind of output is printed for the first day of the run and for the day of each succeeding month.

The complete program listing for MERGER is given in Section IV-B. Comments in the listing show how the program may be modified to merge five sets of data. These comments also indicate how the organization of the output records in such a case would differ from those described above for four or fewer inputs.

\section{Determining Eigenvectors of Covariance Matrix}

1. Background

The computer programs described in the following sections make use of some subroutines from the International Mathematical and Statistical Library (IMSL). These subroutines perform some of the standard matrix operations that are required, such as the calculation of thh covariance matrix, the determination of the eigenvectors of the matrix, and the calculation of the inner products of the eigenvectors and each of the hourly input data vectors. An attempt has been made to include sufficient comments in the program listings so that the user can substitute his own standard subroutines for the IMSL ones, if that software package is not available.

\section{Calculations to be Performed}

a. The Covariance Matrix

The covariance matrix elements $C_{i j}$ are defined as

$$
C_{i j}=\sum_{k=1}^{N}\left(\bar{P}_{i}-P_{i k}\right)\left(\bar{P}_{j}-P_{j k}\right)
$$

where $\mathrm{N}$ is the number of data sets, and $P_{i k}$ is the $i^{\text {th }}$ element of the $k^{\text {th }}$ data set; $\bar{P}_{i}$ is the average of $P_{i k}$ over all values of $k$. In different notation, the covariance matrix is defined as:

$$
C=P P^{T}
$$

where $\mathrm{P}$ is a $[\mathrm{V} \times \mathrm{N}]$ matrix; $\mathrm{V}$ is the number of variables and $\mathrm{N}$ is the number of cases. Each element of $P$ is the difference between the input data variable and its mean over all $N$ cases. The matrix $P^{T}$ is the $[\mathbf{N} \times \mathrm{V}]$ transpose of $\mathrm{P}$. We have used the IMSL subroutine BECOVM to calculate the covariance matrix $C$.

\section{b. The Eigenvectors}

The matrix of eigenvectors $\mathrm{E}$ is defined as the matrix that satisfies the following matrix equation:

$$
\begin{aligned}
& E E^{T}=I \\
& E C E^{T}=D
\end{aligned}
$$


where $I$ is the identity matrix and $\mathrm{D}$ is a diagonal matrix.

The determination of the matrix $E$ is a standard problem. It requires the determination of the eigenvectors of the covariance matrix. Most statistical sof tware packages have routines available for doing this. In the program given later, the IMSL subroutine EIGRS is used.

\section{c. The Transformed Input Data Set}

We can consider a set of transformed variables, $\mathrm{Q}$, where $\mathrm{Q}$ is the $[\mathrm{V} \times \mathrm{N}$ ] matrix defined by $\mathrm{Q}=E \mathrm{P}$ and $Q^{T}=P^{T} E^{T}$. Remembering that $C=P P^{T}$, it is apparent that the covariance matrix for the transformed variables $\left(Q Q^{T}=D\right)$ has only diagonal elements. This means that the transformed data set has no cross-correlations among the variables. As noted before, this characteristic would provide a method of reducing the number of required input variables while still retaining most of the available information in the original data set.

The calculations to be performed are those that provide the transformed [ $\mathrm{V} x$ N] input data matrix, Q. Matrix multiplications of this type are quite staightforward.

\section{Inputs}

The card inputs required for program XFORM are on one card. The first field (I3) is used to describe the number of variables (NVAR) beng used. The second field (I4) provides the number of days being treated. The merged data file output from MERGER is also used. The merged data file is read from logical unit number 16 .

\section{Outputs}

There are two different sets of outputs from the program XFORM. The first set provides the eigenvectors and the means of the input variables in a form that can be used easily by the COMPLEX model. The other output is the transformed input data file. It is this transformed data file that is used later to reconstruct the hourly winds at the site.

The listing of the program XFORM is given in Section IV-C.

\section{The COMPLEX Model Program}

A flow diagram of the COMPLEX program is shown in Figure A-5. This program is principally based on the COMPLEX model concepts described in the main body of this report. It has been designed to provide the user with the capability of basing his analyses on either a one-grid system or a two-grid system (coarse and fine). By using two grids it is possible to focus down on small-scale terrain features that could be significant at some locations.

In the COMPLEX program, the observed anemometer level winds at data stations are first extrapolated to the grid top (ZTOP) which is prescribed to be $1000 \mathrm{ft}(305 \mathrm{~m})$ above the highest terrain elevation. A power law similar to Equation (23) is used for extrapolation with parameter $\alpha$ set at 0.2 . The lowest level used with power law can be the actual anemometer level which in this study has been assumed to be $10 \mathrm{~m}$. Grid point values of wind at ZTOP are obtained by using a technique developed by Mancuso and Endlich (1973) and Mancuso and Wolf (1974). This technique involves least square fitting of a first degree polynomial to the extrapolated observed data at ZTOP and wind analyses are performed by analyzing wind speed and 


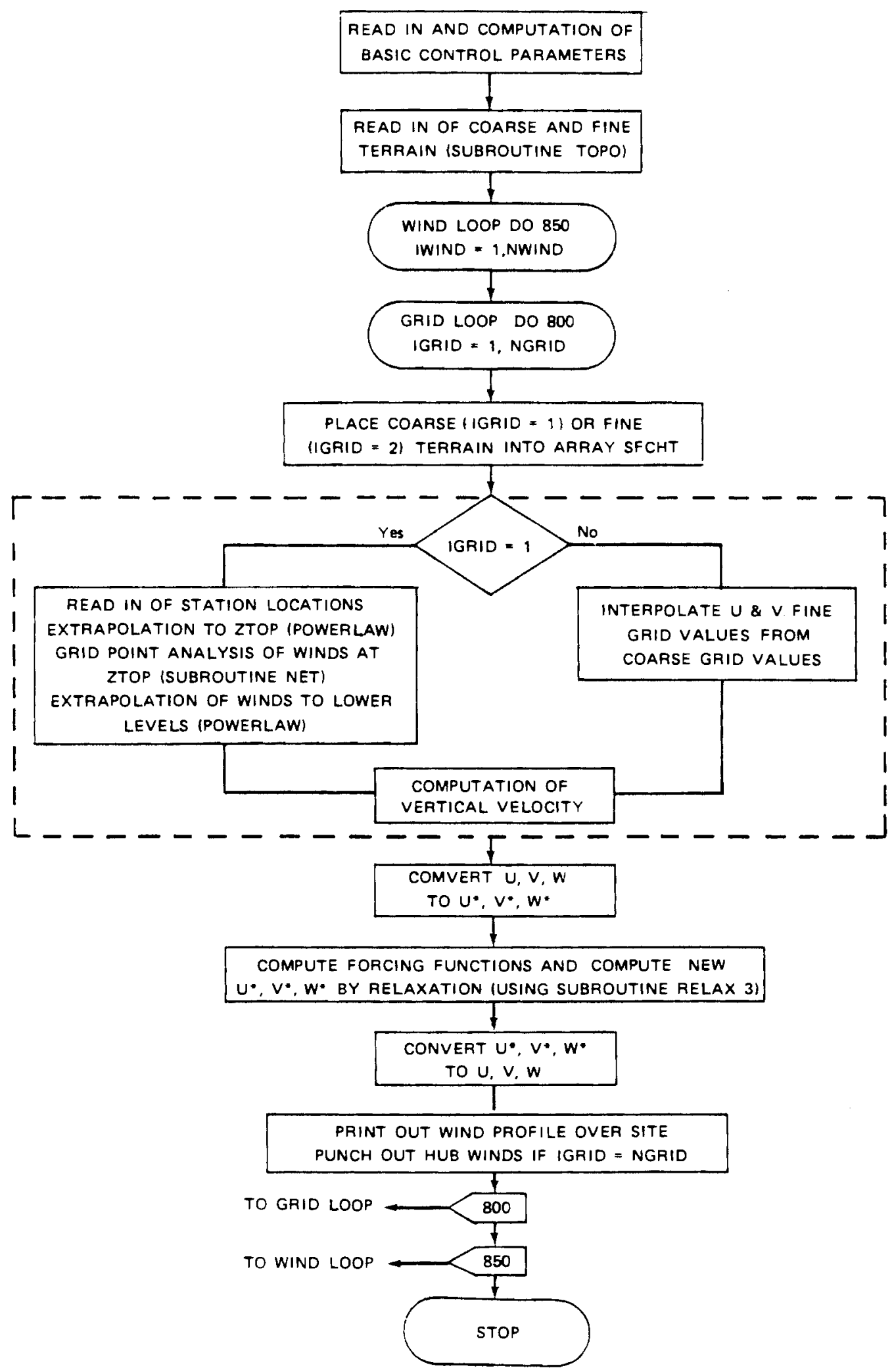

FIGURE A.5. FLOW DIAGRAM FOR THE COMPLEX MODEL 
direction. Grid point values for each horizontal grid at ten vertical heights are then obtained by extrapolating the grid point values at ZTOP by using the power law,

$$
V_{Z}=V_{T O P}\left(\frac{Z}{Z_{T O P}}\right)^{0.2}
$$

We believe that this technique can be used to minimize the effect of non-uniform anemometer heights by using their actual values instead of $10 \mathrm{~m}$ as used by us in this study. The procedure described above establishes values for a network of horizontal and vertical points that are used in the COMPLEX model as the first-guess field to produce mass-conserved wind fields consistent with the local terrain. If a single grid system is used, this is the final product. If a two-grid system is used, this initial product is used to interpolate first-guess values for the fine grid, and a second COMPLEX calculation is made based on the more detailed terrain of the fine grid. The maximum number of rows or columns for either the coarse or fine grid is 21. The number of vertical levels is set at 10 , where level 4 is set to correspond with the hub height of the site. Thus, the values computed at level 4 of the grid point overlying the site provides the final output.

A complete description of the card input data for the COMPLEX program is given in Table A-3. With the input cards designated as $A$ through $\mathrm{C}$, one can specify for a given site the grid system (either a single grid or a coarse and fine grid), the number of wind cases or eigenvectors to be processed, the sizes and relative locations of the grids, and the grid point of the wind energy site. The cards designated as $E$ through $F$ are for inputting the terrain height values, and the cards designated $G$ and $H$ are for inputting the data station locations and the wind data.

The program is written in CDC FORTRAN and has been operated on the SRI/CDC 6400. Some modification may be necessary if it is to be used on other types of computers. The storage requirements on the CDC 6400 are 150,000 octal words. The computation time can vary considerably, depending on the grid size. For a single 21 -by-15 grid, the central processor time for the CDC 6400 was 30 , while for a two-grid run in which fine grid size was $(21,15)$, the central processor time was 40. A listing of the COMPLEX program is given in Section IV. D.

\section{E. Determining the Hourly Values at a Site}

\section{Background}

The program REWND calculates the hourly winds at a WECS site according to the following equations:

$$
\begin{aligned}
& U_{h}=\sum_{i=1}^{N} U_{i} q_{i h}+\bar{u} \\
& V_{h}=\sum_{i=1}^{N} V_{i} q_{i h}+\bar{v}
\end{aligned}
$$


Table A-3

INPUT CARDS FOR COMPLEX MODEL

\begin{tabular}{|c|c|c|c|c|c|c|c|}
\hline Card & $\begin{array}{l}\text { Card } \\
\text { Columns }\end{array}$ & $\begin{array}{l}\text { Column } \\
\text { Format }\end{array}$ & $\begin{array}{l}\text { Parameter } \\
\text { Symbol }\end{array}$ & $\begin{array}{l}\text { Parameter } \\
\text { Units }\end{array}$ & $\begin{array}{c}\text { Parameter } \\
\text { Value } \\
\text { Limits }\end{array}$ & $\begin{array}{l}\text { Typical } \\
\text { Value }\end{array}$ & Description of Parameter \\
\hline A & $1-5$ & 15 & JSITE & None & $>0$ & 2 & SITE identification ( $1-8$ for this project) \\
\hline B & $\begin{array}{l}1-5 \\
6-10\end{array}$ & $\begin{array}{l}15 \\
15\end{array}$ & $\begin{array}{l}\text { NWIND } \\
\text { NGRID }\end{array}$ & $\begin{array}{l}\text { None } \\
\text { None }\end{array}$ & $\begin{array}{l}>0 \\
1 \text { or } 2\end{array}$ & $\begin{array}{l}9 \\
2\end{array}$ & $\begin{array}{l}\text { No. of wind cases ( } 9 \text { for this project) } \\
\text { No. of grids for this site }\end{array}$ \\
\hline \multirow[t]{5}{*}{$\mathrm{C}$} & $\begin{array}{l}1-5 \\
6-10 \\
11-15 \\
16-20 \\
21-25\end{array}$ & $\begin{array}{l}\text { IS } \\
\text { I5 } \\
\text { I5 } \\
\text { I5 } \\
\text { I5 }\end{array}$ & $\begin{array}{l}\text { MI } \\
\text { NI } \\
\text { MR } \\
\text { NR } \\
\text { IB }\end{array}$ & $\begin{array}{l}\text { None } \\
\text { None } \\
\text { None } \\
\text { None } \\
\text { None }\end{array}$ & $\begin{array}{l}1 \text { to } 21 \\
1 \text { to } 21 \\
1 \text { to } 21 \\
1 \text { to } 21 \\
\cdots\end{array}$ & $\begin{array}{l}20 \\
20 \\
21 \\
21 \\
15\end{array}$ & $\begin{array}{l}\text { No. grid points E-W on coarse grid } \\
\text { No. grid points N-S on coarse grid } \\
\text { No. grid points E-W on fine grid } \\
\text { No. grid points N-S on fine grid } \\
X \text { location of fine-grid origin in fine- } \\
\text { grid units }\end{array}$ \\
\hline & $26-30$ & I5 & $\mathrm{JB}$ & None & -- & 14 & $\begin{array}{l}\text { Y location of fine-grid origin in fine- } \\
\text { grid units }\end{array}$ \\
\hline & $31-35$ & I5 & IZ & None & $>1$ & 3 & $\begin{array}{l}\text { Coarse-grid increment (DSI) divided by } \\
\text { fine-grid increment (DSR) }\end{array}$ \\
\hline & $41-50$ & F10.2 & DSI & $\mathrm{km}$ & $>0$ & 3.00 & Coarse-grid increment $(\mathrm{km})$ \\
\hline & $\begin{array}{l}51-60 \\
61-70\end{array}$ & $\begin{array}{l}\text { F10.2 } \\
\text { F10.2 }\end{array}$ & $\begin{array}{l}\text { DSR } \\
\text { ZTOP }\end{array}$ & ft $x 10^{-1}$ & $>0$ & $\begin{array}{l}1.00 \\
670.00\end{array}$ & $\begin{array}{l}\text { Fine-grid increment }(\mathrm{km}) \\
1000 \mathrm{ft} \text { above highest terrain }\left(Z_{\max }\right)\end{array}$ \\
\hline \multirow[t]{4}{*}{$\mathrm{D}$} & $1-5$ & IS & IXZ & None & 1 to $\mathrm{MI}$ & 10 & $\begin{array}{l}\text { X location of site on a coarse grid } \\
\text { (UTM coordinates) }\end{array}$ \\
\hline & $6-10$ & I5 & JYZ & None & 1 to $\mathrm{NI}$ & 9 & $Y$ location of site on a coarse grid \\
\hline & $11-15$ & I5 & IXSS & None & 1 to $M R$ & 14 & $\mathrm{X}$ location of site on fine grid \\
\hline & $\begin{array}{l}16-20 \\
21-30\end{array}$ & $\begin{array}{l}\text { I5 } \\
\text { F10.2 }\end{array}$ & $\begin{array}{l}\text { JYSS } \\
\text { HSITE }\end{array}$ & $\begin{array}{l}\text { None } \\
\text { ft } x 10^{-1}\end{array}$ & 1 to NR & $\begin{array}{c}12 \\
442.00\end{array}$ & $\begin{array}{l}\text { Y location of site on fine grid } \\
\text { Elevation of site in tens of feet }\end{array}$ \\
\hline $\begin{array}{c}E 1^{*} \\
J=1, N 1\end{array}$ & $1.4 \times \mathrm{MI}$ & 2014 & $\begin{array}{l}X F(I, J) \\
I=1, M I\end{array}$ & $\mathrm{ft} \times 10^{-1}$ & 10000 & 422 & $\begin{array}{l}\text { Terrain height (tens of feet) at grid } \\
\text { points--coarse grid }\end{array}$ \\
\hline $\begin{array}{c}E 2^{*} \\
J=1, N R\end{array}$ & $1.4 \times M R$ & 2014 & $\begin{array}{l}\mathrm{YF}(\mathrm{I}, \mathrm{J}) \\
\mathrm{I}=1, \mathrm{MR}\end{array}$ & ft $\times 10^{-1}$ & 10000 & 422 & $\begin{array}{l}\text { Terrain height (tens of feet) of grid } \\
\text { points--fine grid (if NGRID 2) }\end{array}$ \\
\hline $\mathrm{F}$ & $\begin{array}{l}1-10 \\
11-20\end{array}$ & $\begin{array}{l}\text { I10 } \\
\text { F } 10.4\end{array}$ & $\begin{array}{l}\text { JT } \\
\text { OS }\end{array}$ & $\begin{array}{l}\text { None } \\
\text { None }\end{array}$ & $\begin{array}{l}1 \text { to } 5 \\
0\end{array}$ & $\begin{array}{c}4 \\
0.2000\end{array}$ & $\begin{array}{l}\text { No. of data stations } \\
\text { Exponential factor of extrapolating wind }\end{array}$ \\
\hline \multirow[t]{3}{*}{$\mathrm{J}=1, \mathrm{JT}$} & $1-10$ & F10.2 & $X S(J)$ & None & None & -16.67 & $\begin{array}{l}X \text { position of data station (Using } \\
\text { coarse grid units) }\end{array}$ \\
\hline & $11-20$ & $\mathrm{~F} 10.2$ & YS $(J)$ & None & -. & -14.18 & $\begin{array}{l}\text { Y position of data station (using } \\
\text { coarse grid units) }\end{array}$ \\
\hline & $21-30$ & F10.2 & $\mathrm{ES}(\mathrm{J})$ & ft $\times 10^{-1}$ & -- & 225.00 & $\begin{array}{l}\text { Elevation (tens of feet) of station } \\
\text { (including anemometer height) }\end{array}$ \\
\hline $\mathrm{H}$ & $1-10$ & $\mathrm{I} 10$ & IV & None & 0 & 2 & Wind or eigenvector ID $9=$ mean \\
\hline I & $1-10$ & $\mathrm{~F} 10.2$ & US $(J)$ & $\mathrm{cm} / \mathrm{s}$ & None & 38.07 & $\mathrm{U}$ component of resultant wind \\
\hline $\mathrm{J}=1, \mathrm{JT}$ & $1-10$ & F10.2 & $\operatorname{VS}(\mathrm{J})$ & $\mathrm{cm} / \mathrm{s}$ & & .73 .16 & $\mathrm{~V}$ component of resultant wind \\
\hline
\end{tabular}

"Note: NI (or NR) records are read for northernmost row of terrain heights to southernmost. 
where:

$U_{h}$ and $V_{h}$ are the wind components at the $h^{\text {th }}$ hour.

$U_{i}$ and $V_{i}$ are the components of the solution obtained from COMPLEX for the $i^{\text {th }}$ eigenvector.

$\overline{\mathrm{u}}$ and $\overline{\mathrm{v}}$ are the components of the solution obtained from COMPLEX for the mean inputs. $q_{\text {ih }}$ is the $i^{\text {th }}$ transformed input variable for the $h^{\text {th }}$ hour. $\mathrm{N}$ is the number of eigenvectors being used--this will generally be equal to twice the number of wind stations available.

After the wind components are determined, they are used to obtain the wind speed, $S_{h}$, and direction, $d_{h}$ :

$$
\begin{aligned}
& S_{h}=\sqrt{U_{h}^{2}+V_{h}^{2}}\left(m s^{-1}\right) \\
& d_{h}=270-\arctan \left(\frac{V_{h}}{U_{h}}\right)(\text { degrees })
\end{aligned}
$$

where direction follows the meteorological convention and is measured in degrees clockwise from north, and indicates the direction from which the wind blows.

\section{Inputs}

The required inputs are of two kinds. First are the card inputs, which define the number of eigenvectors, the eigenvectors themselves and the mean. Table A-4 summarizes these inputs. The second set of inuts are the hourly sets of transformed variables. These are read from logical unit 1 in the same format in which they were written by the program XFORM.

Table A-4

\begin{tabular}{|c|c|c|c|}
\hline $\begin{array}{l}\text { Card } \\
\text { No. }\end{array}$ & $\begin{array}{l}\text { Variable } \\
\text { Name }\end{array}$ & Format & Remarks \\
\hline 1 & NVECT & $20 \mathrm{X}, \mathrm{Il}$ & $\begin{array}{l}\text { Number of eigenvectors to be } \\
\text { used; right justify NVECT } 8\end{array}$ \\
\hline 2 & $\begin{array}{l}\text { CONST1 } \\
\text { UMEAN }\end{array}$ & $8 \times, 9 F 8.1$ & $\begin{array}{l}\text { NVECT values of } \bar{u}_{i}(\mathrm{~cm} / \mathrm{sec}) \\
\text { and } \bar{u}(\mathrm{~cm} / \mathrm{sec})\end{array}$ \\
\hline 3 & $\begin{array}{l}\text { CONST2 } \\
\text { VMEAN }\end{array}$ & $8 X, 9 F 8.1$ & $\begin{array}{l}\text { NVECT values of } v_{i}(\mathrm{~cm} / \mathrm{sec}) \\
\text { and } v(\mathrm{~cm} / \mathrm{sec})\end{array}$ \\
\hline
\end{tabular}

INPUT CARDS FOR PROGRAM REWND

\section{Outputs}

The outputs of the program REWND consist of hourly values of the wind components and the speed and direction. Six-word records are written to logical unit 2 . The first 
word is the record number, the second is the hour of the day, words 3 and 4 are the $u$ and $v$ components $\left(\mathrm{m} \mathrm{s}^{-1}\right)$. Words 5 and 6 are speed $\left(\mathrm{m} \mathrm{s}^{-1}\right)$ and direction (meteorological convention, degrees clockwise from north). These very short records have been chosen to facilitate the subsequent use of a specific standard statistical package. Much greater efficiency could be achieved if larger records were used, combining several hours' data.

The listing of program REWND is given in Section IV-E.

\section{F. Estimating Hub Height Wind Characteristics at a Site}

\section{Background}

The output of program REWND is a sequence of estimated wind speeds and directions. Once such a sequence has been produced, it can be treated just like a sequence of observed winds. Hence, any programs that can be used with actual wind observations for deriving such common wind statistics as average speed, frequency distribution of speed or direction, joint frequencies, diurnal variability etc., could also be applied to the outputs of REWND. In our case, we have chosen a widely used software package, "Statistical Package for the Social Sciences SPSS (Nie et al., 1975) for determining and displaying wind speed frequency distributions and the joint frequencies of speed and direction. This SPSS program (written by Ms. Kathleen Chaiken) is presented in Section IV. We have also written a FORTRAN program, WINDY, for determining run durations and seasonal and diurnal average wind speeds. That program is described in Section III-F-2, below.

\section{Program WINDY, for Determining Run Duration Statistics}

In general, the standard statistical packages do not treat the problem of run duration very well. The problem is to determine how often the wind speed remains within certain limits for extended periods of time. The specific limits, as defined in the contract, are less than or equal to and above $4 \mathrm{~m} \mathrm{~s}^{-1}$ and between 10 and $25 \mathrm{~m} \mathrm{~s}^{-1}$. A simple program WINDY has been written to determine the numbers of occurrences of runs of various duration. The required input is the output file from program REWND, which is read from logical unit number 1 . A single card input is also required. This card gives the Julian date (number of days since January 1) of the first day's data. It is required for determing the seasons as the input data are processed.

\section{SPSS Program for Obtaining Statistical Summaries}

The SPSS program will provide tabulated frequencies of speed and direction from the outputs of the program REWND. It also produces joint frequency distribution of speed and direction. In the version given here the frequency class intervals for speed are $2 \mathrm{~m} \mathrm{~s}^{-1}$. The joint freuency tabulations use $4 \mathrm{~m} \mathrm{~s}^{-1}$ wind speed class intervals and a 16-point wind direction classification.

A peak gust analysis can be performed by using the frequency distribution for hourly mean wind speeds. The hourly mean wind speeds are multiplied by 1.4 to obtain approximate gust speeds, and the abcissa of the hourly speed frequency distribution can be labeled to represent wind speeds gusting above a prescribed cut-off speed.

The listing of the program WINDY and the SPSS program is given in Section IV-F. 


\section{PROGRAM LISTINGS}

A. Program SFCOBS 1

PROGRAM SFCOBS1 (INPUT,OUTPUT, TAPE 1, TAPE2)

CUMMON /REC/ IONE.ITWO.NF.NR.NP. IYR.IMO.IDA.IHR. STANO

COMMON IUAT/ A.ID(50).DAT(9A), IH.DAY,WS (24), ICLD(24), IJS(24)

COMMON /CSTAG/ SPIBO.CPIHO.ITYP. ISICT.ICEIL.ICLUUD

DIMENSION CLCUO(2), HEADER(25)

DATA ITYP.ISICT.CLOUD $/ 2.2 .4 H O . C . .4 H C . C . /$

FOFMAT (1H1.25A3)

FORMAT (//1H * *NO. OF REC. READ $=\$ 15, *$ AND NU. OF REC $=$ WRITTEN $=*$

(. IS)

FORMAT (4F10.0.215)

FORMAT (25A3)

INPUT $\ldots$

STANO = STATION NO.

EDATE = EEGINNING DATE OF INTEREST.

EDATE = ENDING UATE OF INTEREST.

SLAT = STATION LATITUDE (DEGREES)

ISICT = I (OPAQUE CLOUOS) AND ISICT $=2$ (CLOUD COVER) USED TO DETERMINE S.I.

READ 5, STAN, BCATE, EOATE, SLAT, ISICT

PRINT 5. STAN, EDATE, EDATE. SLAT, ISICT

READ 6. HEADEF

PAST = EDATE -1

NLIBC=0.0174533*SLAT\&SP180=SIN(PL1BO) SPIBO=COS(PL18O)

IREC $=0$

HRINT 1. HEADER

C TRAP STATIOV aNo cate of INTEREST.

5C CALL RECORD

IONE =I \& ITWO=2 \$ CALL DATES

IF(DAT(2) - LT. HOATE)GO TO 50

IF(STAN DNE. STANCISTOPSO

DAT (1) = STANU

3 FURMAT (/IH.*FECORU NO.*15.5X 2F10.1/)

PRINT 3. NR,DAT (1),DAT (2)

$100 \quad N=2$ IH $=C$ FROCHSS CATA FUR 01000600 HOURS.

IONE $=9$ \$ ITWC $=49$ \& CALL PROCESS

C PRUCESS DATA FUR 0700-2300 HOURS

DU $120 \quad 1=1 \cdot 3$

CALL RECUHO

IONE $=1$ S ITWU J 48 \& CALL PRUCRSS

11: CONTINUE

CALL RECDGD

IF (NF.LO.O) GC TO $12 C$

DAT $(98)=$ DAT $(34)$

DAT $(97)=$ DAT $(93)$

DAT (;5) = DAT (92)

DAT (95) = DAT(S1)

UU) TU 130

C PRIJCESS CATA FCR 24 CO HOURS.

12C IUNE=I S IT NC=E \& CALL PROCESS

c

ISC CINTINUE

VITITE(2) UAT 
SUERCUTINE CLQUDO (IND.CLD)

THIS SUGRULTINE CECOOES CLQUD COVER INFO-OEITHEK OPAQUE UR UTHER CONMON /DAT, N. IO(5C).OAT(98). IH.OAY.WS(24), ICLO(24), I JS(24)

COMMON /CSTAB/ SPI8O,CP180. ITYP. ISICT. ICEIL. ICLOUD

FURMAT $(B X . R 1.1 X)$

FORMAT $(7 X, 21,2 X)$

FORMAT $(A 1.9 \times)$

FUFMAT $(8 \times 13.9 \times)$

If (ISICT.GT.1) GO TO 50

DECODE $(10.1$. IOIIND) ICLCUD

GO TO 70

50 DECUDE (10.2.ID(IND) ICLOUO

DECUDE $(10.3 \cdot 10(I N D-3))$ ICI

IF (ICI.EO.1H .OR.ICI.EQ.IH*) GD TO 60

DECUDE $(20.4$. ID(INO-4) ICEIL

ICEIL =ICEIL $I$ CO

GO TO 70

60 ICEIL $=1000000$

TC IF (ICLOUD.EO.1R-) GO TO 100

IF (ICLOUD.EG.IR ) GO TO 80

$C L D=I C L O U O=($ I CLCUC.AND.77日 $)-33 B$

RETURN

S0 $C L D=I C L O U D=-399$

RETURN

$100 \quad$ CLD $=I C L O U D=10$

RETURN

END

SUERUUTINE DIGIT (ICIG. ISIGN)

IF (IOIG.LT.IAA) GO TO 110

IS $1 G N=+1$

IF (IDIG.EO.IFS) GC TO 100

IDI IU IDIG.ANO.77M

RETULN

$10 C$ IDIG $=0$

RETURN

110 ISIGN $=-1$

IF (IUIG.LO.IF\%) GO TO 120

$I L I G=(I D I G$. AND.77E) IIP

RETURN

$120 \quad 10 I G=0$

LETUFN

END 
SUBRUUTINE WINDS (IND) 
SUERCUTINE TENP (INC)

SUBROUTINE FCF DECODING TEMPERATURE AND DEWPOINTINOT USEDI

CUMMON /DAT, N.IO(5O).OAT(98), IH.OAY,WS(24), ICLO(24), IJS(24)

DATA IBK /55甘/. FACT /O.55555/

FORMAT (R1.5X,R1.3X)

FORMAT $(I 2, R I, 3 X, I Z, R 1,1 X)$

FORMAT $\left(6 \times, 12, R_{1}, 1 \times\right)$

FORMAT $(12 . R 1.7 X)$

UECOUE $(10.1$.ID(IND)) IT.IOP

IF (IT.EQ.IEK) GO TO $10 \mathrm{C}$

IF (IOP.EO.IBK) GO TO 120

DECODE (10.2.IDIINO)) ITI.ITZ.IDPI.IDPZ

CALL OIGIT (ITZ.ISIGN)

I TEMP = I T I $* 10+I T 2$

IF (ISIGN.LT•C) ITEMP =- ITEMP

C CALL DIGIT (ICP2,ISIGN)

C IOPT $=$ IOPI $1 * 10+10 R 2$

C IF (ISIGN.LT.O) IDPT=-IDPT TEMPERATURE AND DEW POINT ARE OK.

$N=N+13$ DAT $(N)=F A C T *($ ITEMP-32)

C $N=N+1$ S DAT $(N)=F A C T *(I D P T-32)$

RETURN

100 IF (IDP.EO.IBK) GO TO 110

C DECUDE $(10,3,10(I N D))$ IDP $1.10 P 2$

c CALL DIGIT (ICP2, ISIGN)

C $\quad I D P T=I D P I * 10+I D P 2$

C IF (ISIGN.LT.O) IUPT =-IOPT

C TEMPERATURE IS INVALID... DEW POINT IS OK.

$N=N+1$ D DAT $(N)=-999.0$

C $\quad N=N+1 \$ \operatorname{DAT}(N)=F A C T *(10 P T-32)$

RE TURN

$c$

$110 \quad \begin{array}{lll}N=N+1 & \text { DAT }(N)=-999.0 \\ N=N+1 \$ D A T(N)=-999.0\end{array}$

c

RETURN

$12 \mathrm{C}$ DECDDE $(10.4, I C(I N C))$ ITI.IT2

CALL DIGIT (ITZ,ISIGN)

ITEMP $=I T I * 10+1 T 2$

IF (ISIGN.LT.C) ITEMP=-I TEMP

6 TEMPERATURE IS OK...DEW POINT IS INYALIO.

$N=N+1$ DAT $(N)=F A C T *(I T E M P-32)$

C $\quad N=N+1$ S DAT $(N)=-999.0$

RETURN

END 
B. Program MERGER

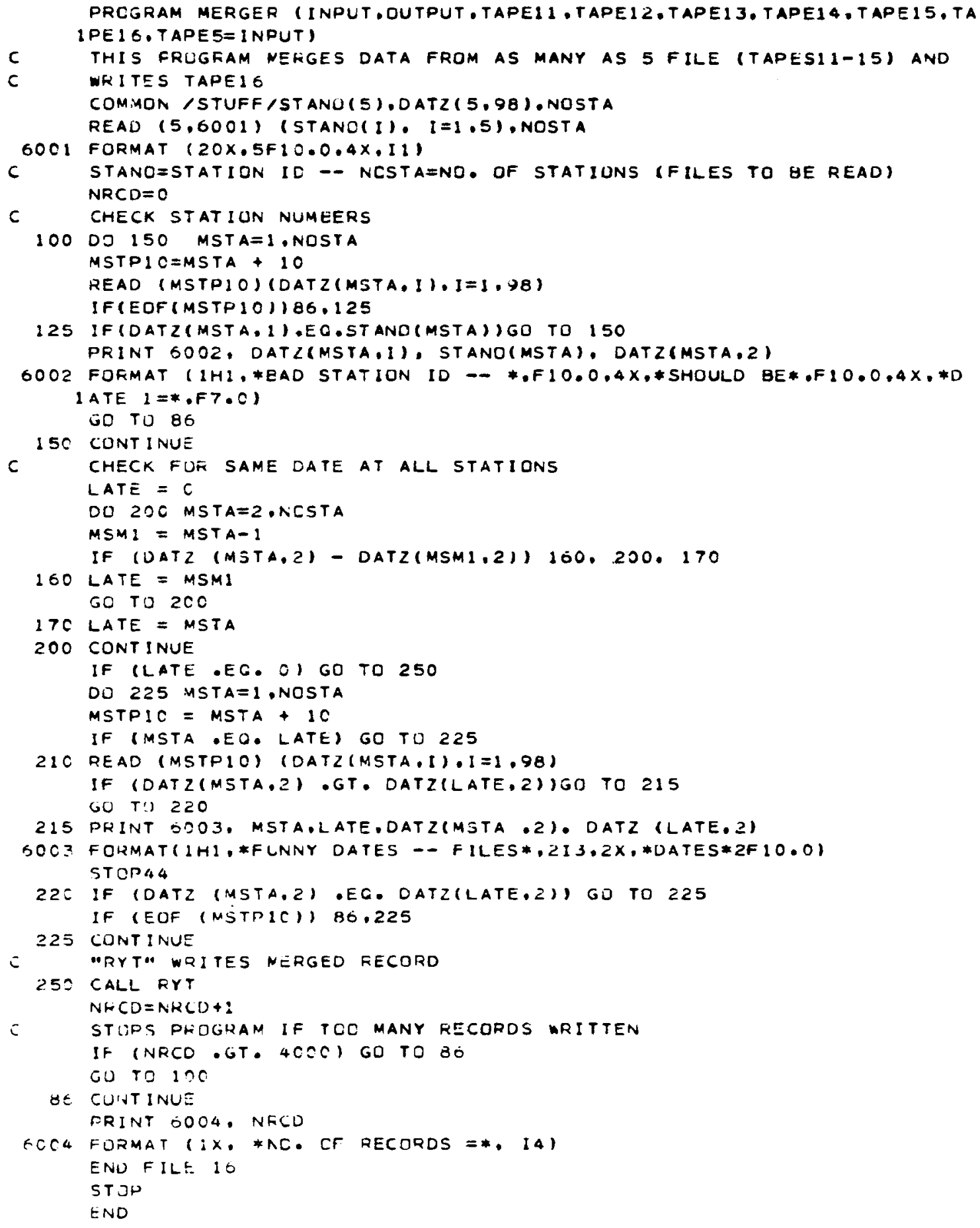




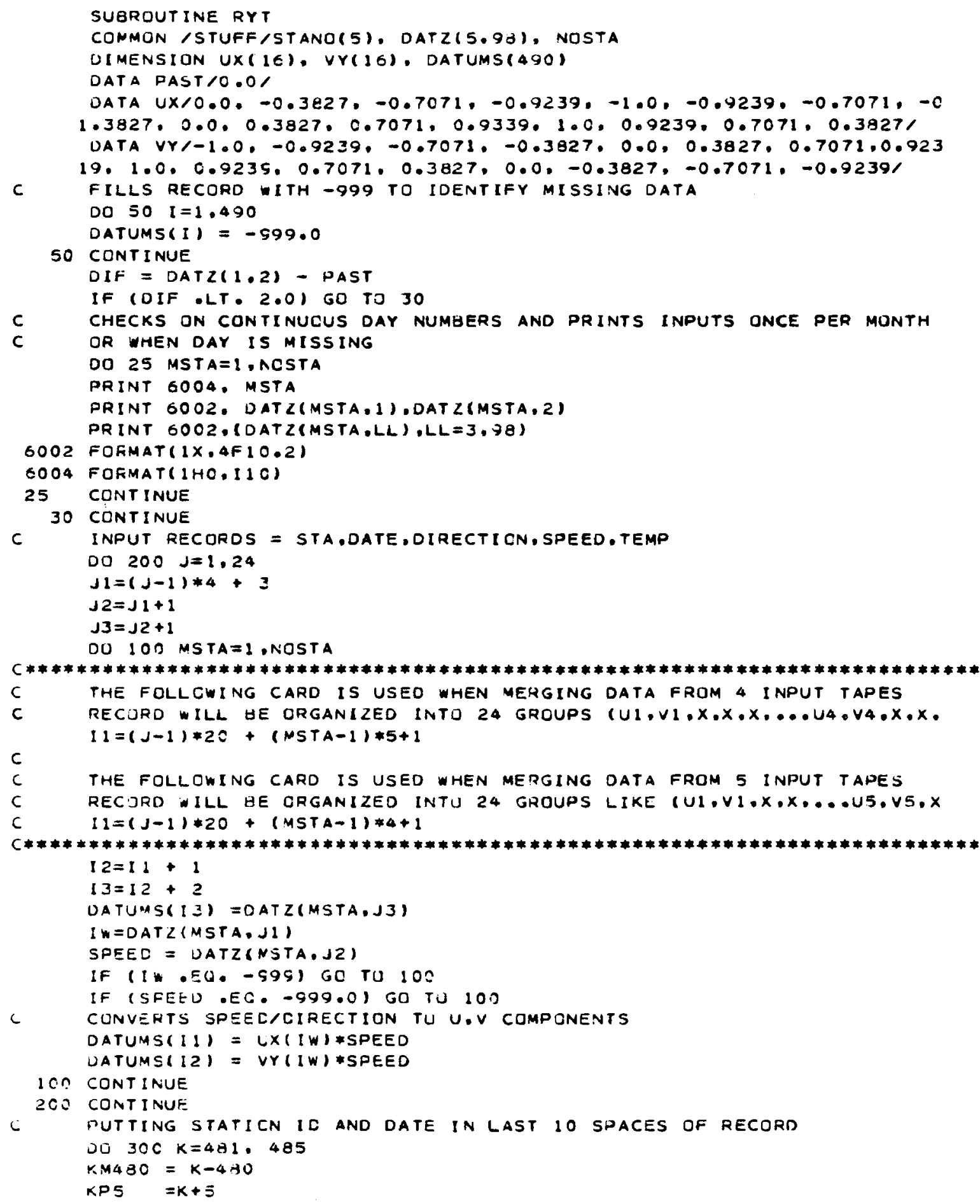




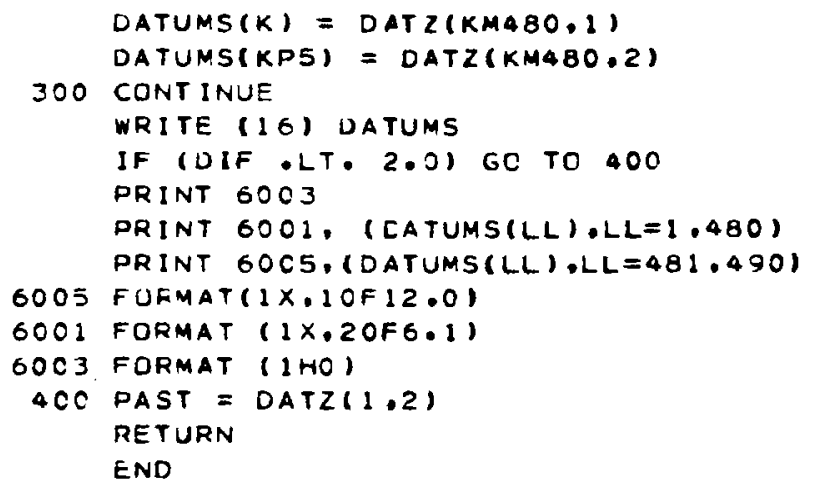


C. Program XFORM

PROGRAM XFORM (INPUT. UUTPUT, TAPE16. TAPE3. PUNCH)

DIMENSION X(3000.10).XM(10).DATA(490).NBR(6).TEMP(10).A(10.101.

\#D(10).Z(10.10),WK( 10$)$

READ 31. NVAR. NDAYS.MISS

31

FORMAT ( 3 I 3 )

IF (MISS.LT.1)MISS=0

NRECS $=$ ND AYS*24

NUR ( 1$)=N \vee A R$

NBR ( 2$)=$ NRECS

$\operatorname{NaR}(3)=2208$

NBR $(4)=1$

NER $(5)=1$

$\operatorname{NBR}(6)=0$

$I X=2200$

CALL SUBI (X.XM.DATA.NER.NVAR,NDAYS.NRECS.IX,TEMP,A.D.Z,WK.

*M(SS)

STOP

END

SUEROUTINE SUEI(X.XM.OATA.NGR,NVAR, NDAYS, NRECS,IX, TEMP.A,D,Z,WK, *MISS)

UINENSION X(2208,NVAR), XM(NVAR), DATA(490),NBH(6),

*VCVIIOO), TEMP(NVAR), A( 10$), 0$ (NVAR), Z(NVAR,NVAK),WK(10)

CIMENSIUN SUMU(10). SUMV(10)

DATA SUMU/10*1.0/

DATA SUMV/10*0./

C MATSUB=NO. OF SUEMATRICES READ--GENERAL $4 / Y E A R$

C MISSEDATA PAIR TO UE SKIPPED

C If ALL DATA TC EE USED. SET MISS.GT. 5

MAT SUB $=4$

NCASES $5=C$

$M \vee A R=N \vee A R / 2$

$M \vee P=M \vee A R$

IF (MISS.LE.S) MVF=MVP+I

DO $15 \mathrm{C} N \mathrm{NN}=1$, MATSUB

UU $100 \mathrm{~L}=1.72$

$N K=(L-1) * 24 * 1$

REAO $(16)$ (DATA(I). I = 1.450$)$

IF (ELF(1E).NE.O)GCTC 99

IF (NCASES IGT. NDAYSIGOTO Y9

$N C A S E S=N C A S E S+1$

UD $160 \quad x=1.24$

$N=(k-1) * 20$

DO 1 CO $I=1$, MVP

IF(I.EO.MISS)GUTO ICC

LK $=$ I

IF (I.GT.MISS) LK $=I-1$

5

C*****FUF USE WITH TAPES WITH SSTA--5 GRCUPS OF 4 VARIABLES

$N P I=N+(I-1) * 4+1$

C*\#\#FUR USE WITH TAPES WITH 4 STA- $\rightarrow 4$ GRUUPS OF 5 VARIABLEJ

$N P I=P+(I-1) \neq 5+1$ 
$N P I P I=N P I+1$

$J=(I-1) * 2+1$

IF(I.GT.MISS) J=J-2

$J P I=J+1$

$K R=N R+(K-1)$

$c$

IF (DATA(NPI).EQ.-999.) GOTO 2000

C SUMU.SUMV=MOST RECENT GOOD DATA

SUMU $(L K)=D A T A(N P I)$

SUMV $(L K)=D A T A$ (NPIPI)

$X(K R, J)=D A T A(N P I)$

$X(K R \cdot J P I)=D A T A(A P I P I)$

GOTO 2002

$2000 \times\left(K R_{0} J\right)=$ SUMU $(L K)$

$X(K R, J P I)=S U M V(L K)$

2002 CONTINUE

100 CDNTINUE

99 CONTINUE

CALL BECOVMIX,IX,NER,TEMP,XM,VCV, IER I

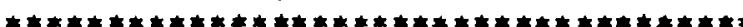

THE FOLLOWING CESCRIFTION OF SUBROUTINE BEVCOVMIX,IX.NBR, TEMP,XM,VC V.IERI IS FROM THE INSL MANUAL.

CALCULATES MEANS AND VARIANCE CDVARIANCE MATRIX $X---O N$ INPUT $X$ IS A NBR(3) EY NBR(1) SUEMATRIX OF THE MATRIX (CALL $T X X)$ CF DATA FOF WHICH MEANS, VARIANCES AND COVARIANCES, OR CORREC TED SUYS UF SOUARES ANDCROSS-PRDOUCTS ARE DESIRED. THE LAST SUBMATR IX IN XX MAY HAVE FEWER THAN NBR(3) ROWS.

ON OUTOUT. THE ROWS GF $X$ HAVE BEEN ADJUSTED BY THE TEMPORARY MEANS IX---RUW DIMENSION OF $X$ AS UIMENSIONED IN THE CALLING PROGRAM.

NBR---INPUT VECTCR CF LENGTH G. NERIII CONTAINS. WHEN $1=1$, NUMBER OF VARIABLES

$I=2$. NUEEF LF CESERVATIONS PER VAHIABLEIN $X X$

$1=3$, NUMBER OF OBSERVATIONS PER VARIABLE IN F.ACH SUBMATRIX $X$, NOT INCLUDING THE LAST SUGMATRIX WHERE THE NUMBER MAY he LESS THAN OR EQUAL TC NBR(3). HOWEVER. NOR(3) SHDULD BE

THE SAME FOR ALL CALLS.

$I=4$. THE NUMEER OF THE SUBMATRIX STURED IN $X$.

I =5. THE TEMPORARY MEAN INOICATOR. IF NBR(5)=0. THE USER SUPPL LIES TEMPORARY MEANS IN TEMP. OTHERWISE. THE IST ROW OF $X X$ ICR FIRST OF $X$ WHEM NHR(4)=1) IS USED.

$I=6$, WHEN THE $V C V$

$I=6$. THE VCV CPTICN. IF NUR $(6)=0$, VCV CONTAINS THE VARIANCECUVARIANCE MATRIX. JTHERWISE VCV CONTAINS THE CORRECTED S UMS CF SOUARES ANO CROSS-PROUUCTS MATRIX.

TEMP---INDUT VECTOR CF LENGTH NBR(1). IF NUR(5)=0 TEMP MUST CONTAIN THE TEMPOFAFY MEANS WHEN NAR(A)=1 OTHERUISE TEMP IS WURK STOR AGE.

XM---DUTPUT VECTOR UF LENGTH NBR(1) CONTAINING THE VARIADLE MEANS. VCV---OUTPUT NERII) BY NBR(I) MATRIX STORED IN SYMMETFIC STOTAGE MO DE

CLE FEUUIFIAG (NBF(1) *NBR(1)+1) I/2 STURAGE LUCATIONS. VCV CONT AINS THE VARIANCE COVARIANCE MATRIX OR THE CORRECTED SUM OF SO UARES AND CROSS PROUUCTS MATRIX. AS CONTRULLED GY VCV OPTION. NOK(S).

IER---ERROR DARAMETER, TERMINAL ERROR =129+N. N=1 INDICATES THAT NGR(4) IS LESS THAN I OR THAT NBR(3) *(NBR(4)-1) EXCEEOS NB.2(2) $N=2$

$N=2$ INOICATES THAT NBR(1) IS LESS THAN I OR NHR(2) IS LESS THA

$N$ C OF THAT NHR(3) EXCEEDS NHR(2). 


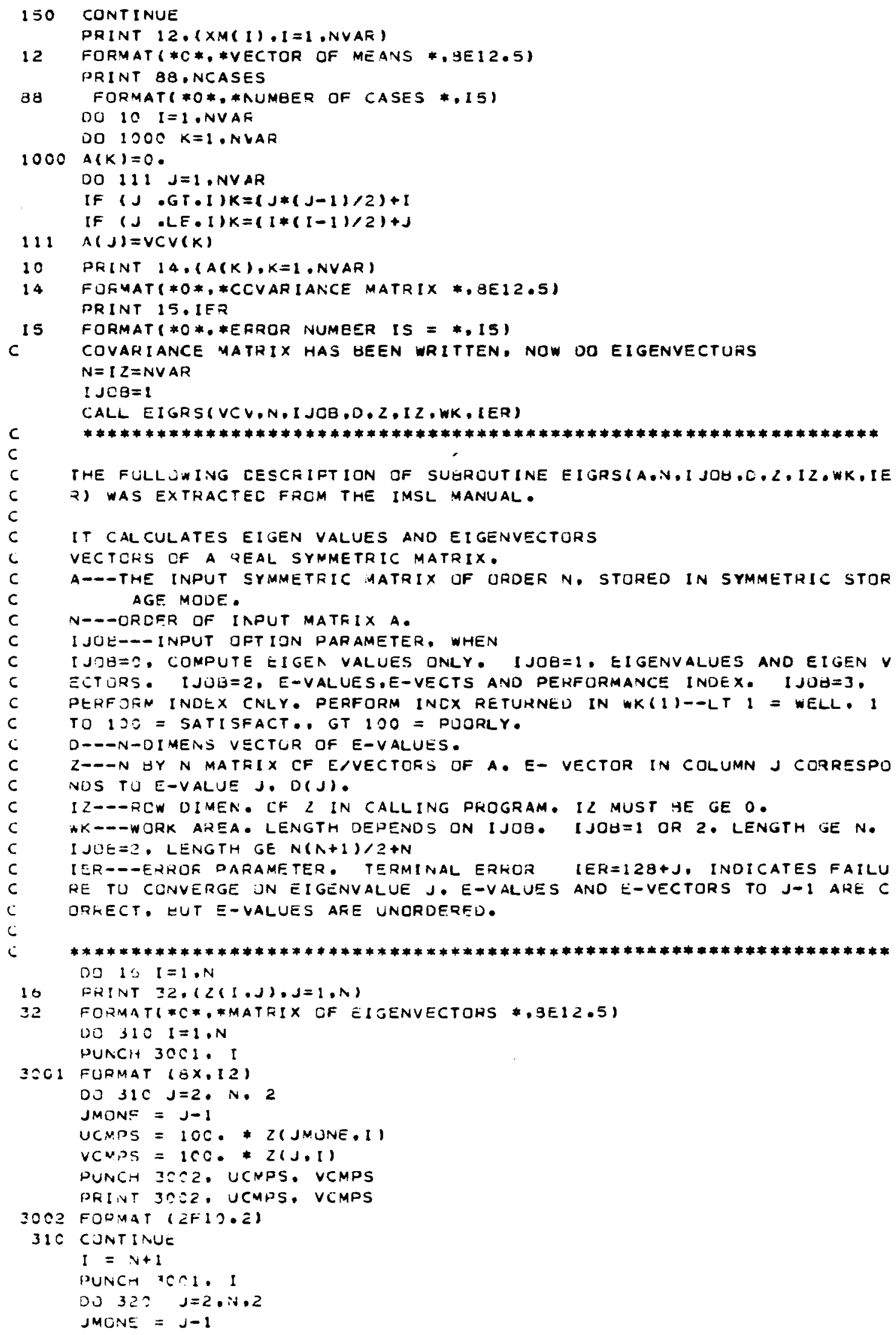




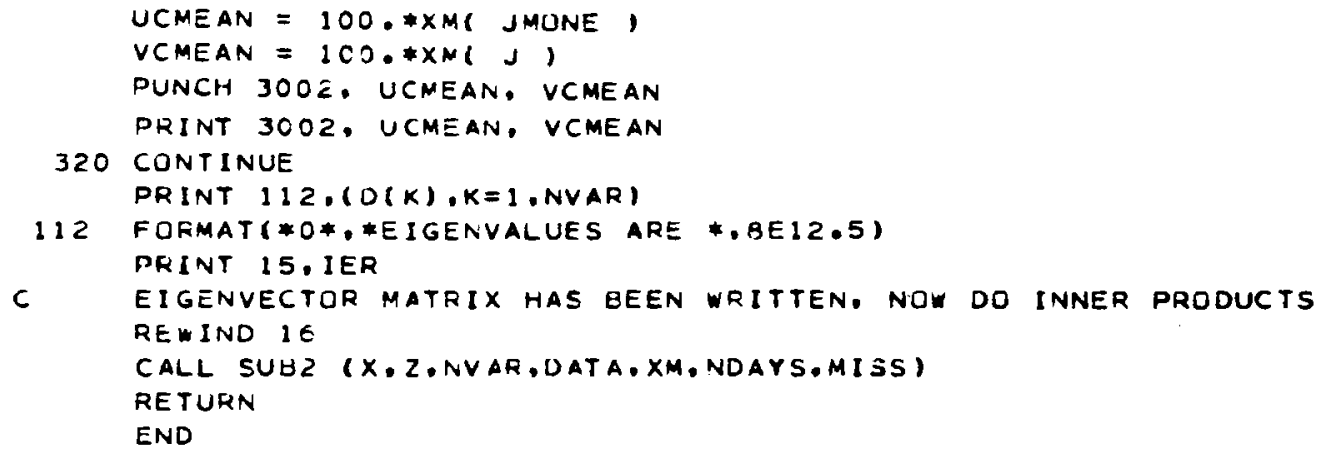




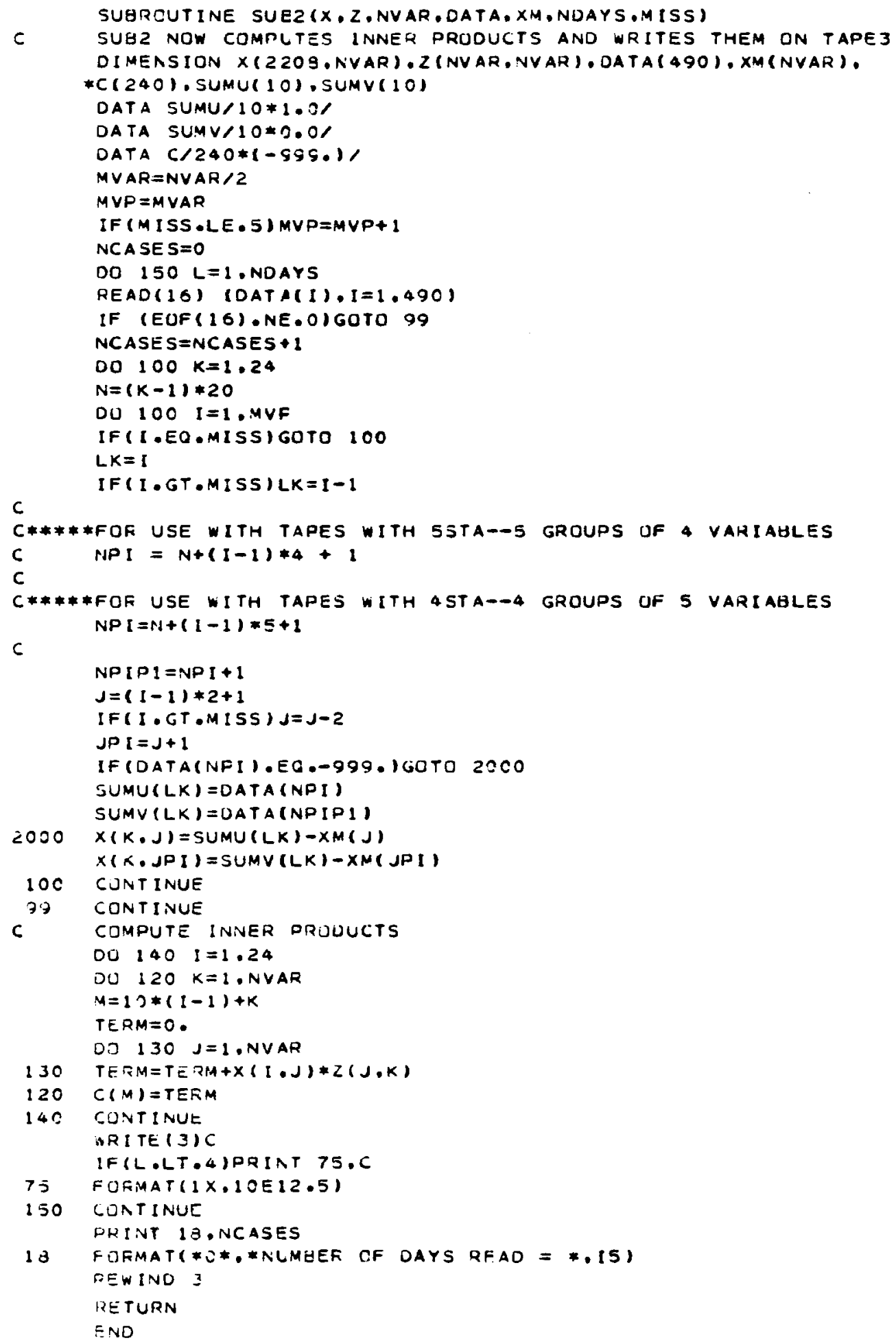


D. Program COMPIEX

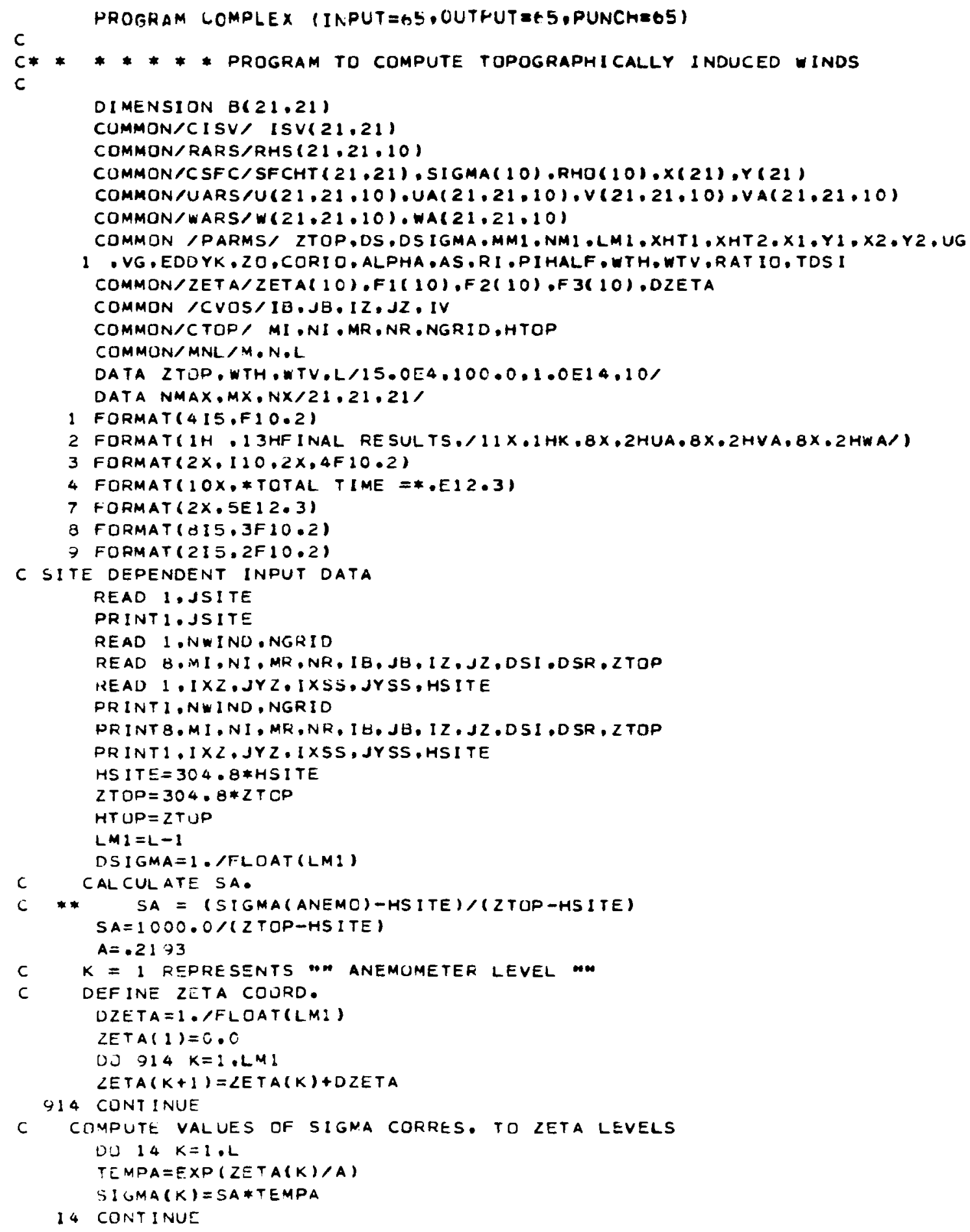


DO $916 \mathrm{~K}=1 . \mathrm{L}$

$F I(K)=A / S I G M A(K)$

$F 2(K)=-F 1(K) * F 1(K) / A$

$F 3(K)=F !(K) * F 1(K)$

916 CONTINUE

CALL TOPO(O)

C LOOP THRUUGH NWINO SETS.

DO 850 I WIND $=1$, NWIND

$I \times S=I \times Z$

$J Y S=J Y Z$

$M=M[$

$N=N I$

DS $=D S I$

C LOJP THROUGH NGRID SYSTEMS.

DO BOO IGRID=1. NGRID

$W T H=900.0 /(D S * D S)$

OS=US*1. OES

$M M 1=M-1$

$N M I=N-1$

RATIOI=WTH/WTV

TOSI $=1 . /(2.0 \% D S)$

C ESTABLISH GRID COOROINATES

$x(1)=0.0$

DO $12 I=1 . M M I$

$X(I+1)=x(I)+D S$

12 CONTINUE

$Y(1)=0.0$

DO $13 \mathrm{~J}=1 \cdot \mathrm{NM} 1$

13 CONTINUE

$Y(J+1)=Y(J)+D S$

C COMPUTE DENSITY DISTRIBUTIONS

DU $50 \quad K=1, L$

$R H O(K)=1 \cdot 0$

50 CONTINUE

C OUTAIN HEIGHT OF TERRAIN(SFCHTI

CALL TOPO(IGRID)

C UETAIN DATA FOR VELOCITIES

C VELOCITIES SHOULD BE EXTRAPOLATEDI WITH PUWER LAW I AT ZETA(K) LEVELS IF (IGRID.EO.1.ANO.IWINO.EQ.I) CALL VOUSER(O)

CALL VOBSER(I GRID)

C.. INITIALIZE adjusted arRays. -

52 DO $15 \mathrm{~J}=1 . \mathrm{N}$

DO $15 I=1, M$

IF (IGRID.EQ.2) ISV $(I, J)=0$

טO $15 K=1, L$

UA $(I \cdot J \cdot K)=0$

$V A(I, J, K)=C$

15 CONT INUE

213 CONTINUE

IF (IGRID.GT.I) GO TO 800

C * * * * * Convert velocitr components into starreo form *

DO $654 \quad I=1 . M$

DU $054 \mathrm{~J}=1, N$ 
DD $654 K=1 . L$

$C$ PUT $W$ IN TERMS DF SGMDOT

OHOX = (SFCHT $(1+1, J)-\operatorname{SFCHT}(1-1, J)) *$ TOS 1

DHOY $=($ SFCHT $(I, J+1)-S F C H T(I, J-1) *$ TOSI

TEMPI $=U(I, J, K)$ \#DHDX + V(I,J,K) \#DHDY

TEMP2 $=$ SIGMACK) -1.0

TEMP 3 = TEMP1 * TEMP2

TEMPA $=T E M P 3+W(I, J \cdot K)$

$Z V A R=Z T O P-S F C H T(I, J)$

SGMDOT $=$ TEMP4 /ZVAR

$W(I, J, K)=R H O(K) * S G M D O T$ ZVAR

$W(I \cdot J \cdot I)=0.0$

$W(I \cdot J \cdot L)=0.0$

$W A(I, J, K)=W(I, J, K)$

654 CONTINUE

DO $5 \quad I=1, M$

DO $5 \mathrm{~J}=1, N$

DO $5 K=1, L$

$Z V A R=Z T O P-S F C H T(1, J)$

$U(I, J, K)=K H O(K) * Z V A R * U(I, J, K)$

$V(I, J, K)=R H O(K) * Z V A R * V(I, J, K)$

$U A(I, J, K)=U(I, J, K)$

$V A(I, J \cdot K)=V(I, J \cdot K)$

5 CONTINUE

C * * * * * * * * VElocitr components are in starRed form

C COMPUTE FORCING FOR W OR RHO\#SIGMADOT EOUATION

C COMPUTE FIRST TERM ON RIGHT HAND SIDE

FDSDI $=1 . /(4.0 * D S * D Z E T A)$

DSSI $=1 . /(D S * D S)$

DO $80 \quad 1=2$, MMI

DO $80 \mathrm{~J}=2, \mathrm{NM} 1$

DO $80 \mathrm{~K}=2$, LMI

C COMPUTE DIVERGENCE OF WIND SHEAR

DUDZE $=U(1+1, J, K+1)-U(1+1, J, K-1)$

DUDZW=U( $I-1, J \cdot K+1)-U(1-1, J, K-1)$

DSUD $X=(D U D Z E-D U D Z W) * F D S D$ I

$D S U D X=D S U D X * F I(K)$

UVDZN=V(1,J+1, K+1)-V(I,J+1,K-1)

DVDZS $=V(1, J-1, K+1)-V(1, J-1, K-1)$

DSVDY $=(D V D Z N-D V D L S) * F D S D I$

OSVDY $=D S V D Y * F 1(K)$

FIFST =RATIO*(DSUDX +DSVDY)

C COMPUTE LAPLACIAN

$W L A P=W(I, J+1, K)+W(I, J-1, K)+W(I+1, J, K)+W(I-1, J, K)-4,0 * W(I, J, K)$ SECUN $=W L A P * D S S I$

RHS $(I, J, K)=S E C O N-F I R S T$

BO CONTINUE

$C H=R A T I O$

(ALL RELAX $3($ WA, RHS, CH)

C juUndary conditidas fGr ua and va are Set * * * * * * * * *

C * * cumputation of ua, and VA GY RELAXATIUN

DO $630 \quad I=2, M M I$

DO $630 \quad J=2$.NMI

D) $63 C \quad K=2, L M 1$

$V \times N=V(I+1, J+1, K)-V(1-1, J+1, K)$ 
$v \times S=v(1+1, J-1, K)-v(1-1, J-1, K)$

DSVOY $=(V X N-V X S) \neq D S I / 4.0$

$w \times B=w(1+1, J, K-1)-w(1-1, J, K-1)$

$w \times T=w(I+1, J, K+1)-w(I-1, J \cdot K+1)$

OSWOZ $=(W X T-W X \theta) * F D S O I$

OSWDZ=DSWDZ*F $1(K)$

$F I R S T=D S V D Y+D S W 0 L$

$U Y Y=U(I, J+1, K)+U(I, J-1, K)-2 \cdot 0 * U(I, J, K)$

UYY $=U Y Y * D S S I$

$U Z Z=U(I, J, K+1)+U(I, J, K-1)-2,0 * U(I, J, K)$

$U Z Z=U Z Z * R A T I O /(D Z E T A * D Z E T A)$

$U Z Z=U Z Z * F Z(K)$

$U Z=U(I, J, K+1)-U(I, J, K-1)$

$U Z=U Z * F Z(K) /(2.0 * 0 Z E T A)$

$U Z \angle=U Z Z+U Z * R . A T I O$

$S E C O N=U Y Y+U Z Z$

RHS $(I, J, K)=S E C O N-F I R S T$

6QO CONTINUE

CALL RELAX3(UA,RHS, CH)

DO $780 \quad 1=2$. MM 1

DO $780 \mathrm{~J}=2$. NM 1

DO $780 K=2, L M 1$

$U Y E=U(I+1, J+1, K)-U(I+1, J-1, K)$

UYW $=U(1-1, J+1, K)-U(I-1, J-1, K)$

DSUUX $=(U Y E-U Y W) * D S S I / 4.0$

$W Y T=W(I, J+1, K+1)-W(1, J-1, K+1)$

$W Y B=W(1, J+1, K-1)-W(1, J-1, K-1)$

$D S W D L=(W Y T-W Y B)$ FDSDI

$D S W D \angle=D S W D Z * F 1(K)$

$F I R S T=D S U D X+D S W O Z$

$v x x=v(I+1, J, K)+V(I-1, J, K)-2, C * V(I, J, K)$

$v \times x=v x x * 0$ sst

$V Z L=V(1, J, K+1)+V(1, J, K-1)-2, C * V(I, J, K)$

$V Z \angle=V Z Z * R A T I O /(D \angle E T A * D Z E T A)$

$V Z L=V Z Z * F 3(K)$

$V Z=V(I, J, K+1)-V(I, J, K-1)$

$V Z=V Z * F 2(K) /(2.0 * D Z E T A)$

$V Z Z=V Z Z+V Z$ RATIO

SECUN $=V X X+V Z Z$

RHS $(I, J, K)=S E C O N-F I R S T$

PBC CONTINUE

CALL RELAX3 (VA,RHS,CH)

C END OF CUMPUTATION OF UA ANO VA BY RELAXATIUN

C CONVERT MOMENTUM INTO IND

UU $O I=1, M$

DO $5 \quad J=1 \cdot N$

OO $S K=1,2$

$Z V A R=Z T U P-S F C H T(I, J)$

UA $(I, J, K)=U A(I, J, K) /(R H O(K) * Z V A R)$

$V A(I, J, K)=V A(I, J, K) /(R H O(K) * Z V A R)$

$W A(I, J, K)=W A(I, J, K) /(R H O(K) * Z V A R)$

C UA ANO VA ARE IN VELOCITY UNITS. WA IS SIGMAUUT

C CUIVVERT WA(SIGMADCT) INTU VERTICAL VELOCITY

$T E M P I=W A(I, J, K) *(\angle T O P-S F C H T(I, J))$

$T \because M P 2=1.0-S I G M A(K)$ 


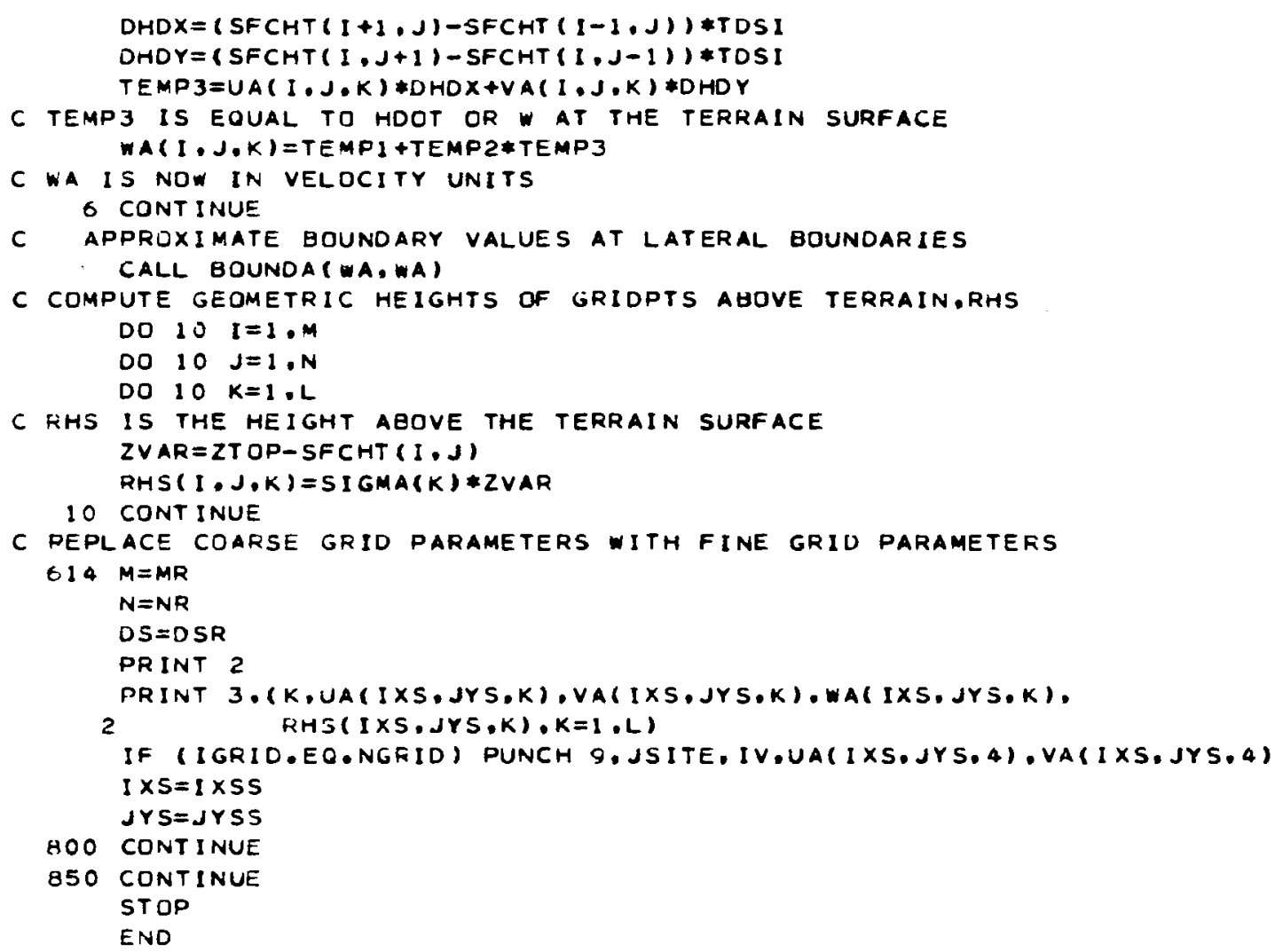




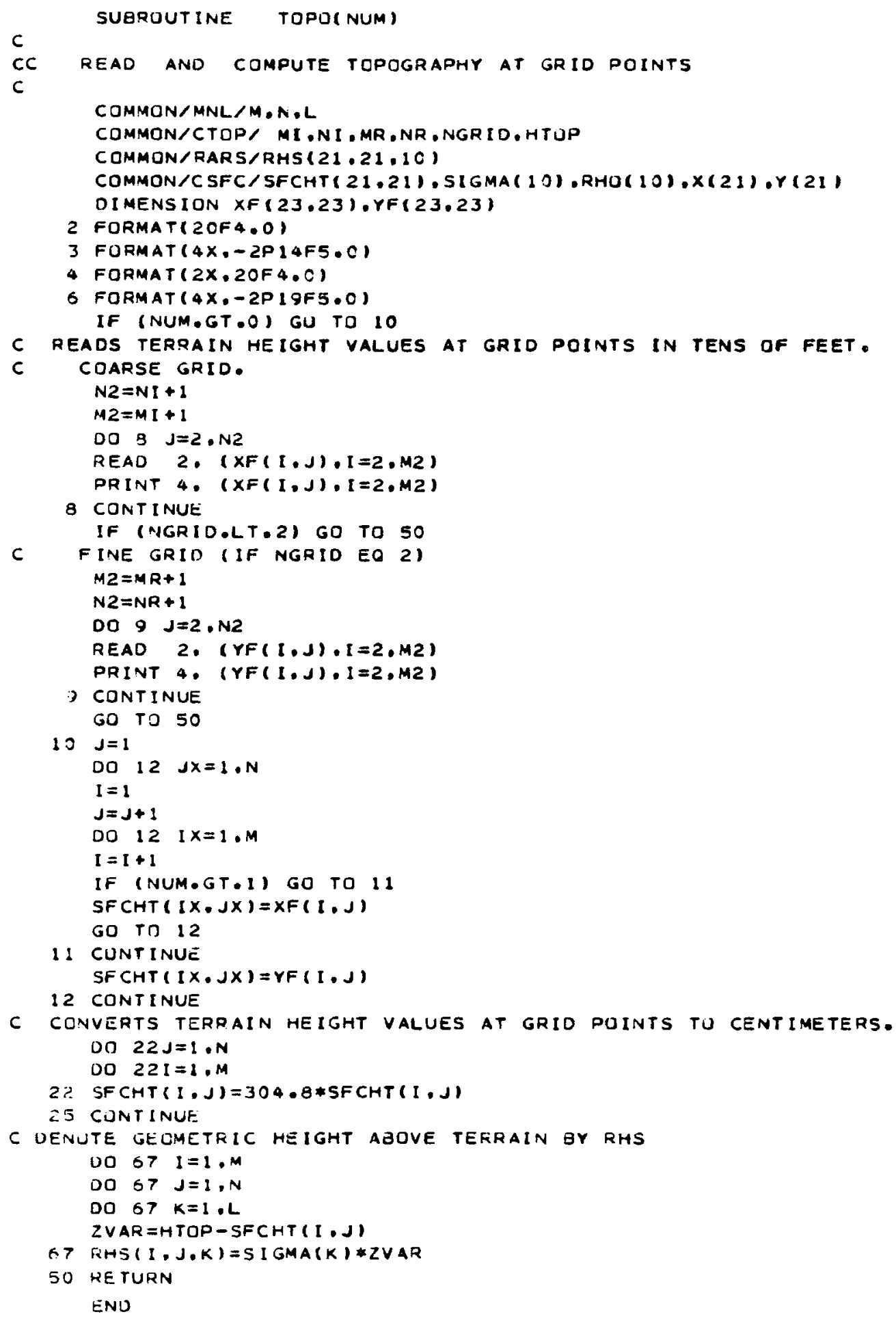




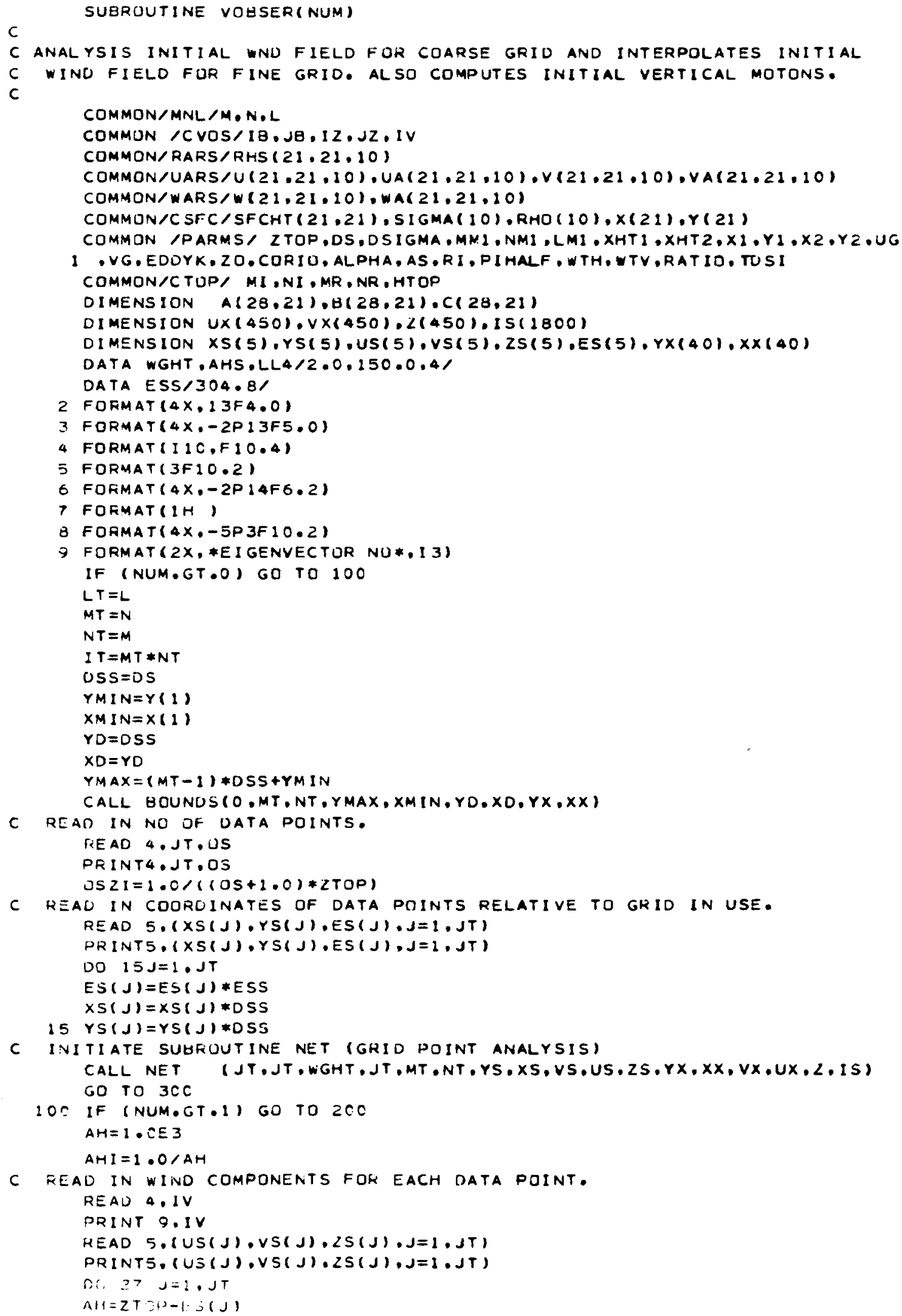


$27 Z S(J)=S O R T(U S(J) * U S(J)+V S(J) * V S(J))$

$A H I=1.0 / A H$

C USE SUHROUTINE NET(GRID POINT ANALYSIS)

CALL NETR1.1.0.05.JT,MT.NT,YS,XS.VS.US,ZS,YX,XX,VX,UX,Z,ISI

CALL NET(2,1.0.05,JT.MT.NT,YS,XS.VS.US.LS,YX,XX,VX,UX,Z,IS)

$I=0$

DO $50 M V=1, M T$

$I=(M T-M V) * N T$

DU SONVI, NT

$I=I+1$

RAT $=1 \cdot C$

SPO=SORT $(U \times(I) * U X(I)+V \times(I) * V \times(I)$ IS RAT=RAT*Z(I)/(SPO+0.0001)

$U X(I)=U X(I) * R A T S \quad V X I I)=V X(I) \neq R A T$

$A H I=1.0 /(\angle T O P-S F C H T(N V . M V))$

DO $\triangle O L V=1 \cdot L T$

$Z L=R H S(N V, M V \cdot L V)$

RAT $=$ (AHL $* Z L) \neq \# O S$

$U(N V, M V \cdot L V)=R A T * U X(I)$

$V(N V, M V, L V)=R A T * V X(I)$

40 CONTINUE

$Z(I)=0.01 * S F C H T(N V . M V)$

UX(I)=U(NV.MV.LL4)\$ $V X(I)=V(N V \cdot M V \cdot L L 4)$

50 CONT INUE

DO $70 L V=1 \cdot L T$

$I=0$

DO $6 O M V=1, M T$

$I=(M T-M V) * N T$

DO $6 O N V=1$. NT

$I=I+1$

$U T=U(N V \cdot M V \cdot L V)$

$V T=V(N V, M V, L V)$

$60 Z(I)=C .02$ *RHS (NV.MV.LL\&)

70 CUNT INUE

Go TO 250

200 CONT INUE.

C INTERFOLATES VALUES GF Fine gRIU FROM VALUES of COARSE gRID.

$I Z I=\lfloor Z-1$

$X D=(I E * 1 \cdot C) / 1 Z$

$Y O=(J \forall-1 \cdot 0) / J Z$

$I G=X D$

$J G=Y D$

$I D=(X D-I G) * I Z+0.00001$

$I E=\lfloor\theta+M$

$J E=J B+N-1$

$I \mathrm{H} H=I \mathrm{IG}+\mathrm{I} Z+1$

$I E E=(I E+I Z-2) / I Z$

$I E E=I E E * I Z+1$

DO $180 \quad K=1, L$

DO $1 ? 0 \mathrm{I}=\mathrm{I} \mathrm{HB}$. IEE. I Z

$10=(1-1)<1<+1$

$I X=I-I \quad H B+:$

UO $1>0 \quad \mathrm{~J}=\mathrm{J}, \mathrm{J}, \mathrm{JE}$

$J X=J-J \theta+1$

$r I=(J-1.0) / J Z+1 \cdot 0$

$J I=r I$

$J 2=J l+l$

$F J=Y I-J 1$

$n(I x \cdot J x)$

$H(I, J X)$

$C(I X, J X)$

$=F J *(U A(I 0, J 2, K)-U A(I 0 . J I, K))+U A(I 0 . J 1 . K)$

$=F J *(V A(I 0 . J 2, K)-V A(I 0 . J 1 . K))+V A(I 0 . J 2, K)$

170 CONTINUE

$=F J *($ WA $(I 0, J 2, K)-W A(I 0, J I, K I)+W A(I J, J I, K)$

$I X=0$ 


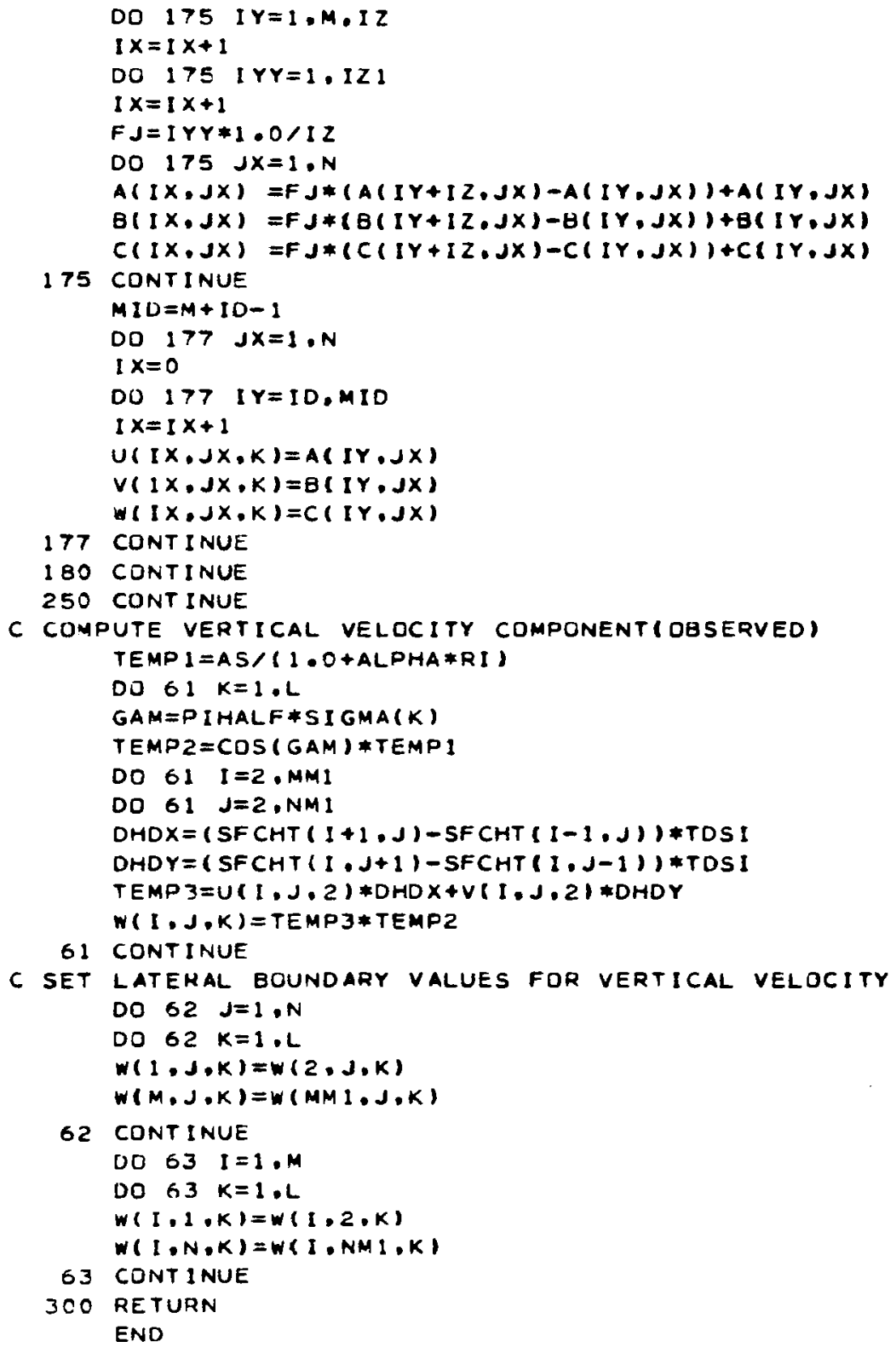


SUBROUTINE BOUNOS(MER,MT,NT,YMAX,XMIN,YD,XD,Y,X)

DIMENSION Y(1),X(1)

DO $10 M=1 \cdot M T$

$Y M=Y M A X+(1-M) \neq Y D$

$Y(M+M T)=Y M$

$10 Y(M)=Y M$

DO $20 N=1, N T$

$X N=X M[N+(N-1) \neq X 0$

$X(N+N T)=X N$

.

$20 X(N)=X N$

RETURN

ENO

SUGROUTINE BOUNDA (AB, VARB)

COMMON/MNL/M,N,L

DIMENSION AB $(21,21.10) \cdot V A R B(21,21.10)$

$M M 1=M-1$

$N M 1=N-1$

DO $927 \quad I=1 . M$

DO $927 J=1, N$

DO $927 K=1 . L$

$A B(I, J, K)=V A R B(I, J, K)$

927 CONTINUE

DO $778 \mathrm{~J}=1, \mathrm{~N}$

DO $778 \quad K=1 . L$

$A B(1, J, K)=V A R B(2, J, K)$

$A B(M, J, K)=V A R B(M M 1, J, K)$

778 CONTINUE

DO $779 \quad I=1 . M$

DO $779 \quad K=1 . L$

$A B(I, 1, K)=\operatorname{VAR} B(I, 2, K)$

$A B(I, N, K)=\operatorname{VAR} B(I, N M I, K)$

779 CONTINUE

RETURN

END 
SUBROUTINE NET(KO,IDS.WIN.JJ,MG,NG,YS,XS.VS.US,HS,Y,X,V.U.H,ISI DIMENSION DS(150), JS(150), IOI150)

DIMENSION YS(1).XS(1), YS(1).US(1),HS(1)

DIMENSIUN Y(1),X(1),V(1),U(1),H(1), IS( 1$)$

DATA KSW.ALPH,UNIL/4.2.5.5000.0/

OATA OYL,OCK/1.0E12,3.2E7/

IF $(K 0 . G T \cdot 2)$ GC TO 18

$K 05=K Q-1+K 555$

$L=0$

$M=L$

$1=0$

$75 M=M+1$

IF $(M-M 9) 77.77,100$

$77 N=0$

$Y L M=Y(M)$

$80 \mathrm{~N}=\mathrm{N}+1$

IF $(N-N 9) 81.81 .75$

$81 L=L+1$

$N O D=0$

$K=N O D$

$X L N=X(N)$

IF $(K O-1) 82.82 .83$

$82 U(L)=0 \cdot C$

$V(L)=U(L)$

$H(L)=V(L)$

NOD $=0$

$D \vee M=0 \cdot C$

$D U H=O V H$

$D H M=D U H$

$D N H=D H H$

GD TO 84

83 OYVH $=0 . C$

DYUH=DYVH

DYHH=DYUH

DXVH=OYHH

OXUH=DXVH

$D X H H=D X U H$

DYYH=DXHH

OXXH=DYYH

$D X Y H=D X X H$

$D Y H=D X Y H$

$D X H=D Y H$

$W=W I N$

UNH=

$N O D=1$

$K=0$

$O H H=H(L) * W$

$D U H=U(L) * W$

$D \vee H=V(L) * W$

$94 K=K+1$

If $(K-K S) 85.85 .90$

$384 I=I+K 5-K$

GU TO 90

B5 $I=I+1$

IF $(N D D-K O 5) 86,324,384$

$80 \mathrm{~J}=1 \mathrm{~S}(1)$

IF (J) 84.34 .37

87 IF (AHSIUS(J)).GT.UNIL)GO TO 84

$x S J=x S(J)$

$r S J=Y S(J)$

US $J=U S(J)$

$\vee S J=V S(J)$

$H S J=H S(J)$

DYS $=Y S J-Y L M$ 
$D \times S=X L N-X S J$

DYS $2=0$ O $S * D$ Or $+D \times S * 0 \times S$

DXS2 $=0.5 *$ ors 2

IF (IUS.EO.0)GO TO 385

USK $=$ USJ

$V S K=V S J$

IF (KO.EO.1)GO TO 388

$U S K=U S J+U(L)$

$V S K=V S J+V(L)$

388 DXS $1=L S K * U S K+V S K * V S K+0.01$

DXS2 $=($ USK $* 0 Y S-V S K * D \times S)$

$0 \times 52=0 \times 52 * 0 \times 52 / 0 \times S 1$

$385 \omega=O Y L /(O Y S 2+D \times S 2 * A L P H+O Y L)$

$N O D=N O D+1$

$D N H=D N H+W$

HSJ $=H S J * W$

USJ=USJ**

$V S J=V S J * W$

DHH=DHH+HSS

DUH $=$ DUH+USJ

$D V H=D V H+\vee J J$

IF $(K O-1) 89.84,89$

89 DYH $=D Y H+D Y S * W$

$D X H=O X H+D \times S * W$

$D X Y H=O X Y H+D X S * D Y S * W$

$D \times X H=O X X H+D \times S * D \times S * W$

DYYH $=$ DYYH+OYS*OYS $* W$

DXHH=DXHH+HSJ*DXS

DYHH $=$ OYHH+HS $J *$ OYS

$D X U H=D X U H+U S J * D X S$

DYUH=OYUH+USJ $* D Y S$

$D X V H=D X V H+V S J * D X S$

DYVH=DYVH+VSJ*DYS

GO TO 84

90 CONTINUE

IF $(K O-1) 94,91,94$

91 IF $(N O D-2) 80.92,92$

92 IF (DNH)80.80.93

93 UNH $=1.0 / 0 N H$

$H(L)=D H H * D N H$

$U(L)=D U H \approx O N H$

$V(L)=O V H * D N H$

GO TO 80

94 IF (NOD-3)80,80.95

95 D=OYH*OYH-ONH\#DYYH

$E=D \times Y H \neq D Y H-O X H * D Y Y H$

$A=D X H * D Y H-D N H * D X Y H$ $B=O \times X H * U Y H-D \times H \neq U \times Y H$ $\triangle D A E=\theta \neq D-A=E$

IF ( $U O A E) 97.80 .97$

97 UI $=1, C / 6 O A E$ $C=D X H H * O Y H-D H H * O X Y H$ $F=O Y H H * O Y H-D H H * D Y Y H$ $C U=O X U H * D Y H \rightarrow O U H * D X Y H$ $F U=D Y U H * D Y H-D U H * D Y Y H$ $C V=D X V H * D Y H=D V H * D X Y H$ $F V=U Y Y H * D Y H-D Y H \neq D Y Y H$ $H(L)=(B * F-C * E) * \theta I$

$U(L)=(B * F U-C U * E) * B I$

$V(L)=(\theta * F V-C V * E) * \theta I$

GO TU 80

100 CUNTINUS

RETURN

19 CONTINUF 
$K S=K 0$

$K S S S=10 S$

DLCK $=D C K * D C K$

$J C T=150$

$J S(J C T)=-1$

DS ( JCT ) = DLCK

$J C 2=J C T-2$

$L=0$

$M=L$

$I=0$

$20 \quad M=M+1$

$N=0$

$Y L M=Y(M)$

$25 N=N+1$

$L=L+1$

$J=0$

$J T=J J$

$X L N=X(N)$

$X L C K=D L C K$

$29 \mathrm{JC}=\mathrm{C}$

$J=J C$

$30 \mathrm{~J}=\mathrm{J}+1$

OYS $=Y S(J)-Y L M$

$O X S=X L N-X S(J)$

DL $S=D Y S * D Y S+D \times S * D \times S$

If (DLS-XLCK) $32.33,33$

$32 J C=J C+1$

IF (JC.LT.JCT)GO TO 3 !

$X L C K=X L C K * 0.75$

GO TO 20

31 OS $(J C)=O L S$

$J S(J C)=J$

I $S=0$

IXS $=1$

IF $(0 \times S \cdot L T \cdot O)$ IXS $=2$

IF (OYS.LT.O)IYS=2

$I O(J C)=I Y S+I \times S$

33 IF $(J-J T) 30,34,34$

$34 K P=0$

$K=6$

$I S W=1$

$J O=I S W$

$J X=J C$

IF $(K S W \cdot L T \cdot 2)$ ISW=2

$35 K=K+1$

$S I L=O L C K$

$J=0$

$I=I+1$

$K P=K P+1$

$J C=J C T$

$40 \mathrm{~J}=\mathrm{J}+1$

IF $(J \cdot L E \cdot J X) G C$ TO $(41.42)$ ISW

GU T. 45

41 IF (IG(J).NE.JC)GC TO 40

42 IF $\cos (J)-S I L 144,4 \mathrm{C} .40$

44 SIL $=$ DS $(J)$

$J C=J$

SU TO 40

$45 D S(J C)=D L C K$

IS(I) $=J S(J C)$

$J O=J O+1$

It $(J O . G T .4) J Q=1$

IF (KP.EO.KSW) ISW=2

IF (JC.LT.JCT)GO TO 49 
IF (KP.GT.KSW) GO TO 49

$K=K-1$

$I=I-I$

GO TO 35

49 If $(K-K S) 35.50 .50$

50 IF (N-N9)25.55,55

55 IF $(M-M 9) 20.60 .60$

60 CONT INUE

RE TURN

END

SUBRQUTINE RELAX3(FA.RHT. WDW)

CUMMON/MNL/M.N.L

COMMON/CISV/ ISV(21.21)

COMMON/RARS/RHS $(21,21.10)$

COMMON/UARS/U(21,21.10).UA(21.21,10).V(21.21.10).VA(21.21.10)

COMMON/WARS/W(21.21.10).WA(21.21.20)

COMMON/CSFC/SFCHT $(21.21)$.SIGMA( 10$)$. RHU(10).X(21).Y(21)

COMMON /PARMS/ ZTOP.DS.DSIGMA,MMI, NM1.LM1,XHT1,XHT2,X1,Y1,X2,Y2,UG

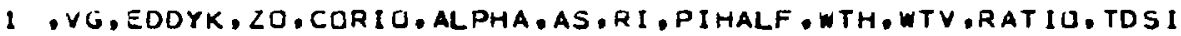

COMMON/ZETA/ZETA(10),FIIIC),FZ(10),F3(10).OZETA

DIMENSION FA(21.21.10).RHT(21.21.10)

DATA FACTOR.EPS.IA, $1.5 .1 .0 E-02.5 \mathrm{C} /$

$D M=1 \cdot 0 /$ (DS $+D S)$

$D M 4=4.0 \neq D M$

$D P \rrbracket=1 \cdot 0 /(D Z E T A * D Z E T A)$

WOP $=W D W$ *DPI

$O Z I=0.5 * m D W / O Z E T A$

NSC $=$ ?

38 REMX $=0.0$

DO $1 K=2$, LM!

$F 2 K=F 2(K) \neq 0 Z I$

$F 3 K=F 3(K) \neq W D P$

$P K=1.6 /(D M 4+F 3 K+F 3 K)$

DO I I $=2, M M I$

UD $1 J=2, N M 1$

IF (ISVII.J).FO.1) GU TO 1

$F A I=F A(I, J, K)$

$F A Z=F A 1+F A 1$

AH $H=(F A(I+1, J, K)+F A(I-1, J, K)+F A(I, J+1, K)+F A(I, J-1, K)-F A 2-F=A 2) \neq D M$

1 $+(F A(I, J, K+1)-F A(I, j, K-1)) \neq F Z K$

$C C=\quad F 3 K *(F A(I, J \cdot K+1)+F A(I, J \cdot K-1)-F A 2)$

$R E=(R H T(l, J, K)-E E-C C) * P K$

$F A(I, J \cdot K)=F A !-F A C T O R+F E$

IF (AGS(RE).GT. REMX) REMX = AQS(RE)

1 CONTINUE.

$N S C=N S C+1$

IF(HENX-EPS) 89.89 .85

85 IF ( VSC-【A) $8 B .88 .39$

89 CUNTINUE

; FOHMAT $(2 \times .13$ HSCAN CCUNT $=.15 .5 \times .15 H M A \times$ RESIUUAL $=. .11 .31$

WFITE(3.O) NSC.REMX

rit TULN

ENo 


\section{E. Program REWND}

PRCGAAM REWND (INPUT.CUTPUT, TAPE3. TAPE2. TAPEB=INPUT)

c

THIS PRUGRAM CAL CULATES EIGE

THIS PROGRAM CALCULATES HOURLY WINDS FROM EIGENVECTOR SOLUTIONS AND

HOURLY TRANSFORMED OESERVATIONS AT SURROUNDING SITES.

DIMENSION C(240), CONST1 (11), CONST2(11)

READ 33 . NREC, NVAR

$K C=N \vee A R+1$

33 FORMAT(2I5)

DU 199 LL $=1 . K C$

READ $(8.201)$ JSITE.IV.CONSTI (IV).CONST $2(I V)$

PRINT 222, JSITE, IV.CONSTI (IV), CONSTZIIVI

222

FORMAT (215.2F 10.2$)$

201 FORMAT(2I5.2F10.2)

199 CONTINUE

UMEAA $=$ CONST I $(K C)$

VMEAN $=$ CONST $2(K C)$

100 FORMAT( $*$ C * *NUMBER CF RECORDS $=* .18)$

C COMPUTE NEWUS AND NEW VS

$J=C$

NCASE $S=0$

C READ IN DATA,DO EOF CHECK, TAKE OUT C ARRAY DO $202 \quad I=1$, NREC

READ (3) $C$

55 FUFMAT(1X.10F 10.3$)$

IF(EUF(3) . NE.0) GOTO 99

$J=J+1$

DU 202 LUD $=1.24$

TERM $1=0$.

TERM2 $=0$.

DO $79 \mathrm{KC}=1$, NVAR

$K=10 *(L \cup D-1)+K C$

TERMI $=T E R M I+C(K) * C O N S T 1(K C)$

79 TERM2 $=$ TEKM $2+C(K) * C O N S T 2(K C)$

$C$ COMPLTE U AND V.SPEED.DIRECTION

$U=($ UMEAN+TERM 1$) * .01$

$V=(V M E A N+T E R M 2) * .01$

$\mathrm{S}=\operatorname{SORT}((U * 2)+(V * * 2))$

$D=(A T A N 2(V \cdot U)) * 57.2719$

$D=270 \cdot-D$

IF $(D \cdot L T \cdot 0 \cdot 1 D=D+36 C$.

$D=A M O O(D, 360$.

HOUR=LUD

$X J=J$

WFITE (2) XJ.HOUF,U.V.S.D

2OC FORMATC*O*,*CASE $=* .18 . *$ HOUR $=* . F 10.5 /$

* U $U=*, F 10.5 . * V=*, F 10.5 /$

* SPEED $=*, F: C .5 . *$ CIRECTIUN $=* . F 10.51$

NCASES $=$ NCASES+1

202 CONTINUE

Э9 PRINT $100 . \mathrm{J}$

DRINT $100 . N C A S E S$

O3 PRINT 200,J.HCUF,U,V.S,D

PRINT $55 . \mathrm{C}$

REWIND 2

STOP

END 


\section{F. Statistical Programs}

1. Program WINDY

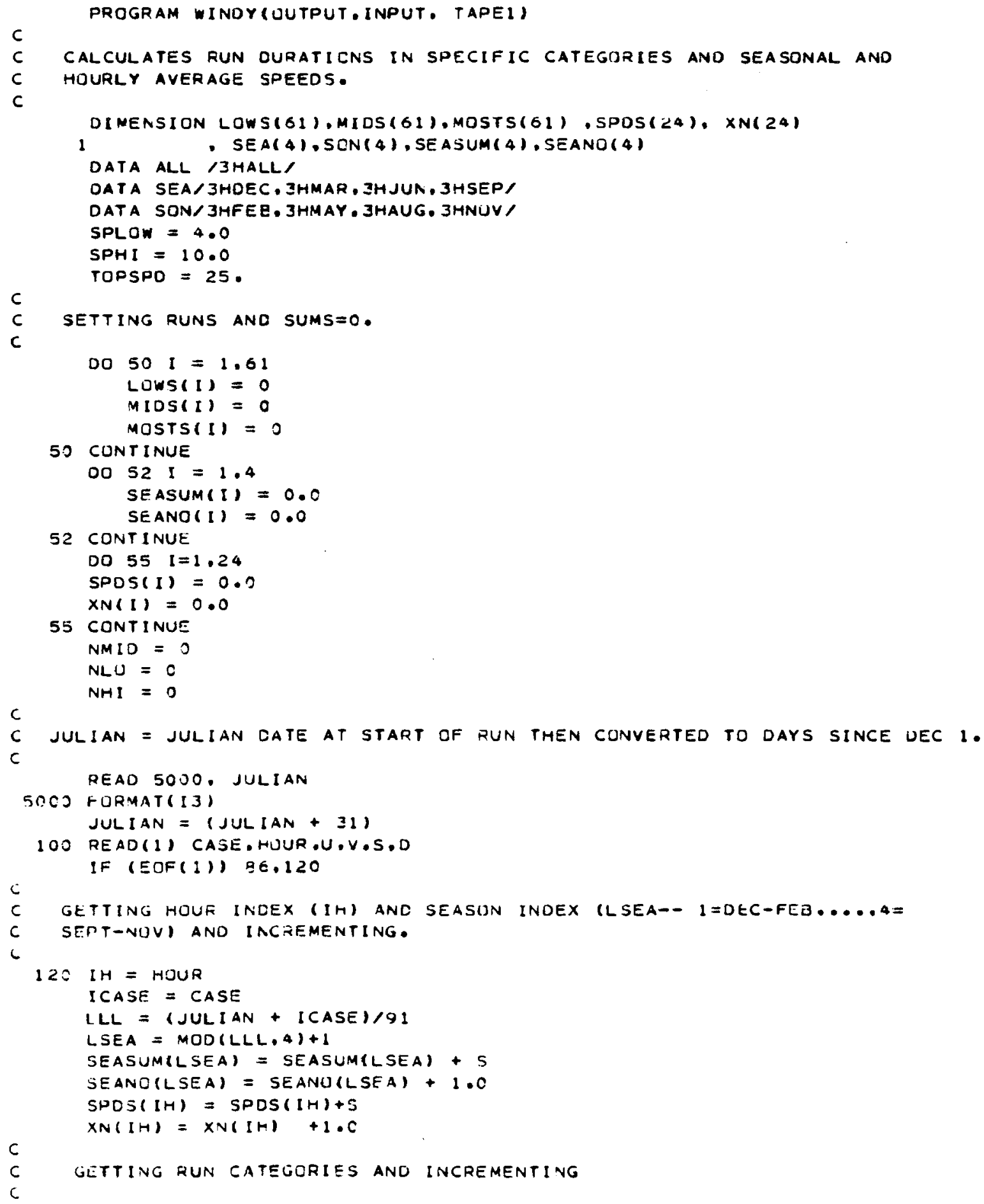




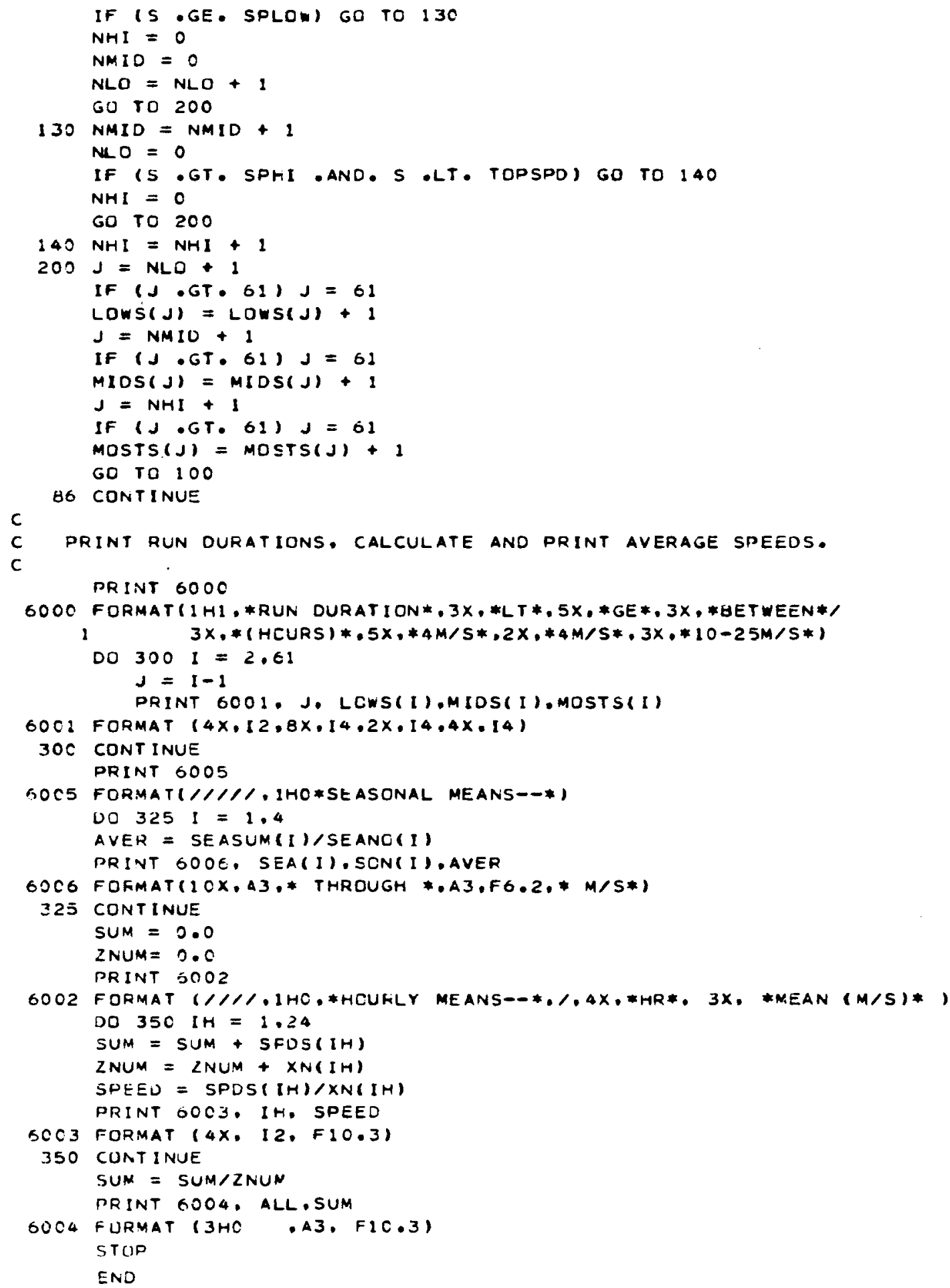




\section{SPSS Program}

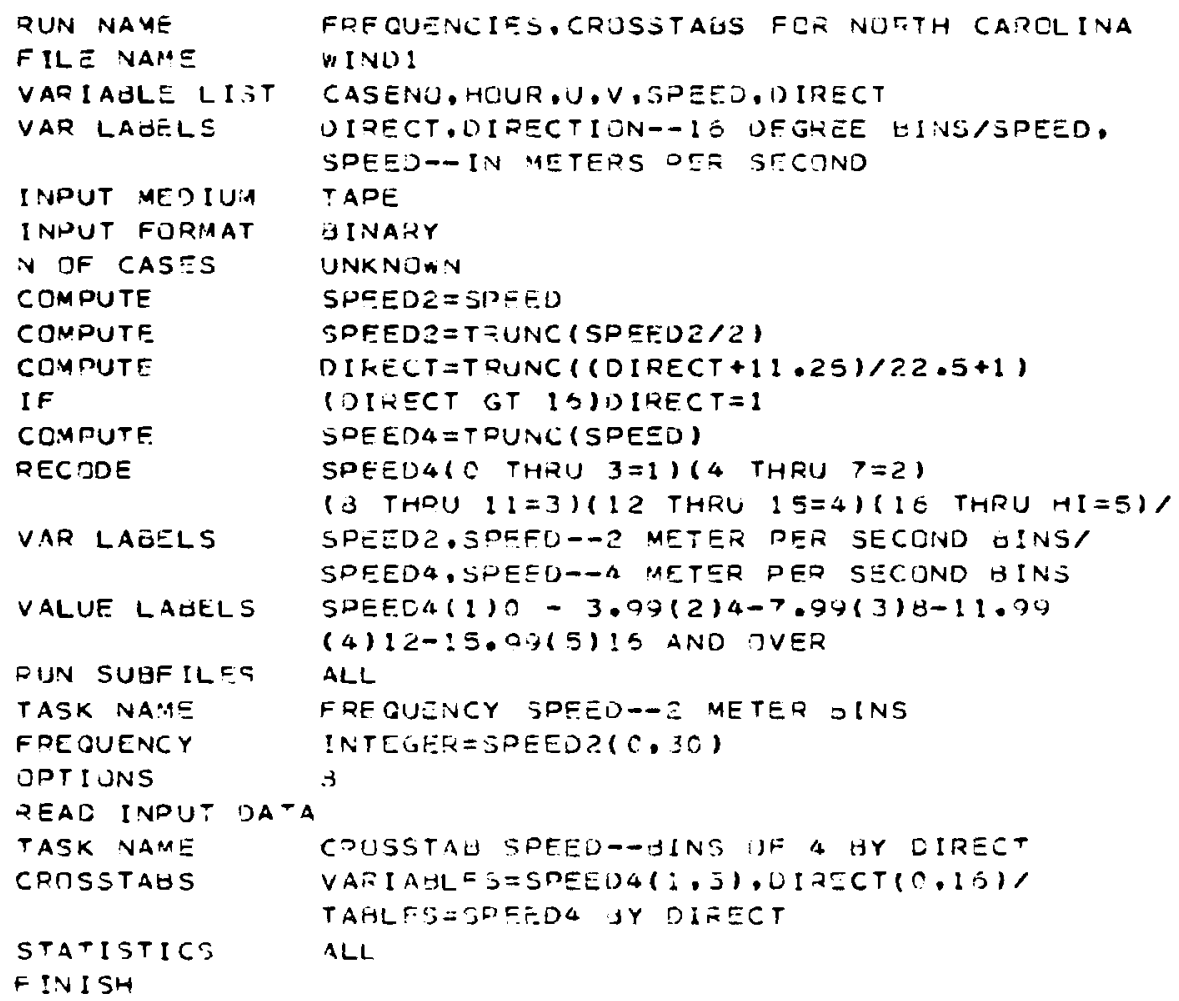




\section{REFERENCES}

Changery, M.J., 1975: 'Initial Wind Energy Data Assessment Study,' Data Assessment Meting, Asheville, North Carolina, July 29-31, 1976, U.S. Dept. of Commerce, NOAA, Env. Data Service, National Climate Center, Asheville, North Carolina, 125 pp.

Changery, M.J., W.T. Hodge, and J.V. Ramsdell, 1977: 'Index-Summarized Wind Data,' BNWL-2220 WIND-II, Battelle Pacific Northwest Laboratories, Richland, Washington.

Mancuso, R.L. and R.E. Endlich, 1973: 'Wind Editing and Analysis Program--Spherical Grid (WEAP-1A), 'User's Manual, Contract DAHC04-71-C-0013, Stanford Research Institute, Menlo Park, California.

Mancuso, R.L. and D.E. Wolf, 1974: 'Numerical Procedures for Analyzing and Predicting Tropical Weather Patterns,' Final Report, Contract DAHC04-71-C-0073, Stanford Research Institute, Menlo Park, California, 59 pp.

Nie, N.H., 1975: Statistical Package for the Social Sciences SPSS, 2nd Ed., McGraw-Hill Book Co., New York, N.Y., 675 pp. 


\section{DISTRIBUTION}

No of

Copies

OFFSITE

A. A. Churm

DOE Chicago Patent Group

9800 S. Cass Avenue

Argonne, IL 60439

C. I. Aspliden

Department of Energy

600 E Street N.W.

Washington, DC 20545

G. P. Tennyson

Raytheon Service Company

141 C Wyoming BouTevard, N.E.

A1buquerque, NM 87123

27 DOE Technical Information Center

10 C. M. Bhumralker

SRI International

333 Ravenswood Avenue

Mento Park, CA 94025

\section{ONSITE}

2 DOE Richland Operations Office

P.0. Box 550

Richland, WA 99352

H. E. Ransom

R. K. Stewart
No of

Copies

ONSITE

37 Pacific Northwest Laboratory

Battelle Boulevard

Richland, WA 99352

W. R. Barchet

J. R. Connell

J. C. Doran

R. L. Drake

C. E. Elderkin

D. L. Elliott

T. R. Hiester

P. R. Partch

W. T. Pennell

E. H. Phinney

D. C. Powel1

J. V. Ramsdell

D. S. Renné

H. L. Wegley

L. L. Wendel1

R. K. Woodruff

Technical Information - Library (5)

Publishing Coordination (2) 
